Rodrigo Domingos Barrera

VECTOR TUGS ACTUATION MODELING FOR SHIP MANEUVERING SIMULATORS 
Rodrigo Domingos Barrera

\section{VECTOR TUGS ACTUATION MODELING FOR SHIP MANEUVERING SIMULATORS}

Master Thesis presented to the Escola Politécnica, Universidade de São Paulo to obtain the degree of Master of Science 
Rodrigo Domingos Barrera

\section{VECTOR TUGS ACTUATION MODELING FOR SHIP MANEUVERING SIMULATORS}

Master Thesis presented to the Escola Politécnica, Universidade de São Paulo to obtain the degree of Master of Science

Concentration area: Control and Automation

Advisor: Prof. Dr. Eduardo Aoun Tannuri 
Autorizo a reprodução e divulgação total ou parcial deste trabalho, por qualquer meio convencional ou eletrônico, para fins de estudo e pesquisa, desde que citada a fonte.

Este exemplar foi revisado e corrigido em relação à versão original, sob responsabilidade única do autor e com a anuência de seu orientador.

São Paulo, de de

Assinatura do autor:

Assinatura do orientador:

\section{Catalogação-na-publicação}

Barrera, Rodrigo

VECTOR TUGS ACTUATION MODELING FOR SHIP MANEUVERING SIMULATORS / R. Barrera - versão corr. - São Paulo, 2019.

$174 \mathrm{p}$.

Dissertação (Mestrado) - Escola Politécnica da Universidade de São

Paulo. Departamento da Engenharia Mecânica.

1.Vector Tugs 2.Static Equilibrium 3.Indirect Maneuver 4.Tugboat Force Prediction 5.Push/Pull Operations I.Universidade de São Paulo. Escola Politécnica. Departamento de Engenharia Mecânica II.t. 


\section{ACKNOWLEDGEMENT}

First of all, I would like to thank my father, Junior, and my mother, Sylvia, for always being by my side, supporting me in every decision made and on every challenge faced. I would like to thank my sister, Juliana, my aunt, Sonia, and my grandmother, Helena, for their care and passion about our family, always holding the rope and maintaining us together. I would like to thank my girlfriend, Júlia, for always being my best friend and being so understandable about my research and the amount of time I needed to spend during weekends and holidays. Without these people, I would not be able to complete my research.

Secondly, and not less important, I would like to thank my advisor Dr. Eduardo Aoun Tannuri for supporting and believing me to complete this work. His care for our laboratory and the students who work here is something unbelievable, which has always impressed me. Over the past 2.5 years, I have learned lessons with him that go beyond the thesis itself. He taught me how to be a better researcher, a better person, and a better leader.

Additionally, I would like to thank all my LAB mates, represented here by André Inagui and Gustavo Silva. All your knowledge transmitted throughout our endless discussions has been essential for the development of this work.

Finally, I would like to, respectively, thank the official Eduardo Nascimento and the researcher Dr. Daniel Vieira for the direct support throughout the validation of the model proposed and the results regarding wave shadowing. In addition, I would like to thank CAPES for the research grant provided and PETROBRAS for the continuous support towards our laboratory. 


\begin{abstract}
Key-words: vector tugs; static equilibrium; push operations; pull operations; indirect maneuver; Ship Manoeuvring Simulator; tugboat force prediction.

Ship Manoeuvring Simulators have proved to be powerful tools on analyzing the feasibility of new maritime maneuvers and new port constructions. In order to provide a complete immersive and real environment, such simulators must correctly represent the dynamics of the controlled vessel as well as the actuation of the tugboats, which have been extremely used over the last years due to the increasing complexity on the maritime maneuvers. Although few simulators can correctly model the dynamics of the tugboats, they still represent their actuation through the so-called "vector tug model". This is usually the case because it is expensive to run several integrated-simulators in real-time and the simulator centers do not have trained tugboat captains available.
\end{abstract}

The vector tugs are usually represented as simplified external forces actuating on a vessel. The simplicity of such models causes a loss of realism during a maritime simulation due to the fact that neither the forces exerted on a towed vessel nor the tugboat's actuation position are accurate. In addition, tugboats' actuation response time is usually not taken into account under the current vector tug models used on Ship Manoeuvring Simulators.

The main objective of this work is to provide an innovative approach for vector tug actuation modeling in such a way that the towing force magnitude and actuation positions are accurate either in push or pull operation modes. The author will expand the static equilibrium model for tugboat force prediction presented in Brandner (1995) and Artyszuk (2014) and combine it along with optimization techniques in order to accurately obtain the tugboats' actuation either working under the direct maneuver (i.e., tugboat uses solely its propeller power in order to exert force on a towed vessel) or working under the indirect maneuver (i.e., tugboats use the environmental disturbances and the hull drag in order to maximize their actuation force on a towed vessel). The implementation of the new mathematical model provides a new level of reality when vector tugs are used in Ship Manoeuvring Simulators. 


\section{RESUMO}

Palavras-chave: rebocadores vetoriais; equilíbrio estático; operações em modo empurrar; operações em modo puxar; manobra indireta; Simulador de Manobras de Navio; predição da força de rebocadores.

Simuladores Navais têm provado ser poderosas ferramentas, tanto na análise de viabilidade de novas manobras portuárias, quanto na construção de novos portos. De modo a conseguir criar um ambiente imersivo e realista, tais simuladores devem conseguir representar corretamente a dinâmica de um navio a ser controlado e a atuação dos rebocadores portuários no mesmo. Embora alguns simuladores consigam modelar corretamente a dinâmica de rebocadores portuários, eles ainda representam tal atuação utilizando o modelo comumente chamado de "rebocadores vetoriais". Tal fato normalmente acontece pois é muito caro utilizar diversos simuladores conectados em tempo real. Além disso, em muitas ocasiões, os centros de simulação não têm disponível um comandante de rebocador treinado e capaz de manusear o mesmo de forma correta.

Os rebocadores vetoriais normalmente são representados com modelos simplificados de forças externas atuantes em um navio a ser rebocado. A simplicidade de tais modelos gera uma grande perda de realismo durante uma simulação marítima dado que tanto as forças exercidas em um navio a ser rebocado quanto as posições de atuação dos rebocadores são imprecisas. Ainda, os tempos de resposta para a atuação dos rebocadores normalmente não é levado em conta nos modelos de rebocadores vetoriais presentes atualmente.

O principal objetivo deste trabalho é prover uma abordagem inovadora para a modelagem da atuação de rebocadores vetoriais, de tal modo que a magnitude da sua força de reboque e seu posicionamento, tanto atuando no modo empurrar quanto no modo puxar, sejam fidedignos a realidade. $O$ autor irá expandir o modelo de equilíbrio estático para predição de forças de atuação de rebocadores apresentado tanto em Brandner (1995) quanto em Artyszuk (2014), e irá introduzir técnicas de otimização de modo a obter a configuração precisa de atuação dos rebocadores tanto na manobra de modo direto quanto na manobra de modo indireto. As implementações propostas elevarão o nível de realidade de Simuladores Navais quando rebocadores vetoriais forem empregados. 


\section{FIGURES LIST}

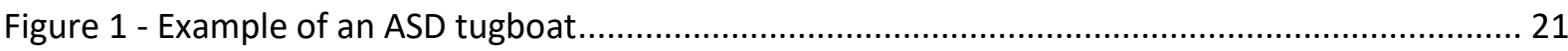

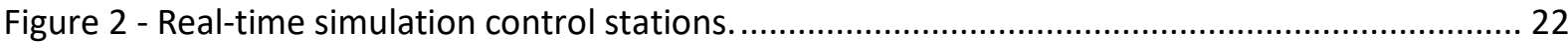

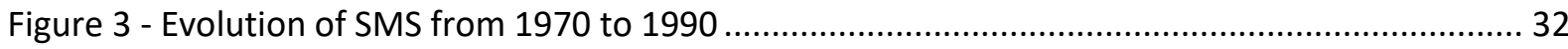

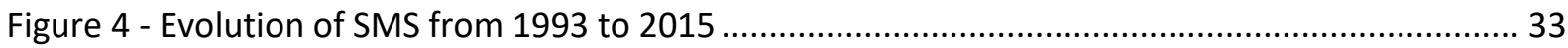

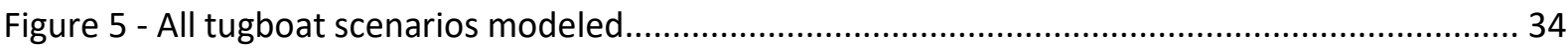

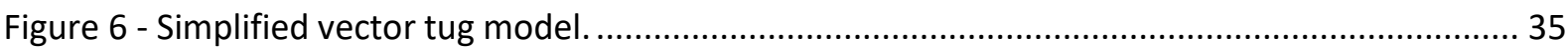

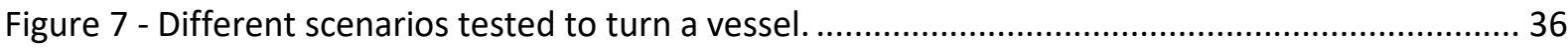

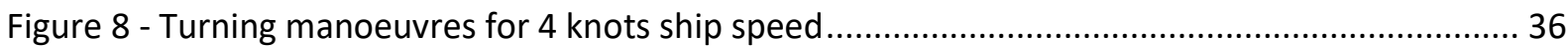

Figure 9 - Tugboat Operational Performance Prediction Software .................................................. 37

Figure 10 - Forward brake mode graphical configuration ................................................................. 38

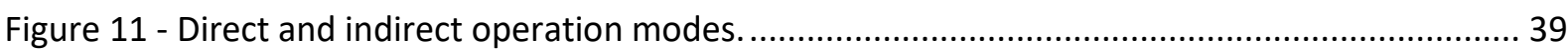

Figure 12 - Evolution on tugboat models and operation from 1984 to 2000 .................................... 42

Figure 13 - - Evolution on tugboat models and operation from 2006 to 2015 .................................. 42

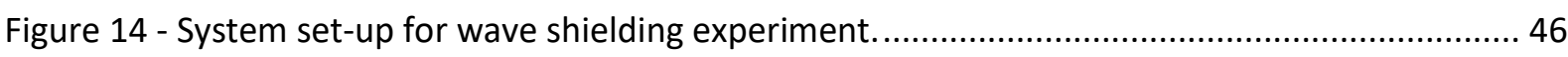

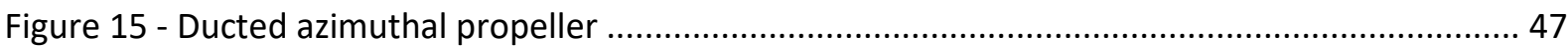

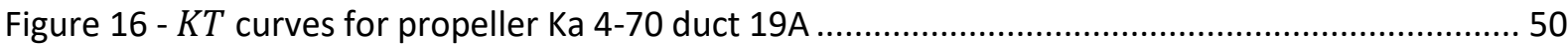

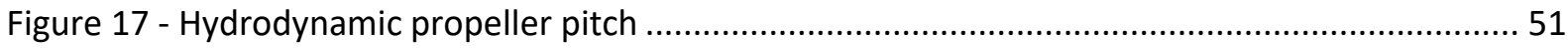

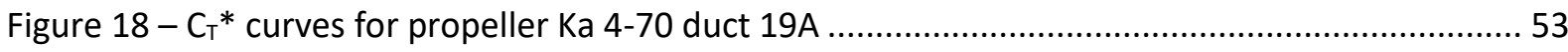

Figure 19 - Comparison between original $K T$ curve and $K T$ curve obtained from $C T * \ldots \ldots \ldots \ldots \ldots \ldots . . . .54$

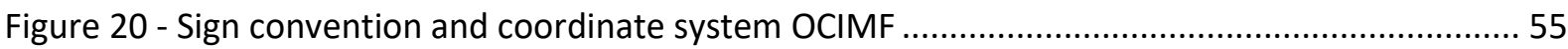

Figure 21 - $C c x$ non-dimensional hydrodynamic coefficient curve ................................................. 55

Figure 22 - Ccy non-dimensional hydrodynamic coefficient curve ................................................... 56

Figure 23 - CCZ non-dimensional hydrodynamic coefficient curve …............................................. 56

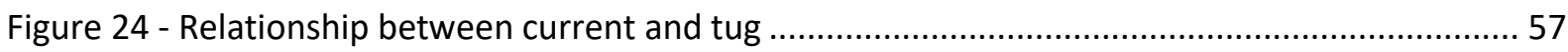

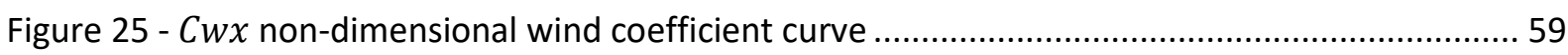

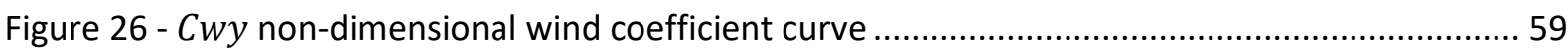

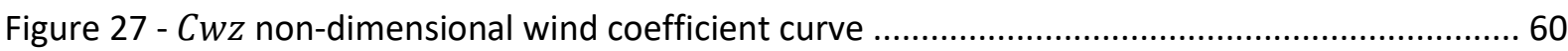

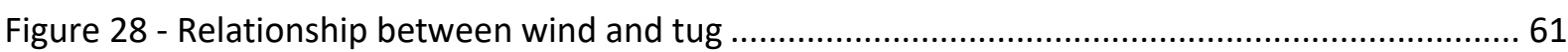

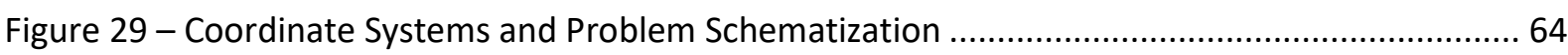

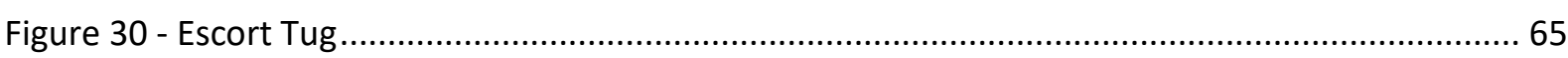

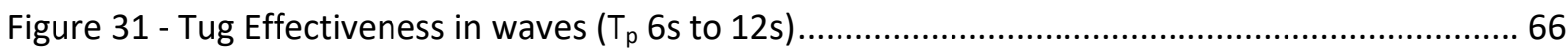

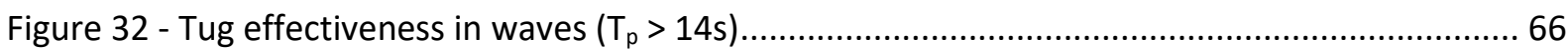

Figure 33 - Wave maps for the Containership with $8 \mathrm{~m}$ draft (Left) and $15 \mathrm{~m}$ draft (Right)............... 68 
Figure 34- Wave maps for the Tanker with $8 \mathrm{~m}$ draft (Left) and $15 \mathrm{~m}$ draft (Right)......

Figure 35 - Relationship between $w p$ and Wave $H$ Multiplier ....................................................... 70

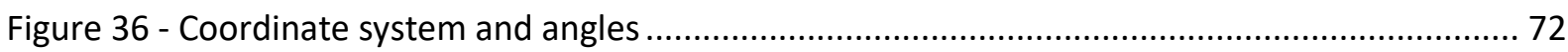

Figure 37 - Coordinate system and angles on most used situation ..................................................... 72

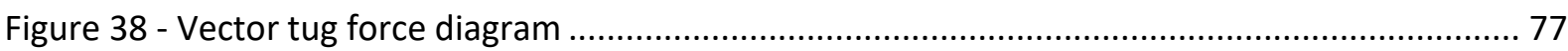

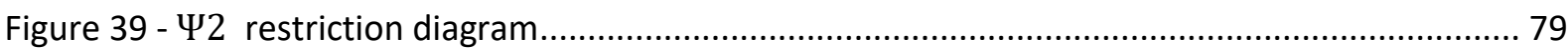

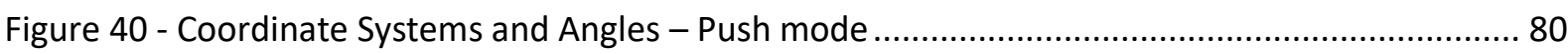

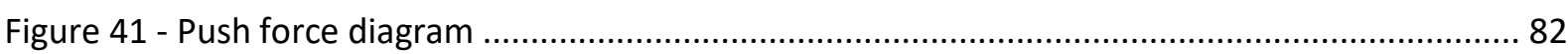

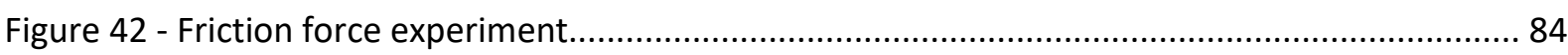

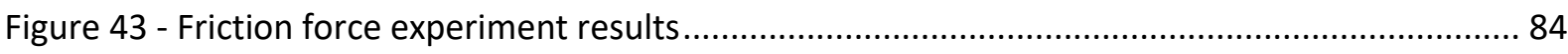

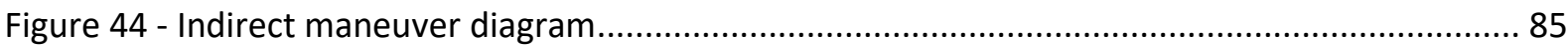

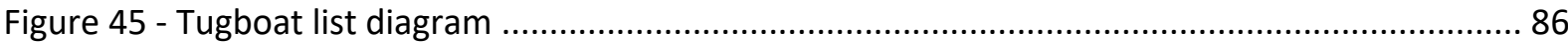

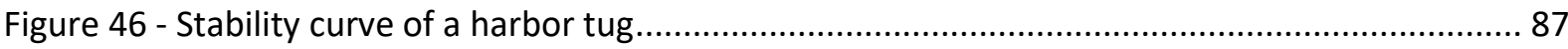

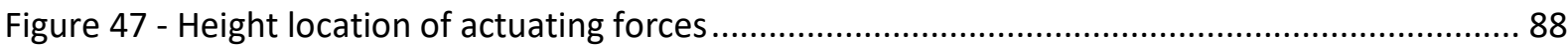

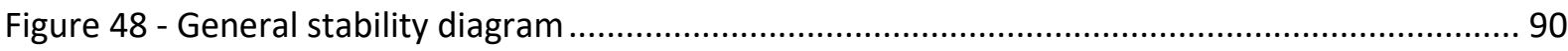

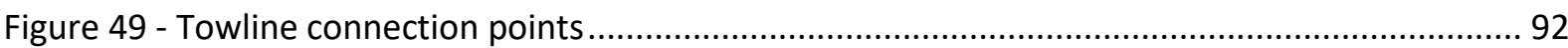

Figure 50 - Towline force $\left(F_{t}\right)$ for the 2 kn scenario. Left - towline at the bow; Right - Towline at the aft.

Figure 51 - Towline force $\left(F_{t}\right)$ for the 4 kn scenario. Left - towline at the bow; Right - Towline at the aft.

Figure 52 - Towline force (Ft) for the 6 kn scenario. Left - towline at the bow; Right - Towline at the aft.

Figure 53 - Relative angles $\left(\Psi_{2}-\right.$ red; $\delta$ - green) for the 2 kn scenario - Towline at the tugboat's bow.

Figure 54 - Vector tug actuation model for a towed vessel navigating with 2 knots (towline angles of $0^{\circ} ; 45^{\circ} ; 90^{\circ} ; 135^{\circ} ; 180^{\circ}$ ) - Left: Towline at the tugboat's bow; Right: Towline at the tugboat's aft. 95

Figure 55 - Relative angles ( $\Psi_{2}$-red; $\delta$-green) for the 4 kn scenario - Towline at the tugboat's bow.

Figure 56 - Vector tug actuation model for a towed vessel navigating with 4 knots (towline angles of $\left.0^{\circ} ; 45^{\circ} ; 90^{\circ} ; 135^{\circ} ; 180^{\circ}\right)$ - Left: Towline at the tugboat's bow; Right: Towline at the tugboat's aft.

Figure 57 - Relative angles ( $\Psi 2$ - red; $\delta$-green) for the 6 kn scenario - Towline at the tugboat's bow. 
Figure 58 - Vector tug actuation model for a towed vessel navigating with 6 knots (towline angles of $0^{\circ} ; 45^{\circ} ; 90^{\circ} ; 135^{\circ} ; 180^{\circ}$ ) - Left: Towline at the tugboat's bow; Right: Towline at the tugboat's aft.

Figure 59 - Stability of equilibrium position 99

Figure 60 - Stability curve for the 6 Kn scenario. Left - towline at the tugboat's bow; Right - towline

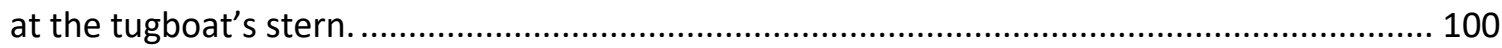

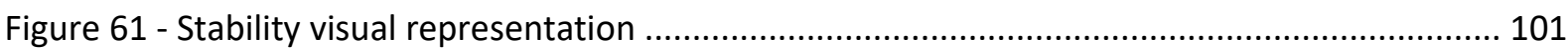

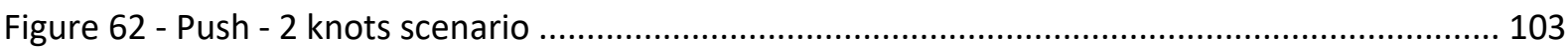

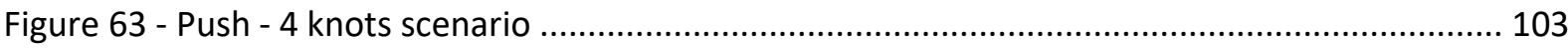

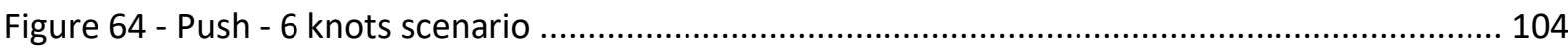

Figure 65 - Visual representation for the 2 knots scenario............................................................ 105

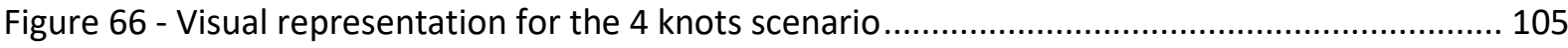

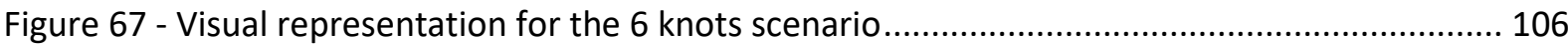

Figure 68 - Propeller angle of actuation for each scenario ............................................................ 106

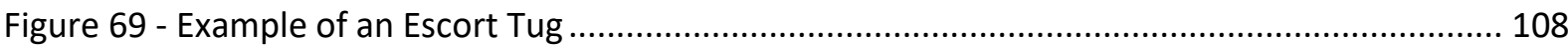

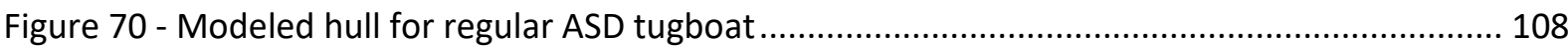

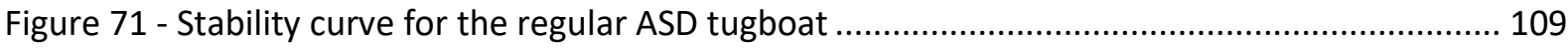

Figure 72 - Scenario 1: Regular ASD tugboat in indirect maneuver with advance speed of $8 \mathrm{kn} . . . . . .110$

Figure 73 - Scenario 2: Regular ASD tugboat in indirect maneuver with advance speed of $10 \mathrm{kn} . . . .110$

Figure 74 - Scenario 3: Regular ASD tugboat in indirect maneuver with advance speed of $12 \mathrm{kn} . . . .111$

Figure 75 - Situation where maximum towing force occurs for the 8, 10 and 12 kn scenarios (set of solutions 2)

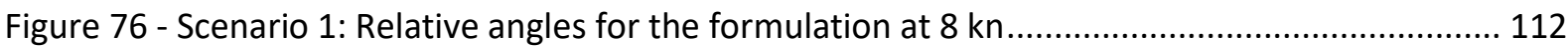

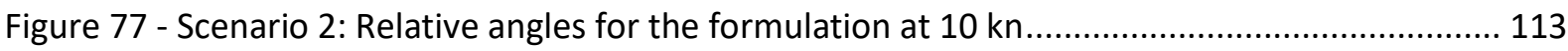

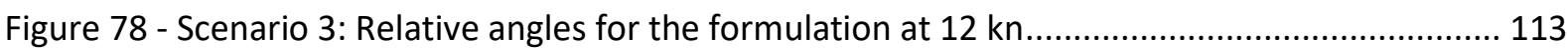

Figure 79 - Situation where maximum towing force occurs for the 8, 10 and $12 \mathrm{kn}$ scenarios (set of

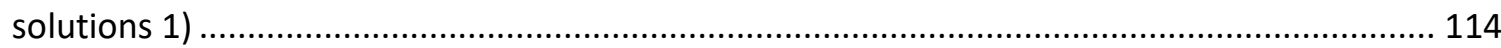

Figure 80 - Listing angles for all scenarios - Regular ASD …........................................................ 115

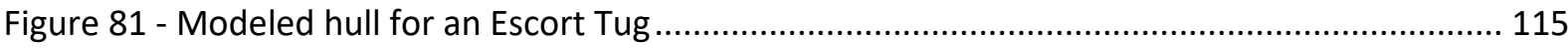

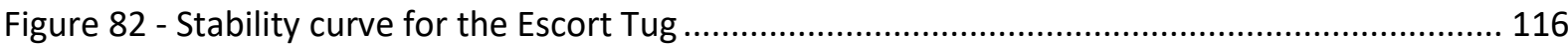

Figure 83 - Scenario 1: Escort Tug in indirect maneuver with advance speed of $8 \mathrm{kn}$...................... 117

Figure 84 - Scenario 2: Escort Tug in indirect maneuver with advance speed of $10 \mathrm{kn}$..................... 117

Figure 85 - Scenario 3: Escort Tug in indirect maneuver with advance speed of $12 \mathrm{kn}$..................... 118

Figure 86 - Listing angles for all scenarios - Escort Tug .............................................................. 118 
Figure 87 - Situation where maximum towing force occurs for the 8, 10 and $12 \mathrm{kn}$ scenarios - Escort

Tug 119

Figure 88 - Scenario 1: Relative angles for the formulation at 8 kn - Escort Tug ............................ 120

Figure 89 - Scenario 2: Relative angles for the formulation at $10 \mathrm{kn}$ - Escort Tug ............................. 120

Figure 90 - Scenario 3: Relative angles for the formulation at 12 kn - Escort Tug ............................. 121

Figure 91 - Listing angle comparison between Regular ASD and Escort Tug - 8 kn ........................... 122

Figure 92 - Listing angle comparison between Regular ASD and Escort Tug - 10 kn ........................ 122

Figure 93 - Validation set-up (sky view on a portable pilot unit) ..................................................... 125

Figure 94 - Maneuvering of manned tugboat in order to perform the experiments. ...................... 126

Figure 95 - Towing force on equilibrium for $0^{\circ}$ case at 2 knots speed ........................................... 128

Figure 96 - Results comparison for the $0^{\circ}$ case at 2 knots speed ................................................ 128

Figure 97 - Results comparison for the $45^{\circ}$ case at 2 knots speed ............................................... 129

Figure 98 - Results comparison for the $90^{\circ}$ case at 2 knots speed ................................................ 130

Figure 99 - Results comparison for the $135^{\circ}$ case at 2 knots speed ............................................. 130

Figure 100 - Results comparison for the $180^{\circ}$ case at 2 knots speed ............................................ 131

Figure 101 - Results comparison for the $0^{\circ}$ case at 4 knots speed ................................................ 132

Figure 102 - Results comparison for the $45^{\circ}$ case at 4 knots speed .............................................. 133

Figure 103 - Results comparison for the $90^{\circ}$ case at 4 knots speed .............................................. 133

Figure 104 - Results comparison for the $135^{\circ}$ case at 4 knots speed ............................................ 134

Figure 105 - Results comparison for the $180^{\circ}$ case at 4 knots speed .............................................. 134

Figure 106 - Results comparison for the $0^{\circ}$ case at 6 knots speed ................................................... 136

Figure 107 - Results comparison for the $45^{\circ}$ case at 6 knots speed ................................................. 136

Figure 108 - Results comparison for the $90^{\circ}$ case at 6 knots speed .............................................. 137

Figure 109 - Results comparison for the $135^{\circ}$ case at 6 knots speed .............................................. 137

Figure 110 - Results comparison for the $180^{\circ}$ case at 6 knots speed ........................................... 138

Figure 111 - Approximations of steering forces of a 36-tons tractor tug ........................................ 140

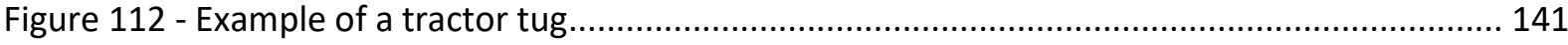

Figure 113 - Direct/Indirect comparison chart for proposed models ............................................ 142

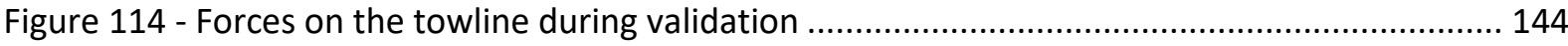

Figure 115 - Comparison between theoretical and simulated results............................................ 144

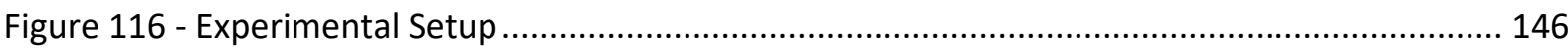

Figure 117 - Peaks for towline length of $60 \mathrm{~m}$ - Regular ASD....................................................... 147

Figure 118 - Peaks for towline length of $80 \mathrm{~m}$ - Regular ASD ....................................................... 147

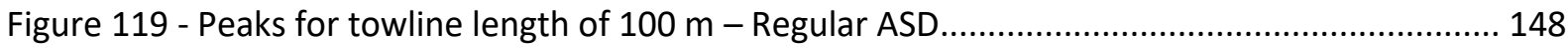

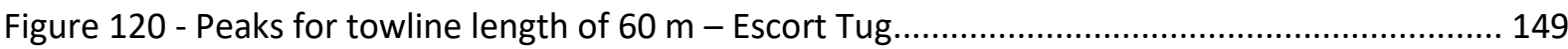




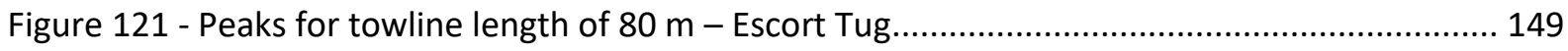

Figure 122 - Peaks for towline length of 100 m - Escort Tug.......................................................... 150

Figure 123 - Situation 1: tugboat only experiences rotation ....................................................... 151

Figure 124 - Situation 2: tugboat transitioning between push and pull modes ................................ 152

Figure 125 - Situation 3: tugboat transitioning from port to starboard ............................................ 153

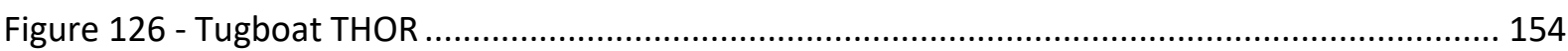

Figure 127 - Transition time by every length of tug's line from Push to Pull .................................... 157

Figure 128 - Transition time by every length of tug's line from Pull to Push................................... 157

Figure 129 - Tugboat's movement experiment during Pull mode maneuvers .................................. 159

Figure 130 - Movement time experiment for advance speed of 0 knots ........................................ 160

Figure 131 - Movement time experiment for advance speed of 2 knots ......................................... 161

Figure 132 - Movement time experiment for advance speed of 4 knots ......................................... 161

Figure 133 - Movement time experiment for advance speed of 6 knots ......................................... 162

Figure 134 - Movement time experiment for advance speed of 8 knots ......................................... 162

Figure 135 - Static equilibrium calculation software - Initial Configuration ..................................... 172

Figure 136 - Static equilibrium calculation software - Final Configuration....................................... 173

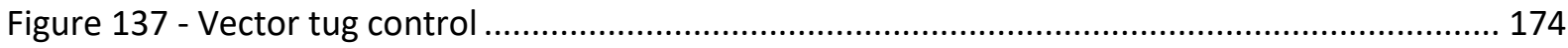

Figure 138 - Individual control panel for each vector tug............................................................. 174 
TABLES LIST

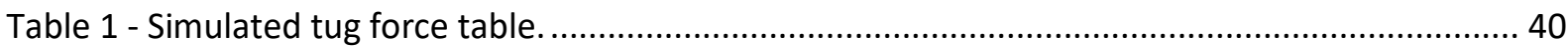

Table 2 - Coefficients for propeller Ka 4-70 duct 19A to calculate $K T$................................................ 49

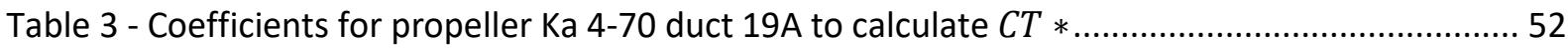

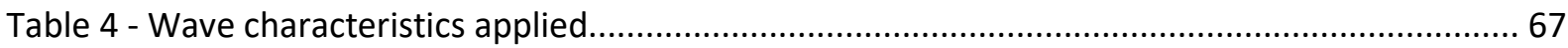

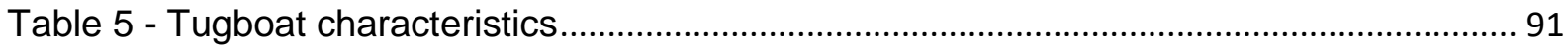

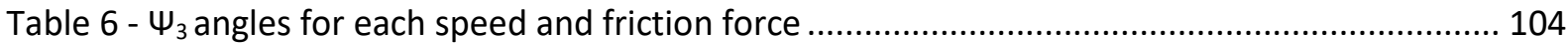

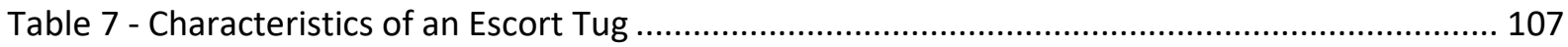

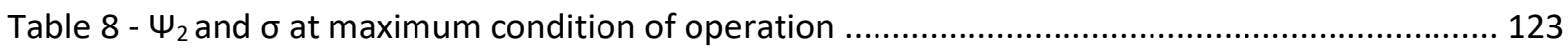

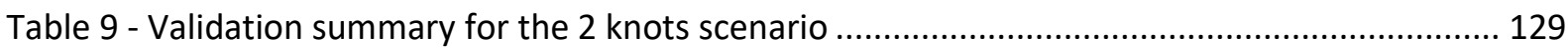

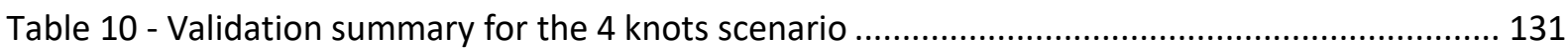

Table 11 - Validation summary for the 6 knots scenario .................................................................... 135

Table 12 - Results obtained for the Direct and Indirect maneuvers ............................................... 142

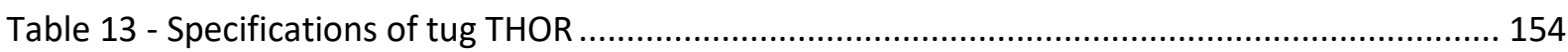

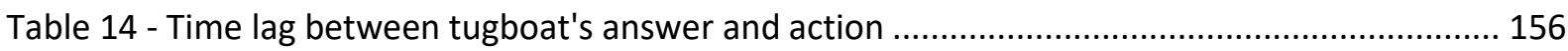

Table 15 - Average tugboat speed for each scenario....................................................................... 163 


\section{ABBREVIATIONS LIST}

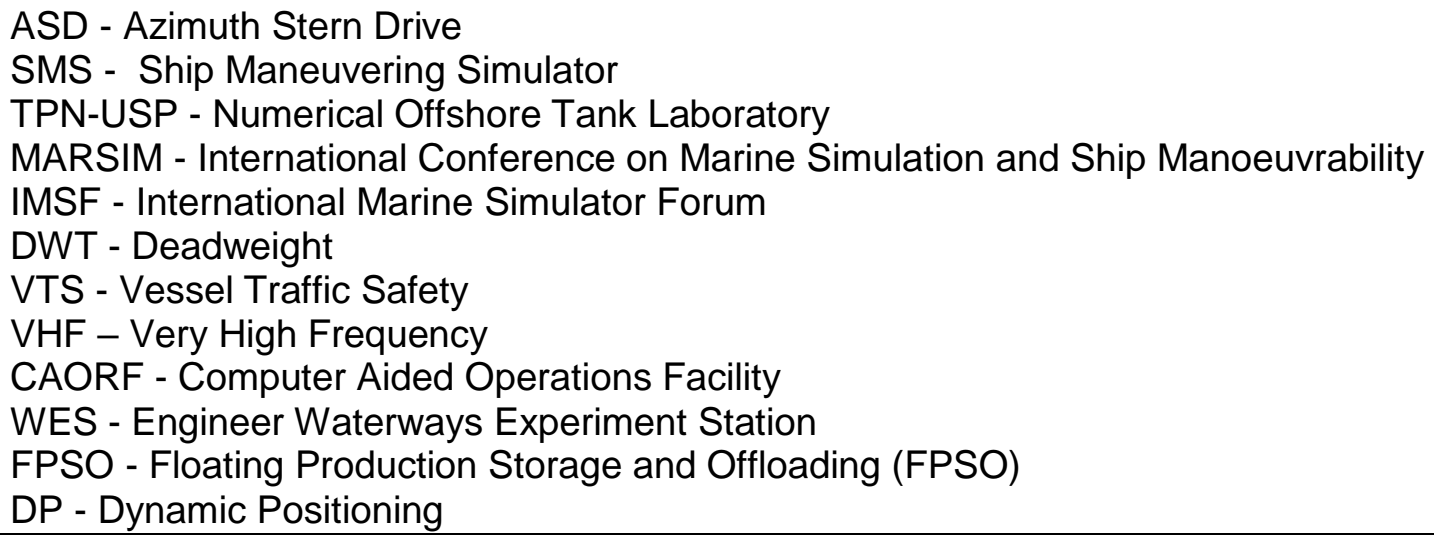




\section{SYMBOLS LIST}

$A_{\text {frontal }}$ - the tug's frontal emerged area

$A_{k}$ - coefficients of the Fourier series in order to obtain $C_{T}{ }^{*}$ curve

$A_{\text {lateral }}$ - the tug's lateral emerged area

$A_{x, y}-$ coefficients of the Fourier series in order to obtain $\mathrm{K}_{\mathrm{T}}$ curve

$B_{0}-$ initial center of buoyance of the body

$B_{k}$ - coefficients of the Fourier series in order to obtain $C_{T}{ }^{*}$ curve

$C_{T}{ }^{*}$ - four-quadrant thrust coefficient

$C_{c x}, C_{c y}, C_{c z}$ - non-dimensional hydrodynamic coefficients

$C_{w x}, C_{w y}, C_{w z}-$ wind non-dimensional coefficients

$D$ - propeller diameter

$d x_{G}$ - variation of center of gravity in surge

$d_{L}-$ towline length variation

$d x_{P}$ - variation of tugboat's connection point in surge

$d y_{G}$ - variation of center of gravity in sway

$d y_{P}-$ variation of tugboat's connection point in sway

$d z_{G}$ - variation of center of gravity in heave

$d z_{P}-$ variation of tugboat's connection point in heave

$d \theta$ - variation in pitch

$d \varphi-$ variation in roll

$d \psi-$ variation in yaw

$F_{c x}-$ current force on the tugboat-fixed longitudinal axis

$F_{c y}$-current force on the tugboat-fixed transversal axis

$F_{e x}$ - external forces on the tugboat-fixed longitudinal axis

$F_{e y}$ - external forces on the tugboat-fixed transversal axis

$F_{i}(j \omega)$ - force RAO

$F_{P}$ - the magnitude of thruster force (always positive)

$F_{p x}$ - propeller force on the tugboat-fixed longitudinal axis

$F_{p y}$ - propeller force on the tugboat-fixed transversal axis

$F_{S}$ - static friction force

$F_{t}$ - the magnitude of towing force (always positive)

$F_{t x}$ - towing force on the tugboat-fixed longitudinal axis

$F_{t y}$ - towing force on the tugboat-fixed transversal axis 
$F_{w x}$ - wind force on the tugboat-fixed longitudinal axis

$F_{w y}$ - wind force on the tugboat-fixed transversal axis

$G$ - tugboat's center of gravity point

$G M$ - metacentric height

$G Z$ - righting arm

$H$ - wave significant height

$H_{i}(j \omega)$ - force-to-motion RAO

$H_{s}$ - wave significant height

$J$ - advance coefficient

$K_{Q}$ - torque coefficient

$K_{T}$ - thrust coefficient

$L$ - the tug's length

$M$ - Meta Centre

$M_{C Z}$ - current moment around tugboat-fixed vertical axis

$M_{e x}$ - Moment developed by the external forces around the x-axis

$M_{e z}$ - external moments around tugboat-fixed vertical axis

$M_{p x}$ - Moment developed by the propeller around the x-axis

$M_{p z}$ - propeller moment around tugboat-fixed vertical axis

$M_{t x}$ - Moment developed by the towline around the x-axis

$M_{t z}$ - towing moment around tugboat-fixed vertical axis

$M_{w z}-$ wind moment around tugboat-fixed vertical axis

$n$ - propeller rotation (rps)

$P$ - tugboat's connection point

$P / D$ - propeller's pitch to diameter ratio

$\boldsymbol{R}_{\mathbf{1}}^{\mathbf{0}}$ - rotation matrix from coordinate system 1 to coordinate system 0

$\boldsymbol{R}_{2}^{1}$ - rotation matrix from coordinate system 2 to coordinate system 1

$\boldsymbol{R}_{\mathbf{3}}^{\mathbf{2}}$ - rotation matrix from coordinate system 3 to coordinate system 2

$\boldsymbol{R}_{\mathbf{3}}^{\mathbf{0}}$ - rotation matrix from coordinate system 3 to coordinate system 0

$S(\omega)$ - wave spectrum

$T$ - propeller thrust

$T_{p}$ - wave peak period

$\boldsymbol{u}_{\boldsymbol{L}}-$ unit vector located at $\mathrm{P}$

$V_{a}$ - oceanic current velocity projected on the propeller entrance.

$\mathrm{V}_{\mathrm{c}}$ - the current speed

$\left|V_{\text {rel }}\right|_{c}$ - the relative velocity modulus between the water and the tug 
$V_{\text {rel_cx }}$ - the longitudinal component of the relative velocity between the current and the tugboat

$V_{\text {rel_cy }}$ - the transversal component of the relative velocity between the current and the tugboat

$\left|V_{\text {rel }}\right|_{w}$ - the relative velocity between the wind and the tug

$V_{r e l \_w x}$ - the longitudinal component of the relative velocity between the wind and the tugboat

$V_{\text {rel_wy }}$ - the transversal component of the relative velocity between the wind

and the tugboat

$V_{w}$ - the wind speed

wave $_{\text {factor }}$ - wave factor that affects tugboat's propeller efficiency

$w_{p}$ - wave period

$X_{0} / Y_{0}$ - global earth-fixed coordinate system

$X_{1} / Y_{1}$ - vessel-fixed coordinate system

$X_{2} / Y_{2}$ - towline-fixed coordinate system

$X_{3} / Y_{3}$ - tug-fixed coordinate system

$X_{p}$ - position vector from $\mathrm{P}$ to $\mathrm{G}$

$x_{p}$ - thruster location related to the tugboat's midship section (negative if at the tug's stern)

$x_{t}-$ thruster location related to the tugboat's midship section (positive if at the tug's bow)

\section{Greek Symbols:}

$\alpha_{c}$ - the angle of attack between the current and the tug

$\alpha_{w}$ - the angle of attack between the wind and the tug

$\beta$ - propeller's hydrodynamic pitch angle

$\beta_{c}$ - the global angle of the current

$\beta_{t}$ - tugboat global angle

$\beta_{v}-$ towed vessel global angle

$\beta_{w}$ - the global angle of the wind

$\Delta$ - tugboat displacement

$\delta$ - the thruster angle within the interval $\left[0^{\circ}, 360^{\circ}\right]$ increasing in the counter-

clockwise direction $\left[^{\circ}\right]$

$\eta$ - tugboat efficiency

$\mu_{s}$ - static friction coefficient of rubber-steel subject to sea-water droplet lubrication. 
$\xi_{i}$ - wave motion response in time domain

$\rho_{w}$ - water density

$\rho_{\text {wind }}$ - the air density $\left[\mathrm{kg} / \mathrm{m}^{3}\right]$

$\phi_{w}$ - random wave phase

$\Psi_{1}$ - angle between the vessel-fixed and the towline-fixed coordinate systems

$\Psi_{2}$ - angle between the towline-fixed and the tug-fixed coordinate systems

$\Psi_{3}$ - angle between the tugboat and the towed vessel during push maneuvers

$\Psi_{4}$ - roll angle

$\omega$ - wave frequency

$\omega_{0}$ - wave spectrum peak frequency 


\section{CONTENTS}

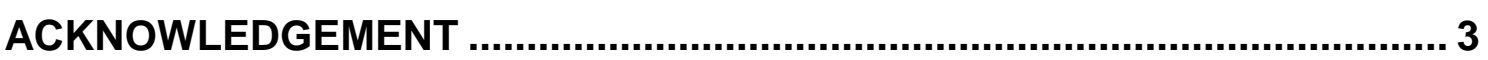

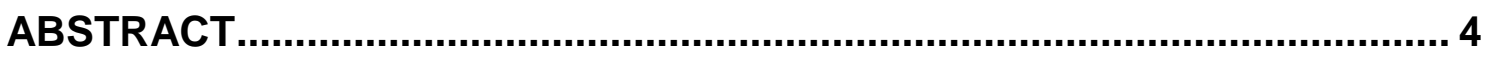

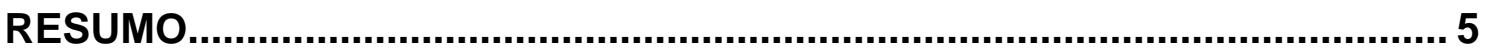

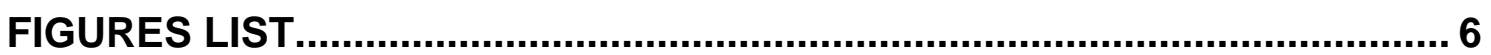

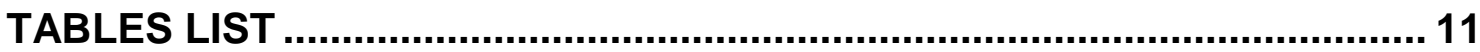

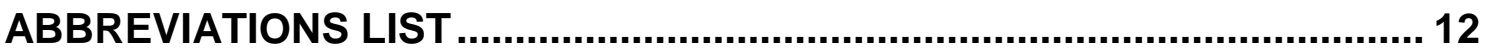

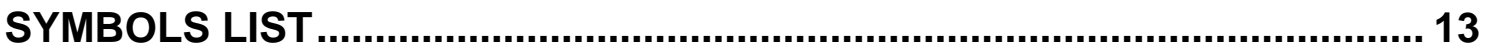

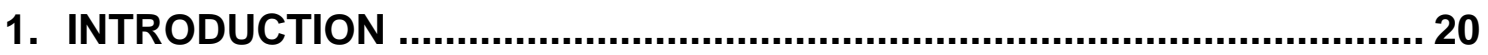

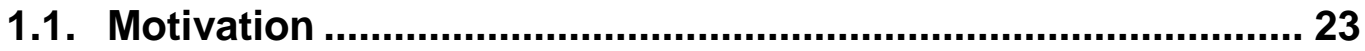

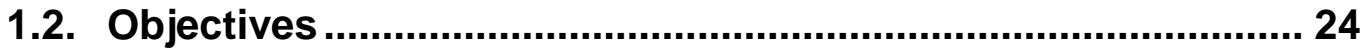

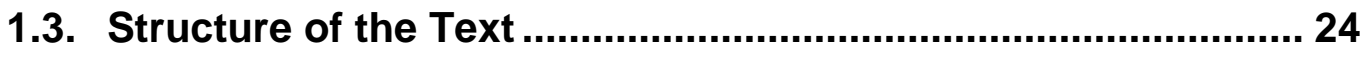

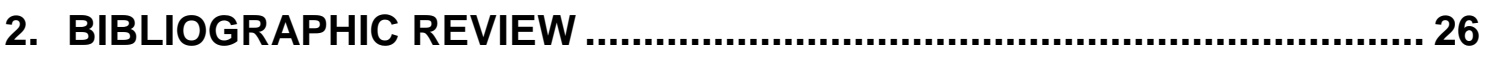

2.1. Naval Numerical Simulators Evolution - MARSIM .....................26

2.2. Tugboat Operation and Actuation Modeling for Simulation Purposes - MARSIM ..................................................................... 33

2.3. Tugboat Operation and Actuation Modeling for Simulation Purposes - Practical Guidelines............................................... 42

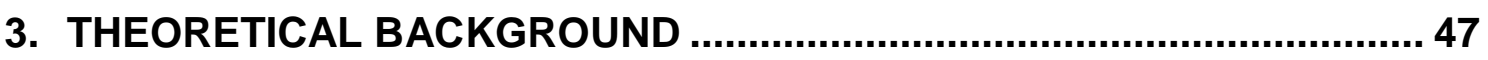

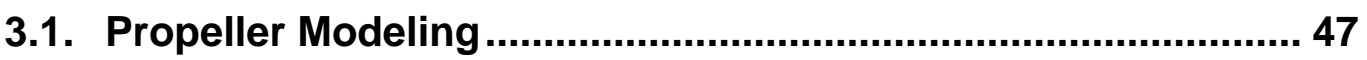

3.2. Current Force Modeling .............................................................. 54

3.3. Wind Force Modeling …......................................................... 58

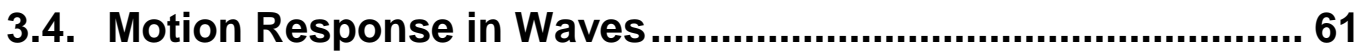

3.5. Peak Loads on the Towline due to the Motion on Waves........ 63

3.6. Tugboat Towing Force Attenuation Due to the Presence of

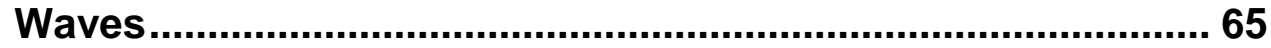

3.7. Tugboat Towing Force Incrementation Due to Wave Shadowing 
4.1. Pull Operations - Direct Maneuver ........................................... 71

4.1.1. Coordinate Systems and Planar Space......................... 71

4.1.2. Rotation Matrixes........................................................... 73

4.1.3. Static Equilibrium Formulation ....................................... 74

4.1.4. Propeller Force Model ................................................... 76

4.1.5. Towing Force Model ..................................................... 77

4.1.6. External Force Model .................................................... 78

4.1.7. Optimization Formulation................................................. 78

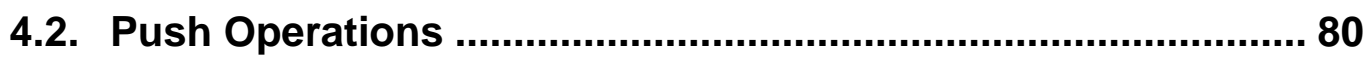

4.2.1. Coordinate Systems and Planar Space.......................... 80

4.2.2. Rotation Matrixes............................................................. 81

4.2.3. Towing Force Model ....................................................... 81

4.2.4. Optimization Formulation................................................. 82

4.3. Pull Operations - Indirect Maneuver ........................................ 85

4.3.1. Angle Orientation and Static Equilibrium Formulation ...... 86

4.3.2. Towing, Propeller and External Force Model................... 88

4.3.3. Optimization Formulation................................................ 89

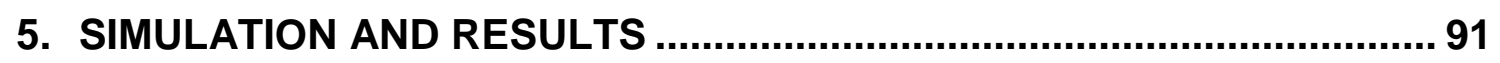

5.1. Pull Mode - Direct Maneuver ……………............................... 92

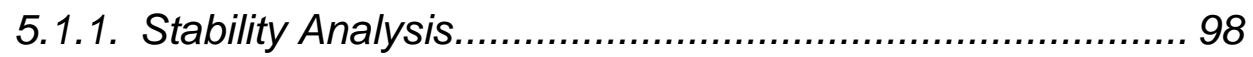

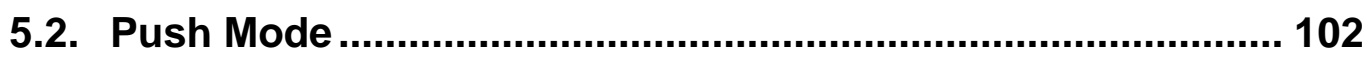

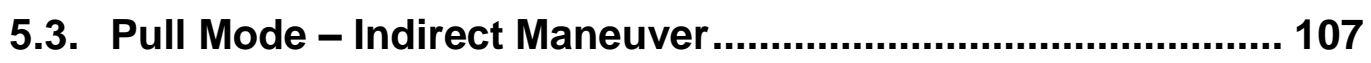

5.3.1. Regular ASD Tugboat ................................................ 108

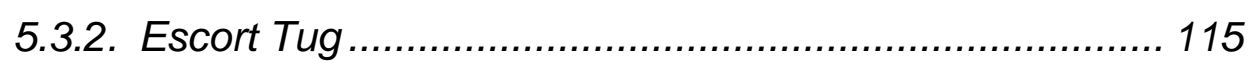

5.3.3. Comparison Between Regular ASD and Escort Tug Results 121 
6.1. Pull Mode - Direct Maneuver ................................................ 124

6.1.1. Vessel's Advance Speed of 2 Knots............................. 126

6.1.2. Vessel's Advance Speed of 4 Knots.............................. 131

6.1.3. Vessel's Advance Speed of 6 Knots .............................. 135

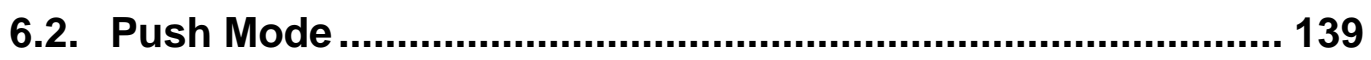

6.3. Pull Mode - Indirect Maneuver.................................................. 140

6.3.1. Literature Validation................................................... 140

6.3.2. Simulator Validation..................................................... 143

7. TUGBOAT DYNAMIC IN WAVES - TOWLINE PEAK LOAD CASE

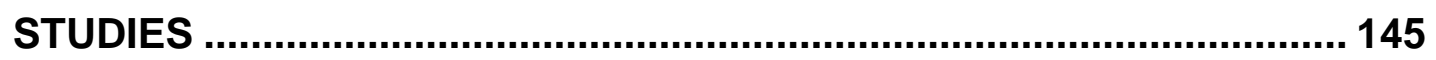

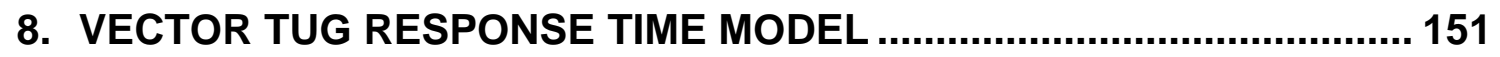

8.1. Situation 1: Tugboat Rotating About a Fixed Point Without Translation. 154

8.2. Situation 2: Tugboat Transition Between Push and Pull Modes 156

8.3. Situation 3: Tugboat Movements When Actuating in Pull Mode 159

9. CONCLUSIONS 164

REFERENCES. 166

APPENDIX - DEVELOPED SOFTWARES FOR VECTOR TUG ANALYSIS172

A1: Static Equilibrium Software 172

A2: Vector Tug Graphical Interface. 173 


\section{INTRODUCTION}

The goods produced within the industrial revolution dated back in the $18^{\text {th }}$ century, created the necessity for the development on the means of transport. In order to carry these products in a cost-effective way, the maritime transportation was seen as the best solution. For this reason, vessel's each time larger and heavier have been developed. Still today, the maritime transportation is of extreme importance to Brazil, transporting more than $90 \%$ of all the cargo commercialized abroad (ROCHA, 2015).

Although the vessels' size and draught were augmenting, the channels and ports did not catch up with this development, making the maritime maneuvers each time more complicated. At that time, it was clear that the development of a tool to support the vessels during the maneuvers was needed. For this reason, the tugboats were created. The tugboats are small vessels when compared to the cargo ones, but they have a great power, great static force traction, and great maneuverability (FRAGOSO and CAJATY, 2012).

There are different types of tugboats worldwide, and they are usually classified regarding their propulsion type (i.e., how the propellers/actuators are displaced along the hull), position of towing point, and hull characteristics. Nowadays, the most used tugboat in Brazil is the Azimuth Stern Drive (ASD), which can also operate as a conventional or a reverse tractor tug. This tugboat, in which the focus will be on throughout this work, has two propellers located astern, which are free to rotate in $360^{\circ}$, thus providing the capability to move and tow in any direction. In addition, this tugboat has connection points either at its aft or at its bow, allowing it to perform a variety of towing maneuvers. In Figure 1, an ASD tugboat is shown. For information about other types of tugboats, (HENSEN, 2003) is the most recommended reference.

During a maritime maneuver, the tugboats are responsible to control the dynamics of the bigger vessels through the application of a force either by hull to hull direct contact, or by the tow lines. This force is generated by the combination of two external forces acting on the tugboat: the propeller force and the hull force. The propeller's force is generated directly by them while the hull's force is a 
combination of all the other external factors affecting the tugboat such as hydrodynamic reactions, winds, oceanic currents, and waves. Note that all the external factors affect the tugboat in different ways, which are function of the interaction between the tugboat and the environment (i.e., relative angle between the tugboat and incoming current/wind/wave, etc.). To provide a reasonable resultant force on a vessel, the tug master needs to find an appropriate position where he can counter-act the environmental forces or even take advantage of them to maximize its actuation power

Figure 1 - Example of an ASD tugboat

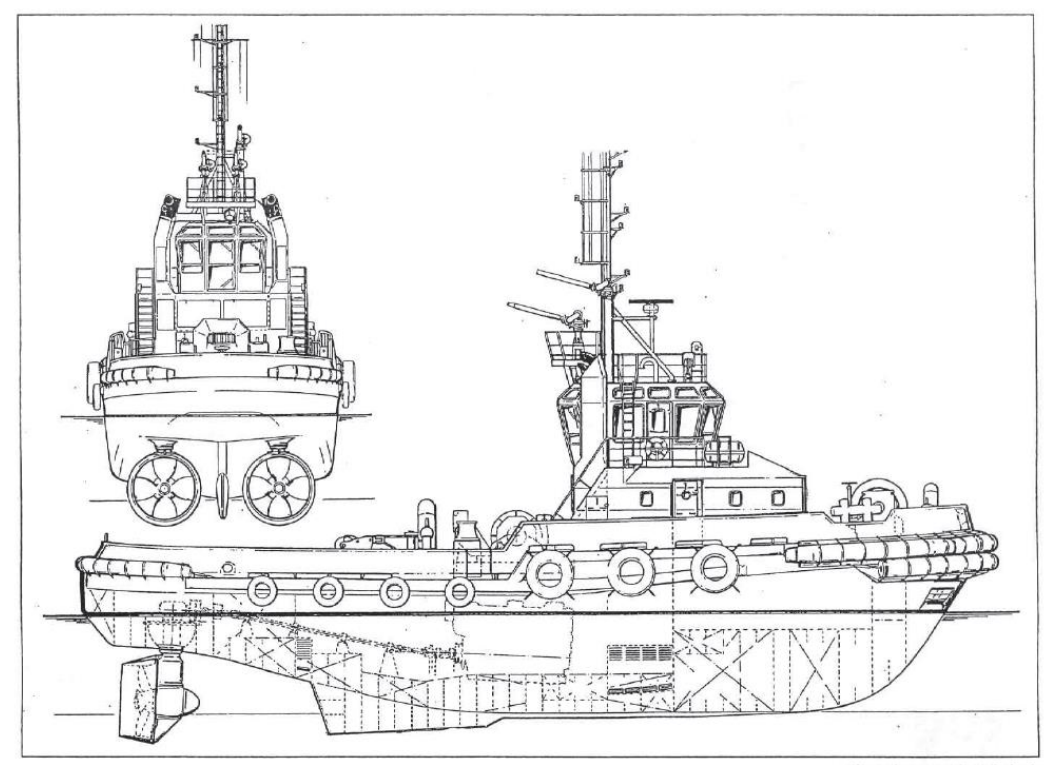

Source: (HENSEN, 2003)

The constant desire for naval innovations in relatively small-time frames and wasting the minimum amount of resources as possible as well as the desire for the development of new engineering and analysis tools were some of the main reasons for the augment on investments in science and technology, especially on companies and institutions focused on the development of Ship Maneuvering Simulators (SMS). Normally, these simulators correctly represent the mathematical model of a vessel subjected to external disturbances. However, most of these simulators struggle to correctly represent the actuation forces that the tugboats exert on a vessel during a maneuver. Usually, the maritime simulators represent such actuation as external forces, with really simplified models, calling such tugboats as vector tugs. 
Although few simulators do have the tugboat's dynamics modeled, they usually still use the vector tugs. This is the case because experienced tug masters are not always available in the simulator centers to perform the maneuver. In addition, to run a maritime simulation with several manned tugs would require several integrated simulators running together in real time, which is appreciably more expensive than running a single simulator. The Figure 2 shows a simulation using the full mission cabin to model the main vessel, one cabin to control the manned tug and a vector tug control station to command the remaining tugs presented in the maneuver.

Figure 2 - Real-time simulation control stations.

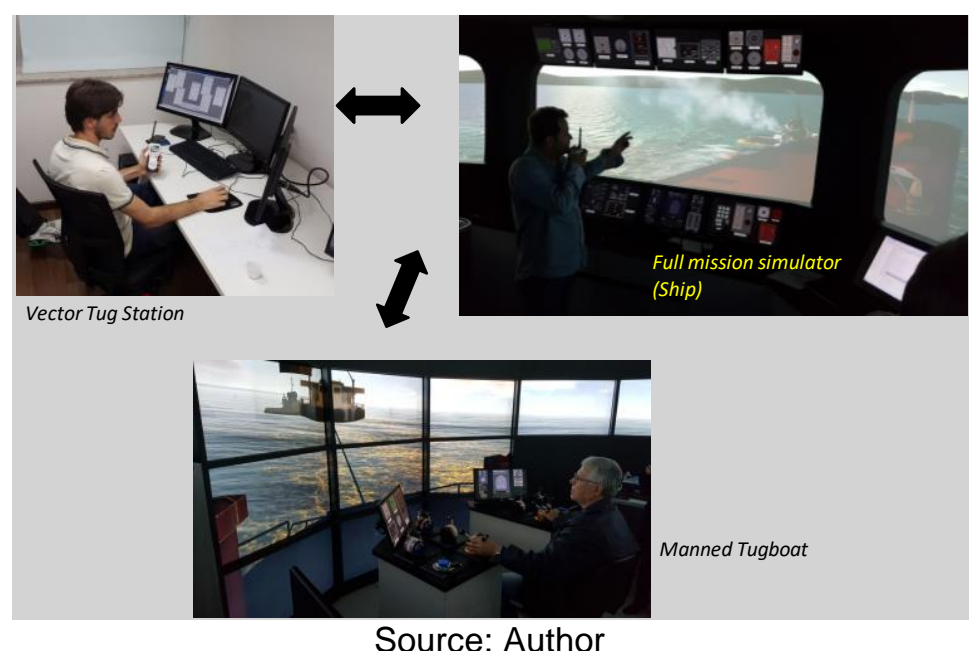

As seen in Figure 2, only one operator is needed to control several vector tugs, while a tug master is necessary to control each manned tug. This makes clear that the man-machine interaction on a manned tug is extremely intense. As mentioned, there are several factors affecting the tugboat actuation and performance, thus requiring an elevated level of attention from the tug master. By proposing a new model that can accurately represent a tugboat actuation with a significantly reduction of operation complexity will enhance and extend the capabilities of SMS.

As most of the SMS worldwide, the Maritime Simulator, presented in the Numerical Offshore Tank Laboratory (TPN - USP), has been looking for new model developments in order to enhance its vector tugs. Therefore, this work will be focused on improving such actuation model in such a way that both the actuation forces as well as the navigation of a vector tug will become as similar 
as possible to the performed by the manned tugs, thus bringing the maritime simulations to a new level of reality when vector tugs are used.

\subsection{Motivation}

About 40 years ago, the marine training on land was comprised by only basic radar simulators which were linked to a visual display that solely provided the ships navigational lights. Due to this lack of technology, the maritime personnel could only learn the 'rules of road' and the bridges procedures prior to boarding, thus performing most of their training facing real life situations, inside of a vessel (SPEIGHT and STRANNIGAN, 2015).

The poor training of the maritime personnel was one of the reasons for several incidents of groundings, collisions and total constructive loss that have happened over the years, becoming more frequent with the increase of vessel traffic (LLOYD and RODRIGUES, 2012). Such accidents have evidenced a real necessity to improve the knowledge and the skills of the mariners prior to their boarding. In order to fill this gap and minimize the navigation risks, SMS started to be developed.

The SMS are a combination of several mathematical models that are able to properly represent the behavior of water vehicles (vessels, tugboats, etc.) subjected to external disturbances in real time. The main advantage of using such a tool for maritime training is its flexibility. On a SMS one can iteratively alter several parameters such as the environmental conditions of current, winds and wave in order to train the mariners for every possible situation they would face overseas.

Over the last years, the applicability of the SMS has been extended and they started to be used for feasibility analysis of port constructions and maritime maneuvers. As an example, the TPN-USP has used its simulation capacity to study the feasibility of a large port in Espírito Santo, which will be called Porto Central. In addition, the same laboratory studied new containerships with lengths of $366 \mathrm{~m}$ at the Santos port, under certain constraints. Note that, in the past, the largest vessel allowed to transit at the Santos port was $336 \mathrm{~m}$ long. 
In order to perform feasibility studies, tugboats are normally implemented to assist in the simulated maneuvers. Since tugboat captains are not normally available in SMS, the called vector tugs are commonly used.

Although vector tugs have been little studied in the literature, the incorrect representation of their behavior in SMS may impact the conclusions of the feasibility analyzes performed, thus motivating a deep investigation regarding the proposed theme.

\subsection{Objectives}

The main objective of this work was to develop an actuation model to allow the vector tugs used in SMS to behave in the same manner manned tugs would. The new vector tug model was implemented and tested on the simulator located at TPN-USP.

During the development of the vector tug model, the author focused in the following aspects: the correctly representation of vector tugs forces exerted either in push or pull operation modes; the interaction of the vector tugs with the external agents such as winds, currents and waves and how such interaction affected the vector tugs efficiency and consequently its towage force; the dynamics of the vessel and tugboats in waves, and how it can be used during a simulation in order to measure towline peaks; the response time of vector tugs changing position around a vessel.

In addition, a user-friendly graphical interface for operators to control the vector tugs at TPN-USP was developed, considering the indirect towing maneuver, an advanced towage technique that takes advantage of the hydrodynamic forces to maximize the force on the towline.

\subsection{Structure of the Text}

Chapter 2 starts with an overview on the evolution and application of SMS along the years. Afterwards, it focusses on the analyzes regarding tugboat modeling and operation, specially focusing on the ones performed to fulfill the needs of SMS. 
In chapter 3, a theoretical background regarding the propeller modeling as well as the current and wind force models that direct influence a tugboat operation are provided. In addition, it presents a model to calculate the losses of efficiency a tugboat would experience when subjected to wave motion as well as efficiency gains when entering wave shadow regions. Finally, it presents a model to calculate peaks on the towline due to wave motion.

In chapter 4 , the static equilibrium models, which are the base for the calculation of the actuation forces of a tugboat, are presented for 3 different types of operation: Pull-Direct, Pull-Indirect and Push. In addition, the optimization problem for each scenario is proposed.

In chapter 5, some case studies to test the models developed are presented along with the obtained results.

In chapter 6, the results obtained in the case studies were validated either with data obtained from manned tugs presented on the TPN-USP simulator (PullDirect) or with data obtained from other works (Pull-Indirect).

In chapter 7, the dynamics of both a Regular ASD and an Escort Tug under the presence of waves are analyzed for an escorting maneuver at the Açu port. The towline peaks are presented for both tugboats, allowing conclusions to be taken regarding the operability of each one of them.

In chapter 8, a study regarding the response time of vector tugs are presented for 3 specific situations: tugboat rotating around its central axis without translation; tugboat transitioning between push and pull operation modes; tugboat changing board (i.e., going from port to starboard or vice-versa).

In chapter 9, the conclusions of the work are exposed. 


\section{BIBLIOGRAPHIC REVIEW}

On the following sections, an overview on the evolution and usage of SMS will be presented as well as the evolution of tugboat operation and actuation modeling for simulation purposes. These two initial sections will be based on articles obtained from the International Conference on Marine Simulation and Ship Manoeuvrability (MARSIM), one of the most important in the area and the only one strictly focused on modeling for SMS. The third section will continue to focus on tugboat operation and actuation as well as the disturbances and actuators affecting this system, but from other bibliographic sources.

\subsection{Naval Numerical Simulators Evolution - MARSIM}

By the late 60's, large vessels began to arrive at the ports worldwide. Therefore, SMS started to be developed as an engineering tool to analyze different aspects of braking maneuvers. Some initial relevant works on this subject may be found in (CLARKE and WELLMAN, 1971) and (CARD, 1979), with focus on large vessel's stopping distances using either the available astern propeller or auxiliary devices, such as tugboats.

In 1978, the International Marine Simulator Forum (IMSF) was created in order to stablish consensus between the simulators worldwide. This institution is responsible to establish compatible languages and formats for ship equations of motion, thus initiating to implement simulator standards.

In order to spread and create a common knowledge about SMS and their applications, the IMSF idealized the International Conference on Marine Simulation and Ship Manoeuvrability (MARSIM). This conference, considered as one of the most important in the area, started in 1978 and has meetings every 3 years.

On the first MARSIM conference in 1978, the focus was to discuss the costs and benefits as well as the application of SMS. In (MATSUURA, 1978), the IHI Ship Manouvering Simulator is presented and the training of ship steering for helmsmen and ship masters is discussed as a possible application. In (ZADE, 1978), the author states that there is an emerging need to make pilots to 
participate in ship handling courses, thus showing that pilot training should be another application of SMS. In general, the presented papers agreed that all the training performed in SMS would positively impact the safety of the nautical maneuvers.

On MARSIM 1981, the focus was to present how the SMS developed up to date. In (MILLAR and REYNOLDS, 1981), the evolution on the simulators developed in UK is provided. These simulators were developed based on the constant feedback obtained from the maritime personnel. In order to improve the equations of motion, more than 2000 scale tests were performed for each vessel. These simulators could correctly represent the behavior of vessels when navigating under high speeds, but the vessel behavior on low speed was still questionable. In (CARPENTER, NOLAN, and CHEONG, 1981), the capabilities of the M.I.T.A.G.S Ship Simulator are presented. In this SMS, a 160,000 DWT tanker, an 80,000 DWT tanker, a Ro-Ro vessel, two container ships, a twin-screw and diesel, a 20,000 DWT break bulk and a LNG vessel were designed and could be simulated. In addition, in order to enhance the simulator didactic, the instructor was able to: freeze and restart an exercise, simulate steering or propulsion failure, simulate loss of navigation apparels, etc.

The next MARSIM, performed in the Netherlands - 1984, instead of the theoretical background, presented practical application for SMS, focusing on training exercises for the maritime personnel. In (RAWSON, 1984), a cooperative training for a Vessel Traffic Safety (VTS) operator and a ship-master is proposed. The VTS operator should use a radar to supervise 4 vessels navigating in a close proximity to each other. The bridge team simulator was responsible to control 3 target vessels while the shipmaster under training would control the ownship. All the players on the simulation had a VHF radio and they navigated based on the directions provided by the VTS operator. This was basically a communication exercise, where the main objective was to allow the shipmaster and the VTS operator to effectively work together, creating an orderly safe traffic flow at all ship crossing stages. In (BEADON, 1984), a watch keeping course for cadets was proposed with the objective to provide the students a deeper level of experience prior to boarding, thus decreasing the sea service time required to 
obtain the first certificate of competency. During the course, several scenarios were simulated in such a way that the cadets could experience either open sea navigations or berthing maneuvers. At the end of the course, they should be able to: interpret ship maneuvering data and appreciate the ship's turning ability, prepare a passage plan using the navigational information provided, keep a safe navigational watch, etc.

On MARSIM 1987, the main topic of discussion was the usage of SMS to support harbor and waterway designs, an ambitious new application at the time. In (PUGLISI, HOORDER, et al., 1987) the Computer Aided Operations Facility (CAORF) simulation center was used in order to evaluate 8 new possible configurations for the Panama Channel, more specifically at the Galliard Cut region. The main objective was to define the optimal channel configuration that would allow two Panamax class vessels to cross each other in a safe way. In a similar fashion, (DAGGETT, HEWLETT and HELTZEL, 1987) used the US Army Engineer Waterways Experiment Station (WES) ship simulator to test the feasibility of a channel widening on the Savannah Harbor. After several runs conducted in the simulator, it was concluded that the vessel controllability had improved with the new design. In addition, the usage of the simulator allowed the researchers to realize that the area between the Marsh Islands and King Islands was highly susceptible to groundings, thus requiring a higher attention from the pilots when navigating there.

On the fifth MARSIM conference, 1990, more attention to the simulation realism was given, specially focusing on image processing. In (HATTERMANN, 1990), a realistic image generation model was proposed through the usage of parallel and pipeline structures as well as dynamic load-distributions. On this work, a 4-stage process was implemented: Geometry Computation, Illumination Model, Rendering and Color Computation. On the Geometry Computation stage, coordinates and perspective transformations were performed; on the Illumination Model, face brightness, face color and sensor brightness were calculated for each image on the scenario; on the Rendering phase, the hidden surfaces due to a specific angle of view were removed; on the Color Computation phase, the antialiasing was performed as well as the calculation and display of the objects' 
texture. In (VLUGT, LANGENKAMP, et al., 1990), another step-by-step process to provide realist environmental images for maritime simulators was provided. First of all, object data must be developed. Such objects can be easily developed in CAD using no more than 600-1000 polygons. Secondly, a point model object must be generated, which is the $\mathrm{x}, \mathrm{y}$ and $\mathrm{z}$ coordinates of every point of the drawing (in the global coordinate frame). After developing the point model object, distinct colors can be added to each polygon on the scenario. Finally, shade and texture were applied.

On MARSIM 1993 and 1996, the focus continued to be related to realism improvement of SMS, but now focusing on maneuvering behavior in shallow waters as well as hydrodynamic force prediction. In (GRONARZ, 1993), it is shown that the turning circle diameter and the drift angle of a vessel increase under the shallow water influence. In order to take into account the shallow water effects, the author assumed that the dominating influence of the water depth is found at the hull forces, thus this is the only parameter affecting the equations of motion that must be altered. In order to alter such parameters, the nondimensional hydrodynamic coefficients for different water depths must be computed and then interpolated in real-time in order to calculate the correct hull force actuating on a vessel. On both (NONAKA, 1993) and (KIJIMA, FURUKAWA and YUKAWA, 1996) the prediction of the hydrodynamic forces is performed throughout the slender body theory. On the slender body theory, the vessel's draft and breadth must be relatively small compared to the ship's length. On the potential theory, it must be assumed that the fluid is perfect and irrotational. In addition, the flow field around the ship must satisfy 5 fundamental conditions: Laplace's equation, condition on the body surface, condition on the free vortex layer, condition at infinity, separation condition. Using such theory, both authors obtained satisfactory results when comparing to model tests.

On the eighth MARSIM congress, 2000, the discrepancy and disparity among the several SMS around the world turned the conference focus to be the validation and classification of such devices. In (CROSS and OLOFSSON, 2000), the new DNV classification standards for SMS were introduced. According to this work, the SMS must be divided in 4 different categories: Full Mission, Multi Task, 
Limited Task and Single Task. The Full Mission must be "capable of simulating a total environment, including capability for advanced manoeuvring and pilotage training ins restricted waterways"; the Multi Task must be "capable of simulating a total navigation environment, but excluding the capability for advanced restricted-water manoeuvring"; the Limited Task must be "capable of simulating and environment for limited (blind) navigation and collision avoidance training"; Single Task must be "a desk-top simulator utilizing computer graphics to simulate particular instruments, or to simulate a limited navigation/manoeuvring environment but with the operator located outside the environment". Each simulator category must be classified based on 6 aspects: suitability for training and objective assessment; physical realism; behavioral realism; capability of producing a variety of conditions; human interaction; capability for the instructor to control and record exercises.

On MARSIM 2003, the focus changed towards automation and course control of regular vessels and dynamic positioning systems. In (HAMAMATSU, KOHNO, et al., 2003) a Receding Horizon (RH) nonlinear control system was designed to control the course and heading of a 6-azimuth propeller vessel. The author used the way-points method in order to feed its controller with the desired position and heading angle over-time. In addition, the author used optimum thrust allocation methods in order to obtain the best propeller configuration, stressing the actuator as minimum as possible. In (QING, XIU-HENG and ZAO-JIANG, 2003), a vessel's heading autopilot is proposed using a Fuzzy Self-learning control. Although PID controllers have been extremely used for such purpose, their efficiency severely decreases when a vessel is subject to extreme external disturbances. The main idea of using a Fuzzy Self-Learning control is to use previous information to modify the control variables in real-time, thus minimizing the autopilot errors and increasing the controller efficiency.

On MARSIM 2006, the simulators started to be used in a more qualitative way. Several articles used the information obtained in simulator training records in order to understand human error patterns as well as mariners' behavior for avoiding a collision. In (NISHIMURA and KOBAYASHI, 2006), a specific maneuver was tested for two distinct scenarios: one with good visibility and 
another with poor visibility. In each maneuver, the mariner should look for target vessels on the scenario and change its ownship direction to avoid a collision. After analyzing the results, it was concluded that the mariners can easily predict the behavior of target vessels using both the radar and their visual feedback, but they cannot achieve such prediction success only by using the radar, thus explaining why more collisions occur under lower visibilities. In (KOBAYASHI, 2006), 5 main important mariners' behaviors for avoiding a collision were exposed: first detection of target vessel; first recognition of target vessel as dangerous vessel; the situation at starting action for avoiding collision; the situation at the closest point of approach; variation of measured behavior. As one of the main conclusions, the author states that the relative angle of navigation between two vessels does not influence on the moment the mariner first detect the target vessel.

On MARSIM 2009, the focus was to model and study the behavior of vessels when subjected to wave motion. In (QIU, PENG, et al., 2009), nonlinear motions of vessels in waves were solved in time-domain based on the panel-free method. The results of such simulation were validated through scale model comparisons. The wave forces modeled were divided in 3 different components: radiation, diffraction and Froude-Krylov. The radiation and diffraction forces were linearized and solved in the frequency domain. The nonlinear Froude-Krylov forces were solved in real-time and they were based on the vessel's instantaneous wetted surface area. In (YASUKAWA and NAKAYAMA, 2009), a similar mathematical model was proposed to evaluate a vessel turning ability under the presence of regular waves. The main difference between the first work and the second is that the second considered both low frequency and high frequency wave components, while the first one only considered low frequency components.

On the last 2 MARSIM conferences, 2012 and 2015, the focus was to develop mathematical models to correctly represent ship-to-ship interactions as well as the ship-bank interactions. In (XU and SUN, 2012) several experiments of ship crossing were performed. During these experiments, the author varied the speed of the vessels, draught, length, etc and wrote down the force curves experienced by each vessel. Afterwards, the authors applied the Artificial Neural Network 
(ANN) model in order to obtain the interaction forces on the crossing vessels based on previous force curves and the vessels current parameters. In (FURUKAWA, IBARAGI, et al., 2015), a similar procedure was adopted in order to calculate the interaction forces between a bank and a vessel. Several scale tests were performed in order to obtain the suction force curves generated by the bank on the passing vessel as function of the water depth, the width of the waterway, the separation from the sidewall and the vessel drift angle. Afterwards, again, self-learning models considering such parameters were used in order to estimate the interaction forces.

In Figure 3 and Figure 4, a summary of the SMS evolution is presented.

Figure 3 - Evolution of SMS from 1970 to 1990

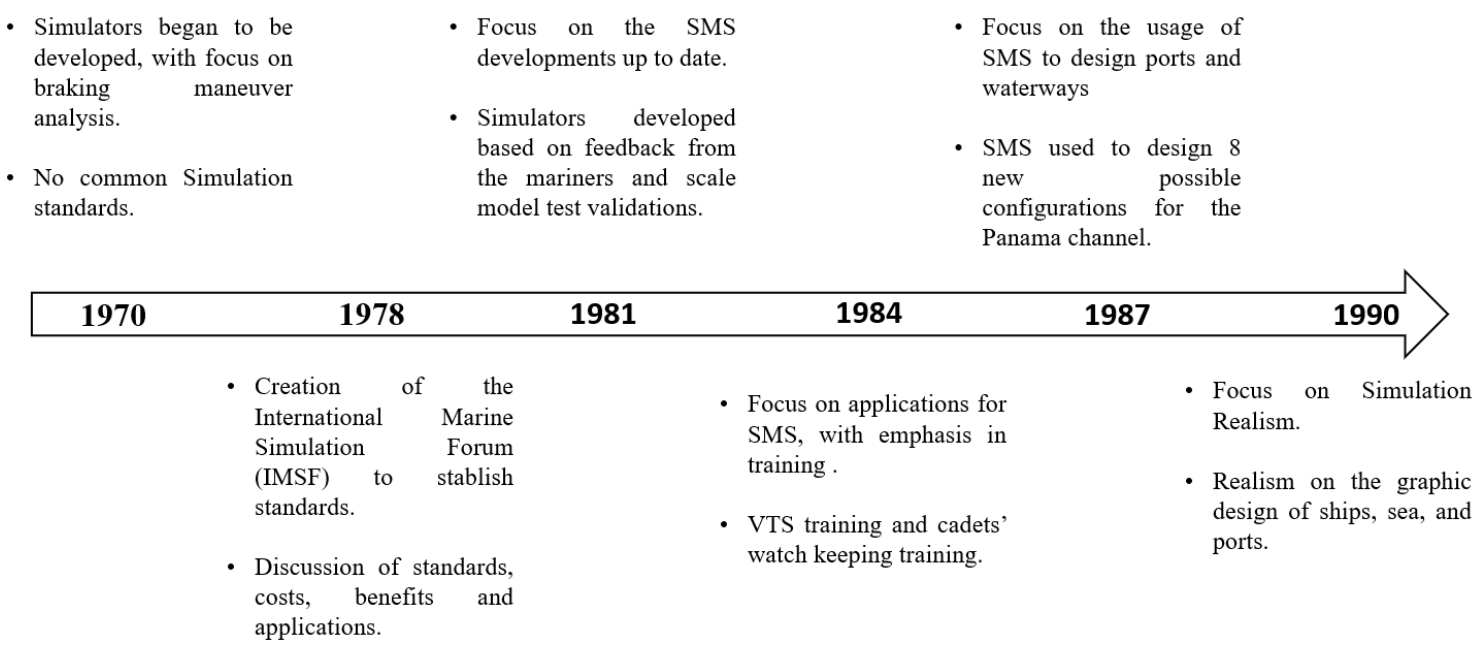

Source: Author 
Figure 4 - Evolution of SMS from 1993 to 2015

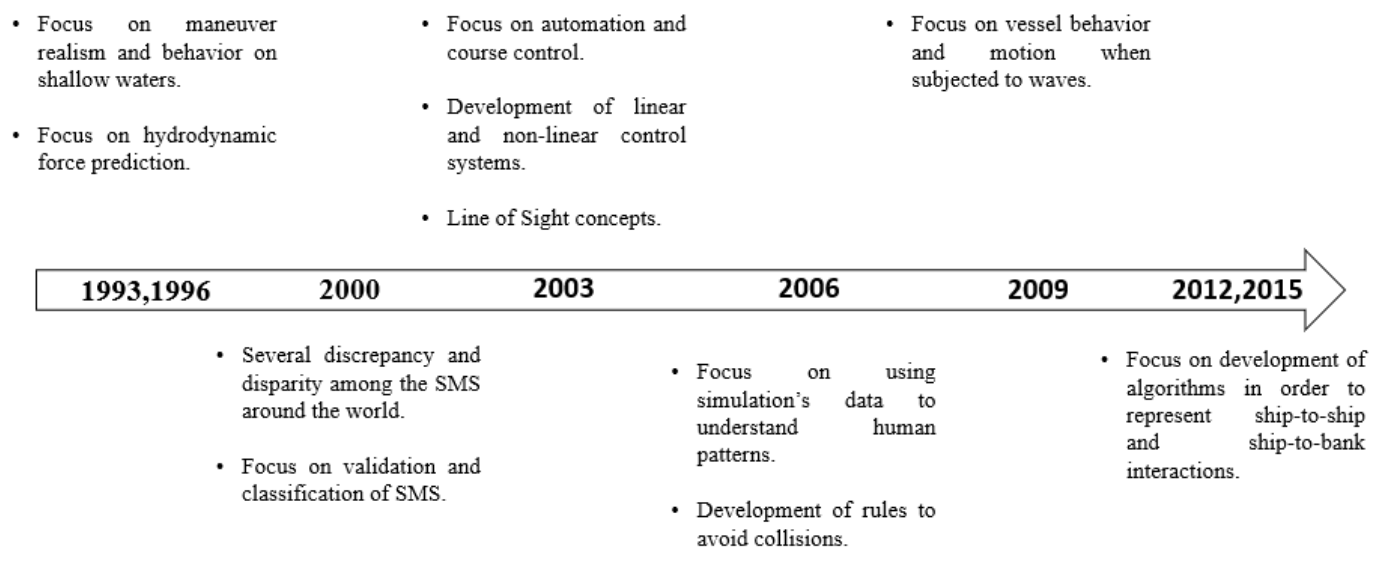

Source: Author

\subsection{Tugboat Operation and Actuation Modeling for Simulation Purposes - MARSIM}

Although the operation of tugboats is essential on the maneuvering of large vessels, the first article focusing essentially on tugboat actuation modeling was only published in 1984. In (TAYLOR, SANBORN and BUCHANAN, 1984), a tugboat with twin screw propellers and two rudders was modeled for 6 different scenarios (Figure 5). In the first scenario, the tugboat was modelled to freely navigate overseas; in the second one, the tugboat was modeled for an operation where it would be pushing a full loaded vessel's stern; in the third case, the tugboat was modeled for an operation where it would be pushing a loaded barge transversally on its hull; in the fourth scenario, the tugboat was modeled for an operation where it would be pushing a light vessel's stern; in the fifth scenario, the tugboat was modeled to be pushing a light vessel's hull in order to provide it a forward motion; in the sixth scenario, the tugboat was modeled to be pushing a light vessel's hull in order to provide it a backward motion. Note that the tugboats for each of these scenarios were modeled in an empirical way. The coefficients of the tugboat's mathematical model were constantly altered in order to match the data obtained in a real maneuver. According to the authors, the first tugboat's mathematical model took so long to be developed because of its complexity when compared to regular vessels' mathematical models. The tugboats have a much faster response and their actuators are not located on the central axis. 
In MARSIM 1990, (KATTAB, 1990) proposed a 4-degree of freedom tugboat model assuming the motions on heave and pitch as negligible, thus leaving the tugboat model free to translate only in the $x$ and $y$ directions as well as to experience a rotation about its vertical and horizontal center axes (yaw and roll). The proposed model considered the hydrodynamic and wind forces as well as the forces provided by two propellers and two rudders. In addition, the model considered the reaction force generated on the tugboat when towing in pull mode. A simulator was generated with this mathematical model in order to help in tugboat design. The main idea was to constantly change the towline position and analyze the tugboat behavior on each scenario. After obtaining the best towing position, a real tugboat could be constructed. The approach proposed would mitigate poor tugboat designs.

Figure 5 - All tugboat scenarios modeled.

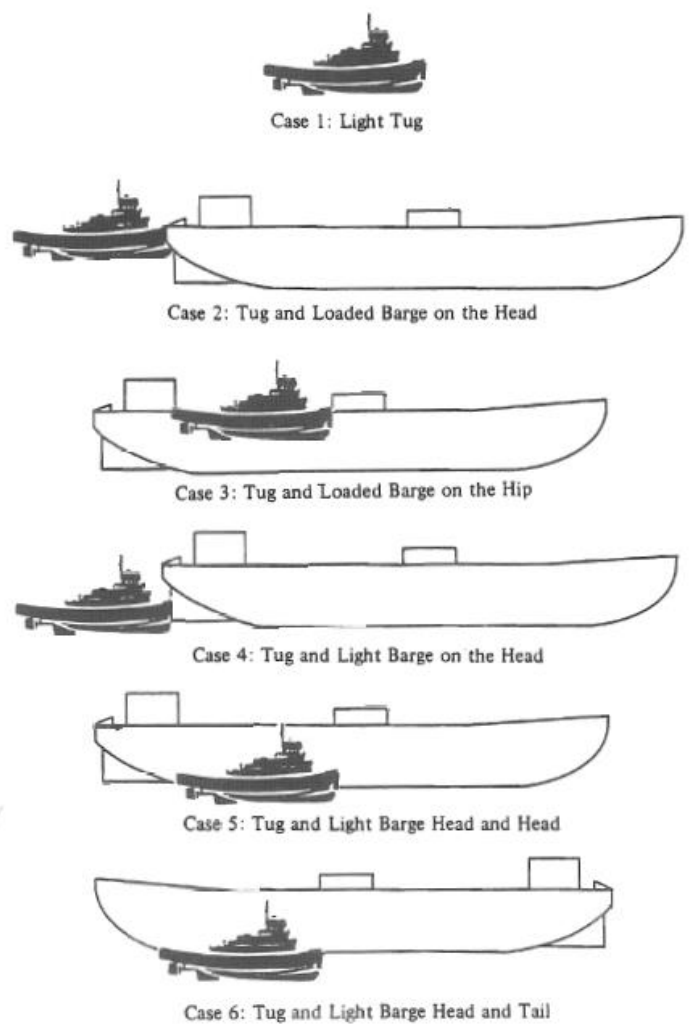

Source: TAYLOR, SANBORN and BUCHANAN, 1984

In (TAKASHINA and HIRANO, 1990), the shallow water effects on a vessel being assisted by tugboats was studied. On this work, the author modeled 3 tugboats actuating as if they were fixed-direction propellers with alternating rotation 
direction, thus characterizing an initial simplified version of vector tugs. As shown in Figure 6, two tugboats would be able to act transversally (on the vessel's bow and stern), while the other tugboat would be able to actuate longitudinally. Several captive tests were performed in order to validate the model proposed. During these tests, fans were responsible to represent the actuation of the tugboats.

Figure 6 - Simplified vector tug model.

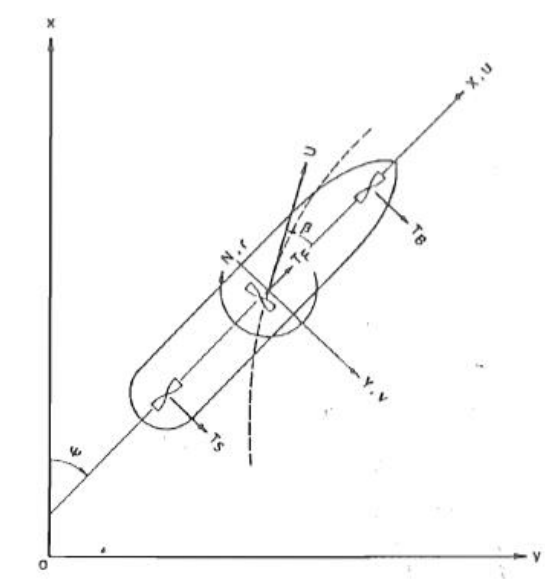

Source: TAKASHINA and HIRANO, 1990

In (ANKUDINOV, MILLER, et al., 1990) several configurations of barges being towed by a tugboat on push mode were modeled. The authors performed several tests with reduced scale models and real size models in order to obtain the hydrodynamic coefficients of the system for many maneuvering scenarios. Afterwards, by using the data obtained during the tests, the author developed a system identification algorithm capable of extrapolating the hydrodynamic coefficients of the system for every possible towing scenario. The extrapolated hydrodynamic coefficients were then used on the 3 - DOF model developed. According to the author, the accuracy of the model proposed would be essential in order to analyze the tugboats behavior under push operation, thus allowing the port channel designers to have one more input information during their analysis.

In (BRANDNER,1993), a static-equilibrium model was used to predict the towing force and tugboat actuation position on both push and pull operations. The main advantage of such model is that no differential equation needs to be solved in order to obtain the tugboat correct actuation for a specific scenario. Still on this 
work, the author used the developed model to study the influence of tug forces on ship manoeuvring in confined waters. After performing tests for a towed vessel navigating under 2, 4 and 6 knots, it was concluded that, for turning the vessel, a tugboat pushing on its quarter is more efficient than the rudder or the same tugboat pushing on its shoulder (Figure 7 and Figure 8).

Figure 7 - Different scenarios tested to turn a vessel.
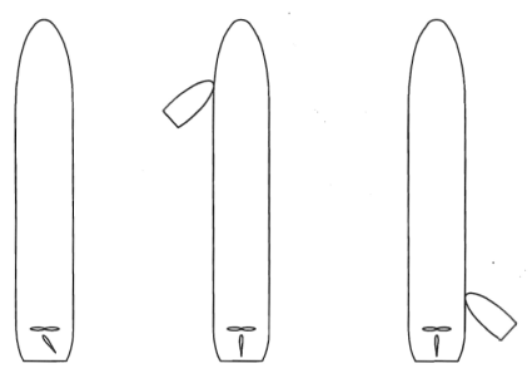

(a) rudder only

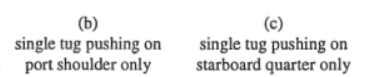

Source: BRANDNER, 1993

Figure 8 - Turning manoeuvres for 4 knots ship speed

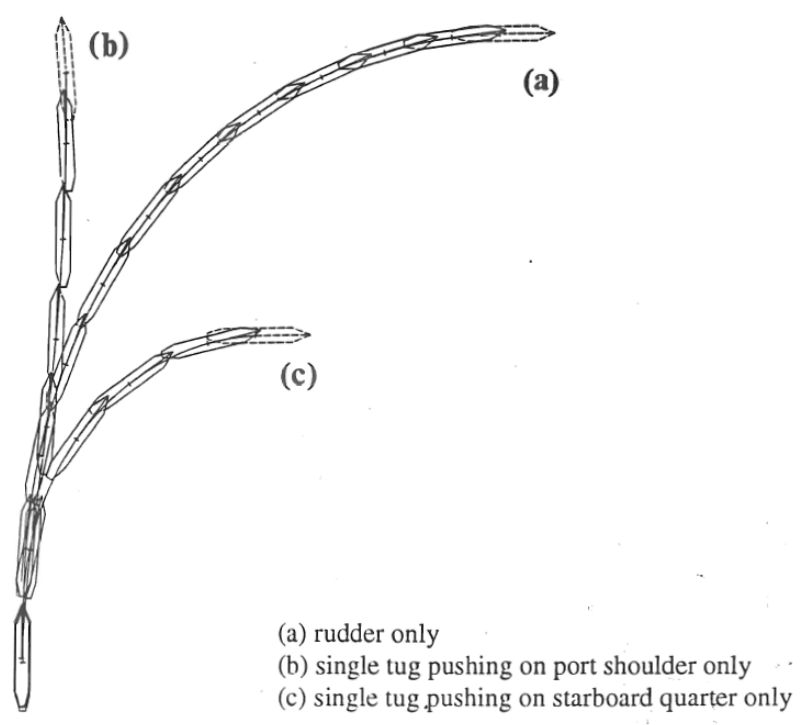

Source: BRANDNER, 1993

In MARSIM 1996, (JAKOBSEN, MILLER, et al., 1996) developed a multi ship handling simulator capable of representing the interaction between a manned 
tugboat and a towed vessel in real-time. In order to include more realism in pull mode, the towline was modeled as a spring with nonlinear characteristics, including effects of the catenary, elasticity and damping. An effective tugboat model must also provide the correct force vector of actuation on a towed vessel, the space the operating tugs need to operate under different scenarios and the reaction time of the tugs. Although the interaction between manned tugboats and towed vessels does increase the maneuver realism, the cost to run several integrated simulators is extremely high. Therefore, the vector tugs are and will continue being extremely necessary for the maneuver's execution.

In MARSIM 2000, 4 works related to tugboat modeling and operation were presented. However, only one of them was available. In (WULDER, HOEBÉE, et al., 2000), a Tug Operational Performance Prediction Software (Figure 9) was developed based on a 6-DOF tugboat manoeuvring model. Such software was able to predict the tugboat actuation force and position for a given towing scenario. The applications for such tool are enormous, but the authors mainly used it as an instruction tool for tug masters during a maneuver and to validate tugboat models on the full bridge simulator.

Figure 9 - Tugboat Operational Performance Prediction Software

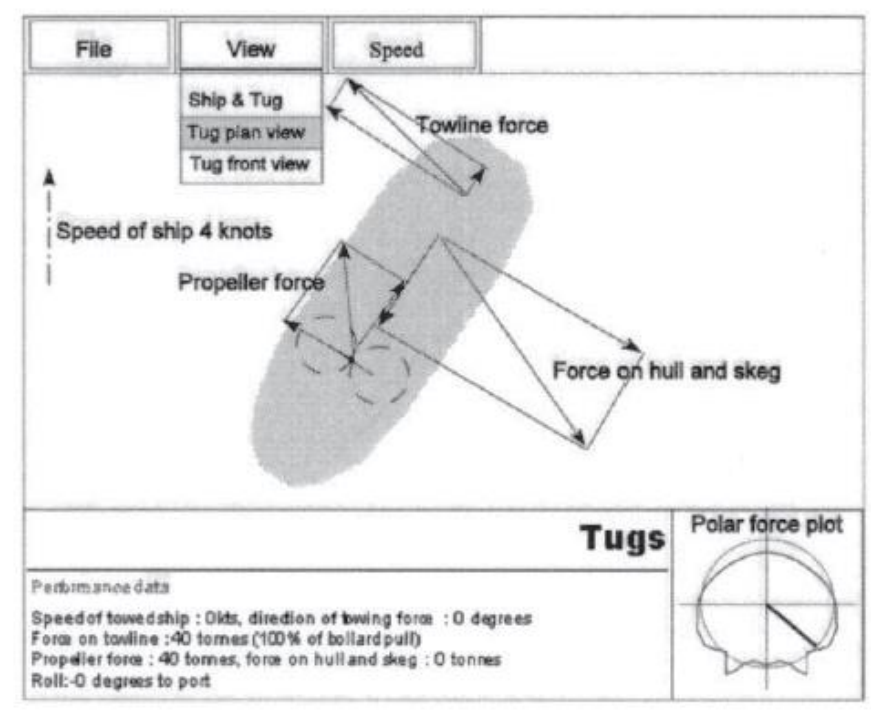

Source: (WULDER, HOEBÉE, et. al., 2000)

The next works concerning tugboats maneuvering and operation appeared only on the 2006 MARSIM. In (HILTEN and WULDER, 2006), SMS were used in order to test and check the feasibility of a new tugboat maneuver called "forward brake" 
(Figure 10). Due to the increasing size of the vessels, a higher speed must be maintained in order to mitigate high drift angles occurrence. However, these high speeds of navigation decreased the tugboats capability to control a vessel's heading angle. In the forward brake mode, the center-bow tugboat would reallocate itself to the towed vessel's port or starboard with a long towline length. This new position of actuation proved to significantly increase the steering forces on a towed vessel, thus recovering the tugboat capability to control a towed vessel's heading angle.

In (VARYANI, BARLTROP, et al., 2006), a multi-body mathematical model for a tugboat towing a disabled tanker in pull mode was proposed considering new generic equations to predict the wind forces on the system. In addition, the drift forces were considered in the model. Several simulation scenarios were studied and limits for a safe tow were imposed. In (EDA, GUEST, et al., 2006), a similar multi-body model for a tanker and a tugboat was proposed. The model developed was used in order to reconstruct a towing scenario where an accident had occurred. After analyzing the towing scenario, the causes of the accident were discovered.

Figure 10 - Forward brake mode graphical configuration

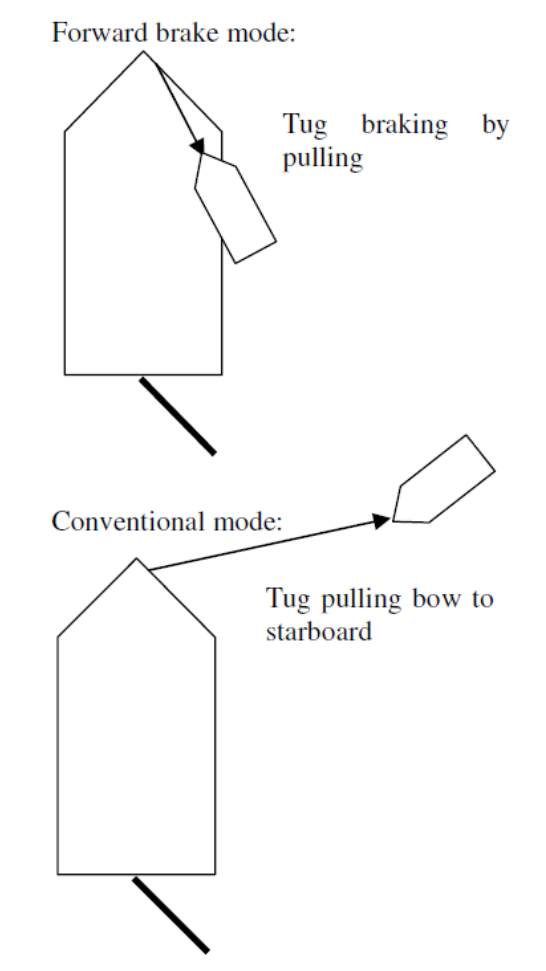


In (XIUFENG, YONG and YECHING, 2006), two methods are proposed to model a Voith Schneider propeller: the chart and spectrum of the propeller arithmetic and the lift coefficients arithmetic. In the first method, the propeller's pulling forces and moments are calculated using mathematical regressions based on open water tests. In the second method, one can calculate the lift force on each of the propeller's blade for a specific scenario and then add up all the blades in order to obtain the total force magnitude exerted by the propeller. In (AGDRUP, OLSEN and JURGENS, 2006), the propeller-hull interaction is also modeled. The authors modeled this interaction based on the wake, thrust deduction and relative rotative efficiency coefficients.

In MARSIM 2009, the focus was turned to the operations of tugboats actuating on the escort mode (i.e., pulling the towed vessel at its stern in order to break or steer it). In (TEJADA, 2009), several simulations were presented to define the best escort operations on the Panama channel. The author defined two operation modes: the direct and the indirect (Figure 11). On the direct mode, the tugboat stays aligned with the towline, actuating on a specific towline angle requested by the pilot. According to this work, this mode is appropriated when the towed vessel is navigating with less than 4 knots, allowing the tugboat to apply $100 \%$ of its bollard pull on the operation. On the indirect mode, the tugboat does not stay aligned with the towline, thus allowing the water to flow around its hull and skeg. This maneuver will cause a high-pressure area in the inner side of the tug's hull (between the tug and the vessel) and a low pressure on the other side, causing lift towards the low-pressure area. According to this author, the indirect maneuver is effective when the towed vessel is navigating with more than 4 knots.

Figure 11 - Direct and indirect operation modes.
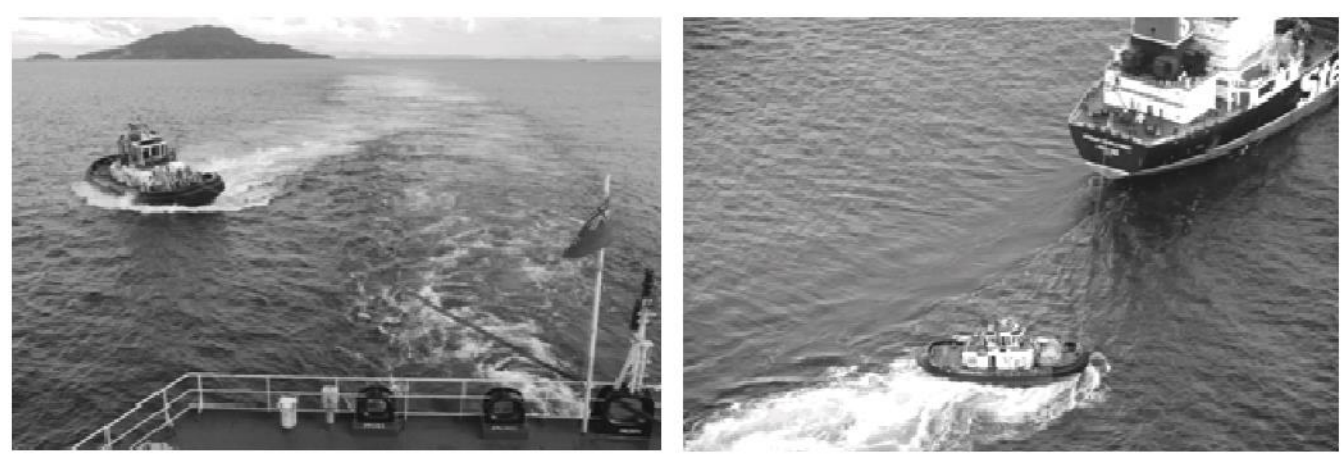

Source: TEJADA, 2009 
In (BROOKS and HARDY, 2009), a similar procedure was performed in order to define the best escort operations in the port of Vancouver, verifying that the tugboats loose efficiency as the towed vessel's speed increase. As shown in Table 1, the direct pull maneuver can still be used when the towed vessel is navigating up to 6 knots. According to the authors, the indirect maneuver is less effective than the direct maneuver when the towed vessel is navigating with less than 6 knots. When the towed vessel's speed is greater than 6 knots, the indirect maneuver becomes suitable for steering, being able to reach up to twice the tugboat's bollard pull. Both studies verified that the tugboats should operate in the direct mode for speeds under 6 knots and they should actuate on indirect mode for speeds higher than 6 knots.

Table 1 - Simulated tug force table.

\begin{tabular}{|c|c|c|c|c|c|}
\hline \multicolumn{6}{|c|}{$\begin{array}{c}\text { Seaspan Falcon/ Seaspan Hawk } \\
\text { Escort @ Stern (44 tons Bollard Pull) }\end{array}$} \\
\hline & \multicolumn{3}{|c|}{ Direct Pull } & Indirect & $\begin{array}{c}\text { Powered } \\
\text { Indirect }\end{array}$ \\
\hline Speed & $\mathbf{1 8 0}$ & $\mathbf{4 5}$ & $\mathbf{9 0}$ & $\mathbf{4 5}$ & $\mathbf{9 0}$ \\
\hline $\mathbf{0}$ & 44 & 44 & 44 & $\boldsymbol{N} / \boldsymbol{A}$ & $\boldsymbol{N} / \boldsymbol{A}$ \\
\hline $\mathbf{2}$ & 44 & 40 & 35 & 4 & 9 \\
\hline $\mathbf{4}$ & 44 & 32 & 28 & 22 & 31 \\
\hline $\mathbf{6}$ & $\mathbf{4 4}$ & $\mathbf{2 7}$ & 20 & $\mathbf{3 6}$ & $\mathbf{4 4}$ \\
\hline $\mathbf{8}$ & $\boldsymbol{N}$ & $\mathrm{N} / \mathrm{A}$ & $\boldsymbol{N} / \boldsymbol{A}$ & $\mathbf{5 4}$ & N/A \\
\hline $\mathbf{1 0}$ & $=$ & $\boldsymbol{N} / \boldsymbol{A}$ & $\boldsymbol{N} / \boldsymbol{A}$ & 45 & N/A \\
\hline
\end{tabular}

Source: BROOKS and HARDY, 2009

In MARSIM 2012, the attention was given to the modeling of tugboat towlines tension as well as the rotor tug types. In (REN, ZHANG and SUN, 2012), two towline tension models were presented: the towline tension with linear strain and the towline tension with nonlinear deformation. In order to obtain the towline stress, the author first assumed that Hooke's Law was satisfied, thus being able to calculate the tension according to the linear strain model. After that, the author would use the calculated tension to determine if Hooke's law was satisfied for a different series of parameters. If Hooke's law was not satisfied, the tension would be recalculated using the nonlinear deformation model. Note that this was an interactive process, thus requiring computational software to mutually solve the towline model equations. In (SORENSEN, DAMSGAARD, and NIELSEN, 2012), a rotor tug model was proposed. Differently from the ASD tugboat that possess two skew-symmetric propellers on the tugboat's aft, the rotor tug possesses two 
skew-symmetric propellers on the tugboat's bow and a third propeller on the tugboat's center-aft. Such propeller configuration allows the rotor tug to have an extreme maneuverability and the ability to work well in narrow spaces. In this work, the main challenge was not to model the tugboat itself, but to consider the thruster-thruster-thruster interaction as well as the thruster-thruster-thruster-hull interaction. Although still little used, the authors believe that the rotor tug will become a worldwide trend soon.

In the 2015 MARSIM conference, the focus was on ASD tugboat modeling. The ASD tugboats are the most used tugboat type nowadays. In (REN, ZHANG and HUO, 2015), a 3-DOF ASD tugboat model was presented, with focus on the design of the tugboat propellers. The regression results for a JD75 tunnel propeller were obtained through open water tests. Such parameters were essential in order to obtain the KT curve, which is one of the aspects that directly affect on the calculation of a propeller thrust. Several turning tests and zig-zag tests were performed to validate the model proposed. In (FUCHS, HWANGE, 2015), several information was gathered from a real tugboat and provided to the reader in order to validate ASD tugboat models in SMS. According to the authors, there are 5 maneuvers that are basic for any ASD tugboat: managing speed, stopping, steering, operating stern first, and moving laterally. Therefore, in order to validate an ASD tugboat, one can perform such maneuvers and compare with the data provided.

In MARSIM 2018, (BARRERA and TANNURI, 2018) extended their previous work regarding tugboat actuation modeling by providing the efficiency curves of a 60 tonnes bollardpull tugboat operating in pull mode. The efficiency curves were obtained for the 5 most requested order by the pilots: $100 \%$ of the tugboats' maximum power; $80 \% ; 50 \% ; 25 \% ; 10 \%$. By using the efficiency charts provided along with the charts regarding the tugboat acuation position for the entire range of towlines angles, one could easily implement a vector tug on a SMS without the need to solve a complex and time consuming optimization algorithm. In addition, this work showed that, by translating the obtained curves in a specific towline range interval, the curves proposed could represent the tugboat actuation for any combination of external current and vessel's advance speed. 
In Figure 12 and Figure 13 a summary of the evolution in tugboat's modeling and operation is presented.

Figure 12 - Evolution on tugboat models and operation from 1984 to 2000

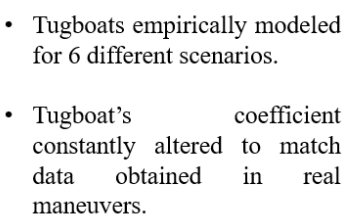

- $\quad$ Static-equilibrium model to predict towing force and tugboat actuation position

- Main advantage: No differential equations need to be solved
Development of a Tug Operational Performance Prediction Software.

- Software able to predict tugboat actuation force and position for a specific scenario.

\begin{tabular}{|c|c|c|c|c|}
\hline 1984 & 1990 & 1993 & 1996 & 2000 \\
\hline & $\begin{array}{l}\text { - Studied the effects of shallow } \\
\text { waters on a vessel assisted by } \\
\text { tugboats. }\end{array}$ & & $\begin{array}{l}\text { - Development of multi-player } \\
\text { simulator. }\end{array}$ & \\
\hline & $\begin{array}{l}\text { - Initial simplified version of } \\
\text { vector tugs }\end{array}$ & & $\begin{array}{l}\text { - Interaction between manned } \\
\text { tug and towed vessels in real- } \\
\text { time. }\end{array}$ & \\
\hline
\end{tabular}

Source: Author

Figure 13 - - Evolution on tugboat models and operation from 2006 to 2015

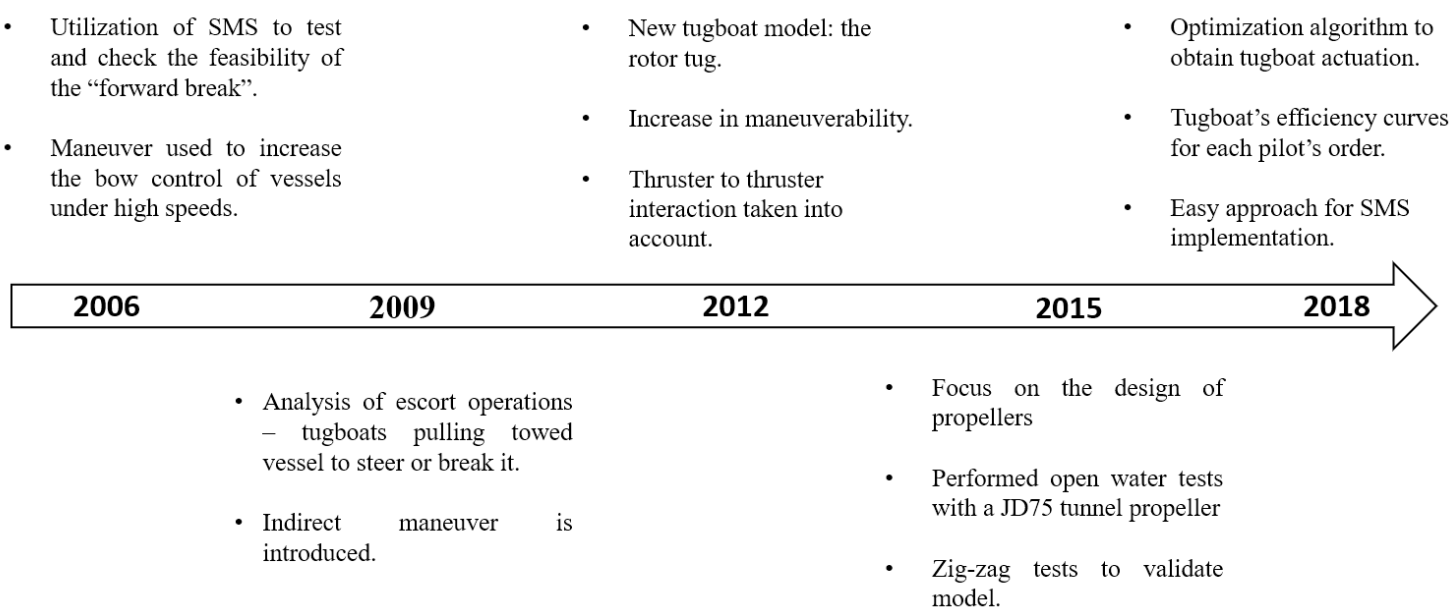

Source: Author

\subsection{Tugboat Operation and Actuation Modeling for Simulation Purposes - Practical Guidelines}

It is also important to cite some additional references that have been extremely used to understand and model tugboat operations. The Tug Use in Ports book (HENSEN, 2003) is considered the bible of towage operations nowadays, and it 
has been extremely used for the whole maritime community since it was first published. In this work, several types of harbor tugboats are studied (Conventional, ASD, Tractor, etc) with focus on their capabilities and limitations. In addition, Henk Hensen provides a detailed study of several tugboat assisting methods (direct method, indirect method, transverse arrest, etc) as well as the efficiency of each tugboat type under each assisting operation. Finally, the author provides some mathematical models to calculate the maximum tugboat bollard pull necessary in a maneuver and he addresses some safety operation procedures that must be executed by tugboat commandants.

Following the same lines of the Tug Use in Ports book, Fragoso and Cajaty (2012) decided to create a Brazilian manual regarding tugboat procedures and operations. In this work, again, the differences between each tugboat type are explained as well as the restrictions and capabilities of them. In addition, the book addresses how the wind, current and wave may affect a tugboat operation. Although (HENSEN, 2003) and (FRAGOSO and CAJATY, 2012) have similar content, the first book is much more quantitative with real data gathered from real maneuvers and port experiences around the world, while the second one is completely qualitative and with an extreme simple language.

In (HENSEN and LAAN, 2016), different design variables are introduced in order to explain the roll static stability of tugboats. In addition, the book provides several stability curves associating righting arms and heeling arms curves. Based on such curves, one can obtain the maximum roll angle where a tugboat stability will occur. Several concepts of reserve stability are also introduced in order to explain the safety limits that must be imposed during tugboat design in order to counteract dynamic heeling effects that are usually not modeled.

In (BRANDNER, 1994), 4-DOF static equilibrium equations were proposed in order to predict a tugboat towing force, considering 3 main contributions affecting the tugboat operation and consequently taken into account in the static equilibrium equations: the tugboat's thruster forces, the hydrodynamic forces on the tugboat's hull, the reaction force on the tugboat when it actuates either in push or pull operation. As a continuation of this work, in (BRANDNER, 1995) a more complete model was proposed, taking into consideration the thruster- 
thruster and thruster-hull interactions in order to calculate the tugboat's propeller force to be input on the static equilibrium equations. In addition, this work presented several scale model tests of tugboats actuating in pull mode. The measured tugboat forces were then compared to the prediction forces of the mathematical model, possessing significant similarity and thus validating the model.

In (ARTYSZUK, 2013), an analytical solution was proposed in order to solve a 3DOF static equilibrium model to predict tugboat towing forces under push operations. To obtain the static equilibrium equations, main control parameters must be analyzed, such as: the tug's propeller thrust; the thruster angle; the tug's hull drift angle for a given towing speed; the resultant towing force; the current speed and its hull drift angle; the wind speed and its hull drift angle. By fixing some of the control parameters, such as the propeller thrust and the vessel advance speed, we can obtain the remaining control parameters such as the propeller's angle of actuation, the tug's hull drift angle and the resultant towage force. In (ARTYSZUK, 2014), a continuation of the previous work was performed. A similar mathematical model was used to predict the tugboat forces under pull operations. For the new model proposed, another control parameter was introduced and fixed: the towline angle.

In (BARRERA and TANNURI, 2017), an extension to (ARTYSZUK, 2014) model was proposed in order to predict the tugboat forces and positions of actuation under pull operations. Instead of analytically solving the static equilibrium equations, Barrera and Tannuri proposed and optimization algorithm along with an interactive solving method in order to obtain the desired equilibrium-state solution. Note that this new approach is interesting since there may exist more than one equilibrium solution for a specific scenario configuration. Since the authors were focused on the direct maneuver analysis, the interactive solution chosen must be the one that would keep the angle between the tugboat and the towline minimized, mimicking what the tugboat commandants do in practice.

The external factors affecting the tugboat towing force prediction model must also be correctly represented, including: the tugboat's propellers, currents, winds and waves. In (OOSTERVELD and OORTMERSSEN, 1972), several open water 
tests were performed with both the 4-bladed B-series screws as well as Ka 4-70 screw series with nozzle no. 19A. Such open water tests along with a regression analysis were enough to model the propeller's thrust coefficient, $\mathrm{K}_{T}$, and the propeller's torque coefficient, $\mathrm{KQ}_{\mathrm{Q}}$, as a polynomial sum as function of the propeller's advance coefficient, $\mathrm{J}$, with the propeller's pitch to diameter ratio as a parameter. In (LEWIS, 1988), a similar procedure was performed for the propellers of the Ka series with a nozzle no. 19A and the same propeller's parameters were obtained.

In (OCIMF, 1997), a guideline for wind and current force calculation is presented as how their actuation severity varies on a vessel, for different situations. The more windedge area above the waterline, more affected by wind forces a vessel will be. On the other hand, the larger the vessel's draft is, a larger area under the waterline will occur, thus making the vessel more susceptible to current forces. Note that, since the water density is around 1000 bigger than the air density, one cannot affirm that a vessel with a small draft is more susceptible to wind forces than current forces. Therefore, such conclusions may only be performed by taking into consideration the vessel's load conditions.

In (BUCHNER, DIERX and WAALS, 2005), several scale tests are performed in order to measure the towing force and the movement amplitude of a tugboat pushing and pulling a LNG Carrier under the presence of waves. Based on the tests performed, it was concluded that, when working on wave unshielded regions, the peak load on the towline and on the tug reached values 4 times large than the actual force applied by the tugboat. In addition, due to the large roll motions and relative wave motions, the tugboat's propeller was coming out of water, which would impair a real operation in the same situations.

Finally, in (PIANC, 2012) several tugboat's efficiency curves were provided for towing under the presence of waves. The curves efficiency were provided as a percentage of the total tugboat's available bollard pull and they were expressed as function of the significant wave height $(\mathrm{Hs})$ and the tugboat's towing operation mode. In (FILHO and TANNURI, 2009), a study presented how a FPSO could generate a wave shadow and considerably decrease the wave significant height around a Suezmax Tanker (Figure 14). Such procedure could be generalized and 
used for any other kind of vessels. By combining both the works cited, one can obtain a better precision when estimating a tugboat's towing force.

Figure 14 - System set-up for wave shielding experiment.

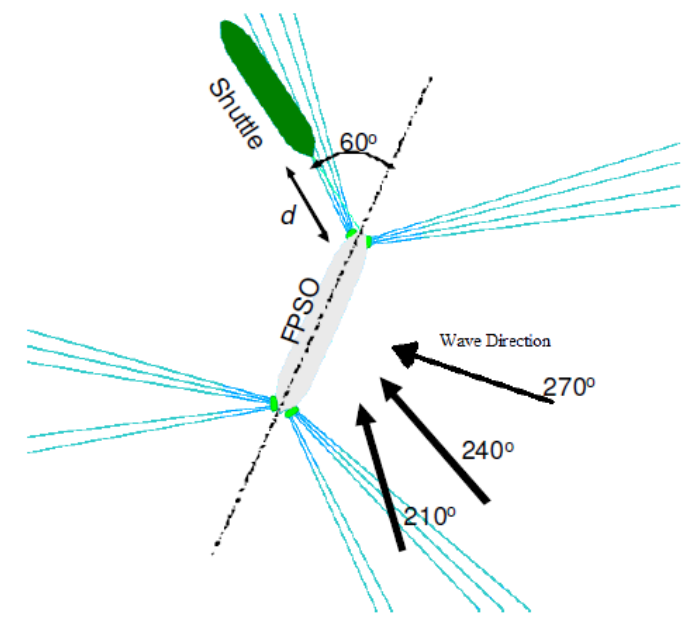

Source: FILHO and TANNURI, 2009 


\section{THEORETICAL BACKGROUND}

\subsection{Propeller Modeling}

Currently in Brazil, more than $80 \%$ of the tugboats are equipped with azimuthal ducted propellers (Figure 15). A duct, also commonly called as nozzle, is a circular structure that surrounds a propeller in order to increase its bollard pull. Although most of the ducts have a symmetric aerofoil cross section area, they may also be modified in order to accommodate wake field flow variations, becoming even more efficient (CARLTON, 2007).

The ducted propellers found its main application on tugboats since they can provide high thrusts when low speeds are being experienced (typical towing situation). In general, a duct contribution is around $50 \%$ of a propeller thrust for low speeds (CARLTON, 2007). The fixed pitch propeller is usually designed for a high efficiency when rotating in the clock-wise direction, but low efficiency when rotating in the counter-clockwise direction. In order to mitigate this problem, the azimuthal configuration was introduced. This kind of propeller can rotate in $360^{\circ}$, maintaining satisfactory efficiencies for any desired direction of thrust.

Figure 15 - Ducted azimuthal propeller

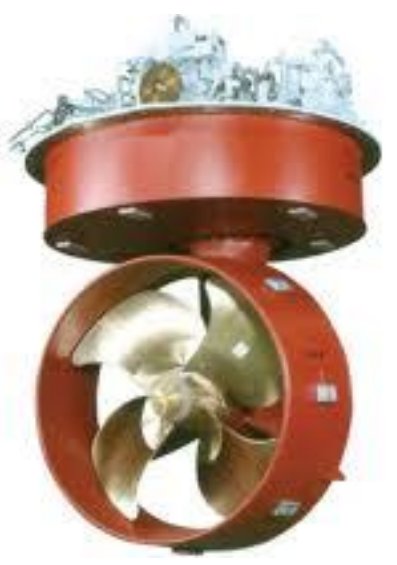

Source: Web 
In Oosterveld and Oortmerssen (1972), several open water tests using a MARIN 19A duct and a Ka 4-70 propeller (usually applied in tugboats) were performed in order to obtain this propeller's characteristics and consequently its thrust coefficient $\left(K_{T}\right)$ curve. Based on a propeller $K_{T}$ curve, which is obtained as a function of the advance coefficient $(J)$, the final thrust can be calculated for any specific scenarios.

$$
J=\frac{V_{a}}{n D}
$$

$$
T=K_{T}(J) \rho_{w} n^{2} D^{4}
$$

where:

$V_{a}$ - relative current velocity projected on the propeller entrance (takes in consideration the tugboat's velocity) $[\mathrm{m} / \mathrm{s}]$.

$n$ - propeller rotation (rps).

$D$ - propeller diameter [m].

$\rho_{w}$ - water density $\left[\mathrm{kg} / \mathrm{m}^{3}\right]$.

$T$ - propeller thrust [N].

Based on the propeller characteristics coefficients (Table 2), Oosterveld and Oortmerssen (1972) were able to fit a polynomial series for the $K_{T}$ curves for this specific propeller. Although these series were extrapolated for a fixed 4-blade propeller, they were function of the advance coefficient $J$, and the propeller's pitch to diameter ratio $(P / D)$. The polynomial series is shown in Eq. (3).

$$
K_{T}=\sum_{x, y=0}^{6} A_{x, y}\{P / D\}^{x} J^{y}
$$


Table 2 - Coefficients for propeller Ka 4-70 duct 19A to calculate $K_{T}$

\begin{tabular}{|c|c|c|c|c|c|}
\hline$x$ & $y$ & $A_{x, y}$ & & & \\
\hline 0 & 0 & 0.030550 & & & \\
\hline & 1 & -0.148687 & & & \\
\hline & 2 & 0.000000 & $x$ & $y$ & $A_{x, y}$ \\
\hline & 3 & -0.391137 & & & \\
\hline & 4 & 0.000000 & 4 & 0 & 0.000000 \\
\hline & 5 & 0.000000 & & 1 & 0.000000 \\
\hline & 6 & 0.000000 & & 2 & 0.000000 \\
\hline & & & & 3 & 0.000000 \\
\hline 1 & 0 & 0.000000 & & 4 & 0.000000 \\
\hline & 1 & -0.432612 & & 5 & 0.000000 \\
\hline & 2 & 0.000000 & & 6 & 0.000000 \\
\hline & 3 & 0.000000 & & & \\
\hline & 4 & 0.000000 & 5 & 0 & 0.000000 \\
\hline & 5 & 0.000000 & & 1 & 0.000000 \\
\hline & 6 & 0.000000 & & 2 & 0.000000 \\
\hline & & & & 3 & 0.000000 \\
\hline 2 & 0 & 0.667657 & & 4 & 0.000000 \\
\hline & 1 & 0.000000 & & 5 & 0.000000 \\
\hline & 2 & 0.285076 & & 6 & 0.000000 \\
\hline & 3 & 0.000000 & & & \\
\hline & 4 & 0.000000 & 6 & 0 & 0.000000 \\
\hline & 5 & 0.000000 & & 1 & -0.017293 \\
\hline & 6 & 0.000000 & & 2 & 0.000000 \\
\hline & & & & 3 & 0.000000 \\
\hline 3 & 0 & -0.172529 & & 4 & 0.000000 \\
\hline & 1 & 0.000000 & & 5 & 0.000000 \\
\hline & 2 & 0.000000 & & 6 & 0.000000 \\
\hline & 3 & 0.000000 & & & \\
\hline & 4 & 0.000000 & & & \\
\hline & 5 & 0.000000 & & & \\
\hline & 6 & 0.000000 & & & \\
\hline
\end{tabular}

Source: Adapted from OOSTERVELD AND OORTMERSSEN, 1972

Based on the formulation proposed, assuming the coefficients for the Screw 4-70 Ka series with $19 \mathrm{~A}$ duct, $K_{T}$ curves for different $P / D$ ratios are obtained, as shown in Figure 16. For slow speeds, a tugboat has larger efficiency with smaller 
$P / D$ ratios; for higher speeds, a tugboat has larger efficiency with larger $P / D$ ratios.

Figure $16-K_{T}$ curves for propeller Ka 4-70 duct 19A

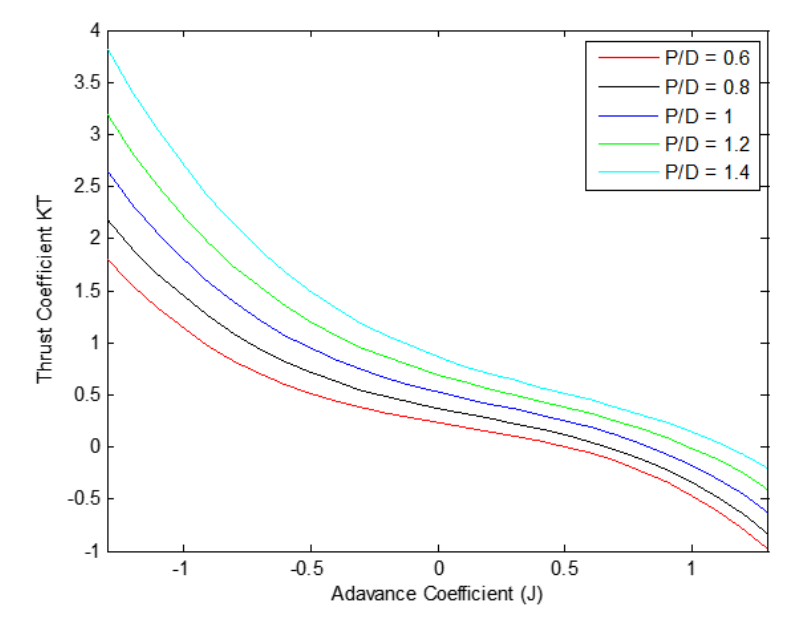

Source: Author

Although the thrust coefficients obtained through the polynomial series provided are accurate for positive advance coefficients, the extrapolation for negative coefficients is inaccurate. Therefore, an additional formulation is necessary in order to obtain the propeller thrust characteristics on the entire propeller operational range.

The four-quadrant formulation divides the propeller operation in 4 quadrants. In the first quadrant, the propeller has a positive inflow speed and a positive rotation, with its hydrodynamic pitch angle varying from $0^{\circ} \leq \beta \leq 90^{\circ}$; in the second quadrant, the propeller has a positive inflow speed and a negative rotation, with its hydrodynamic pitch angle varying from $90^{\circ} \leq \beta \leq 180^{\circ}$; in the third quadrant, the propeller has a negative inflow speed and a negative rotation, with its hydrodynamic pitch angle varying from $180^{\circ} \leq \beta \leq 270^{\circ}$; in the fourth quadrant, the propeller has a negative inflow speed and a positive rotation, with its hydrodynamic pitch angle varying from $270^{\circ} \leq \beta \leq 360^{\circ}$. Since the tugboats have azimuthal propellers, the rotation will always be positive, and the water inflow speed may be either positive or negative, thus characterizing an operation range on the first and fourth quadrant, with a hydrodynamic pitch angle on the range $90^{\circ} \leq \beta \leq 90^{\circ}$ (OOSTERVELD AND OORTMERSSEN, 1972). 
In Oosterveld and Oortmerssen (1972), several open water tests using a MARIN 19A duct and a Ka 4-70 propeller were also performed in order to obtain this propeller's characteristics on its full operational range. For the four-quadrant approach, the objective is to find thrust load coefficient $\left(C_{T}{ }^{*}\right)$, which is a function of the hydrodynamic pitch angle, and then calculate the propeller thrust based on such curve.

For most of the propellers, its pitch is defined at 0.7 of the radius, as shown in Figure 17. Therefore, the propeller's hydrodynamic pitch angle can be derived from the advance speed $V_{a}$ and the blade velocity at 0.7 of the propeller's radius (BRANDNER, 1995).

Figure 17 - Hydrodynamic propeller pitch

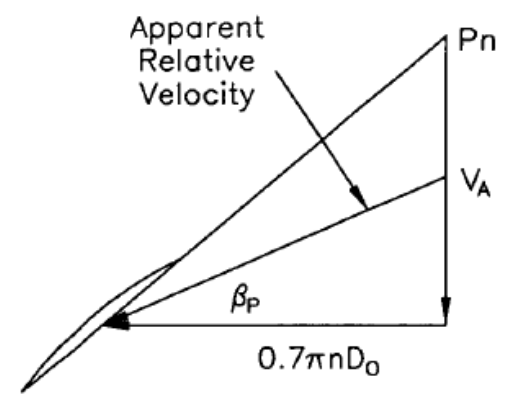

Source: BRANDNER, 1995

$$
\begin{gathered}
\beta=\arctan \frac{V_{a}}{0.7 \pi n D} \\
T_{\text {load }}=\frac{1}{2} C_{T}{ }^{*} \rho_{w}\left[V_{a}{ }^{2}+(0.7 \pi n D)^{2}\right] \frac{\pi}{4} D^{2}
\end{gathered}
$$

Based on the propeller characteristics obtained, Oosterveld and Oortmerssen (1972) also extrapolated a Fourier series capable of reproducing the $C_{T}{ }^{*}$ curves for this specific propeller. After several studies, they concluded that 20 terms were enough to correctly represent the propeller's thrust load characteristics. Note that the Fourier series proposed is only a function of the propeller's hydrodynamic pitch angles and the 21 coefficients obtained (Table 3), as shown in Eq. (6). 


$$
C_{T}^{*}=\sum_{k=0}^{20}\left[A_{k} \cos (k \beta)+B_{k} \sin (k \beta)\right]
$$

Table 3 - Coefficients for propeller Ka 4-70 duct 19A to calculate $C_{T}{ }^{*}$

\begin{tabular}{|c|c|c|c|c|c|c|c|c|c|c|}
\hline \multirow[b]{2}{*}{ K } & \multicolumn{2}{|c|}{$P / D=0.6$} & \multicolumn{2}{|c|}{$P / D=0.8$} & \multicolumn{2}{|c|}{$P / D=1$} & \multicolumn{2}{|c|}{$P / D=1.2$} & \multicolumn{2}{|c|}{$P / D=1.4$} \\
\hline & A & B & A & B & A & B & A & B & A & B \\
\hline 0 & -0.14825 & 0.00000 & -0.13080 & 0.00000 & -0.10985 & 0.00000 & -0.09089 & 0.00000 & -0.07349 & 0.00000 \\
\hline 1 & 0.08470 & -1.08380 & 85 & -1.07080 & 0.14064 & -1.05830 & 0.17959 & -1.10260 & 0.22861 & -0.98101 \\
\hline 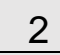 & 6700 & -0.01 & & 0.02 & & & & & & \\
\hline 0 & 97 & 0.11 & & 0.1 & & & & & & \\
\hline 4 & 1475 & -0.0 & & -0.0 & & -0. & 21 & & 41 & \\
\hline 5 & & & & & & & 82 & & 116 & \\
\hline 6 & & & & & & & 29 & & & \\
\hline 7 & 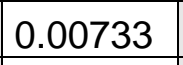 & 71 & 55 & 23 & 4 & 33 & 18 & & 697 & 276 \\
\hline 8 & & 0.0 & & 62 & & -0.1 & & & 206 & -0.0 \\
\hline 9 & 01513 & 0.01 & 08 & 0.01 & 72 & & 19 & & 787 & \\
\hline 10 & 0.00330 & 0.00 & 0.00697 & -0.00034 & & -0.0 & 265 & & 469 & 475 \\
\hline 11 & 0.003 & 0.00 & 0.00 & 0.00 & & & & & & 228 \\
\hline 12 & -0.00211 & -0.00572 & 00145 & -0.00695 & 0 & -0.0 & 57 & & 51 & \\
\hline 13 & & 0.00 & & & & & & & & \\
\hline 14 & 0 & & & & & & 089 & & 241 & \\
\hline 15 & 0412 & -0. & 1 & 16 & 0 & & 0. & & 556 & 337 \\
\hline 16 & 62 & -0.0 & 12 & -0.0 & 026 & & 18 & & 382 & 0.0 \\
\hline 17 & 00128 & 0.00274 & .00380 & 0.00 & 91 & -0.00035 & 0.00216 & 0.0 & 267 & -0.00022 \\
\hline 18 & 00206 & -0.00102 & 0090 & -0.00227 & 00032 & -0.00194 & 0.00035 & 0.00 & 0.00157 & -0.00054 \\
\hline 19 & 0.00342 & 0.00198 & 0.00311 & -0.00037 & 0.00152 & -0.00121 & 0.00258 & -0.00089 & 0.00024 & -0.00352 \\
\hline 20 & -0.00059 & -0.00140 & -0.00011 & -0.00124 & -0.00102 & -0.00032 & -0.00183 & -0.00095 & -0.00004 & -0.00043 \\
\hline
\end{tabular}

Source: Adapted from OOSTERVELD AND OORTMERSSEN, 1972

Based on the formulation proposed, and on the coefficients for the Screw 4-70 Ka series with $19 \mathrm{~A}$ duct, the thrust load coefficients for different $P / D$ ratios are obtained, as shown in Figure 18. 
Figure $18-\mathrm{CT}^{*}$ curves for propeller Ka 4-70 duct 19A

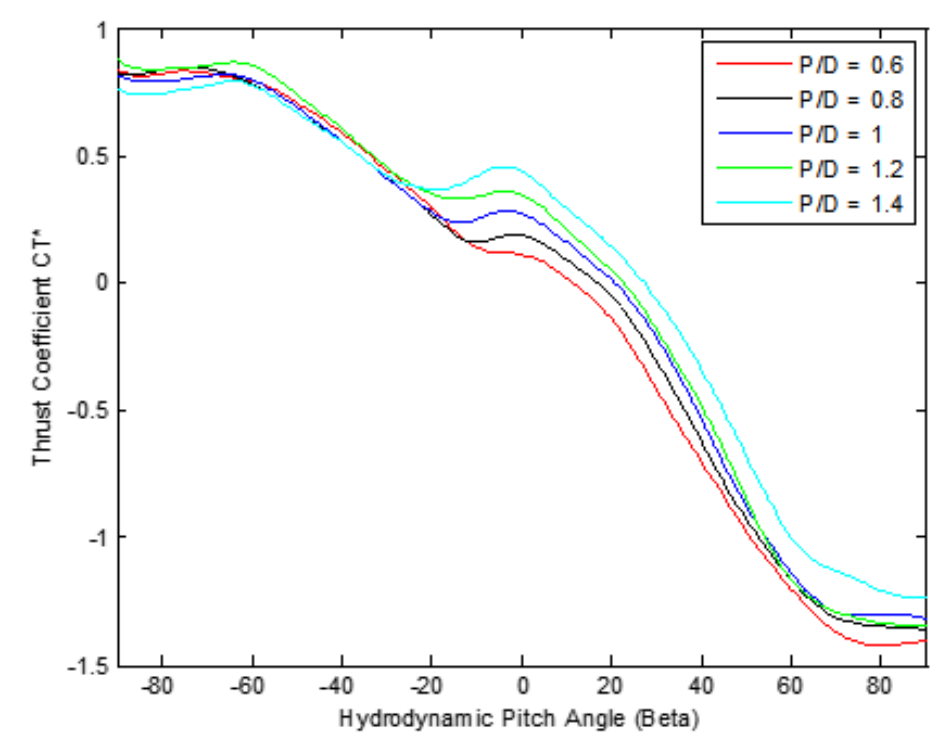

Source: Author

By making Eqs. (2) and (5) equal, one can easily obtain the $K_{T}$ curve in terms of the $C_{T}{ }^{*}$, as shown in Eq. (7).

$$
K_{T}=\frac{\pi}{8} C_{T}^{*}\left[J^{2}+0.7^{2} \pi^{2}\right]
$$

In addition, one can obtain the advance coefficient $J$ in terms of $\beta$ by plugging Eq. (1) in Eq. (4) and solving by $J$ :

$$
J=0.7 \pi \tan (\beta)
$$

In Figure 19, one can see a comparison between the initial $K_{T}$ curve and the final one. Note that both of them are the same in the range where the advance coefficient is positive. However, only the $K_{T}$ curve obtained from $C_{T}{ }^{*}$ is accurate for the negative range of the advance coefficient. Both curves were chosen for the $P / D=1$ ratio since this is the most commonly used one by tugboats nowadays. 
Figure 19 - Comparison between original $K_{T}$ curve and $K_{T}$ curve obtained from $C_{T}{ }^{*}$

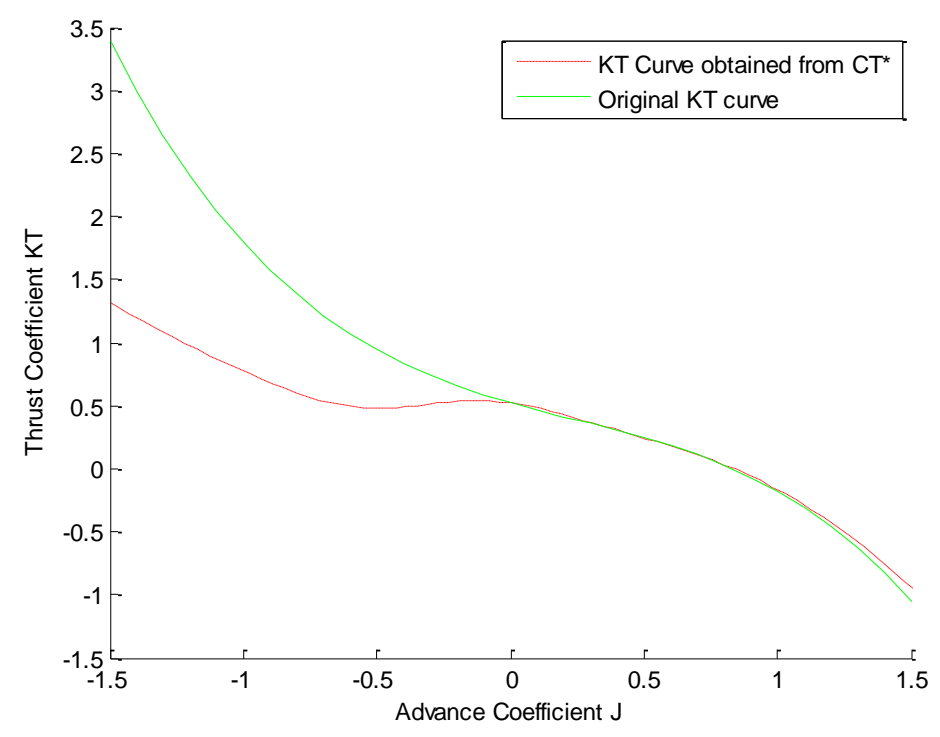

Source: Author

\subsection{Current Force Modeling}

The oceanic currents are slow varying fields. For this reason, we can assume that tugboats are only being subjected to static current forces which act on their longitudinal and transversal directions. Considering the mathematical model proposed by (WICHER, 1988) the static forces generated by the current on a vessel are obtain as a function of the ship's draft, length, hydrodynamic coefficients and the relative overall water velocity (comprising both the vessel's advance speed an externa current) as shown in Eq. (9):

$$
\left[\begin{array}{c}
F_{c x} \\
F_{c y} \\
M_{c z}
\end{array}\right]=0.5 \rho_{w}\left|\boldsymbol{V}_{\text {rel }}\right|_{c}^{2} L T\left[\begin{array}{c}
C_{c x}\left(\alpha_{c}\right) \\
C_{c y}\left(\alpha_{c}\right) \\
L C_{c z}\left(\alpha_{c}\right)
\end{array}\right]
$$

where:

$\left|V_{\text {rel }}\right|_{c}$ - the relative velocity between the water and the tug $[\mathrm{m} / \mathrm{s}]$.

$L-$ the tug's length [m].

$T$ - the tug's draught [m].

$C_{c x}, C_{c y}, C_{c z}$ - non-dimensional hydrodynamic coefficients [-].

$\alpha_{c}$ - the relative angle between the current and the tug in the OCIMF convention with $0^{\circ}$ at the tugboat's stern, increasing counter-clockwise (Figure 20) $\left[^{\circ}\right]$. 
Figure 20 - Sign convention and coordinate system OCIMF

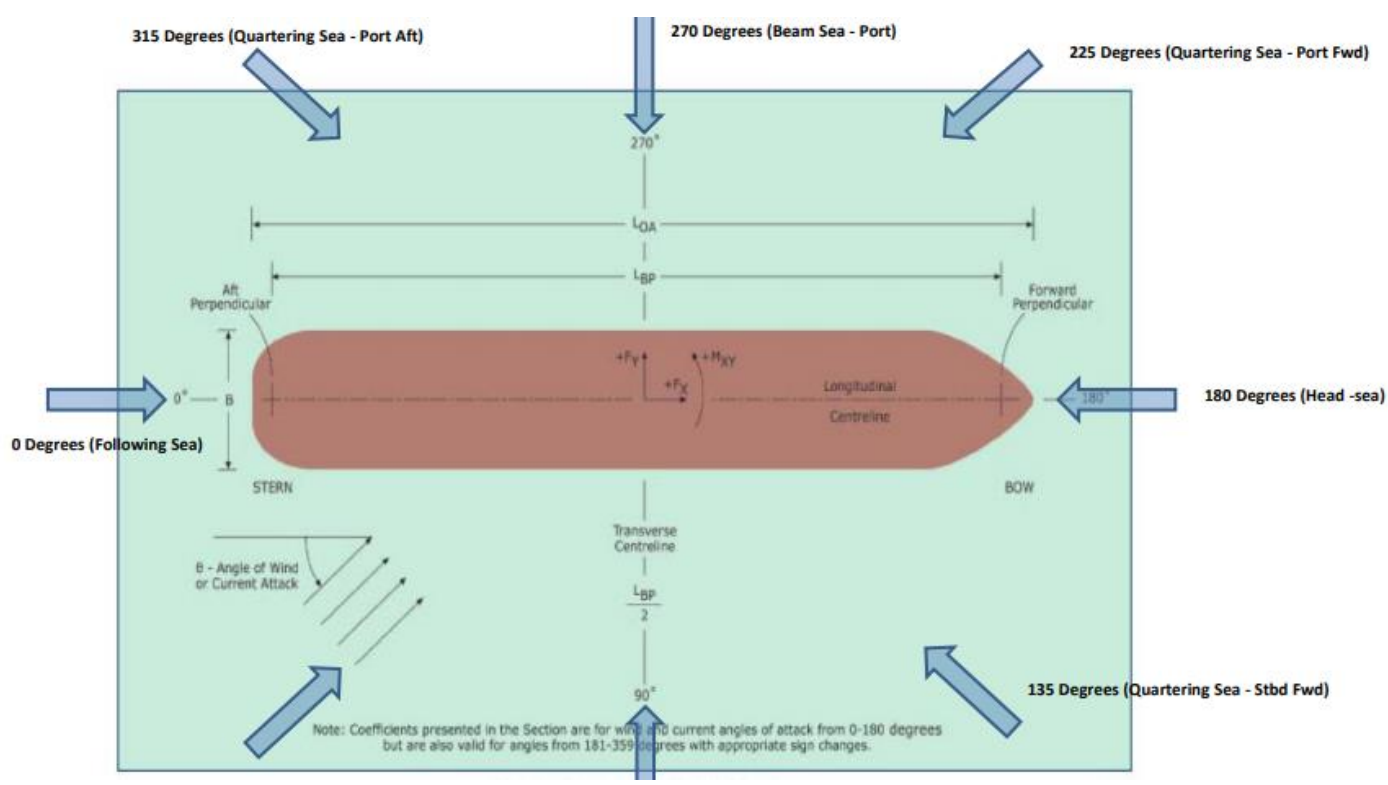

Source: (OCIMF, 1977)

Note that the non-dimensional hydrodynamic coefficients are normally obtained from towing tests or by CFD calculations. In this study, the experimental results from the IPT towing tank (TPN-USP, 2009), which are shown from Figure 21 through Figure 23 as an approximation for slow speeds and deep water, are applied.

Figure $21-C_{c x}$ non-dimensional hydrodynamic coefficient curve

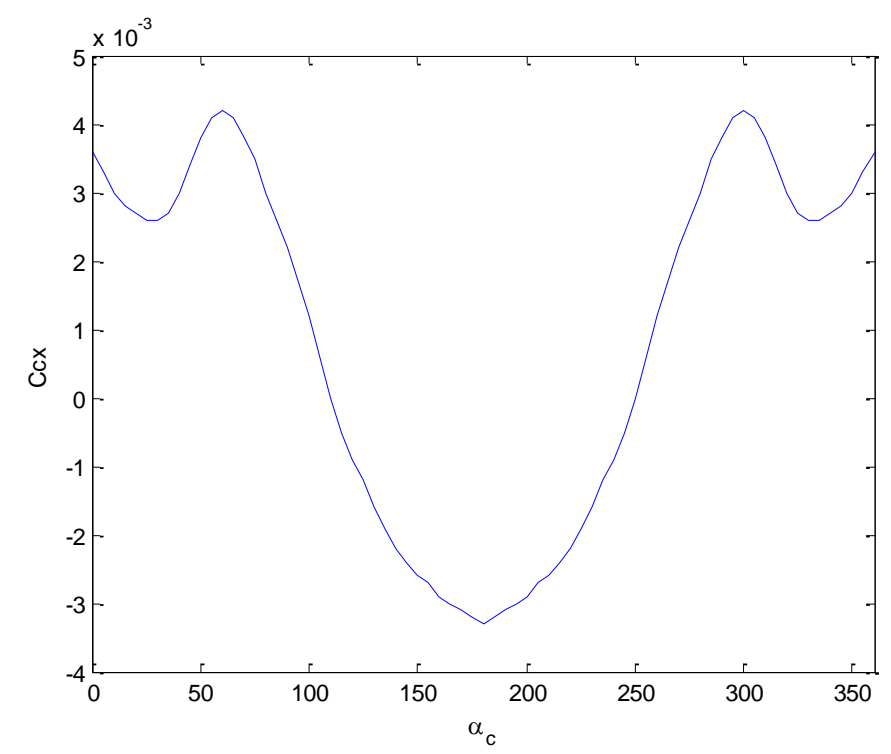

Source: Author 
Figure $22-C_{c y}$ non-dimensional hydrodynamic coefficient curve

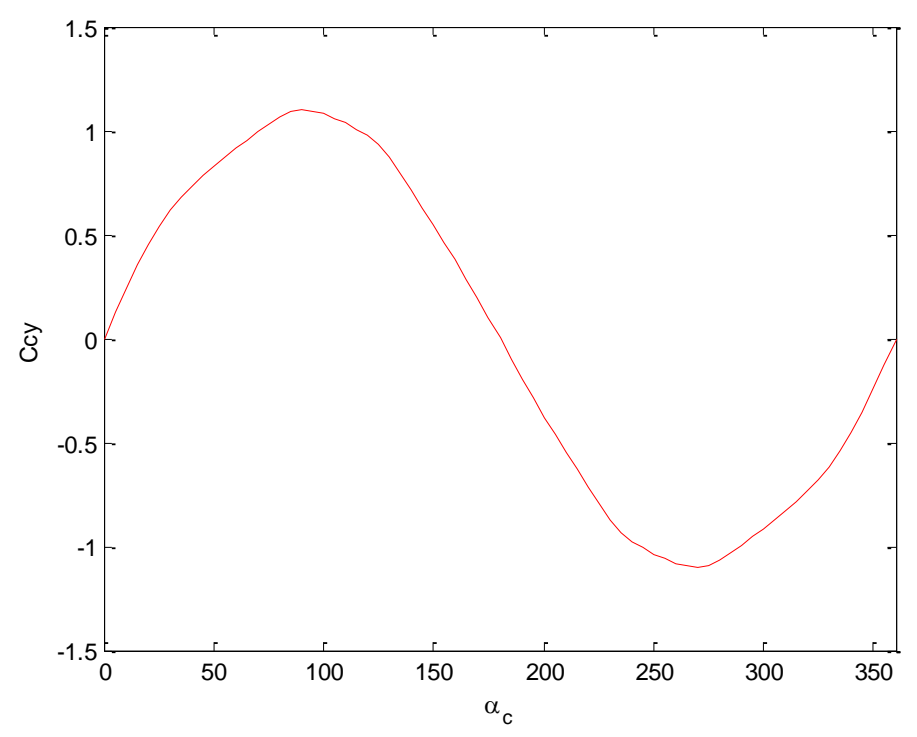

Source: Author

Figure $23-C_{c z}$ non-dimensional hydrodynamic coefficient curve

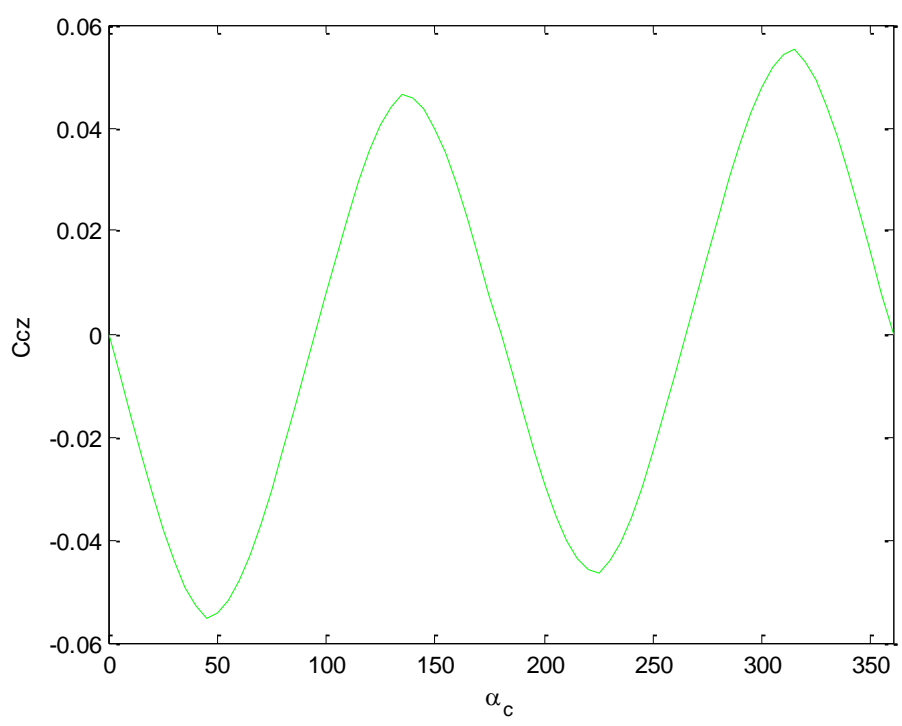

Source: Author

Let's now suppose that a towed vessel is navigating with a speed $U=u(t) i 0+$ $v(t) j 0$ in the earth-fixed frame with a global angle $\beta_{v}$. We will assume that the tug is navigating with the same earth-fixed speed as the vessel. By making this assumption, we take in consideration the current effects generated by the towed vessel's speed on the tug. 
In a given instant, the tug is subjected to a current force generated by the environment with a speed $V_{c}$ actuating in a global angle $\beta_{c}$ (Figure 24). From this information, one can calculate the earth-fixed relative velocity between the tug and the water:

$$
\begin{aligned}
& V_{\text {rel_cx }}=\left[V_{c} \cos \left(\beta_{c}\right)-u(t)\right] i_{0} \\
& V_{\text {rel_cy }}=\left[V_{c} \sin \left(\beta_{c}\right)-v(t)\right] j_{0}
\end{aligned}
$$

where:

$V_{\text {rel_cx }}, V_{\text {rel_cy }}$ - the longitudinal and transversal components of the relative velocity $[\mathrm{m} / \mathrm{s}]$.

$V_{c}$ - the current speed $[\mathrm{m} / \mathrm{s}]$.

$\beta_{c}$ - the global angle of the current $\left[0^{\circ}, 360^{\circ}\right]$.

$\beta_{t}$ - tugboat global angle $\left[0^{\circ}, 360^{\circ}\right]$.

Figure 24 - Relationship between current and tug

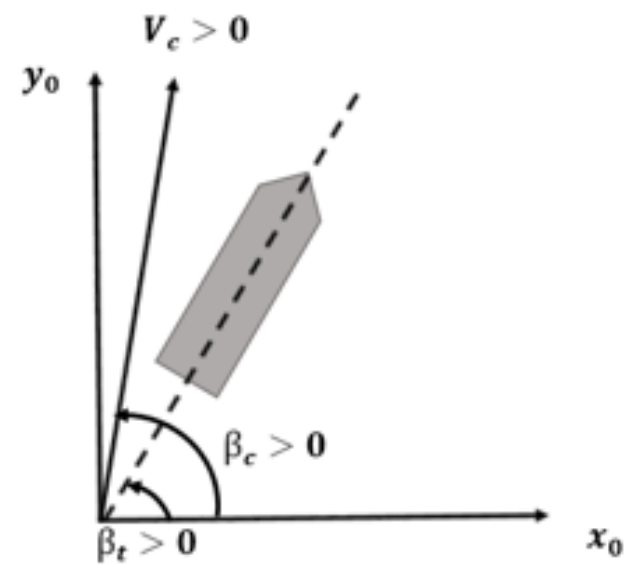

Source: Author

The modulus of the relative velocity can be obtained as follows:

$$
\left|V_{\text {rel }}\right|_{c}=\sqrt{V_{\text {rel_cx }}^{2}+V_{\text {rel_cy }}^{2}}
$$


Finally, the angle between the relative current and the tugboat is given by:

$$
\alpha_{c}=\tan ^{-1} \frac{V_{\text {rel_cy }}}{V_{\text {rel_cx }}}-\beta_{t}
$$

\subsection{Wind Force Modeling}

The longitudinal and transversal forces as well as yaw moments generated by the wind at the tug's emerged areas are modeled as functions of non-dimensional coefficients that can be obtained from wind tunnel experiments in model scales or CFD calculations. Assuming that the wind incidence has constant speed and global angle, one can obtain the following relationships (ISHERWOOD, 1972):

$$
\left[\begin{array}{c}
F_{w x} \\
F_{w y} \\
M_{w z}
\end{array}\right]=0.5 \rho_{w i n d}\left|\mathbf{V}_{\text {rel }}{ }^{2}\right|_{\mathbf{w}}\left[\begin{array}{c}
A_{\text {frontal }} C_{w x}\left(\alpha_{w}\right) \\
A_{\text {lateral }} C_{w x}\left(\alpha_{w}\right) \\
L A_{\text {lateral }} C_{w z}\left(\alpha_{w}\right)
\end{array}\right]
$$

where:

$\rho_{\text {wind }}-$ the air density $\left[\mathrm{kg} / \mathrm{m}^{3}\right]$.

$\left|V_{\text {rel }}\right|_{\mathbf{w}}$ - the relative velocity between the wind and the tug $[\mathrm{m} / \mathrm{s}]$.

$A_{\text {frontal }}$ - the tug's frontal emerged area $\left[\mathrm{m}^{2}\right]$.

$A_{\text {lateral }}$ - the tug's lateral emerged area $\left[\mathrm{m}^{2}\right]$.

$C_{w x}, C_{w y}, C_{w z}$ - wind non-dimensional coefficients [-].

$\alpha_{w}$ - the relative angle between the wind and the tug (OCIMF convention) [ ${ }^{\circ}$.

The wind coefficients adopted are based on (TPN-USP, 2009) where several wind tests were performed in order to obtain the wind non-dimensional coefficients necessary to calculate wind forces over a tugboat. These coefficients are shown from Figure 25 through Figure 27 as function of the relative angle between the tug and the wind. 
Figure $25-C_{w x}$ non-dimensional wind coefficient curve

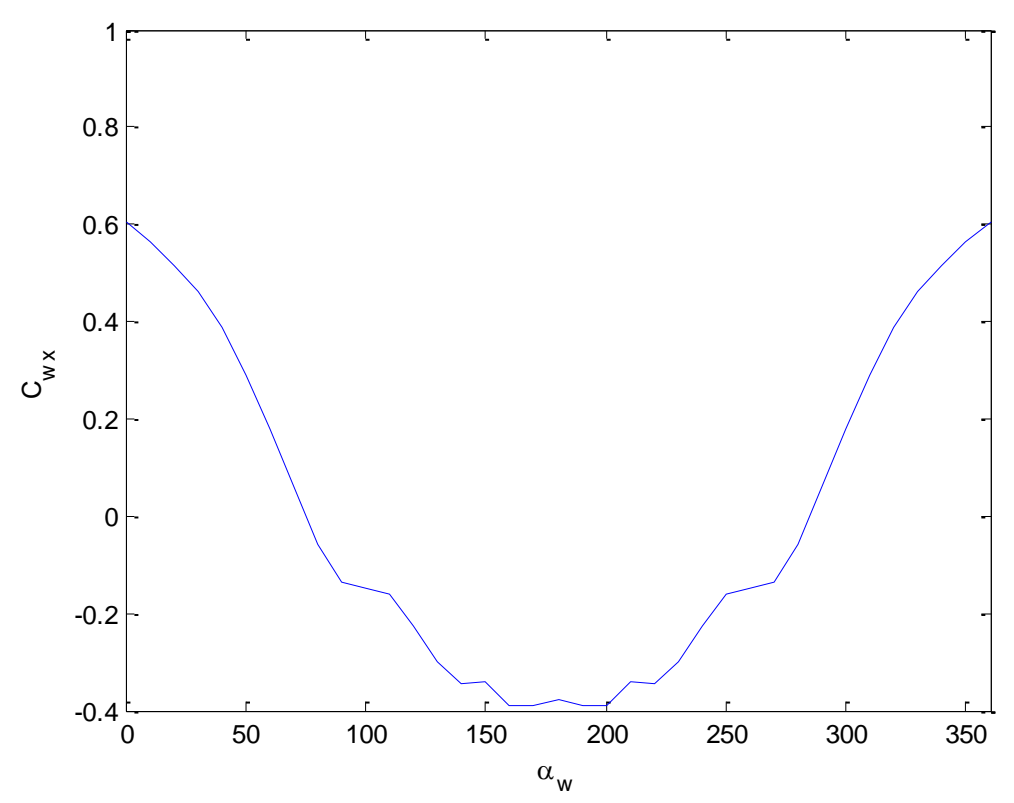

Source: Author

Figure $26-C_{w y}$ non-dimensional wind coefficient curve

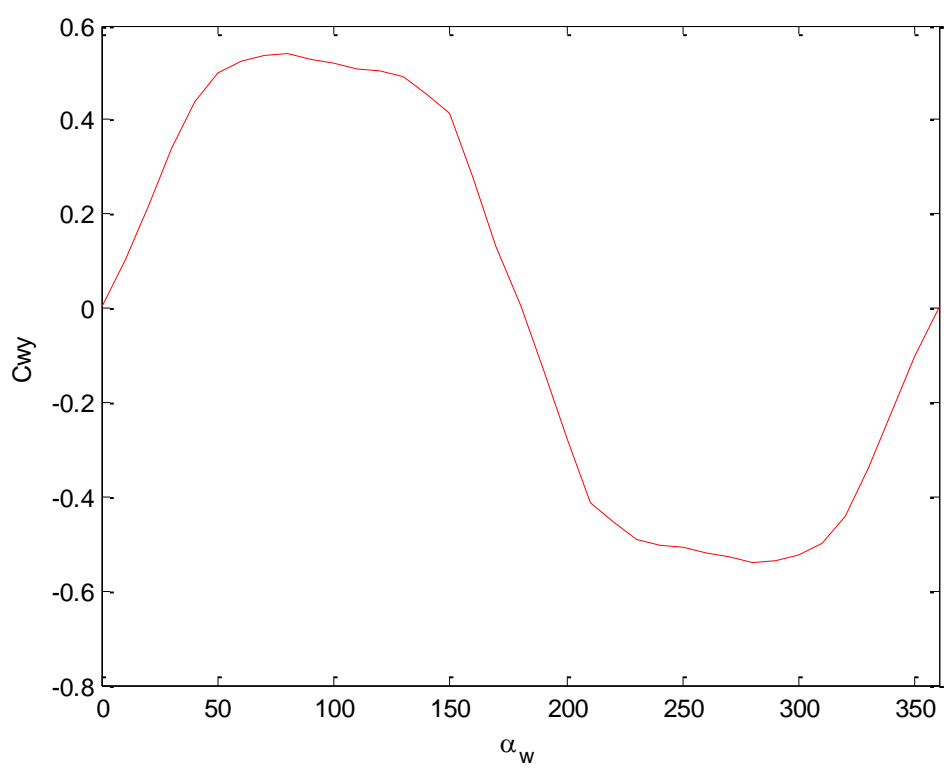

Source: Author 
Figure $27-C_{w z}$ non-dimensional wind coefficient curve

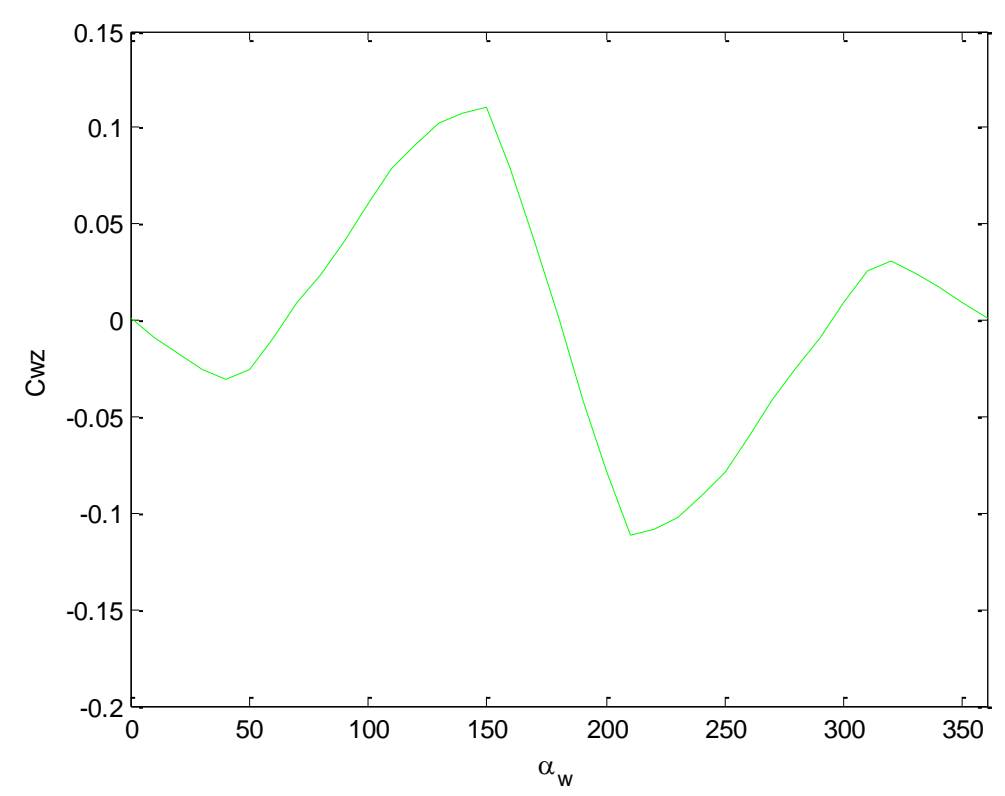

Source: Author

Following a similar theoretical approach to the current modeling, we will assume that the tugboat is navigating with the same global velocity of a towed vessel. In a given instant, the tug is subjected to a wind force generated by the environment with a speed $V_{w}$ actuating in a global angle $\beta_{w}$ (Figure 28). From this information, one can calculate the earth-fixed relative velocity between the tug and the wind:

$$
\begin{aligned}
& V_{\text {rel_wx }}=\left[V_{w} \cos \left(\beta_{w}\right)-u(t)\right] i_{0} \\
& V_{\text {rel_wy }}=\left[V_{w} \sin \left(\beta_{w}\right)-v(t)\right] j_{0}
\end{aligned}
$$

where:

$V_{\text {rel_wx }}, V_{\text {rel_wy }}$ - the longitudinal and transversal components of the relative velocity between tugboat and wind [m/s].

$V_{w}$ - the wind speed [m/s].

$\beta_{w}$ - the global angle of the wind $\left[0^{\circ}, 360^{\circ}\right]$. 
Figure 28 - Relationship between wind and tug

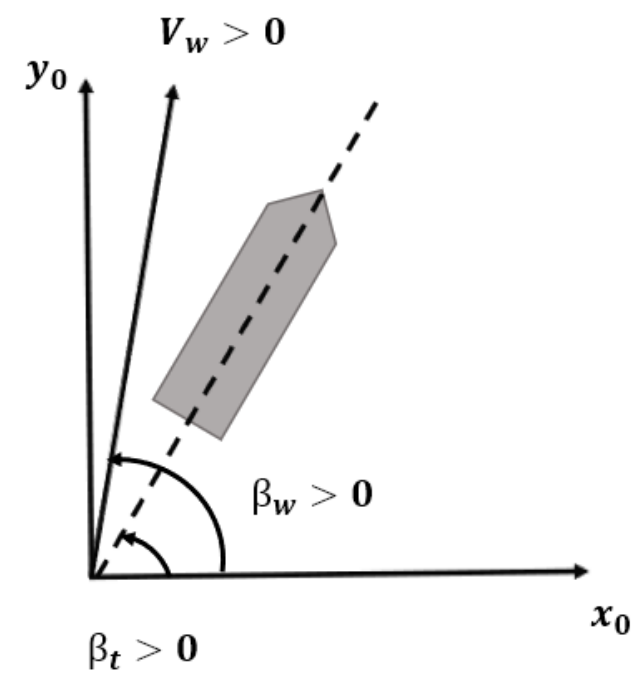

Source: Author

The modulus of the relative velocity between the tugboat and the wind can be obtained as follows:

$$
\left|\mathbf{V}_{\text {rel }}\right|_{\mathbf{w}}=\sqrt{{V_{\text {rel_wx }}}^{2}+V_{\text {rel_wy }}^{2}}
$$

Finally, the angle between the relative wind and the tugboat is given by:

$$
\alpha_{w}=\tan ^{-1} \frac{V_{\text {rel_wy }}}{V_{\text {rel_wx }}}-\beta_{t}
$$

\subsection{Motion Response in Waves}

Sea waves are normally generated by the interaction of the wind and the fluid. During a storm, the short-crested waves absorb most of the energy provided by the wind. Due to this great concentration of energy in high frequencies, this sea state is called "Developing Sea". After breaking, these waves dissipate energy, 
generating longer waves with smaller frequency. At this moment, the sea begins to be called "fully developed", and the energy is uniformly distributed throughout the frequencies.

Fully developed seas are usually expressed in the frequency domain through the Pierson-Moskowitz spectrum (SEIXAS, 1997):

$$
S(\omega)=\frac{\alpha_{0} g^{2}}{\omega^{5}} \exp \left(-\frac{5}{4}\left(\frac{\omega_{0}}{\omega}\right)^{4}\right)
$$

where:

$\alpha_{0}=\frac{5}{16 g^{2}} H_{s} \omega_{0}^{4}$

$\omega_{0}$ - wave spectrum peak frequency

The most used spectral formulation for developing seas is the JONSWAP (Joint North Sea Wave Project), which was introduced at the $17^{\text {th }}$ International Towing Tank Conference (ITTC, 1984) as a generalization of the Pierson-Moskowitz formulation:

$$
S(\omega)=\frac{\alpha_{0} g^{2}}{\omega^{5}} \exp \left(-\frac{5}{4}\left(\frac{\omega_{0}}{\omega}\right)^{4}\right) \gamma^{\exp \left[-\frac{\left(\omega-\omega_{0}\right)^{2}}{2 \sigma^{2} \omega_{0}{ }^{2}}\right]}
$$

where:

$$
\sigma=\left\{\begin{array}{l}
0,07 \text { if } \omega<\omega_{o} \\
0,09 \text { if } \omega>\omega_{0}
\end{array}\right.
$$

The motion of a floating body when excited by the characterized waves may be obtained by crossing the wave spectrum $S(\omega)$ and first order functions that model the free surface pressure effects over the body's hull. These transfer functions are called Response Amplitude Operators (RAO) and are a classical tool to describe a vessel's motion under the incidence of waves. The total motion of the $i^{\text {th }}$ degree of freedom calculated through spectral crossing is given by Eq. (19) (NEWMAN, 1977).

$$
S_{i}(\omega)=\left|H_{i}(j \omega) F_{i}(j \omega)\right|^{2} S_{\zeta}(\omega)
$$


where:

$F_{i}(j \omega)$ - force RAO

$H_{i}(j \omega)$ - force-to-motion RAO

To get the motion response in the time domain, the inverse discrete Fourier transform is applied for $n$ frequencies:

$$
\xi_{i}=\sum_{j=1}^{n} \sqrt{2\left|H_{i}(j \omega) F_{i}(j \omega)\right|{ }^{2} S_{\zeta}\left(\omega_{j}\right) \Delta \omega} \cos \left(\omega_{j} t+\angle\left(H_{i}(j \omega) F_{i}(j \omega)\right)+\phi_{\omega_{j}}\right)
$$

The operator $\angle(\cdot)$ expresses the RAO Phase and $\phi_{w}$ is the random wave phase.

\subsection{Peak Loads on the Towline due to the Motion on Waves}

During a maritime maneuver, one of the limiting factors affecting tugboat operations is directly related to the peaks on the towline. If the waves are severe, peak loads on the towline may be responsible for a towline breakage, disabling the ability of a tugboat to work in Pull mode. Therefore, during a maritime simulation, where the feasibility of the maneuver is being tested, it is extremely important to access the forces on the towline and the probability of towline breakage.

In order to model the towline peak loads with an increased safety factor, one may assume that the tugboat experiences a free motion under the presence of waves in such a way that the towline attachment does not have any influence on such motion. In Figure 29, a schematization of the problem and the coordinate systems of the tugboat's center of gravity and tugboat's connection point are presented. In the possession of the tugboat RAO and using Eq. (20), one may calculate the motion variation for the tugboat center of gravity $(G)$ on its 6-degress of freedom. By using Poisson's equation for relative velocity in a fixed body, one may obtain the motion variation at the connection point $P$ : 


$$
\left[\begin{array}{l}
d x_{p} \\
d y_{p} \\
d z_{p}
\end{array}\right]=\left[\begin{array}{l}
d x_{G} \\
d y_{G} \\
d z_{G}
\end{array}\right]+\operatorname{cross}\left(\left[\begin{array}{l}
d \theta \\
d \varphi \\
d \psi
\end{array}\right], \mathbf{x}_{\mathbf{p}}\right)
$$

where:

$\boldsymbol{X}_{\boldsymbol{p}}-$ position vector from $\mathrm{P}$ to $\mathrm{G}=\left[\begin{array}{l}\left(x_{p}-x_{G}\right) \\ \left(y_{p}-y_{G}\right) \\ \left(z_{p}-z_{G}\right)\end{array}\right]$

Figure 29 - Coordinate Systems and Problem Schematization

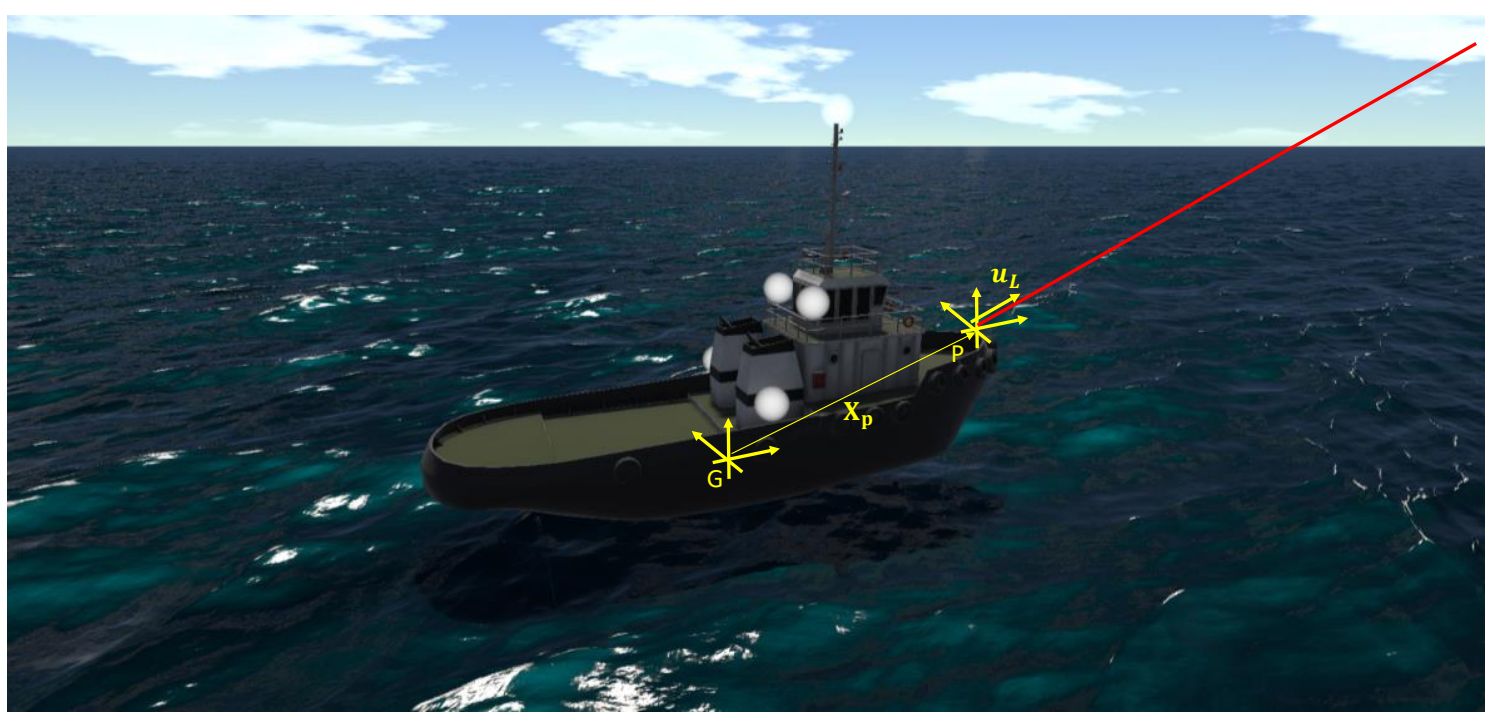

Source: Author

By denoting $\boldsymbol{u}_{\boldsymbol{L}}$ as the unit vector located at $P$, written on the tugboat's local coordinate system and pointing towards the towline, one may obtain the variation on the towline length as shown in Eq. (22):

$$
\left.d L=-\operatorname{dot}\left(\left[\begin{array}{l}
d x_{p} \\
d y_{p} \\
d z_{p}
\end{array}\right], \mathbf{u}_{\mathbf{L}}\right)\right)
$$

Note that, $d L$ will be positive for an increase on the towline length and negative for a decrease. 


\subsection{Tugboat Towing Force Attenuation Due to the Presence of Waves}

The presence of waves during a towing operation has been one of the main factors negatively affecting the efficiency of tugboats. When subjected to wave motions, the tugboats can only fully actuate when located on a wave crest or on a wave through. This is the case because tugboats loose stability during the transition period between a crest and a through. If a tugboat continues to fully operate under a wave transition, it may damage its equipment (towline breakage when operating in pull mode and hull deformation when operating in push mode).

The increasing necessity to perform offshore operations demanded the development of innovative technologies in order to make tugboats more efficient when operating under the presence of waves. Under this scenario, Escort Tugs (Figure 30) and Dynamic Winches were developed. In order to be more efficient on waves, the Escort Tugs have a different hull configuration, with a larger skeg on its longitudinal direction. Although these tugboats gain more stability, they loose on the maneuverability and time response when compared to the regular ASD tugboats. The dynamic winch is a self-controlled winch capable of releasing and shortening the cable in response to wave motion. This technology allows any tugboat to gain great efficiency when actuating in pull mode under the presence of waves.

Figure 30 - Escort Tug

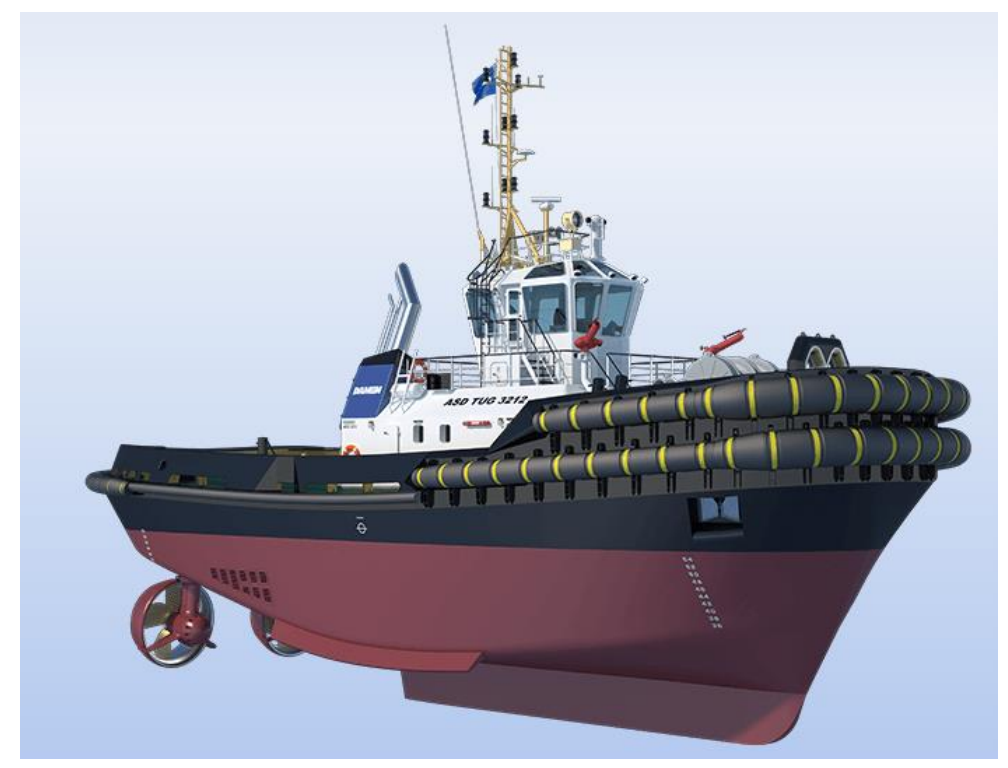

Source: Damen website 
In order to correctly represent a tugboat's towing actuation under the presence of waves, PIANC (2012) provided several charts of tug efficiency considering the wave characteristics (peak period and significant height) as well as the tugboat operation mode (push or pull during either the direct or the indirect maneuver), and winch (static or dynamic). Based on these parameters, the tugboat efficiency loss can be obtained, as shown in Figure 31 and Figure 32. Such efficiency loss must be considered when predicting the vector tugs' towage force. The tug Effectiveness factor is given as a function of the wave significant height $\left(H_{S}\right)$ and peak period $\left(T_{p}\right)$.

Figure 31 - Tug Effectiveness in waves ( $T_{p} 6 s$ to $12 s$ )

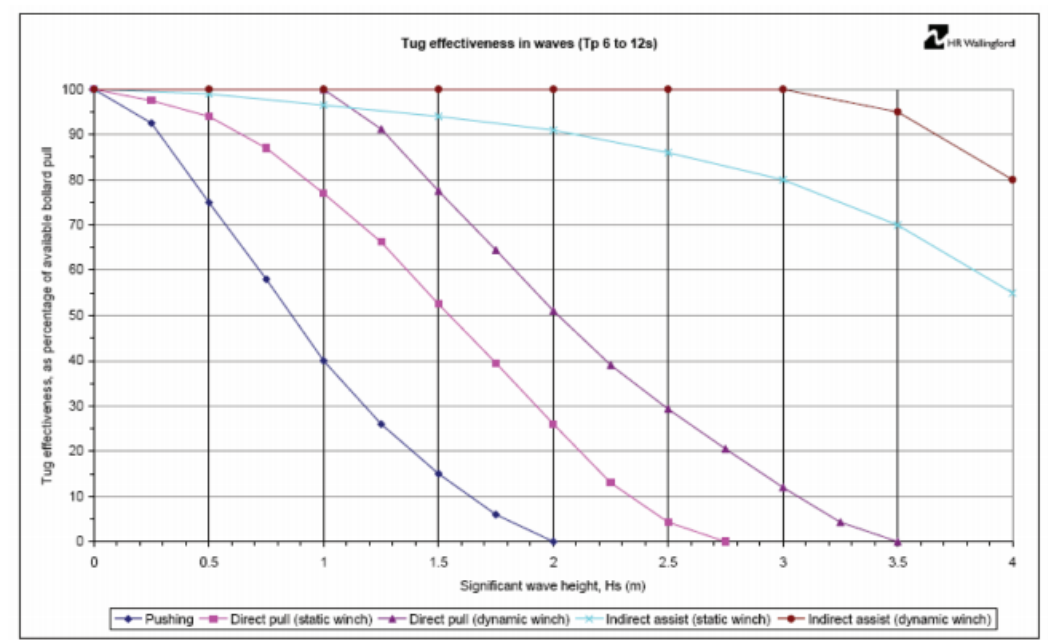

Source: PIANC, 2012

Figure 32 - Tug effectiveness in waves $\left(T_{p}>14 s\right)$

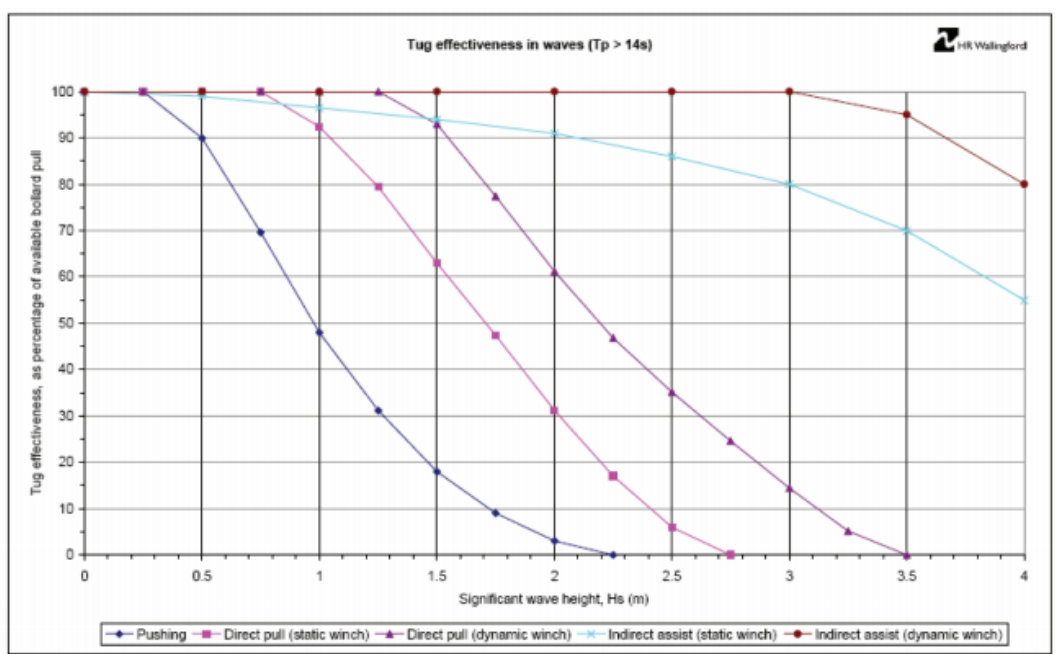

Source: PIANC, 2012 
Based on the charts provided, for a $H_{s}$ of $1.5 \mathrm{~m}$ and a $T_{p}>14 \mathrm{~s}$, the Push and Direct Pull with static winch maneuvers are the ones with more efficiency loss, with a decrease of $80 \%$ and $35 \%$, respectively. By using a dynamic winch in the Pull maneuver, its efficiency increases significantly, about $30 \%$ when compared to the static winch one. For the indirect maneuvers, one may realize that there is little efficiency loss, thus being the most efficient tugboat maneuver under the presence of waves.

\subsection{Tugboat Towing Force Incrementation Due to Wave Shadowing}

Although the presence of waves directly impairs a tugboat's efficiency, one must be aware that tugboats usually operate within close distances to towed vessels, which may create wave shadowing regions. When operating in such regions, the tugboat's efficiency tends to increase since the wave significant height is locally diminished.

In this work, the WAMIT software was used in order to analyze the regular wave behavior in all regions around a typical containership (LOA 333; Beam 48m) and tanker (LOA 272m; Beam 48m) with two drafts: $8 \mathrm{~m}$ and 15m. For each draft, 5 different typical wave periods (Table 4) were applied along with a $H$ of $1 \mathrm{~m}$, reaching the vessel transversally by its port side (i.e., $270^{\circ}$ on the PIANC notation). For this work, only the wave shadowing region was analyzed (vessel's starboard side).

Table 4 - Wave characteristics applied

\begin{tabular}{|c|c|}
\hline W $_{p}-$ Wave Period $(\mathrm{s})$ & $\mathrm{H}$ - Wave Height \\
\hline 5 & 1.00 \\
\hline 7 & 1.00 \\
\hline 9 & 1.00 \\
\hline 11 & 1.00 \\
\hline 13 & 1.00 \\
\hline
\end{tabular}

For each vessel on each scenario (i.e., draft of $8 \mathrm{~m}$ or $15 \mathrm{~m}$ ), it was possible to create wave maps regarding multiplicative factors that should be used along with the wave significant height applied in order to obtain its correct value for a specific wave shadow region. The maps for the Containership are shown in Figure 33, with the left ones being for a draft of $8 \mathrm{~m}$ and the right ones for a draft of $15 \mathrm{~m}$. 
The maps for the Tanker are shown in Figure 34, with the left ones being for a draft of $8 \mathrm{~m}$ and the right ones for a draft of $15 \mathrm{~m}$.

Figure 33 - Wave maps for the Containership with $8 \mathrm{~m}$ draft (Left) and $15 \mathrm{~m}$ draft (Right)
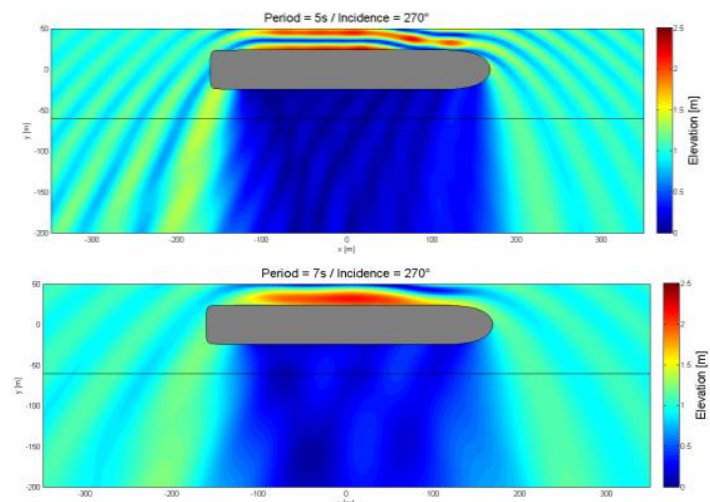

Period $=9 \mathrm{~s} /$ /ncidence $=270^{\circ}$

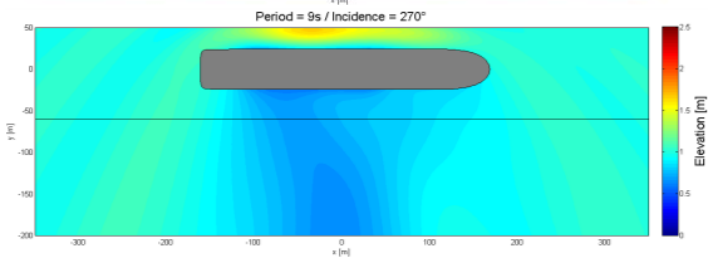

Period $=11 \mathrm{~s} / \mathrm{s} / \mathrm{inc}$ cidence $=270^{\circ}$

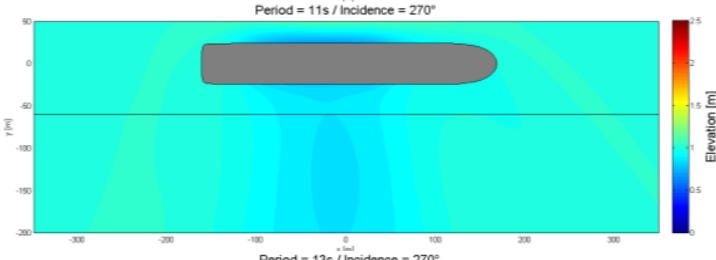

$=13 \mathrm{~s} /$ lincidence $=270^{\circ}$

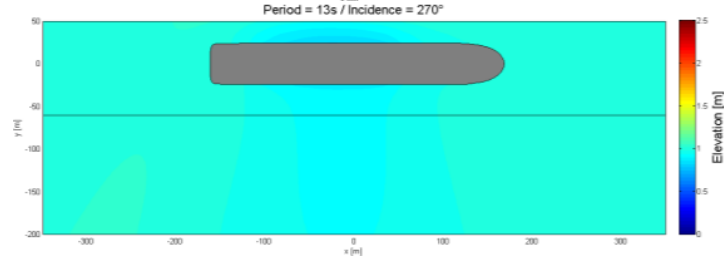

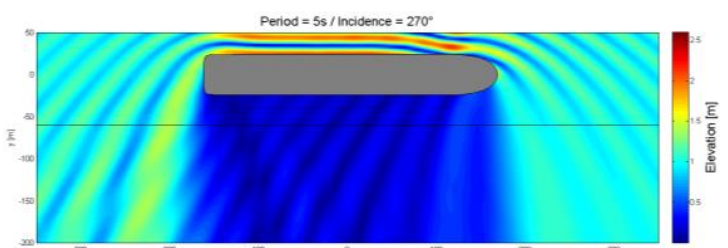

Period $=7 \mathrm{~s} /$ /nindence $=270^{\circ}$

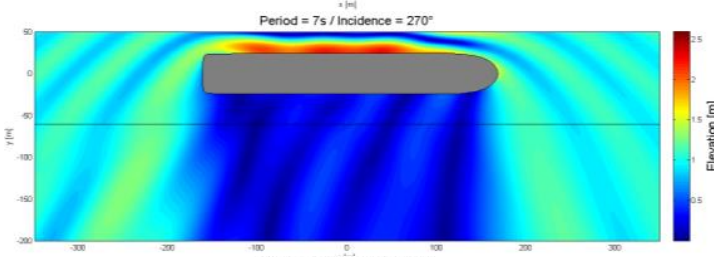

Period $=9 \mathrm{~s} /$ /ncidence $=270^{\circ}$

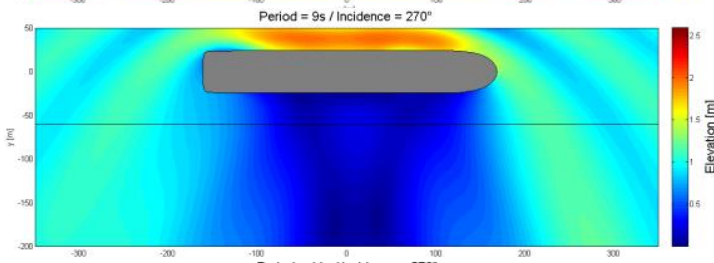

Period $=11$ s $/$ /incidence $=270^{\circ}$

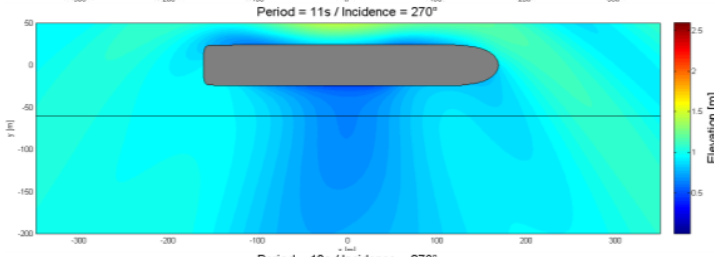

Period $=13 \mathrm{~s} /$ incidence $=270^{\circ}$

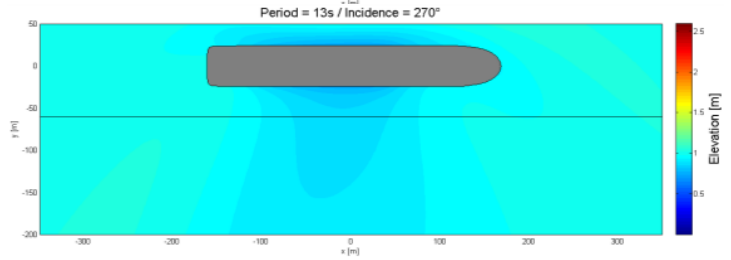

Source: Author 
Figure 34- Wave maps for the Tanker with $8 \mathrm{~m}$ draft (Left) and $15 \mathrm{~m}$ draft (Right)

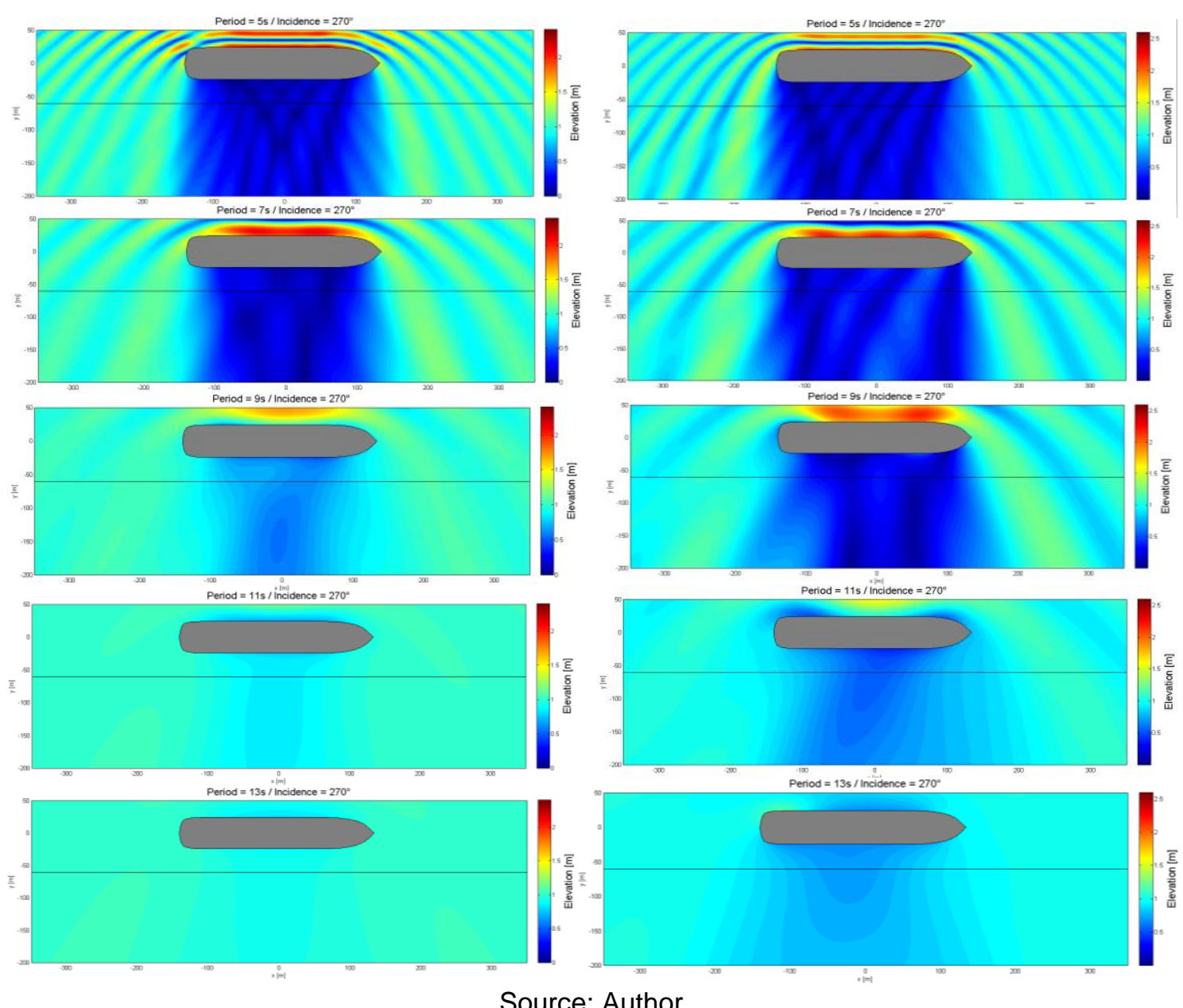

Source: Author

Figure 35 shows the relationship between $w_{p}$ and the mean $H$ Multiplier obtained from the analysis of the previous figures at $-100 \mathrm{~m}<\mathrm{x}<100 \mathrm{~m}$ and $y=-60 \mathrm{~m}$ (related to the vessel center line), which are common tugboat locations of actuation. By analyzing both the Containership and the Tanker scenarios, one may realize that, in general, the smaller the wave period, the smaller will be the $H$ multiplier which turns to decrease the wave $H$. In other words, when actuating on a shadowing region, the tugboat will experience a considerably smaller $H$ if the wave $w_{p}$ is lower than $9 \mathrm{~s}$ for the vessels with $15 \mathrm{~m}$ draft, and $7 \mathrm{~s}$ for the vessel with $8 \mathrm{~m}$ draft. For wave $w_{p}$ higher than $9 \mathrm{~s}$ and $7 \mathrm{~s}$, respectively, the tugboats may experience severe wave $H$, thus severely impairing its operation. By comparing the Containership and the Tanker for a draft of $8 \mathrm{~m}$, one can realize that the Containership will provide better wave shadowing regions for $w_{p}<6.5$ s and the Tanker will provide better wave shadowing regions for $w_{p}>6.5 \mathrm{~s}$. For the $15 \mathrm{~m}$ 
draft scenario, the Containership will provide better wave shadowing regions for $w_{p}<9.5$ s and the Tanker will provide better wave shadowing regions for $w_{p}>$ $9.5 \mathrm{~s}$.

As a general conclusion for $w_{p}$ smaller than $7 \mathrm{~s}$, tugboats will have a greater efficiency when actuating on vessels with smaller drafts; for $w_{p}$ larger than $7 \mathrm{~s}$, tugboats will have a greater efficiency when actuating on vessels with larger drafts.

Figure 35 - Relationship between $w_{p}$ and Wave $H$ Multiplier

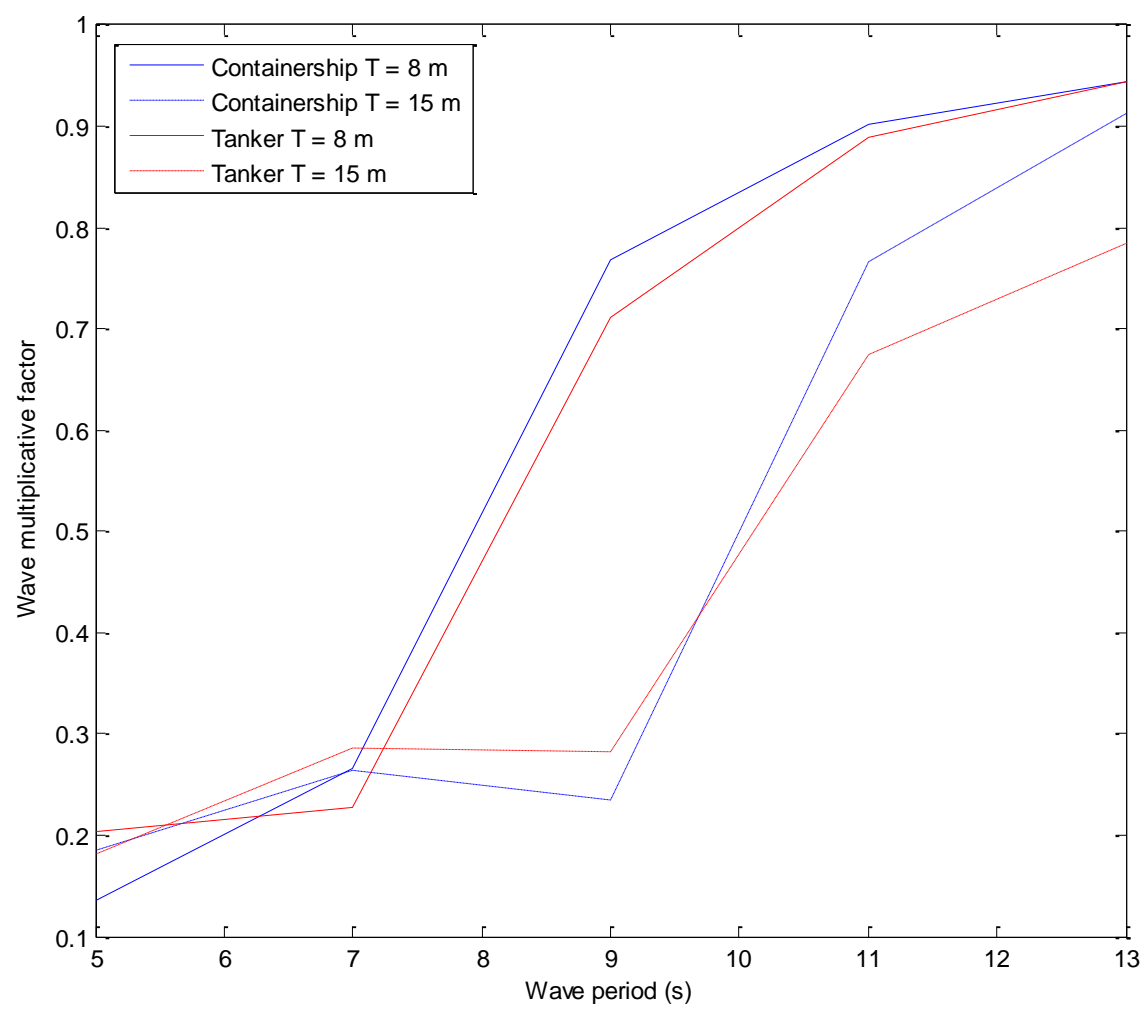

Source: Author 


\section{VECTOR TUG ACTUATION MODELING}

In this section, the proposed vector tug actuation model based on the static equilibrium formulation for operations in either pull or push modes is presented. The main objective of this section is to describe the mathematical formulation in order to obtain the correct parameters that bring a tugboat to static equilibrium on each operation mode.

\subsection{Pull Operations - Direct Maneuver}

\subsubsection{Coordinate Systems and Planar Space}

In order to analyze the tug's static equilibrium problem, four main coordinate systems are necessary, as shown in Figure 36 and Figure 37. The global earthfixed coordinate system is denoted by $X_{0} / Y_{0}$ where $X_{0}$ point towards east and $Y_{0}$ point towards north. The regular angular notation is assumed. In other words, east will correspond to $0^{\circ}$ with the remaining angles increasing in the counterclockwise direction. The vessel-fixed coordinate system is represented by $X_{1} / Y_{1}$ and its origin is positioned, by convenience, at the intersection of the vessel's center plane and midship sections, with $X_{1}$ pointing forward and $Y_{1}$ pointing to port side. The towline-fixed coordinate system is represented by $X_{2} / Y_{2}$ and its origin is positioned at the connection point between one of its extremities and the vessel, with $X_{2}$ pointing towards the line and $Y_{2}$ pointing towards the line's left side. The tug-fixed coordinate system is represented by $X_{3} / Y_{3}$ and similarly to the vessel, its origin is located at the tug's center portion with $X_{3}$ pointing forward and $Y_{3}$ pointing to port side. Note that for all the coordinate systems we have a $Z n$ $[0,3]$ component not shown pointing upwards.

In addition, there are four important angular relationships represented: $\beta_{v}$ represents the angle between the vessel-fixed and the earth-fixed coordinate systems; $\beta_{t}$ represents the angle between the tug-fixed and the earth-fixed coordinate systems; $\psi_{1}$ represents the angle between the vessel-fixed and the towline-fixed coordinate systems; $\psi_{2}$ represents the angle between the towlinefixed and the tug-fixed coordinate systems. Note that all the angles mentioned increase in the counter-clockwise direction and they are comprised within the interval $\left[0^{\circ}, 360^{\circ}\right]$. 
Figure 36 - Coordinate system and angles

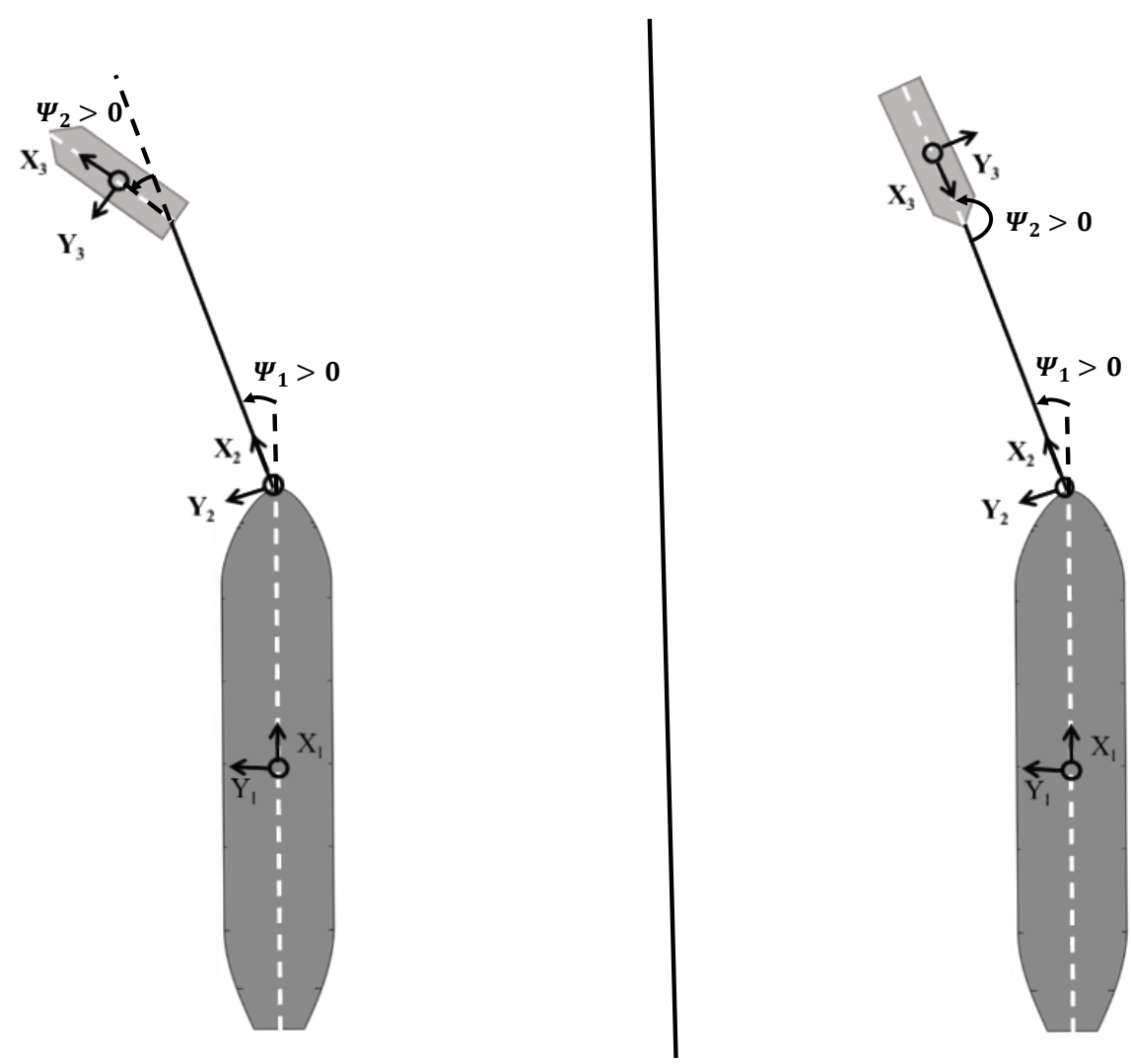

Source: Author

Figure 37 - Coordinate system and angles on most used situation
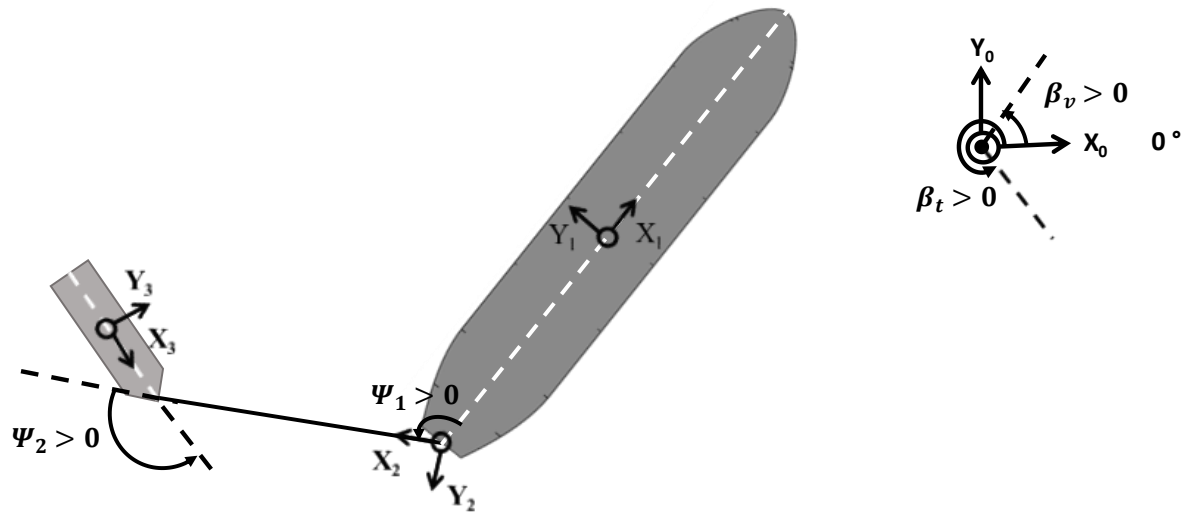

Source: Author 


\subsubsection{Rotation Matrixes}

Let's assume that for every coordinate system, we have three-unit vectors $i_{n} ; j_{n} ; k_{n}$; associated with $x_{n} ; y_{n} ; z_{n}$, respectively. Therefore, by utilizing concepts from vector calculus, one can calculate that the matrix rotation necessary to transform the coordinate systems $x_{n+1} ; y_{n+1} ; z_{n+1}$ into $x_{n} ; y_{n} ; z_{n}$, is (BARUH, 1999):

$$
\boldsymbol{R}_{n+1}^{n}=\left[\begin{array}{lll}
\vec{\imath}_{n+1} \cdot \vec{l}_{n} & \vec{\jmath}_{n+1} \cdot \vec{l}_{n} & \vec{k}_{n+1} \cdot \vec{l}_{n} \\
\vec{\imath}_{n+1} \cdot \vec{\jmath}_{n} & \vec{\jmath}_{n+1} \cdot \vec{\jmath}_{n} & \vec{k}_{n+1} \cdot \vec{\jmath}_{n} \\
\vec{\imath}_{n+1} \cdot \vec{k}_{n} & \vec{\jmath}_{n+1} \cdot \vec{k}_{n} & \vec{k}_{n+1} \cdot \vec{k}_{n}
\end{array}\right]
$$

The three rotation matrixes of our system are given from (24) to (26):

$$
\begin{aligned}
& \boldsymbol{R}_{\mathbf{1}}^{\mathbf{0}}=\left[\begin{array}{ccc}
\cos \left(\beta_{v}\right) & -\sin \left(\beta_{v}\right) & 0 \\
\sin \left(\beta_{v}\right) & \cos \left(\beta_{v}\right) & 0 \\
0 & 0 & 1
\end{array}\right] \\
& \boldsymbol{R}_{\mathbf{1}}^{\mathbf{1}}=\left[\begin{array}{ccc}
\cos \left(\Psi_{1}\right) & -\sin \left(\Psi_{1}\right) & 0 \\
\sin \left(\Psi_{1}\right) & \cos \left(\Psi_{1}\right) & 0 \\
0 & 0 & 1
\end{array}\right] \\
& \boldsymbol{R}_{\mathbf{3}}^{\mathbf{2}}=\left[\begin{array}{ccc}
\cos \left(\Psi_{2}\right) & -\sin \left(\Psi_{2}\right) & 0 \\
\sin \left(\Psi_{2}\right) & \cos \left(\Psi_{2}\right) & 0 \\
0 & 0 & 1
\end{array}\right]
\end{aligned}
$$

By utilizing the post-multiplication concepts, we can define the instantaneous rotation matrix between the tug-fixed coordinate system and the earth-fixed coordinate system as a function of the angle between the tug and the towline; the angle between the towline and the vessel; the angle between the vessel and earth-fixed coordinate system: 


$$
\begin{gathered}
\boldsymbol{R}_{\mathbf{3}}^{\mathbf{0}}=R_{1}^{0} * R_{2}^{1} * R_{3}^{2} \\
\boldsymbol{R}_{\mathbf{3}}^{\mathbf{0}}=\left[\begin{array}{ccc}
\cos \left(\beta_{v}+\Psi_{1}+\Psi_{2}\right) & -\sin \left(\beta_{v}+\Psi_{1}+\Psi_{2}\right) & 0 \\
\sin \left(\beta_{v}+\Psi_{1}+\Psi_{2}\right) & \cos \left(\beta_{v}+\Psi_{1}+\Psi_{2}\right) & 0 \\
0 & 0 & 1
\end{array}\right]
\end{gathered}
$$

An alternative way, is to calculate the instantaneous rotation matrix between the tug-fixed coordinate system and the earth-fixed coordinate system as a function of the global angle between these coordinate systems:

$$
\boldsymbol{R}_{\mathbf{3}}^{\mathbf{0}}=\left[\begin{array}{ccc}
\cos \left(\beta_{t}\right) & -\sin \left(\beta_{t}\right) & 0 \\
\sin \left(\beta_{t}\right) & \cos \left(\beta_{t}\right) & 0 \\
0 & 0 & 1
\end{array}\right]
$$

By making the terms $(1,1)$ of equations (28) and (29) equal, and solving such equation by $\psi_{2}$, the first main relationship is obtained:

$$
\Psi_{2}=\beta_{t}-\beta_{v}-\Psi_{1}
$$

Note that for our formulation, $\Psi_{2}$ is only a function of $\beta_{t}$. The angle between the vessel and the towline $\Psi_{1}$ will be kept fixed, thus it is a parameter. In addition, the angle between the vessel and the earth-fixed coordinate system is usually known based on GNSS devices.

\subsubsection{Static Equilibrium Formulation}

There are three main forces actuating on a tug during pull operations: the forces generated by its propellers $\left(F_{p}\right)$; the reaction force transmitted by the towline $\left(F_{t}\right)$; the sum of the hull forces generated by external disturbances such as winds, currents and waves $\left(F_{e}\right)$. The equilibrium conditions for a tug under the influence of such forces takes the following form in the tug-fixed coordinate system $\left(X_{3}, Y_{3}\right)$ : 


$$
\begin{gathered}
F_{p x}+F_{t x}+F_{e x}=0 \\
F_{p y}+F_{t y}+F_{e y}=0 \\
M_{p z}+M_{t z}+M_{e z}=0
\end{gathered}
$$

where:

$F_{x}, F_{y}$ - the longitudinal and transversal component of each force on the tug-fixed coordinate system $[\mathrm{N}]$,

$M_{z}$ - Moment developed by a specific force with respect to the tugboat's center of mass located at the origin of its coordinate system [N.m].

The towline is assumed as rigid and with negligible mass, thus the reaction force generated by the towline on the tug will be the same as the effective force applied on the vessel. Additionally, since the effective mean force generated by waves is considerably smaller than the forces generated by currents and winds, we will neglect such effects on the tug. However, as seen in section 3.6 and 3.7, the wave motion and wave shadowing may severely affect a tugboat's efficiency, thus such effect must be taken in consideration. Finally, we will assume that the tug has only one propeller at its aft center line, which will be the only actuator of the system, being able to freely rotate in $360^{\circ}$. This assumption is considered due to the complexity of thruster-to-thruster interaction, which is a different field of study out of the scope of this work.

By implementing the proposed formulation, one can fix some control parameters such as the propeller thrust, the towline angle, the towed vessel's speed, the towed vessel's global angle, the wind velocity and its global angle, the current velocity and its global angle, and mutually solve Eqs. (31) through (33) to obtain the tug's global angle, the propeller angle of actuation and the effective force on the towline. Note that more than one equilibrium solution may exist, thus 
optimization techniques must be implemented to obtain the solution desired regarding specific constraints.

\subsubsection{Propeller Force Model}

Based on the propeller formulation provided on section 3.1, one can use the $K_{T}$ curve obtained (Figure 19) and Eq. (2) to obtain a propeller's thrust (T) for a specific situation, in which the demanded rotation $(n)$ is a fixed-parameter, usually requested by a pilot (tugboat demanded force of actuation). After obtaining the propeller thrust, one must realize if the vector tug is in a wave shadow region in order to attenuate its $\mathrm{H}_{\mathrm{s}}$ (theory from section 3.7). Note that, for this formulation, the $\mathrm{Hs}$ attenuation is assumed to be the same for all regions encompassed by a wave shadow. By obtaining the correct wave $H_{s}$ and $T_{p}$ for a specific region, the theory from section 3.6 can be used, in such a way that the tugboat efficiency will be attenuated by a factor obtained in Figure 31 and Figure 32. Therefore, the final propeller force of a vector tug may be given by:

$$
F_{p}=\text { wave }_{\text {factor }} * T
$$

Based on the vector tug force diagram, shown in Figure 38 and on the propeller force obtained from Eq. (28), one may calculate its projection on each degree of freedom of the tugboat:

$$
\left[\begin{array}{c}
F_{p x} \\
F_{p y} \\
M_{p z}
\end{array}\right]=F_{p}\left[\begin{array}{c}
\cos (\delta) \\
\sin (\delta) \\
x_{p} * \sin (\delta)
\end{array}\right]
$$

where:

$F_{P}$ - the magnitude of thruster force (always positive) [N].

$\delta$ - the thruster angle within the interval $\left[0^{\circ}, 360^{\circ}\right]$ increasing in the counterclockwise direction $\left[^{\circ}\right]$. 
$x_{p}$ - thruster location related to the tugboat's midship section (negative if at the tug's stern) [m].

Figure 38 - Vector tug force diagram

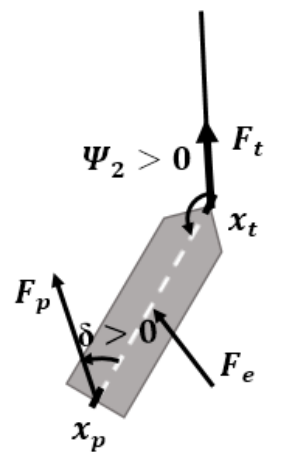

Source: Author

\subsubsection{Towing Force Model}

As mentioned before, the towline will be modeled as a fixed bar, thus the towing reaction force is the same as the effective force exerted on the towed vessel. Note that, although the towing force $F_{t}$ is not directly controlled by a tug master, it is also a variable controller parameter since its magnitude will directly depend on the tugboat's heading angle and propeller angle of actuation.

The towing forces and moments (with full support of signs) are demonstrated below:

$$
\left[\begin{array}{l}
F_{t x} \\
F_{t y} \\
M_{t z}
\end{array}\right]=F_{t}\left[\begin{array}{c}
-\cos \left(\Psi_{2}\right) \\
\sin \left(\Psi_{2}\right) \\
x_{t} * \sin \left(\Psi_{2}\right)
\end{array}\right]
$$

where:

$F_{t}$ - the magnitude of towing force (always positive) [N].

$x_{t}$ - thruster location related to the tugboat's midship section (positive if at the tug's bow) [m]. 


\subsubsection{External Force Model}

Based on the current force model proposed in section 3.2, more specifically the Eq. (9) and the wind force model proposed in section 3.3, more specifically Eq. (13), one may obtain the external force model as follows:

$$
\begin{gathered}
F_{e x}=F_{c x}+F_{w x} \\
F_{e y}=F_{c y}+F_{w y} \\
M_{e z}=M_{c z}+M_{w z}
\end{gathered}
$$

\subsubsection{Optimization Formulation}

As briefly mentioned, the static equilibrium diagram may have several sets of solutions, or, in other words, there are several sets of control parameters combinations that will bring the tugboat to be in static equilibrium when operating in pull mode. Therefore, optimization techniques should be implemented to select the solution that most fits the behavior of a manned tugboat.

Usually, tug masters try to obey a pilot's command by keeping the tugboat as aligned as possible with the towline. Although such a position may not be most suitable one from an efficiency standpoint, it is the most intuitive position to stay, thus representing the main action taken by tug masters. In order to select the solution that represents such behavior, we decided to try to minimize the angle between the tugboat and its towline. Therefore, due to our angular orientations previous stated, the objective function for such configuration may be given by Eq. (40).

$$
G\left(\Psi_{2}\right)=\min \left(\left|\Psi_{2}-180^{\circ}\right|\right)
$$


After defining the desired objective function, one must provide the upper and lower boundaries for $\Psi_{2}, F_{t}$, and $\delta$, which are the variable control parameters of the system. Due to the tugboat's physical structure, it is known that a towline connected at its bow cannot go through its longitudinal portion towards its aft. Therefore, we can define the lower boundary of $\Psi_{2}$ to be approximately $80^{\circ}$ while the upper boundary may be approximated to be $280^{\circ}$ (Figure 39). The boundaries of the towline force and the propeller angle of actuation are more straightforward. Since the variable $F_{t}$ must be positive, its lower boundary will be zero, and its upper boundary will be 4 times larger the tugboat's bollard pull, which is the maximum breaking force that a towline usually supports; the variable $\delta$ is free to rotate in $360^{\circ}$, thus its lower boundary will be $0^{\circ}$ while its upper boundary will be given by $360^{\circ}$. Note that the upper and lower boundaries in $\delta$ are not strictly necessary, but they will be used to keep the angle notation simplicity between the desired interval.

Figure $39-\Psi_{2}$ restriction diagram

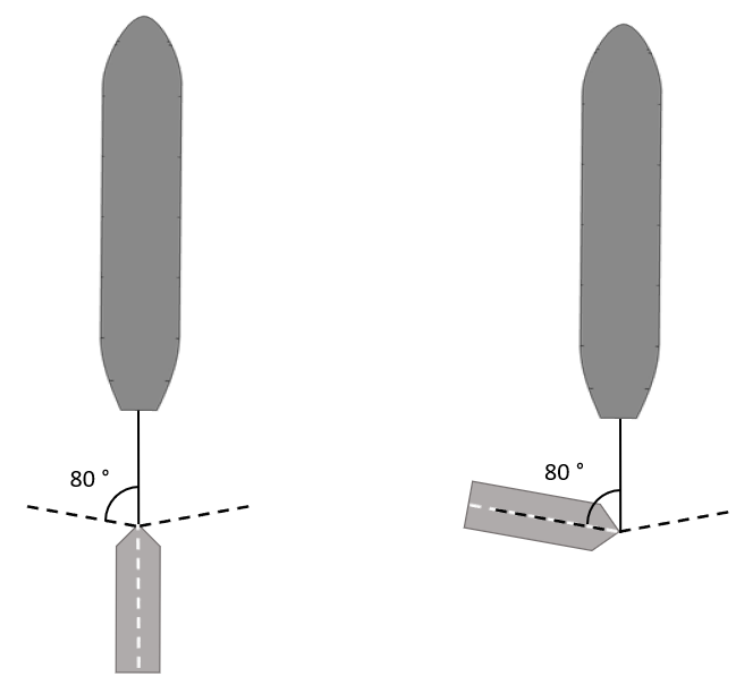

Source: Author

The definition of the objective function, the upper and lower boundaries of the variable parameters and the nonlinear constraints (Eqs. (31) to (33)) allow us to use several optimization techniques to attain the desired goal. For this work, the sequential quadratic programming optimization method (SQP) will be used. 


\subsection{Push Operations}

There are several similarities between the Pull - Direct Maneuver model and the Push model, such as: The Static Equilibrium Formulation, the Propeller Force Model and the External Force Model. Therefore, in this section, we will only be concerned with the Coordinate Systems and Angles Orientations; the Rotation Matrixes; the Towing Force Model; the Optimization Formulation.

\subsubsection{Coordinate Systems and Planar Space}

In Figure 40, we can see the same coordinate systems for the vessel and the tugboat, as earlier shown in Figure 36. The main difference between the two is the absence of the towline's coordinate system and the introduction of a new angular notation: $\Psi_{3} . \Psi_{3}$ represents the angle between the tugboat and the towed vessel during push maneuvers. This angle increases in the counter-clockwise direction and it is comprised within the interval $\left[0^{\circ}, 360^{\circ}\right]$.

Figure 40 - Coordinate Systems and Angles - Push mode

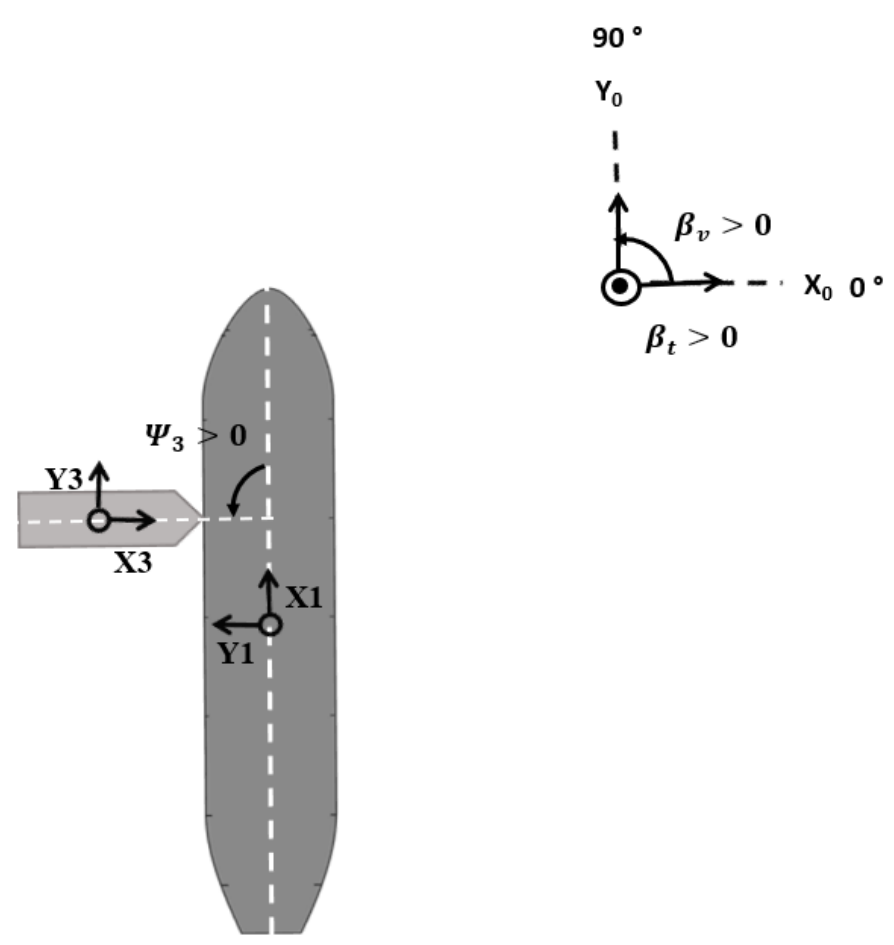

Source: Author 


\subsubsection{Rotation Matrixes}

By using the concepts exposed in Eq. (27), we can calculate the direct rotation matrix between the tugboat and the vessel:

$$
\boldsymbol{R}_{\mathbf{3}}^{\mathbf{1}}=\left[\begin{array}{ccc}
-\cos \left(\Psi_{3}\right) & -\sin \left(\Psi_{3}\right) & 0 \\
\sin \left(\Psi_{3}\right) & -\cos \left(\Psi_{3}\right) & 0 \\
0 & 0 & 1
\end{array}\right]
$$

By utilizing the post-multiplication concepts, we can define the instantaneous rotation matrix between the tug-fixed coordinate system and the earth-fixed coordinate system as a function of the angle between the tug and the vessel and the angle between the vessel and earth-fixed coordinate system:

$$
\begin{gathered}
\boldsymbol{R}_{3}^{\mathbf{0}}=R_{1}^{0} * R_{3}^{1} \\
\boldsymbol{R}_{3}^{\mathbf{0}}=\left[\begin{array}{ccc}
-\cos \left(\beta_{v}-\Psi_{3}\right) & \sin \left(\beta_{v}-\Psi_{3}\right) & 0 \\
-\sin \left(\beta_{v}-\Psi_{3}\right) & -\cos \left(\beta_{v}-\Psi_{3}\right) & 0 \\
0 & 0 & 1
\end{array}\right]
\end{gathered}
$$

In an alternative way, we could calculate the instantaneous rotation matrix between the tug-fixed coordinate system and the earth-fixed coordinate system as shown in Eq. (29). By making the terms $(1,1)$ of Eqs. (29) and (43) equal, and solving such equation by $\Psi_{3}$, we obtain the following relationship:

$$
\Psi_{3}=\beta_{t}+\beta_{v}
$$

\subsubsection{Towing Force Model}

When working in push mode, a tugboat experiences 2 main forces arrived from the hull-to-hull direct contact: the reaction force and the friction force. The reaction force has the same magnitude of the towing force, always actuating perpendicular to the towed vessel, but with an opposite direction, as shown in Figure 41. Such force is responsible for pushing the towed vessel towards a specific direction. On the other hand, the friction force always actuates perpendicularly to the reaction 
force, and it is responsible for keeping the tugboat in a steady position, or in other words, without slipping against the towed vessel's hull. The lift force generated by the "wall effect" during the contact between the tug and the ship is not being considered.

Figure 41 - Push force diagram

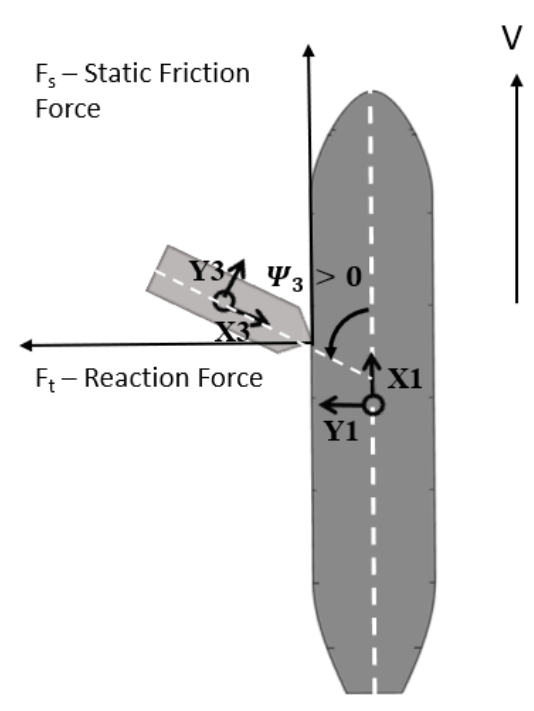

Source: Author

Based on the proposed notation, one can arrive on the towing force formulation proposed in Eq. (45).

$$
\left[\begin{array}{l}
F_{t x} \\
F_{t y} \\
M_{t z}
\end{array}\right]=-\operatorname{sign}\left(\sin \left(\Psi_{3}\right)\right) F_{t}\left[\begin{array}{c}
\sin \left(\Psi_{3}\right) \\
\cos \left(\Psi_{3}\right) \\
0.5 * L * \cos \left(\Psi_{3}\right)
\end{array}\right]+F_{s}\left[\begin{array}{c}
-\cos \left(\Psi_{3}\right) \\
\sin \left(\Psi_{3}\right) \\
0.5 * L * \sin \left(\Psi_{3}\right)
\end{array}\right]
$$

where:

$F_{t}$ - the magnitude of reaction force (always positive) [N].

$F_{S}$ - the static friction force (positive or negative based on optimization) [N].

\subsubsection{Optimization Formulation}

During a push maneuver, the tugboat commandant tries to maintain the tugboat as perpendicular as possible to the towed vessel. In situations where the external disturbances are moderate, such configuration is the one that provides the highest towing net force and is easily achievable. However, in situations where the external disturbances are severe, the tugboat may not be able to stay 
completely perpendicular to the towed vessel, thus only allowing such maneuvers to be performed with a considerable misalignment between the tugboat and the towed vessel's major axis.

In the literature, it is common to find that, during push operations, the maximum misalignment between a tugboat and a towed vessel is about $30-35^{\circ}$. However, most of these formulations do not consider the most important factor on determining such maximum misalignment: the friction force. In push operations, the friction force will be responsible for determining when a tugboat will slip against a vessel's hull. Therefore, the meaning of a friction force larger than the static friction coefficient of the contact point times its normal force means that the tugboat is slipping.

In this formulation, there are 3 variables to be optimized: the reaction force $F_{t}$, which is the same as the towing force exerted on the towed vessel; the friction force $F_{S}$, which may be positive or negative, thus indicating its correct direction of actuation; the propeller angle of actuation $\delta$. The lower and upper boundaries imposed to $F_{t}$ and $\delta$ will be kept the same as shown in section 4.1.7.

Since the tugboat commandants try to be as efficient as possible, for this formulation, we will need to maximize the towing force. Therefore, the objective function will be:

$$
G\left(F_{t}\right)=\operatorname{máx}\left(F_{t}\right)
$$

For this formulation we will have 2 non-linear constraints groups: the static equilibrium constraints, which have already been proposed and can be found in Eqs. (31) through (33) and the friction force constraint, which is shown in Eq. (47). The friction force constraint guarantees that the tugboat will not slip alongside the towed vessel's hull.

$$
-\mu_{s} * F_{t} \leq F_{s} \leq-\mu_{s} * F_{t}
$$

where:

$\mu_{s}$ - static friction coefficient of rubber-steel subject to sea-water droplets lubrication. 
In (ZHOU, WANG and GUO, 2017) an experiment was performed in order to study the friction forces occurring on a rubber-steel contact point when subjected to sea-water droplets lubrication. As show in Figure 42, a piece of nitrile butadiene rubber (NBR) was put in contact with a steel pipe. A set of different normal forces were applied to the system (10 - 40N range) and 2 different tangential loads were applied to the system $(0.062,1.5 \mathrm{~N} / \mathrm{s})$. While applying the forces, sea-water droplets were added, thus simulating a situation that may be analogous to a contact between a tugboat and a vessel's hull.

Figure 42 - Friction force experiment

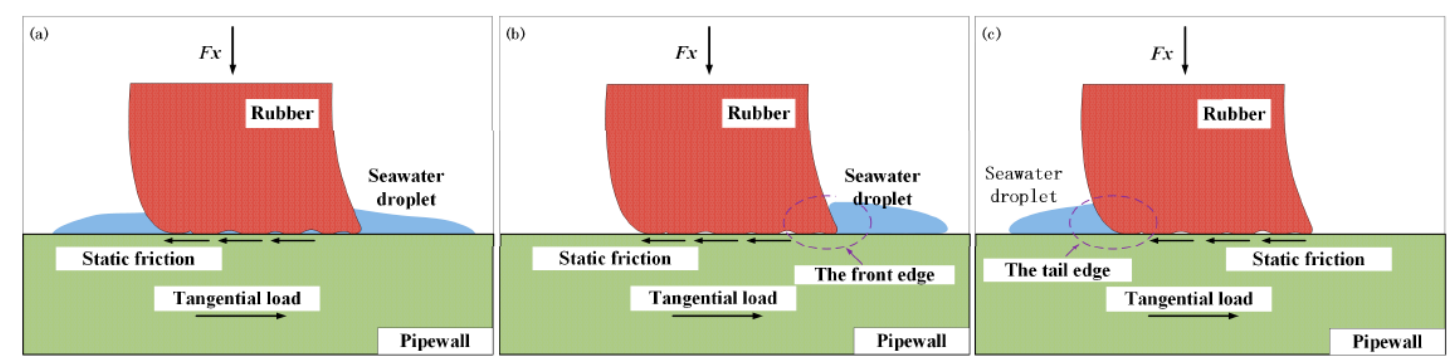

Source: (ZHOU, WANG and GUO, 2017)

For each scenario, as shown in Figure 43, a maximum static friction force was measured. By using the results for the most severe scenario ((a), transverse force of $40 \mathrm{~N}$ and tangential force with an increase rate of $1.5 \mathrm{~N} / \mathrm{s}$ ) one can calculate the static friction coefficient of the contact point to be around $\mu_{s}=0.55$. Such value will be used during the optimization.

Figure 43 - Friction force experiment results

(a)

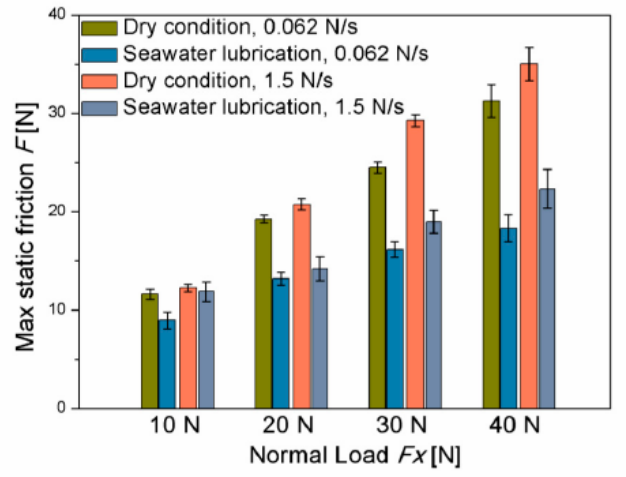

(b)

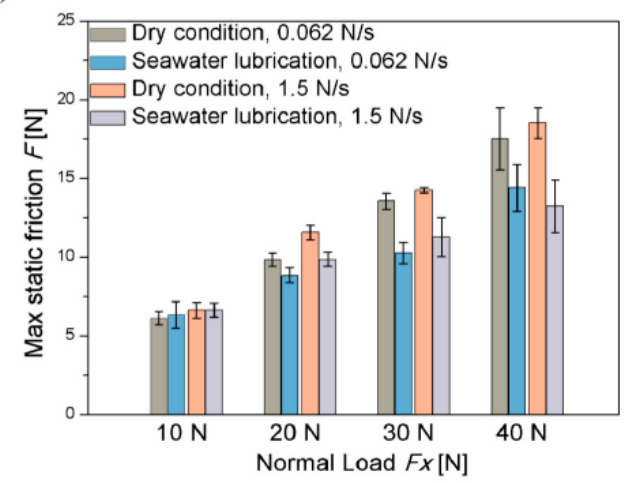

Source: (ZHOU, WANG and GUO, 2017) 


\subsection{Pull Operations - Indirect Maneuver}

As stated throughout this work, the indirect maneuver can only be performed when a tugboat is escorting (i.e., working connected to the towed vessel's stern) a towed vessel at high speeds. In this specific maneuver, the tugboat seeks for great misalignments with respect to the towline in order to use the incoming relative water flow in its favor, maximizing the towing force. In Figure 44, an indirect maneuver diagram is presented.

Figure 44 - Indirect maneuver diagram

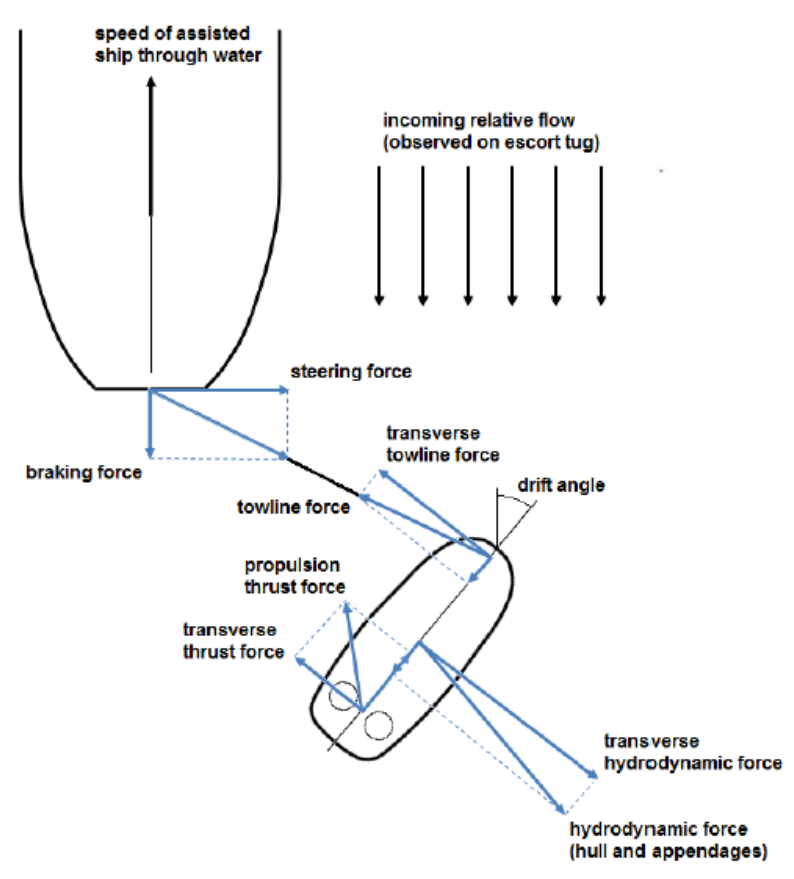

Source: (IMO, 2016)

For this type of maneuver, severe transverse forces actuate along the tugboat's hull, creating heeling moments around the tugboat's $\mathrm{x}_{3}$-axis. For this reason, in order to correctly model such operation, a fourth degree of freedom must be added to the model. Note that, on the following sub-sections, the focus will be the addition of this degree of freedom, and its implications on the model. Please, keep in mind that, all the other formulation proposed on the section 4.1 still holds true. 


\subsubsection{Angle Orientation and Static Equilibrium Formulation}

Suppose a tugboat is steady on water, with no current or propeller forces actuating on it. At this location, only the weight of the tugboat will be exerting force on the body. At the center of gravity $(G)$, there will be a weight force pointing downwards and, based on the Archimedes' law, at the initial center of buoyance $\left(B_{0}\right)$ of the body, there will be a buoyance force pointing upwards.

Suppose now that the tugboat experiences a small list to its port side (Figure 45). The center of buoyance moves to the location $\mathrm{B}_{1}$, and the buoyance force begins to produce a restoring moment with an $\operatorname{arm} G Z\left(G M \cdot \sin \left(\Psi_{4}\right)\right)$. The location where the upward force crosses the tug's centre line is known as the Meta Centre $(M)$. The distance between $G$ and $M$ is known as the metacentric height. Such parameter is extremely important on a tug design, in such a way that it helps to define the tug stability. The larger the tug's $G M$ the better its stability (HENSEN and LAAN, 2016).

Figure 45 - Tugboat list diagram

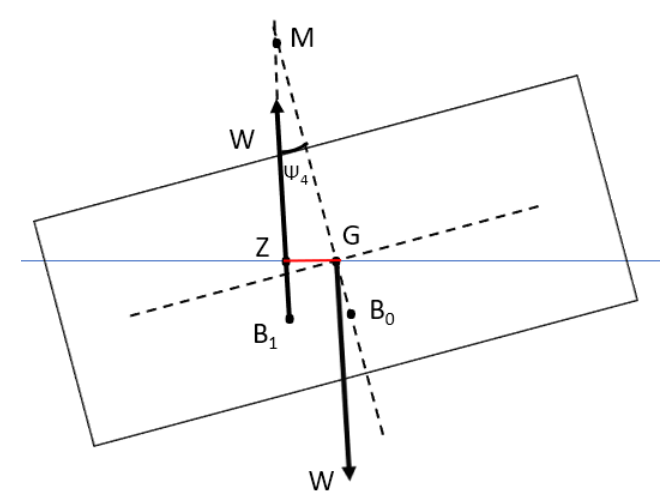

Source: Adapted from (HENSEN and LAAN, 2016)

For our formulation, the angular relationship $\Psi_{4}$ will be introduced. It will characterize the angle around the $x_{3}$-axis, and it will be on the range $\left[-180^{\circ}, 180^{\circ}\right]$, being positive on port side and negative on starboard side.

In order for the tugboat to be in static equilibrium, the moments around the $\mathrm{x}_{3}$ axis must also be taken into account. Based on the previous explanations, such configuration will occur when the moments acting on the tugboat caused by the 
propellers, the towing force and external forces are the same as the restoring moment caused by the buoyance force. The new static equilibrium equation to be added to the model is shown in (48).

$$
M_{p x}+M_{t x}+M_{e x}=\Delta \times g \times G M \times \sin \left(\Psi_{4}\right)
$$

where:

$M_{x}$ - Moment developed by a specific force around the x-axis [N.m].

$\Delta$ - tugboat water displacement $[\mathrm{kg}]$

$g$ - gravity acceleration $\left[\mathrm{m} / \mathrm{s}^{2}\right]$

$G M$ - tugboat's initial metacentric height [m]

Note that the term $G M . \sin \left(\Psi_{4}\right)$ is the same as the righting arm GZ. However, as seen in Figure 46, such transformation is only valid for list angles smaller than $7^{\circ}$. In order to find the $G Z$ values for greater list angles, one must obtain the stability curve for the tugboat in study and obtain the correct $G Z$ value directly from the curve. In Figure 46 an example of a tugboat's stability curve is presented.

Figure 46 - Stability curve of a harbor tug

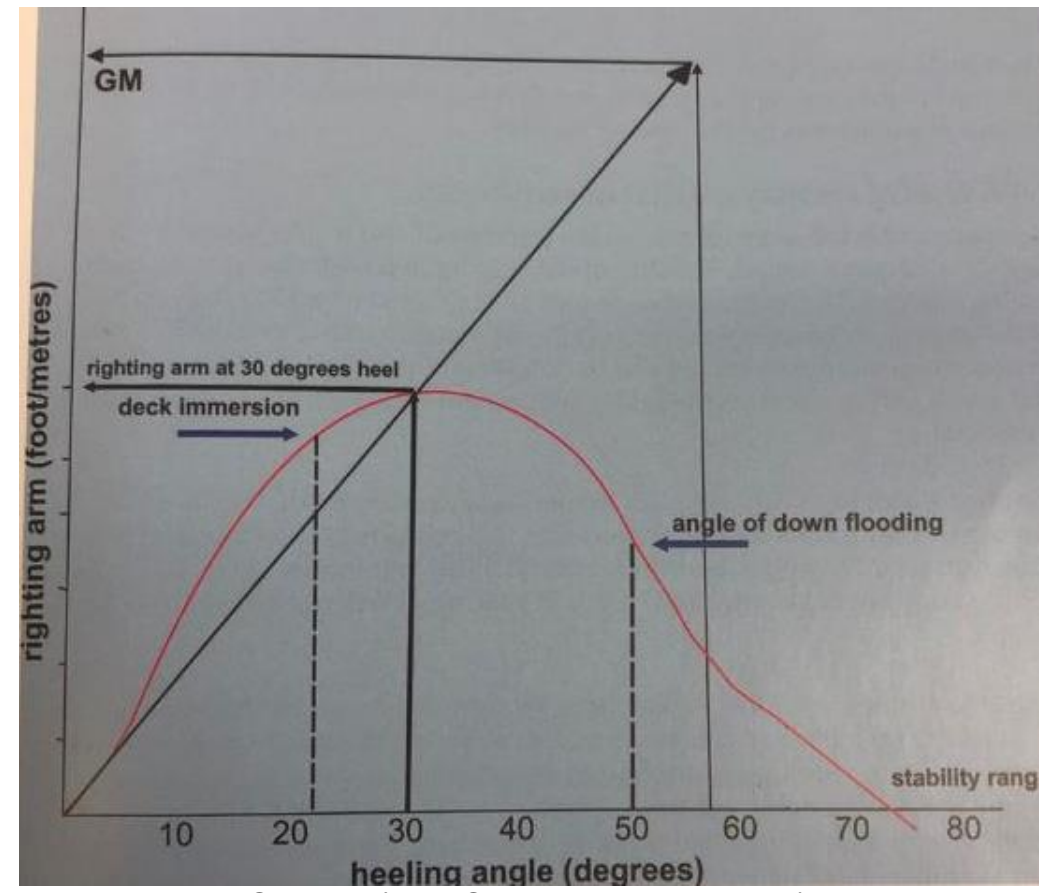

Source: (HENSEN and LAAN, 2016) 


\subsubsection{Towing, Propeller and External Force Model}

As seen in Figure 47, during an indirect maneuver, the main forces actuating on the tugboat are the towing force, propeller force and hull forces. Note that the hull forces are generated solely by the relative current actuating on the tug. Since the indirect maneuver occurs at high speeds, the magnitude of the current force ends up being considerably larger than the magnitude of the wind forces, thus allowing the neglection of the second one.

Each one of the mentioned forces will exert a heeling moment on the tugboat, which will be a function of the heeling arm. The heeling arm of each force will solely be the vertical distance between the force location and the tugboat's center of gravity. Note that, during the indirect maneuver, the towline and the hull forces will produce a moment in the same direction, forcing the tugboat to list. On the other hand, the propeller forces will try to counter act this moment, keeping the tugboat at equilibrium.

Figure 47 - Height location of actuating forces

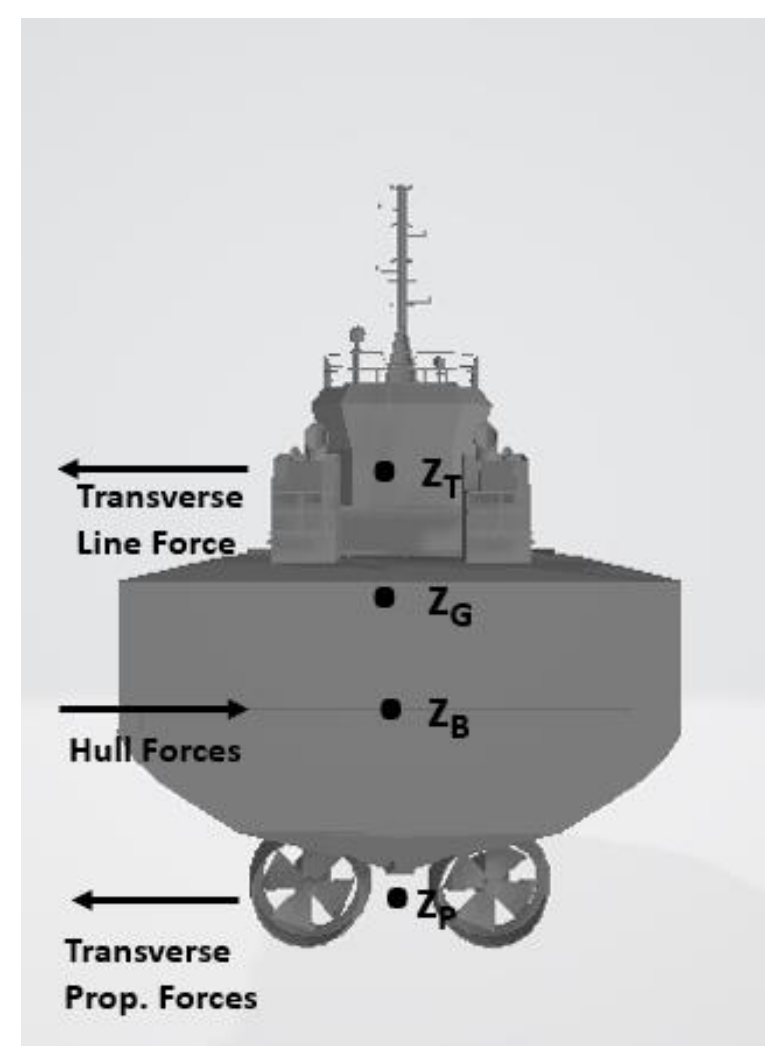

Source: Author 
In Eq. (49) we present the heeling moments caused by the propeller force; in Eq. (50) the heeling moments caused by towing force; in Eq. (51) the heeling moments caused by the current forces:

$$
\begin{gathered}
M_{p x}=-F_{p y} \times\left(z_{G}-z_{P}\right) \\
M_{t x}=F_{t y} \times\left(z_{t}-z_{G}\right) \\
M_{e x}=-F_{c y} \times\left(z_{G}-z_{B}\right)
\end{gathered}
$$

\subsubsection{Optimization Formulation}

Compared to the previous formulation, a new design variable should be introduced: $\Psi_{4}$ Therefore, all the variables that must be optimized are: $\Psi_{2}, F_{t}, \delta$ and $\Psi_{4}$. The upper and lower boundaries for the first 3 variables are kept the same as the Pull-Direct maneuver, while the new variable, $\Psi_{4}$, will have its lower and upper boundary delimited according to IMO's resolution.

According to the resolution MSC.416(97), for ships engaged in escort operations, the equilibrium heel angle corresponding to the first intersection between the heeling lever curve and righting lever curve must be smaller or equal $15^{\circ}$ (IMO, 2016). In a static situation, the heeling forces are not strong enough to give the tug larger heel than such angle ( $\mathrm{C}$ in Figure 48). However, in a dynamic situation, the tugboat's heeling angle will accelerate from its initial condition till $\mathrm{C}$ degrees. At $\mathrm{C}$ degrees, the heeling will start to decelerate. However, the heeling energy built up will make the tugboat to continue heeling, entering the reserve stability area. The limitation of maximum heeling angle of $15^{\circ}$ is imposed in order to make sure that the tugboat will have enough reserve stability to counter-act the built-up heeling energy, coming back to its equilibrium position safely, without the risk of capsizing (HENSEN and LAAN, 2016). Therefore, for our formulation, $\Psi_{4}$ will have a lower boundary of $-15^{\circ}$ and an upper boundary of $15^{\circ}$. 
Regarding to the non-linear constraints, the same ones from the previous section will be maintained, with the addition of the static equilibrium equation for roll (Eq. (48)).

Figure 48 - General stability diagram

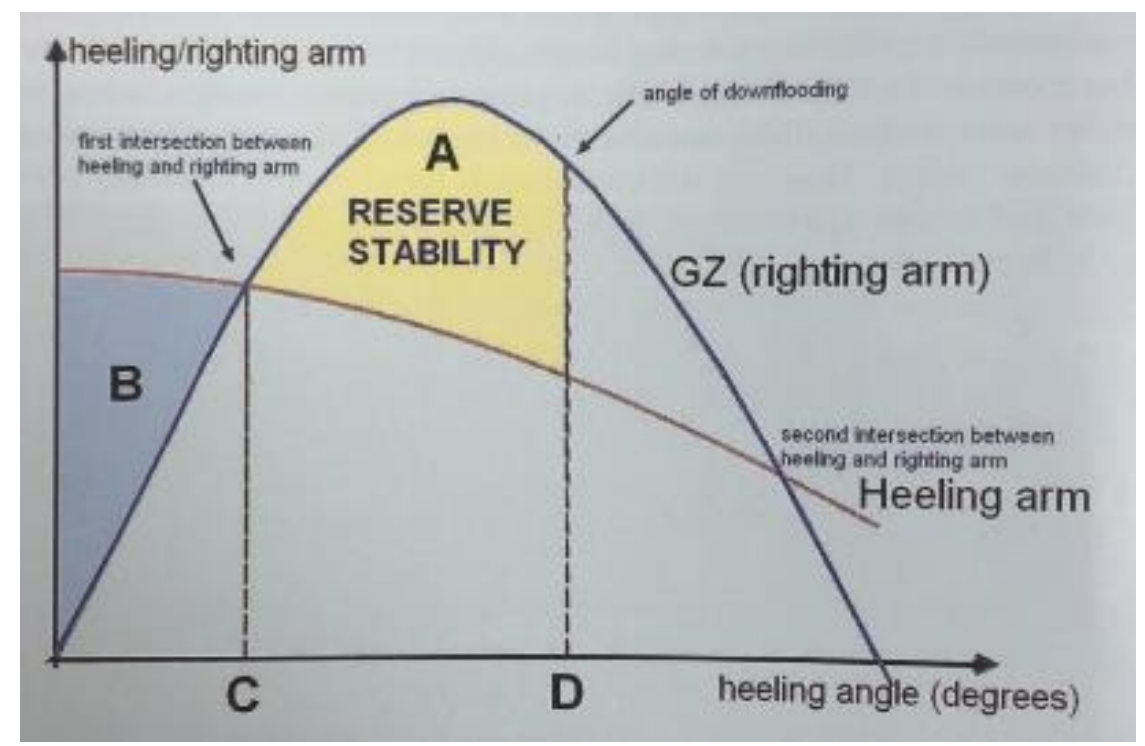

Source: (HENSEN and LAAN, 2016)

Since the indirect maneuver seeks to maximize the towing force, the objective function of the optimization will be:

$$
G\left(F_{t}\right)=\operatorname{máx}\left(F_{t}\right)
$$




\section{SIMULATION AND RESULTS}

For the simulations presented in this section, the tugboat's propeller force is constant at $588 \mathrm{KN}$, which is analogous to assume that a pilot is requesting a tugboat of about 60 tones to work with its full power. The main objective of such simulations is to analyze how the variable control parameters behave for each operation scenario when subjected to external conditions either provided by a pilot or imposed by the environment. For the simulations, we will vary the vessel's advance speed, the towline angle in $1^{\circ}$ intervals for the pull scenarios, and the angle between the tugboat and the towed vessel for the push scenarios. Note that by varying the vessel's advance speed, apparent wind and current fields will be generated, directly affecting the tugboat operation. The physical characteristics for the regular ASD tugboat used in the simulations of section 5.1, 5.2 and 5.3.1 are shown in Table 5.

Table 5 - Tugboat characteristics

\begin{tabular}{|c|c|c|}
\hline Parameter & value & units \\
\hline Length & 32 & $\mathrm{~m}$ \\
\hline Draught & 3.8 & $\mathrm{~m}$ \\
\hline Beam & 12.8 & $\mathrm{~m}$ \\
\hline Displacement $(\Delta)$ & 710 & ton \\
\hline Center of Gravity Height $\left(\mathrm{Z}_{\mathrm{G}}\right)$ & 3.71 & $\mathrm{~m}$ \\
\hline Nominal Metacentric Height $(\mathrm{GM})$ & 2.5 & $\mathrm{~m}$ \\
\hline Buoyance Height $\left(\mathrm{Z}_{\mathrm{B}}\right)$ & 1.9 & $\mathrm{~m}$ \\
\hline Frontal Area & 230 & $\mathrm{~m}^{2}$ \\
\hline Lateral Area & 528 & $\mathrm{~m}^{2}$ \\
\hline Longitudinal Contact Position bow $\left(\mathrm{x}_{\mathrm{t}}\right)$ & 11 & $\mathrm{~m}$ \\
\hline Longitudinal Contact Position aft $\left(\mathrm{x}_{\mathrm{t}}\right)$ & -1 & $\mathrm{~m}$ \\
\hline Contact Position Height $\left(\mathrm{z}_{\mathrm{t}}\right)$ & 9.5 & $\mathrm{~m}$ \\
\hline Longitudinal Propeller Position $\left(\mathrm{x}_{\mathrm{p}}\right)$ & -11.6 & $\mathrm{~m}$ \\
\hline Propeller Position Height $\left(\mathrm{z}_{\mathrm{p}}\right)$ & 1.5 & $\mathrm{~m}$ \\
\hline Propeller Diameter & 2.2 & $\mathrm{~m}$ \\
\hline Bollard pull & 60 & ton \\
\hline
\end{tabular}




\subsection{Pull Mode - Direct Maneuver}

In this section, 3 simulation scenarios will be explored based on the towed vessel's speed. The tugboats commonly operate in pull mode - direct maneuver when the towed vessel navigates with a speed between 2 and 6 knots. Therefore, in the first scenario, the towed vessel will be navigating with 2 knots, with the wind and current fields being generated solely by this advance speed; in the second scenario, the towed vessel will be navigating with $4 \mathrm{kn}$; in the third scenario, the towed vessel will be navigating with $6 \mathrm{kn}$.

Usually, the ASD tugboats have two points to tie the towline: one located at their bow and one located near its center-part, a little moved to their aft. Since most of the tugboats operating in Brazil work with their towline tied at their bow, this will be the focus of the analysis. However, since the tugboat stability is severely impaired when navigating astern with the towline tied at its bow (refer to section 5.1.1), we will also present the force curves for this situation, with the towline tied at the tugboat's aft (right curves of the towline force). Both connection points are showed in Figure 49.

Figure 49 - Towline connection points

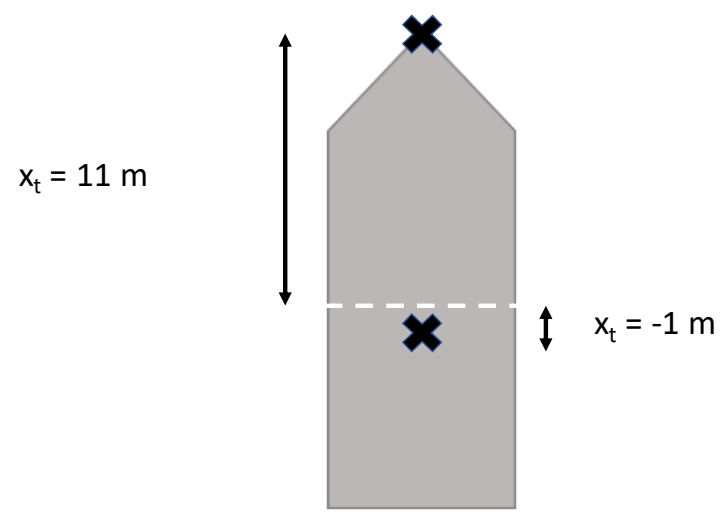

Source: Author

By analyzing the first two simulations, one can realize that the towline force tends to be smaller than the tug's bollard pull when the tugboat operates on the towed vessel's bow center part, constantly increasing while it moves towards the towed vessel's stern (Left - Figure 50 and Left - Erro! Fonte de referência não encontrada.). However, the same does not occur in the third simulation. When the towed vessel is navigating with $6 \mathrm{Kn}$, the towline force tends to decrease 
when the towline angle goes from $30^{\circ}$ to $80^{\circ}$; then it tends to increase when the towline angle goes from $80^{\circ}$ to $150^{\circ}$; finally, it decreases again from $150^{\circ}$ to $180^{\circ}$ (Left - Figure 52). This may be explained by the relative angle between the tugboat and the towline.

Figure 50 - Towline force $\left(F_{t}\right)$ for the $2 \mathrm{kn}$ scenario. Left - towline at the bow; Right - Towline at the aft
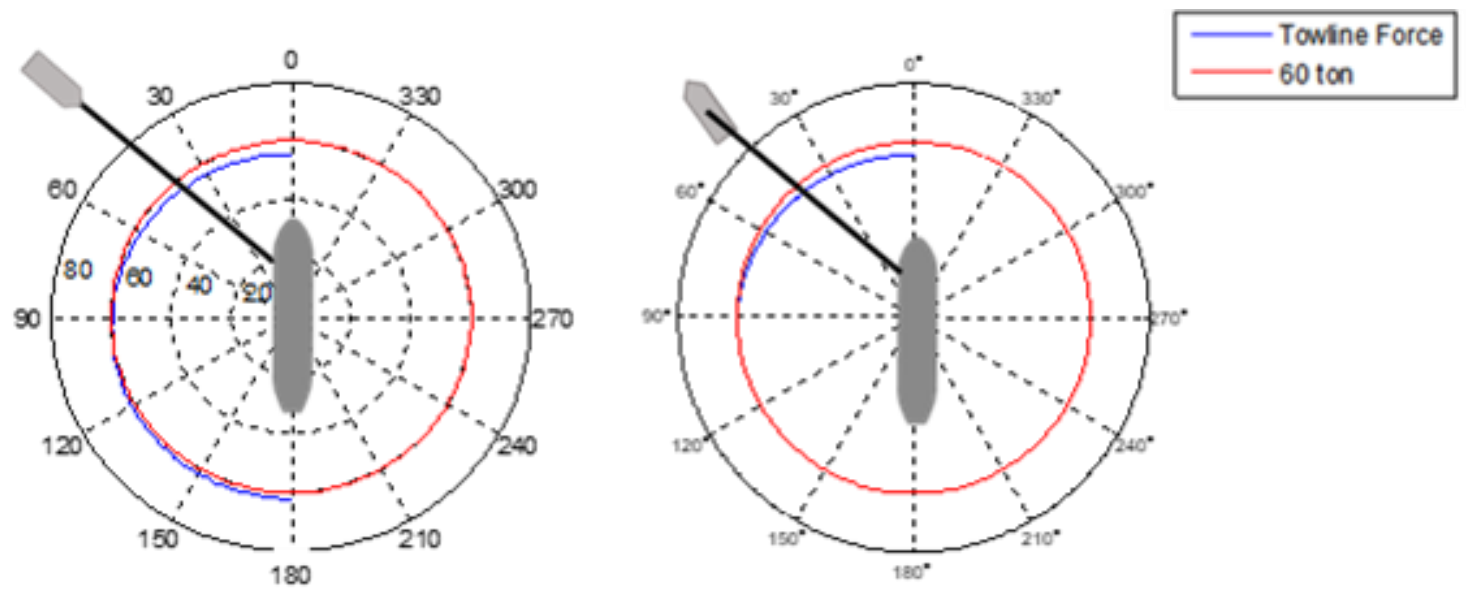

Source: Author

Figure 51 - Towline force (Ft) for the $4 \mathrm{kn}$ scenario. Left - towline at the bow; Right - Towline at the aft
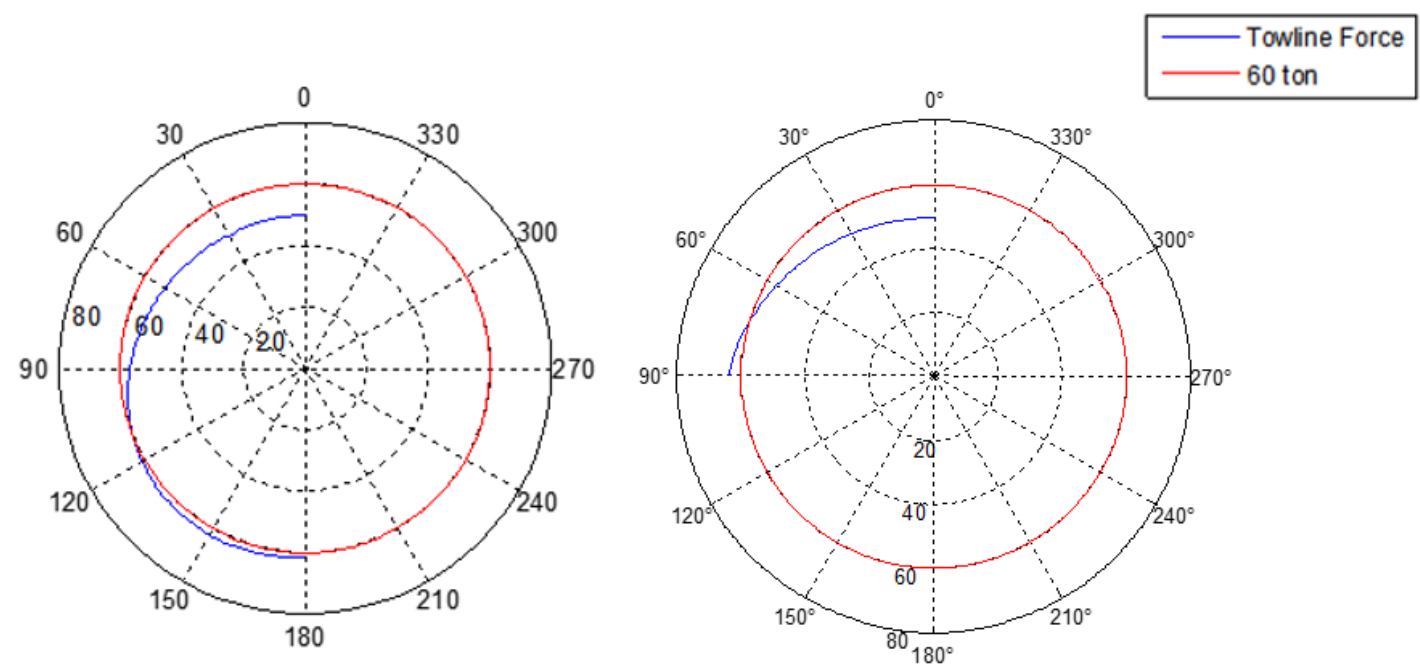

Source: Author 
Figure 52 - Towline force $(\mathrm{Ft})$ for the $6 \mathrm{kn}$ scenario. Left - towline at the bow; Right - Towline at the aft
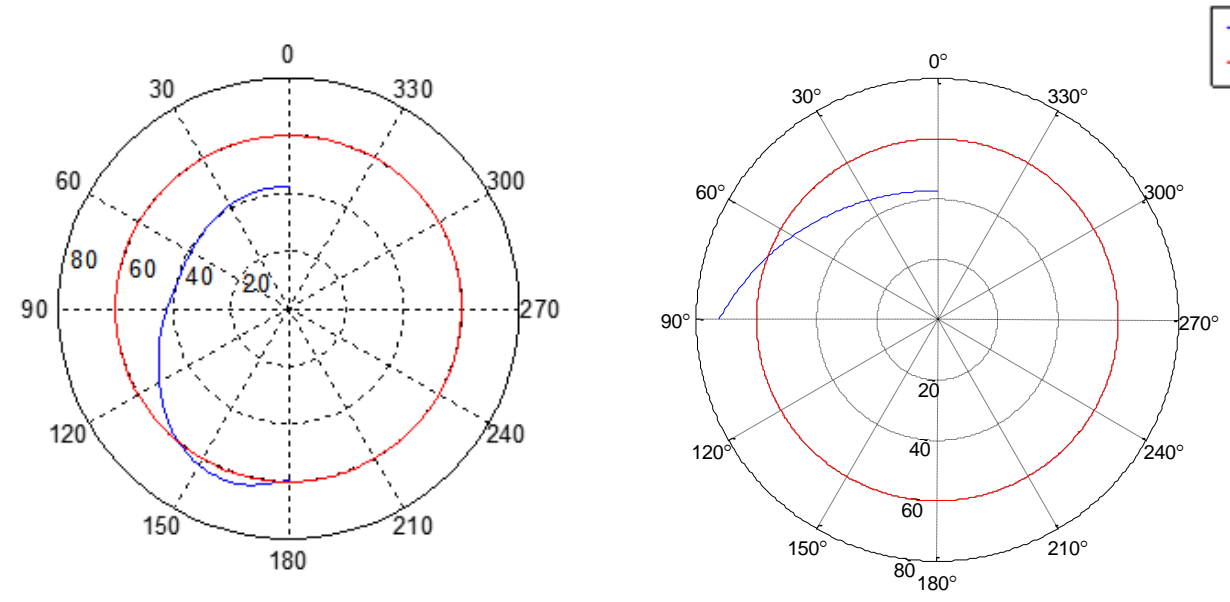

Source: Author

For the first simulation, the relative angle between the tugboat and the towline (tied at the bow) reached a maximum misalignment of around $4.5^{\circ}$ (could be seen in Figure 53 and Figure 54) while in the second simulation it reached a maximum of around $13.3^{\circ}$ (could be seen in Figure 55 and Figure 56). Due to the similarity of the towline force curves for the first and second simulations, one can infer that a maximum misalignment angle of around $13.3^{\circ}$ between the tugboat and the towline was not enough to cause substantial change on the towline force configuration, thus showing that the behavior of such a curve is dominated by the propeller-water interaction. However, for the third simulation, the maximum misalignment angle between the tugboat and the towline reached a maximum of $32.5^{\circ}$ (could be seen in Figure 57 and Figure 58), which characterized a substantial change in the towline force curve, as previously mentioned. This change can be explicitly seen if one compares the tugboat efficiency when the towline angle was $90^{\circ}$. For this specific towline angle, the tugboat had an efficiency of $99.5 \%$ in simulation $1,94.5 \%$ in simulation 2 , and $70.3 \%$ in simulation 3. Therefore, it is clear that, in simulation 3 , the large relative angles between the towline and the tugboat are dominant over the water-propeller interaction, thus characterizing a different behavior of the towline force curve. 
Figure 53 - Relative angles ( $\Psi_{2}-$ red; $\delta$ - green) for the 2 kn scenario - Towline at the tugboat's bow.

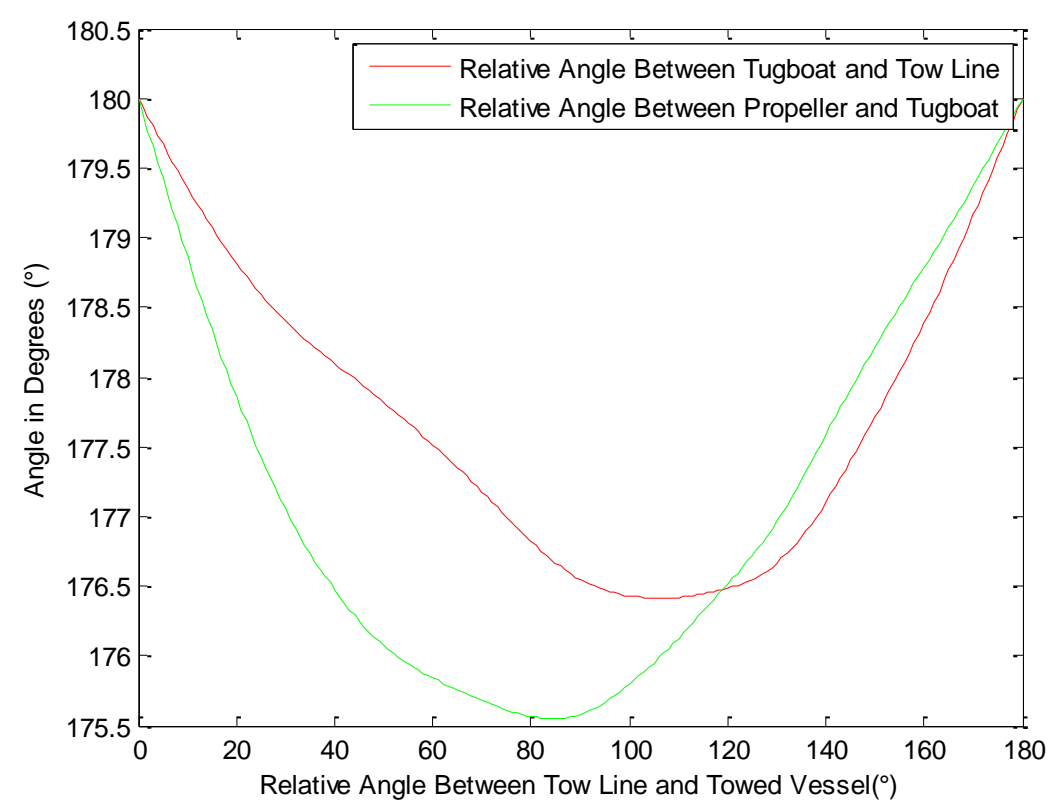

Source: Author

Figure 54 - Vector tug actuation model for a towed vessel navigating with 2 knots (towline angles of $0^{\circ} ; 45^{\circ} ; 90^{\circ} ; 135^{\circ} ; 180^{\circ}$ ) - Left: Towline at the tugboat's bow; Right: Towline at the tugboat's aft.
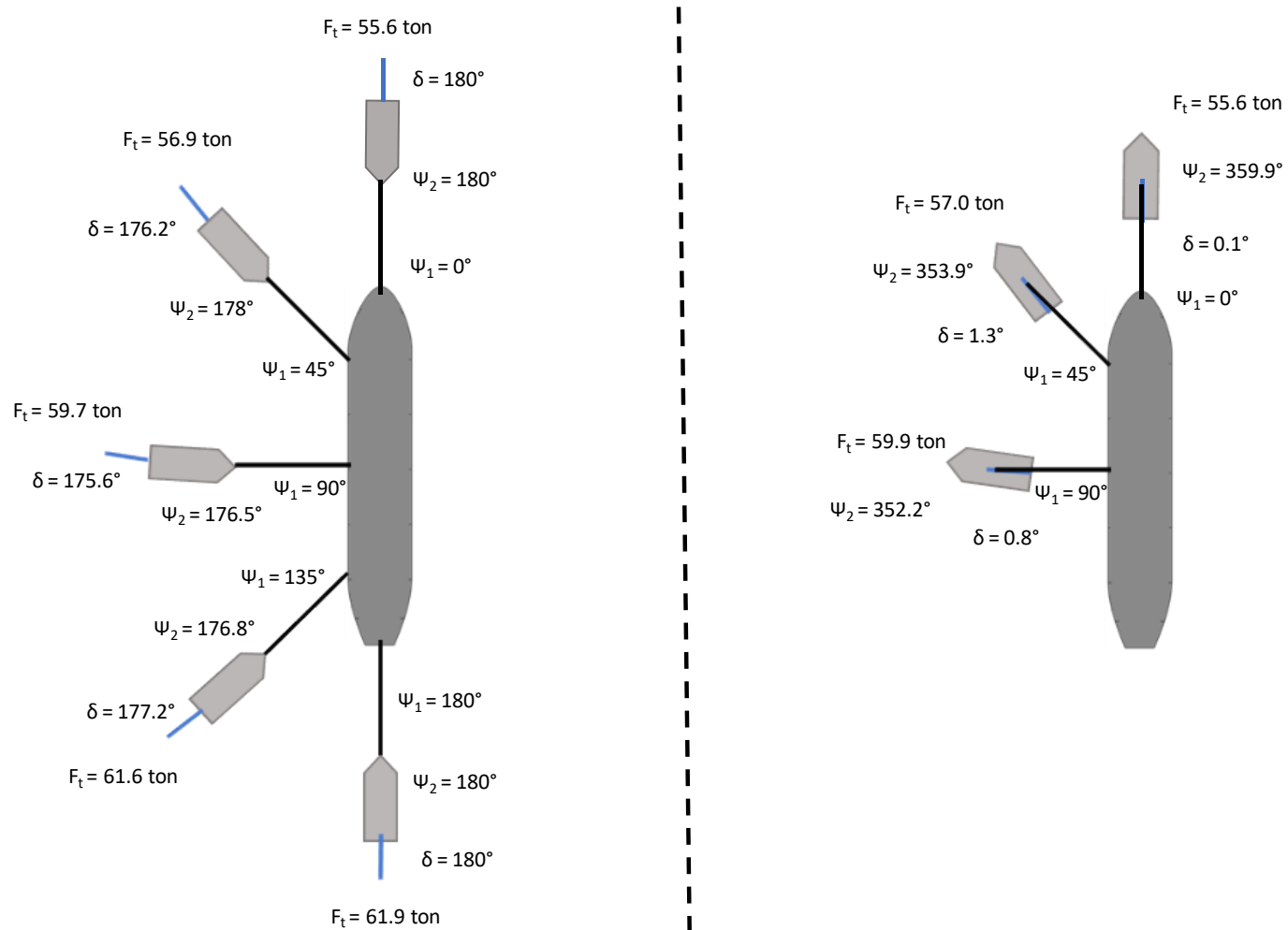

Source: Author 
Figure 55 - Relative angles ( $\Psi_{2}-$ red; $\delta$ - green) for the 4 kn scenario - Towline at the tugboat's bow.

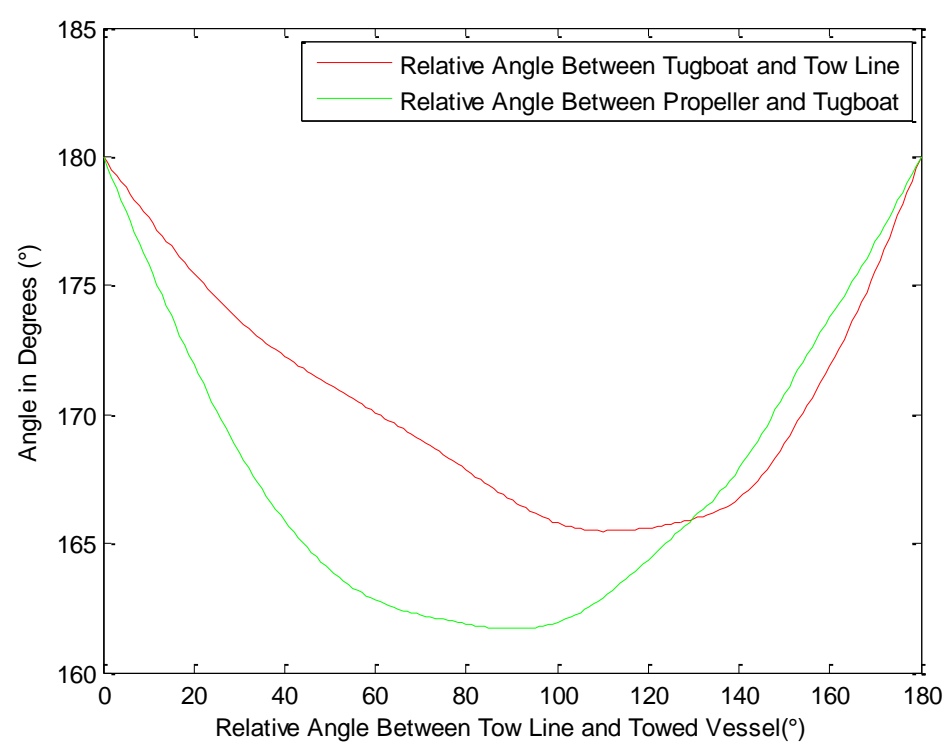

Source: Author

Figure 56 - Vector tug actuation model for a towed vessel navigating with 4 knots (towline angles of $0^{\circ} ; 45^{\circ} ; 90^{\circ} ; 135^{\circ} ; 180^{\circ}$ ) - Left: Towline at the tugboat's bow; Right: Towline at the tugboat's aft.
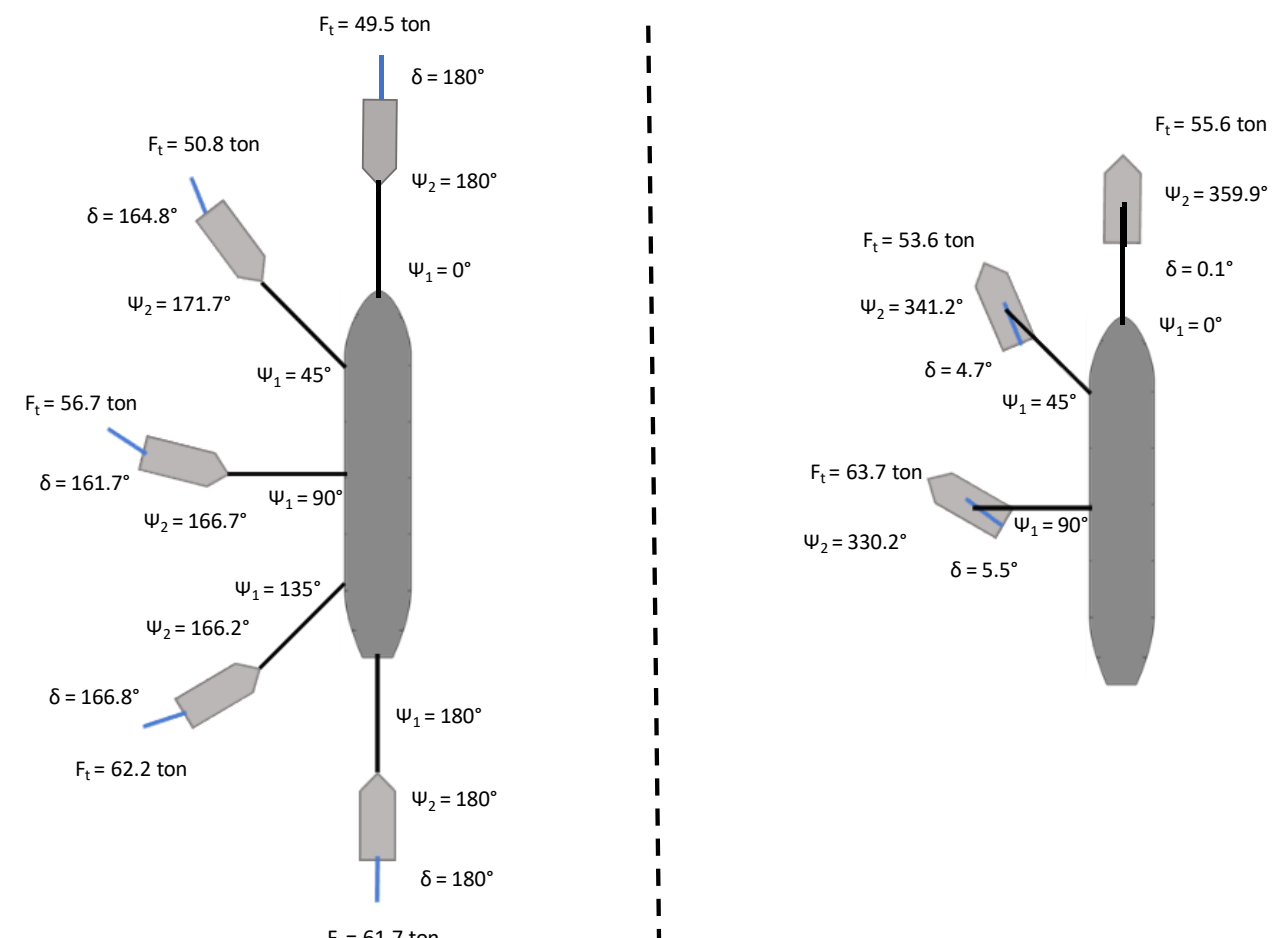

$F_{t}=61.7$ ton

Source: Author 
Figure 57 - Relative angles ( $\Psi_{2}$ - red; $\delta$-green) for the 6 kn scenario - Towline at the tugboat's bow.

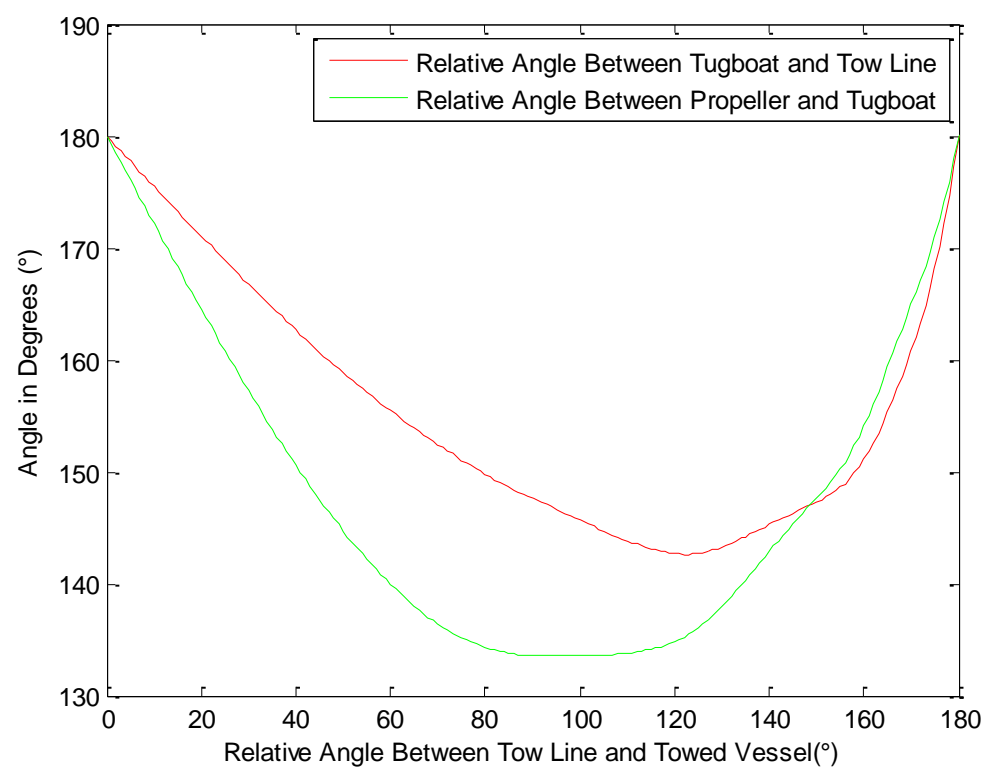

Source: Author

Figure 58 - Vector tug actuation model for a towed vessel navigating with 6 knots (towline angles of $0^{\circ} ; 45^{\circ} ; 90^{\circ} ; 135^{\circ} ; 180^{\circ}$ ) - Left: Towline at the tugboat's bow; Right: Towline at the tugboat's aft.

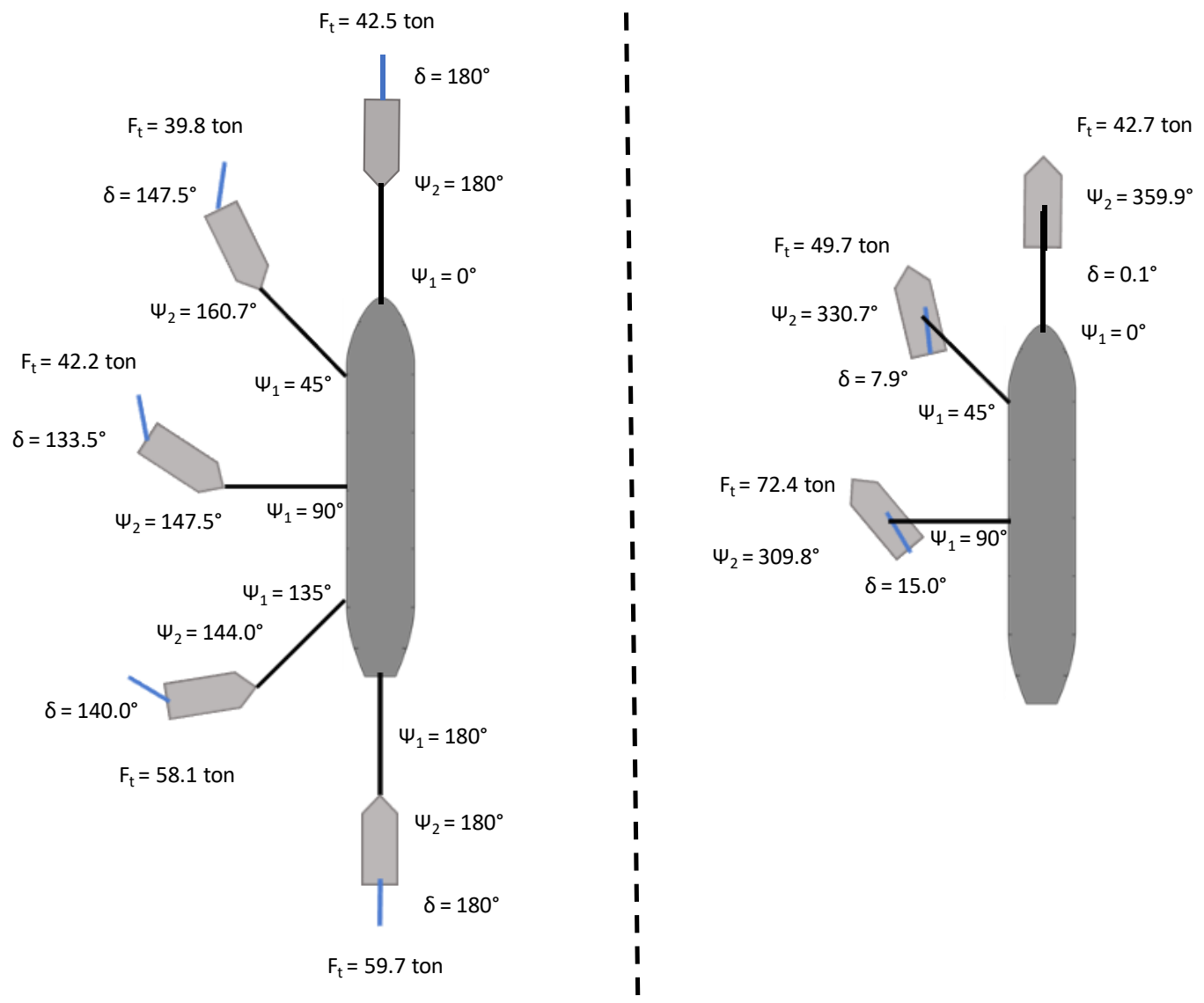

Source: Author 
Finally, by analyzing all the simulations (towline at the bow), one could realize that the graphs regarding the relative angle between the towline and the tugboat as well as the graphs regarding the relative angle between the propeller and the tugboat have similar shape configurations but with different angle amplitudes. By comparing these graphs on every scenario, one can realize that the major amplitude discrepancy occurs when the towline angle is between $60^{\circ}$ and a $100^{\circ}$, reaching a maximum difference of about $16^{\circ}$ on the $6 \mathrm{kn}$ scenario. However, during the towline angle interval between $140^{\circ}$ and $180^{\circ}$, both relative angles have almost no amplitude difference (same angles). Based on the information provided, one can conclude that, since the curves amplitudes differ only by a maximum of $16^{\circ}$, if the tug's heading angle to keep the system in static equilibrium configuration is known, the propeller relative angle to keep such position may be easily found by a numerical method using such initial guess.

\subsubsection{Stability Analysis}

Static Equilibrium configurations may be stable or unstable. Given a small disturbance on the system such as a swell or a change in current, for example, if it was in a stable configuration, it will return to the previous equilibrium solution. On the other hand, if the system is disturbed in an unstable configuration, it will either move to a new equilibrium state or it will require continual control input from the operator (BRANDNER, 1995). In Figure 59, a tugboat is pulling a vessel on its port quarter. If a disturbance is applied on the system and no additional propeller force is used, it may move to one of the non-equilibrium positions showed. For the non-equilibrium solution 1, which has a greater angle of attack in respect with the current, a positive moment is required to move the tugboat back towards equilibrium. For the non-equilibrium solution 2, with smaller angles of attack with respect to the current, a negative moment is required. 
Figure 59 - Stability of equilibrium position

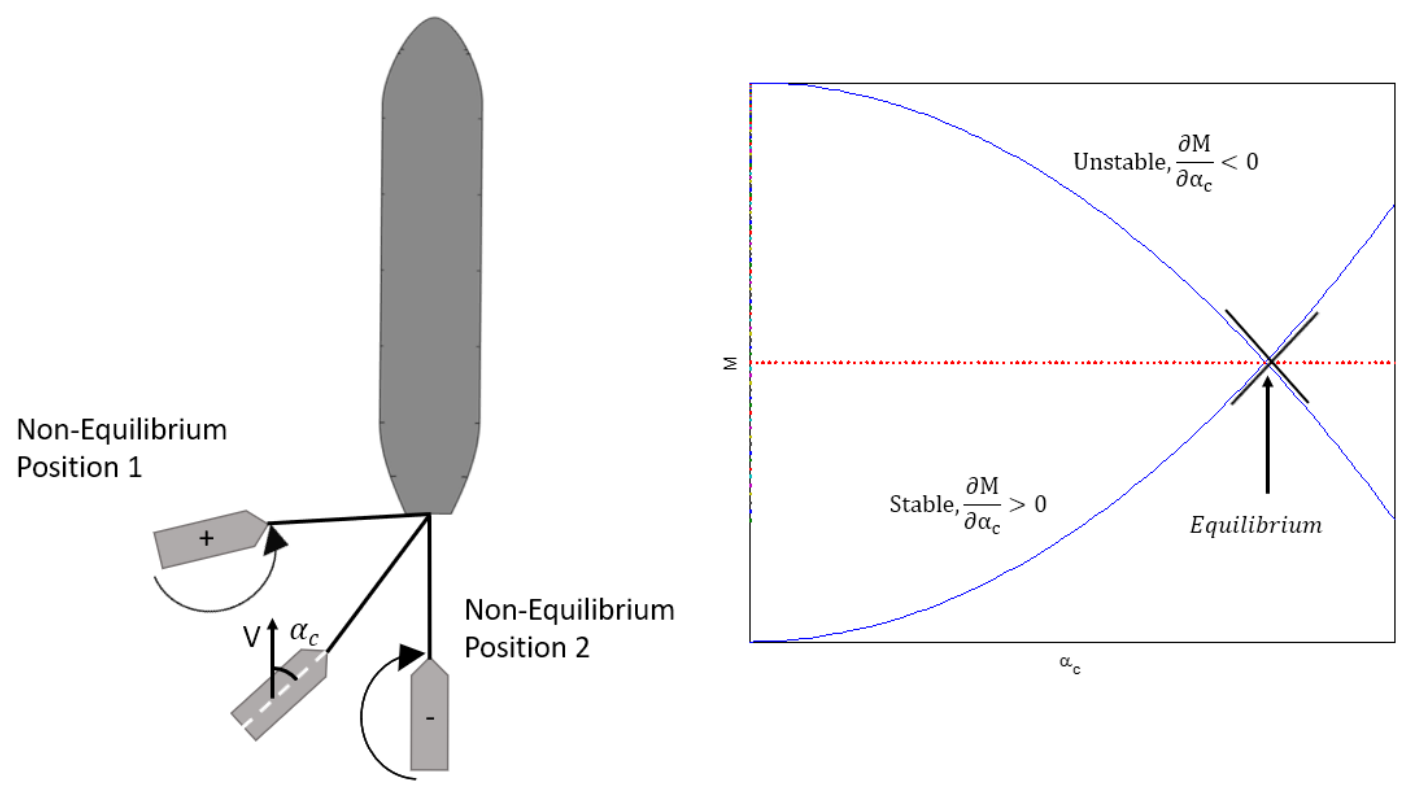

Source: Adapted from (BRANDNER, 1995)

Still on Figure 59, a curve of the sum of the moments acting on the tugboat as a function of the current's angle of attack is generated. By considering the sign of the derivative, $\frac{\partial M}{\partial \alpha_{c}}$, at the point of equilibrium, it is possible to determine whether such configuration is stable or unstable. If the derivative is positive, the equilibrium is stable; if it is negative, the equilibrium is unstable; if it is zero, the equilibrium is neutral. In addition, the magnitude of this derivative will determine the strength of the stabilizing or destabilizing moment.

In Figure 60 - Left, one can see the stability curve for the case where the towed vessel is navigating with $6 \mathrm{Kn}$ and the towline is attached both at tugboat's bow (left) and the tugboat's aft (right). For the case where the towline is attached at the tugboat's bow, the equilibrium solutions found are unstable when the tugboat's aft is the leading edge with respect to the water relative speed. The equilibrium solutions only become stable when the towline angle is greater than $110^{\circ}$, or when the tugboat's bow starts to be the leading edge with respect to the current (Figure 61 - Left). This stability analysis explains why such type of tugboat (ASD with a forward towing point) is so popular for maneuvers at vessels' stern. 
It is important to mention that, for the positions where the equilibrium is unstable, active control of the propellers is constantly necessary, thus requiring more attention from the tugboat commandant. If a disturbance affects the system and the commandant does not respond quick enough, the tugboat position may quickly change, even causing accidents. For this reason, for the towline connected at the tugboat's bow, commandants feel more comfortable actuating on a vessel's stern than when actuating on a vessel's bow.

For the case where the towline is attached at the tugboat's stern, the equilibrium solutions are unstable for towline angles smaller than $97^{\circ}$ and stable for towline angles in between $98^{\circ}$ and $150^{\circ}$. However, by comparing the destabilizing moments for both scenarios for towline angles smaller than $90^{\circ}$, one may note that the magnitude of the destabilizing moments for the towline on the tug's stern are about 5 times smaller than the magnitude of the destabilizing moments for the towline at the tug's bow. In other words, it is much easier for the tugboat commandant to actively actuate on a towed vessel bow maneuver when the towline is attached at the tugboat's stern than when the towline is attached at the tugboat's bow.

Figure 60 - Stability curve for the 6 Kn scenario. Left - towline at the tugboat's bow; Right towline at the tugboat's stern.
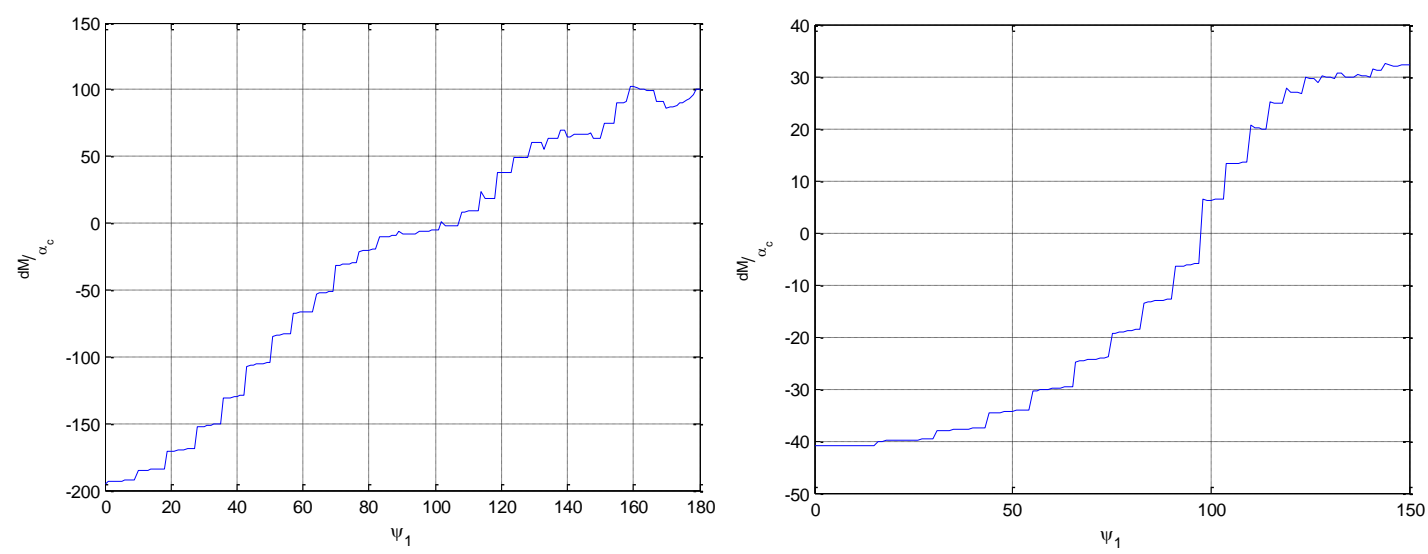

Source: Author 
Figure 61 - Stability visual representation
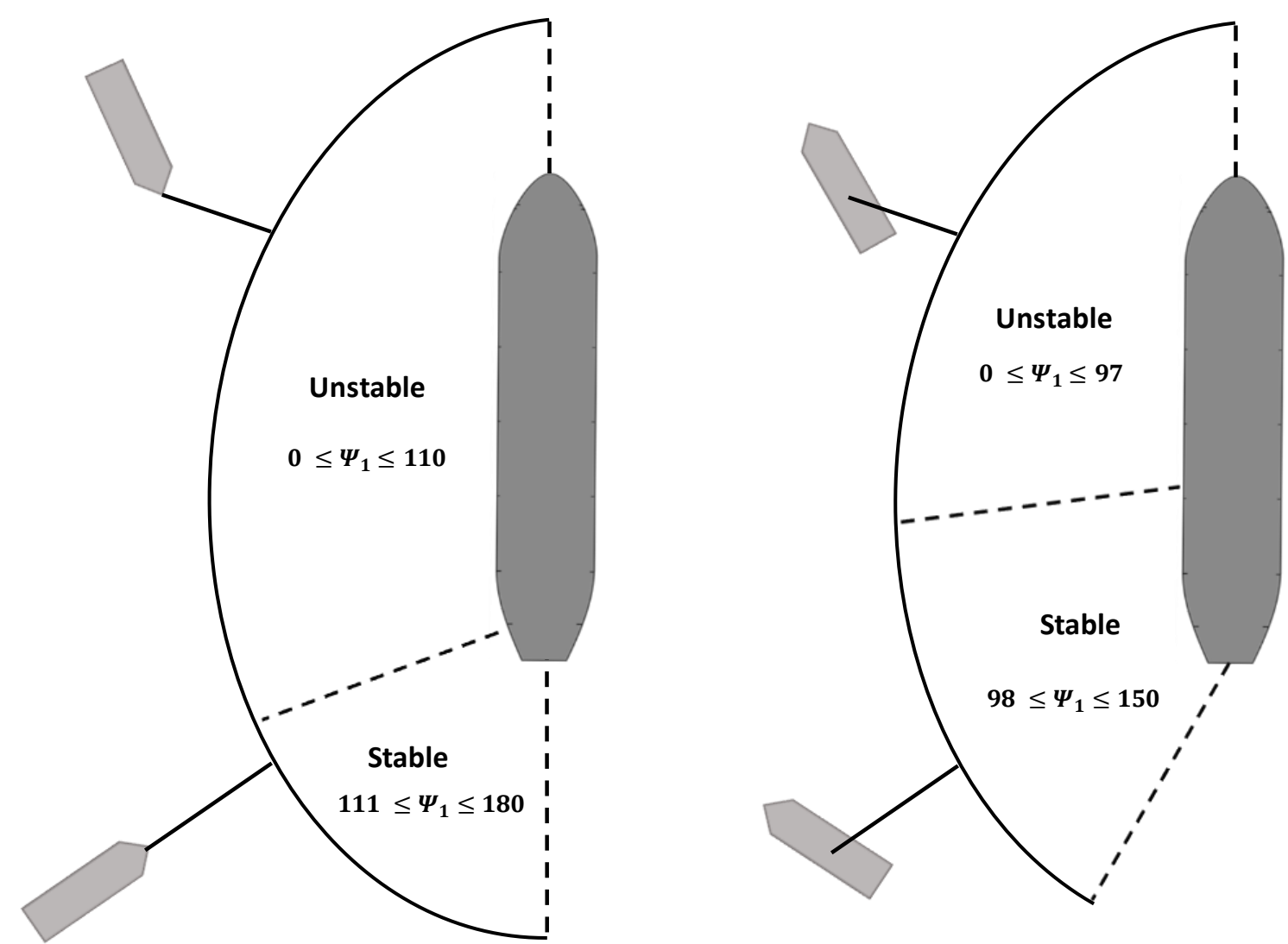

Source: Author

Although the stability analysis is important to understand some phenomena on the system, it will not be used to discard static solutions obtained. This is the case because, due to their experience, and using active control of the propellers, tugboat commandants can maintain their position on an unstable static equilibrium position. 


\subsection{Push Mode}

Again, the 2-6 kn scenarios will be explored. Therefore, in the first scenario, the towed vessel will be navigating with 2 knots; in the second scenario, the towed vessel will be navigating with $4 \mathrm{kn}$; in the third scenario, the towed vessel will be navigating with $6 \mathrm{kn}$.

By analyzing the polar curves for each scenario as a group (Figure 62, Figure 63, Figure 64) one can realize that the towing forces have their maximum value when the friction forces tend to zero. In other words, for these specific static equilibrium positions, the tugboat optimizes its force allocation, exerting a bigger part for towing, and a smaller part to maintain its position.

Going from the $2 \mathrm{kn}$ towards the $6 \mathrm{kn}$ scenario, one can see a drop on towing efficiency forces as well as a larger misalignment between the tugboat and the towed vessel on the location where the friction forces are zero. By increasing the relative water speed, the tugboats need to allocate a greater part of their propeller thrust in order to counter-act the external disturbances, thus diminishing its towing force.

With respect to the friction forces, for each scenario, there are a similar incidence of positive (friction force pointing upwards) and negative (friction force pointing dowards) values. Therefore, one may conclude that the friction force may not always be pointing on the direction of the towed vessel's navigation speed. The correct direction of such force may only be obtained through optimization algorithms. 
Figure 62 - Push - 2 knots scenario
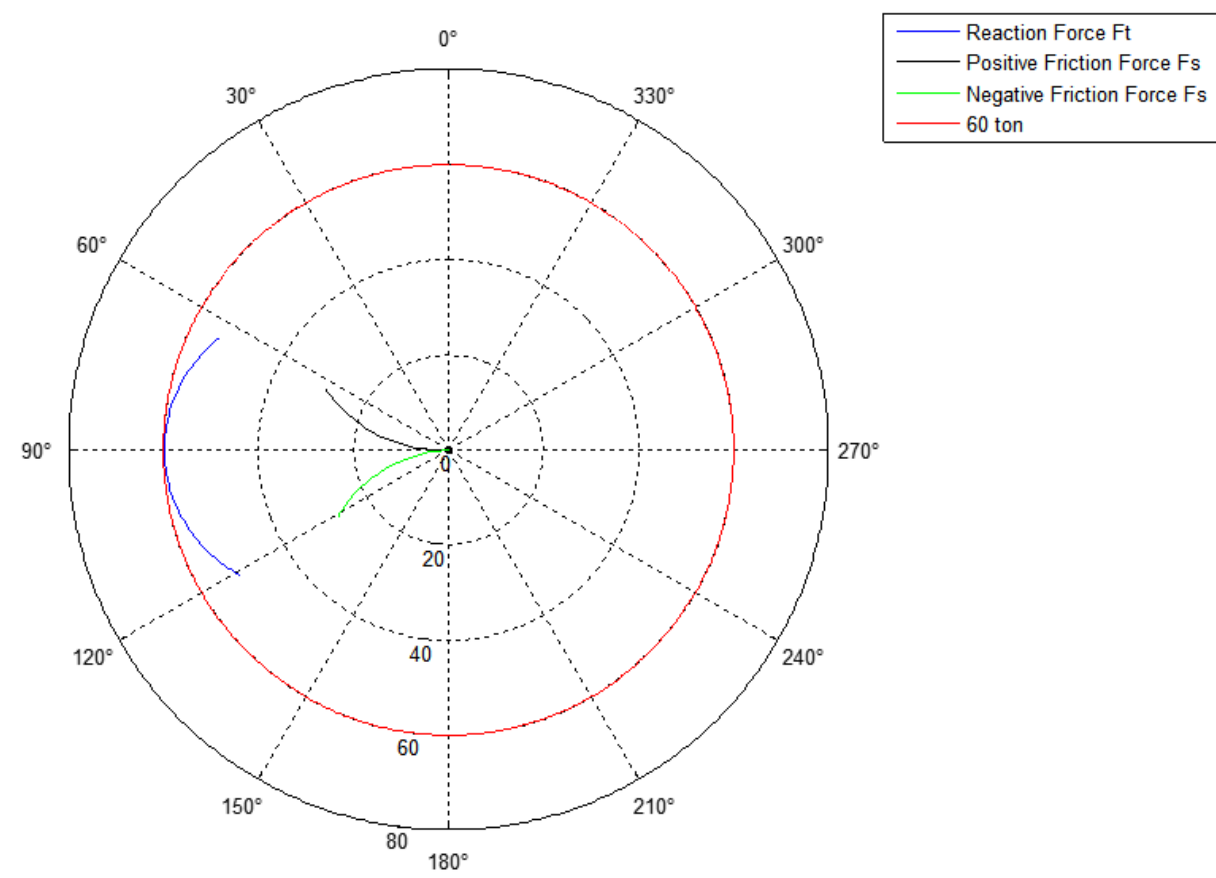

Source: Author

Figure 63 - Push - 4 knots scenario

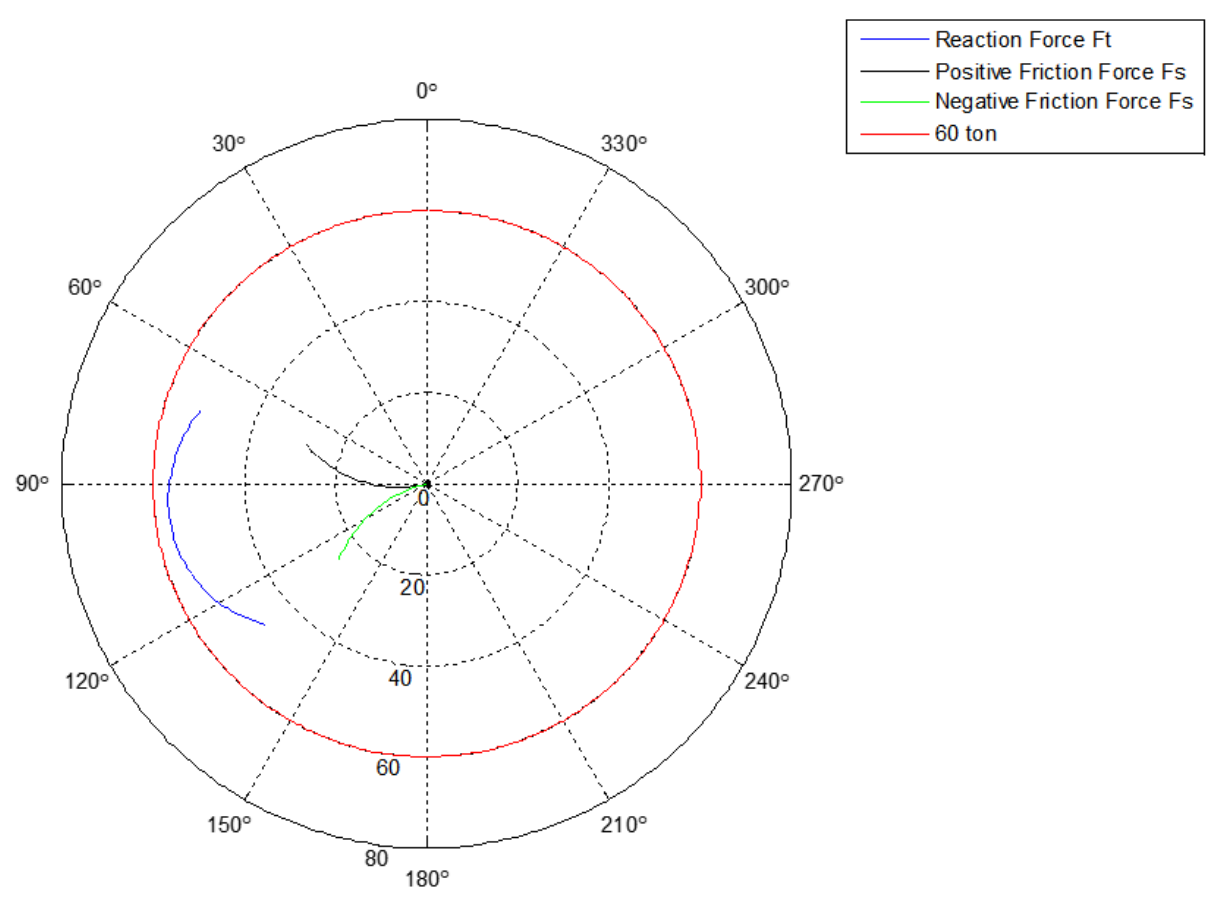

Source: Author 
Figure 64 - Push - 6 knots scenario

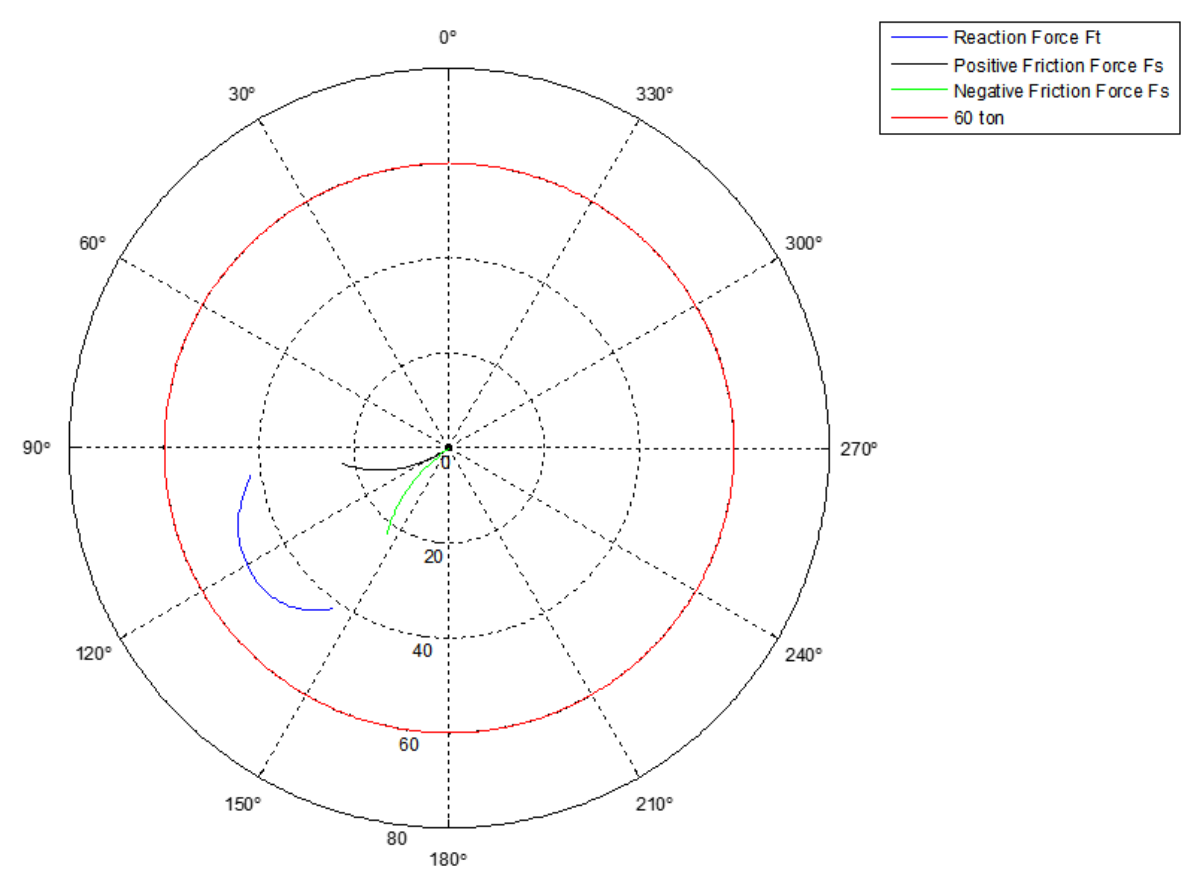

Source: Author

In Table 6 , one can see the values of $\Psi_{3}$ for the situations where the friction force is maximum, zero, and minimum, as well as the range of operational angles. Based on such results, one can conclude that each specific scenario has a unique range of operational angles. Usually in the literature, it is assumed that tugboats working Push mode may actuate in a range of $\pm 30^{\circ}$ from the transversal axis of the towed vessel. Although a range of $\pm 30^{\circ}$ proved not to be a bad estimative, such range should be determined from an origin located at the angle where the friction force is zero. When the vessel is navigating with slow speeds, such angle proved to be close to the transversal axis of the towed vessel. However, for greater speeds, such angle occurs towards the towed vessel aft, being $103^{\circ}$ for 4 knots speed and $124^{\circ}$ for 6 knots speed.

Table $6-\Psi_{3}$ angles for each speed and friction force

\begin{tabular}{|l|l|l|l|l|}
\hline & Fs max & Fs zero & Fs min & range \\
\hline $\mathbf{2 ~ k n}$ & $64^{\circ}$ & $93^{\circ}$ & $121^{\circ}$ & $57^{\circ}$ \\
\hline $\mathbf{4}$ kn & $72^{\circ}$ & $103^{\circ}$ & $131^{\circ}$ & $60^{\circ}$ \\
\hline $\mathbf{6 ~ k n}$ & $98^{\circ}$ & $124^{\circ}$ & $144^{\circ}$ & $47^{\circ}$ \\
\hline \multicolumn{5}{|c}{ Source: Author } \\
\hline
\end{tabular}


In Figure 65, Figure 66 and Figure 67 visual representations for each scenario are showed. Here, the focus is to present the positions where the friction force is max, zero, or min.

Figure 65 - Visual representation for the 2 knots scenario

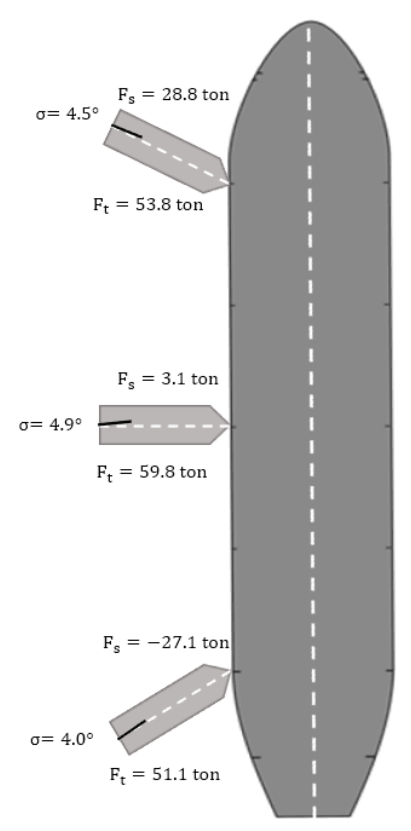

Source: Author

Figure 66 - Visual representation for the 4 knots scenario

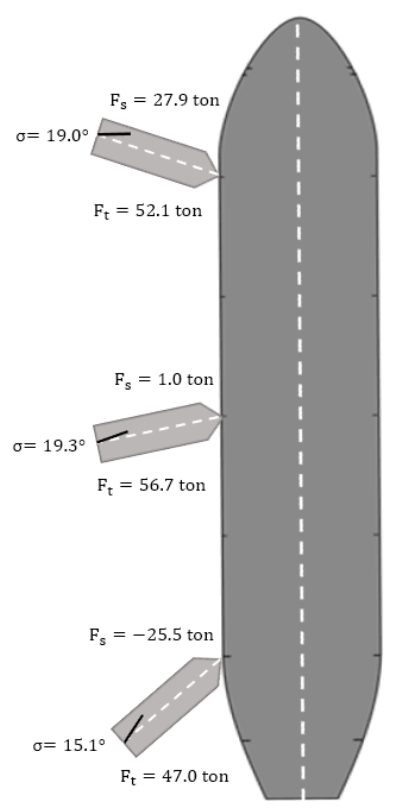

Source: Author 
Figure 67 - Visual representation for the 6 knots scenario

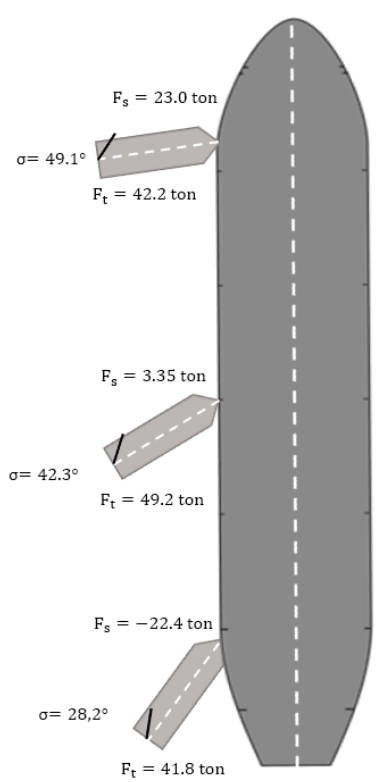

Source: Author

In Figure 68, the tugboat's propeller angles are shown for each scenario. It is clear that, as the relative water speed is increases, the propeller angle must have a larger misalignment with respect to its central axis in order to counter-act the external disturbance and keep the tugboat in equilibrium. Such bigger misalignment is the main cause for the loss in efficiency going from the first to the third scenario.

Figure 68 - Propeller angle of actuation for each scenario

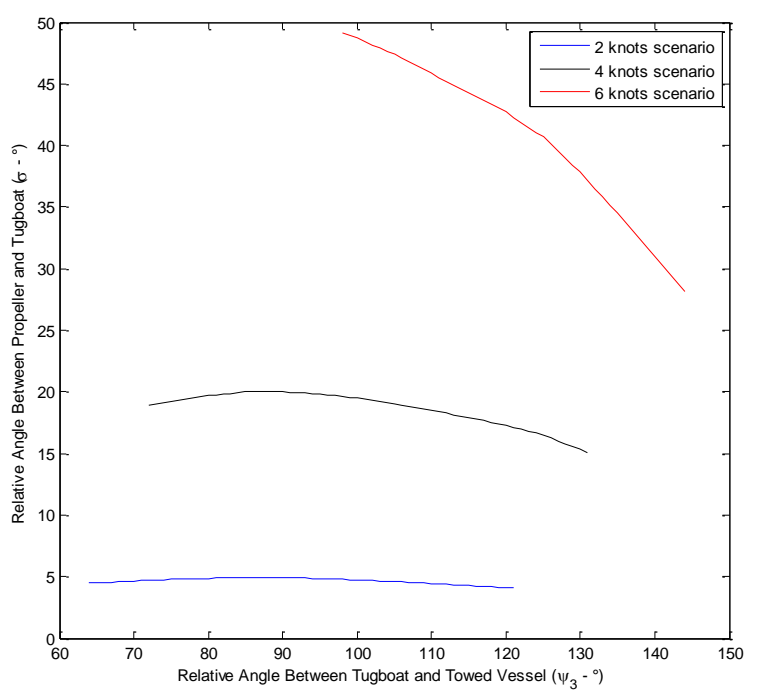

Source: Author 


\subsection{Pull Mode - Indirect Maneuver}

For the Indirect Maneuver, 3 scenarios (8, 10 and $12 \mathrm{kn})$ and 2 different tugboat types are explored: the same regular ASD tugboat that has been used in the previous simulations (characteristics shown in Table 5), and an ASD Escort Tug (characteristics shown in Table 7). Escort Tugs are specially design for escort maneuvers, where assistance is required at high speeds. The main difference between an Escort Tug and a regular ASD tug is the hull configuration. Escort Tugs have a skeg under the hull, which increase their lateral area, and provides a greater stability. The greater stability is in part due to the increase in the metacentric height (GM) and on the modification of the longitudinal and vertical positions of the propeller and towing point. While regular ASD tugboats normally have a metacentric height between 2-2.5 m, escort tugs should have a minimum metacentric height of $3 \mathrm{~m}$ (HENSEN, 2003). In Figure 69 an example of an Escort Tug is presented.

Table 7 - Characteristics of an Escort Tug

\begin{tabular}{|c|c|c|}
\hline Parameter & value & units \\
\hline Length & 32 & $\mathrm{~m}$ \\
\hline Draught & 5.7 & $\mathrm{~m}$ \\
\hline Beam & 12.8 & $\mathrm{~m}$ \\
\hline Displacement $(\Delta)$ & 974 & ton \\
\hline $\begin{array}{c}\text { Center of Gravity Height }\left(\mathrm{Z}_{\mathrm{G}}\right) \\
\text { [respect to keel] }\end{array}$ & 3.5 & $\mathrm{~m}$ \\
\hline $\begin{array}{l}\text { Nominal Metacentric Height } \\
\text { (GM) }\end{array}$ & 3 & $\mathrm{~m}$ \\
\hline $\begin{array}{l}\text { Buoyance Height }\left(\mathrm{Z}_{\mathrm{B}}\right) \\
\text { [respect to keel] }\end{array}$ & 2.1 & $\mathrm{~m}$ \\
\hline $\begin{array}{l}\text { Longitudinal Contact Position } \\
\qquad\left(\mathrm{x}_{\mathrm{t}}\right)\end{array}$ & 9 & $\mathrm{~m}$ \\
\hline Contact Position Height $\left(\mathrm{Z}_{\mathrm{T}}\right)$ & 10 & $\mathrm{~m}$ \\
\hline $\begin{array}{l}\text { Longitudinal Propeller } \\
\text { Position }\left(x_{p}\right)\end{array}$ & -10.5 & $\mathrm{~m}$ \\
\hline Propeller Position Height $\left(Z_{P}\right)$ & 1.5 & $\mathrm{~m}$ \\
\hline Propeller Diameter & 2.8 & $\mathrm{~m}$ \\
\hline Bollard pull & 60 & ton \\
\hline
\end{tabular}

Source: Author 
Figure 69 - Example of an Escort Tug

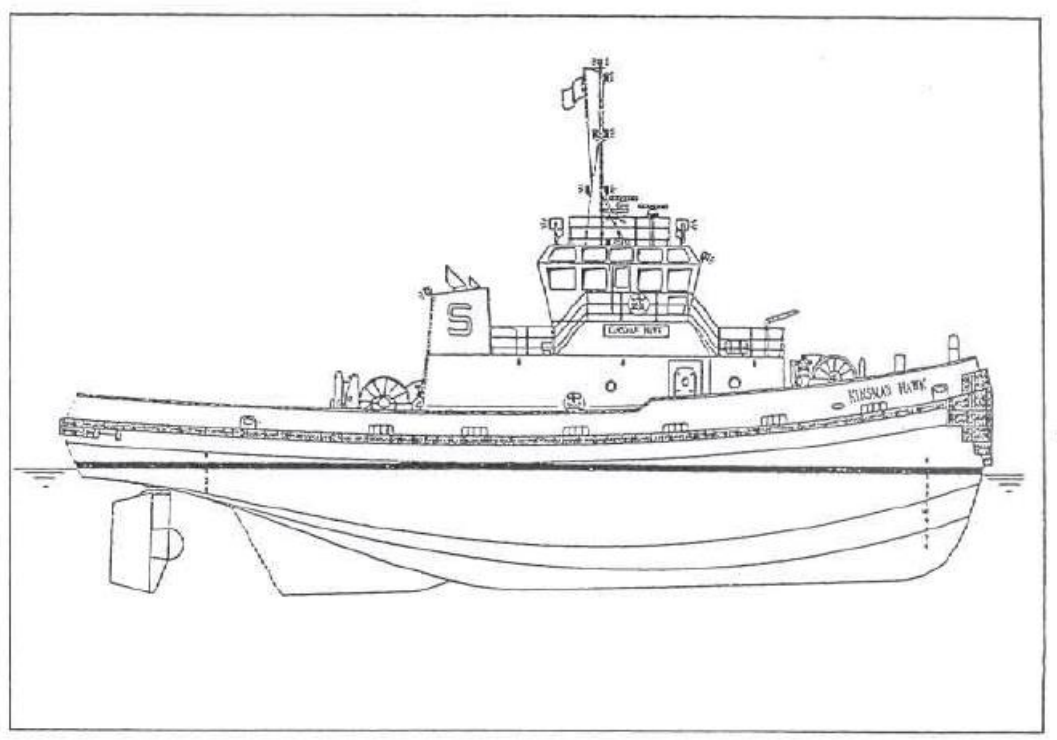

Source: (HENSEN, 2003)

\subsubsection{Regular ASD Tugboat}

In order to feed the mathematical model, the stability curve of this tugboat was necessary. Based on the line curves of a tugboat with similar configuration, a hull was designed using a 3-D drawing software (Figure 70), and the stability curves were generated using a hydrostatic software (Figure 71) .

Figure 70 - Modeled hull for regular ASD tugboat

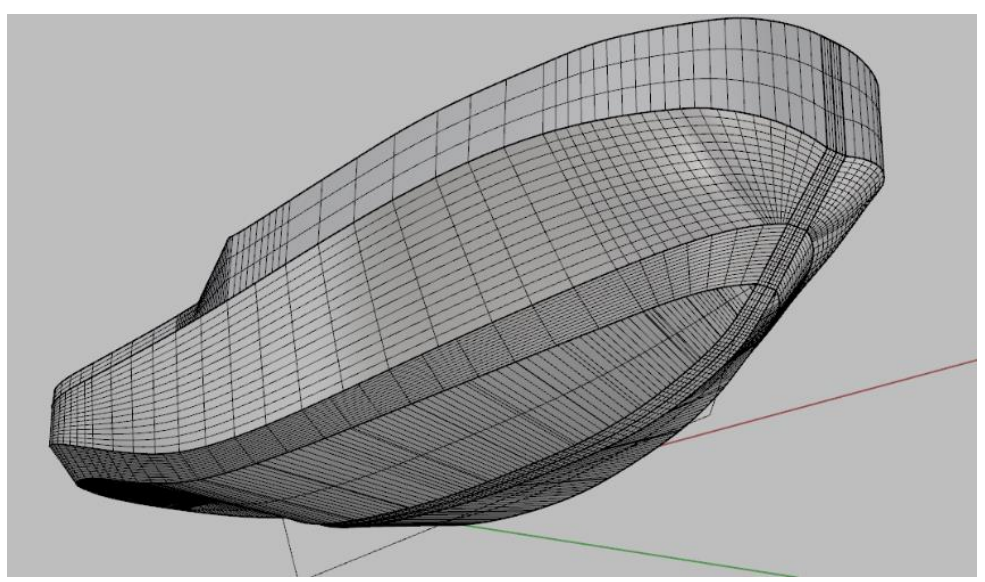

Source: Author 
Figure 71 - Stability curve for the regular ASD tugboat

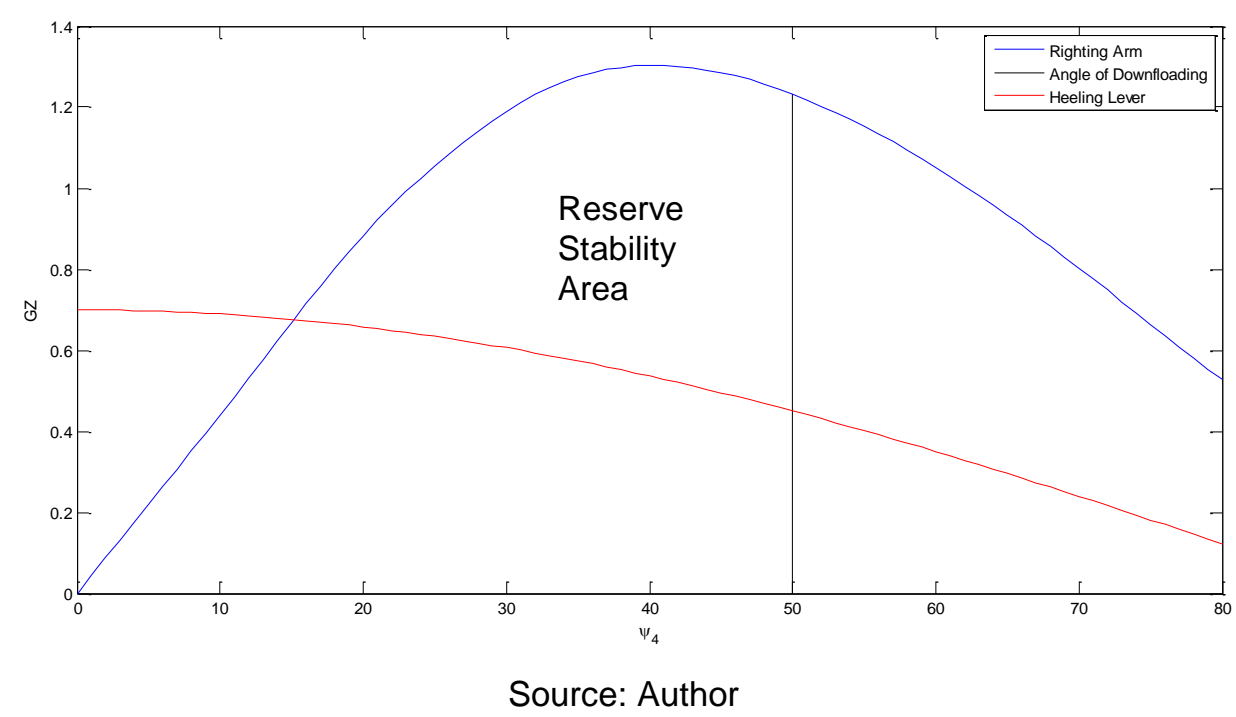

From Figure 72 to Figure 74 one can observe the towing force magnitude for each towline angle and advance speed. Based on the obtained results, one can realize that every scenario has a gap of towline angles where no solution exists, with this gap increasing when augmenting the advance speed from 8 to $10 \mathrm{kn}$, and almost keeping constant when increasing the advance speed from 10 to 12 $\mathrm{kn}$. For the $8 \mathrm{kn}$ scenario, this gap occurs at $150^{\circ}<\Psi_{1}<160^{\circ}$; for the $10 \mathrm{kn}$, $125^{\circ}<\Psi_{1}<159^{\circ}$; for the $12 \mathrm{kn}$ scenario, $110^{\circ}<\Psi_{1}<146^{\circ}$. It can also be noticed that the towline angle where the efficiency is maximum considerably change for each scenario. In the first scenario, the maximum towing efficiency (net towage force divided by bollard pull) is $\eta=111.7 \%$ at $\Psi_{1}=180^{\circ}$; in the second, $\eta=128.6 \%$ at $\Psi_{1}=159^{\circ}$; in the third, $\eta=128 \%$ at $\Psi_{1}=146^{\circ}$. Note that, the efficiency almost does not change from the second to the third scenario, but the towline significantly moves from a breaking location (i.e., tugboat is solely pulling the vessel longitudinally backwards), in a steering/breaking (i.e., tugboat is pulling the vessel both longitudinally and transversally) location of actuation. Therefore, one may conclude that, for scenarios with speeds up to $10 \mathrm{kn}$, the regular ASD tugboat working in indirect mode is more efficient to break the towed vessel, while for scenarios where the advance speed is larger than $10 \mathrm{kn}$, the same tugboat is also efficient to steer the towed vessel (Figure 75). 
Figure 72 - Scenario 1: Regular ASD tugboat in indirect maneuver with advance speed of $8 \mathrm{kn}$

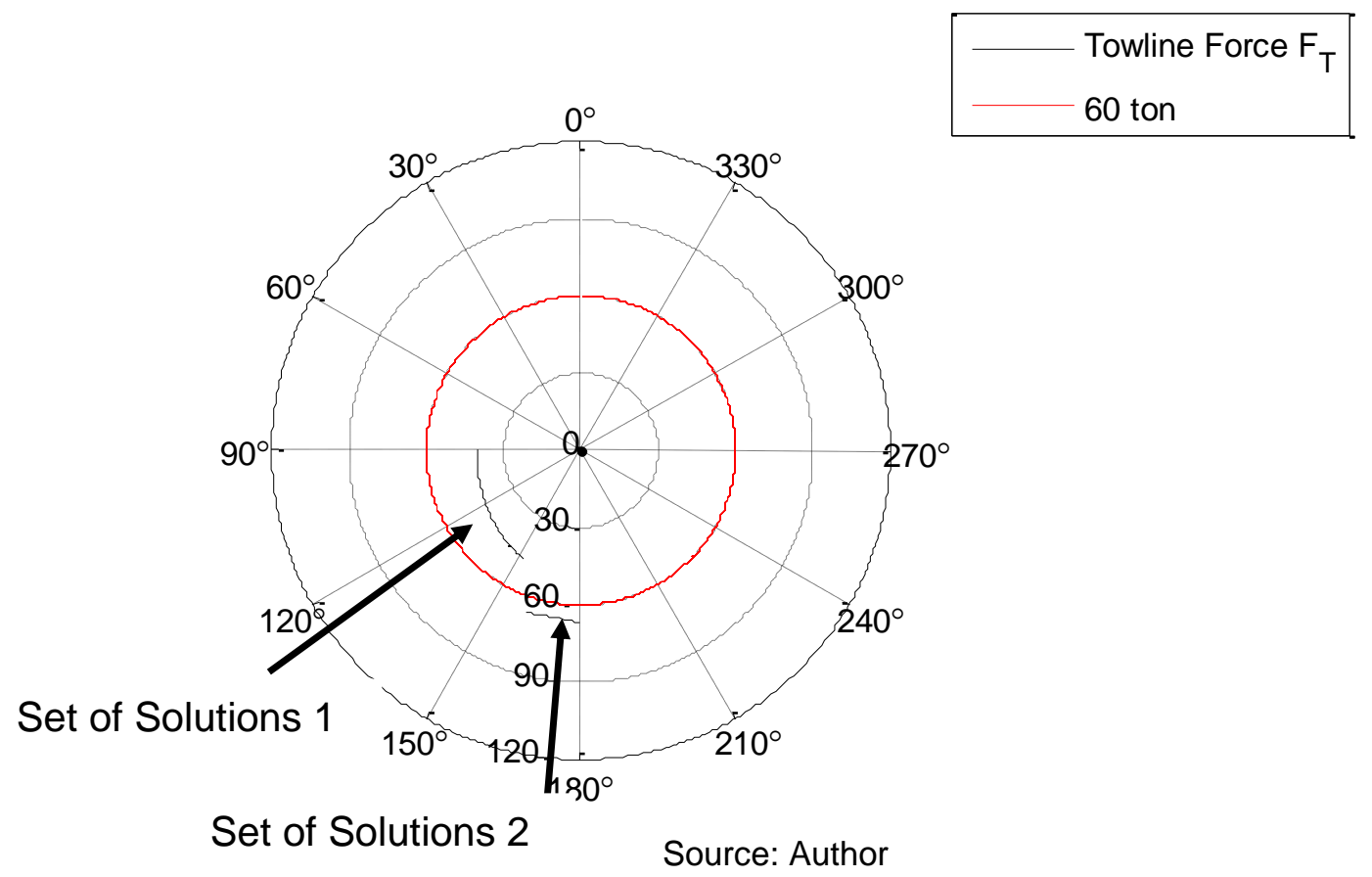

Figure 73 - Scenario 2: Regular ASD tugboat in indirect maneuver with advance speed of $10 \mathrm{kn}$

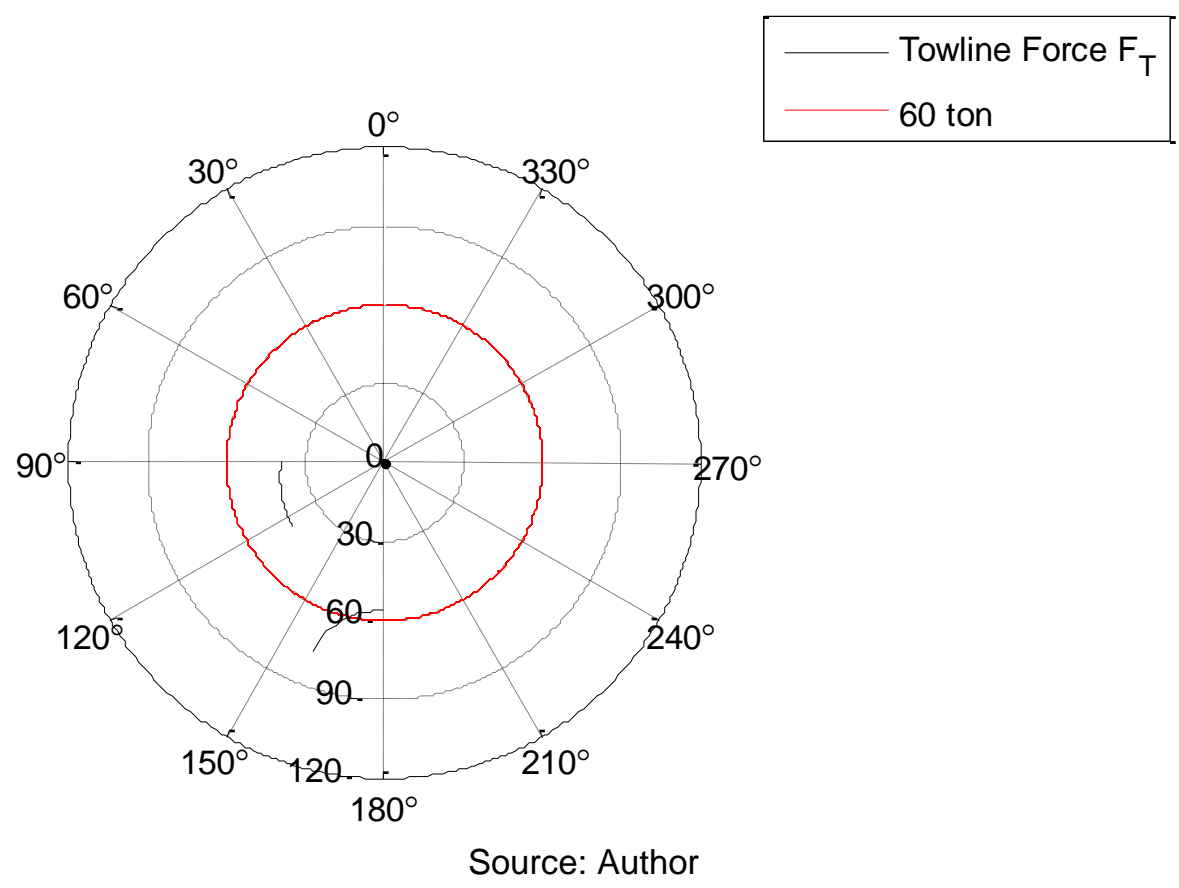


Figure 74 - Scenario 3: Regular ASD tugboat in indirect maneuver with advance speed of $12 \mathrm{kn}$
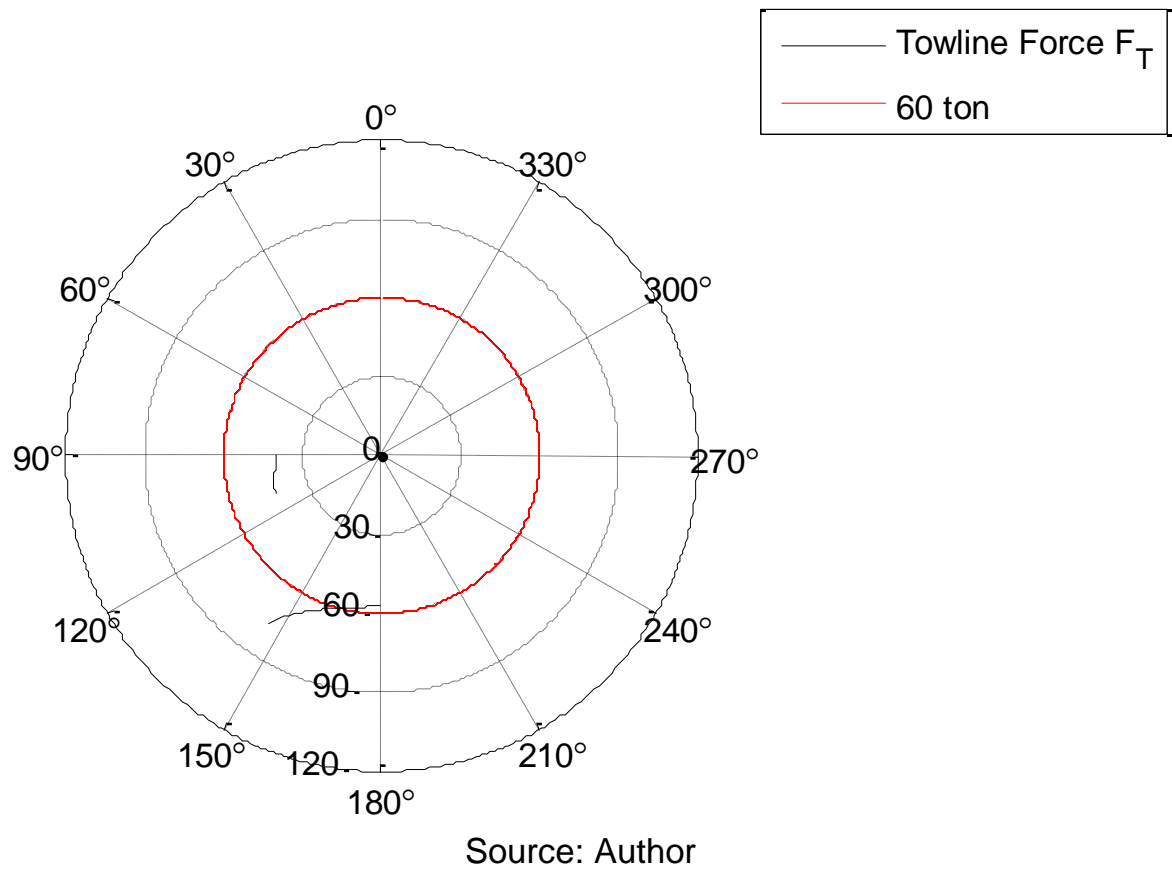

$270^{\circ}$

Figure 75 - Situation where maximum towing force occurs for the 8, 10 and $12 \mathrm{kn}$ scenarios (set of solutions 2)

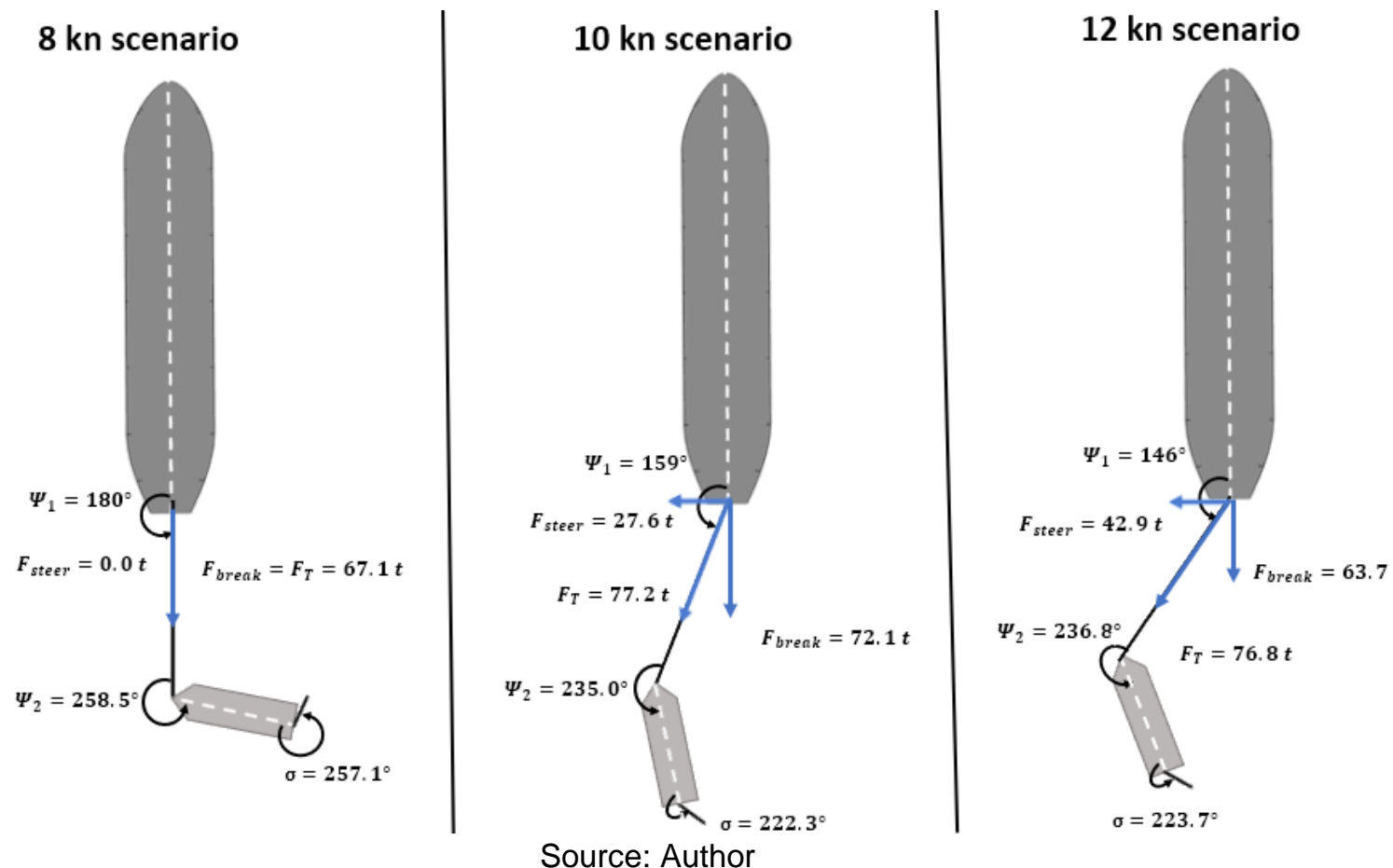


Still considering the polar graphs previous shown, one could divide the sets of solutions in two: the ones obtained prior to the gap and the ones obtained after the gap. By analyzing Figure 76, Figure 77 and Figure 78 one can realize that the maximum towing forces for each set of solutions always occur when the tugboat's misalignments with respect to the towline are maximum. In addition, by analyzing the tugboat's propeller angle, one can see that for the first set of solutions, the propeller is spelling the water in the same direction of the relative current water outflow, thus loosing efficiency when compared to the second set of solutions, where the propeller water outflow is directed against the relative current inflow.

By solely comparing Figure 75 and Figure 79, where the towing forces are maximum for each set of solutions, one could realize that in the indirect maneuver, the tugboat's propeller counter-acts the yaw-moment caused by the relative incoming current in such a way that its lateral area is as exposed as possible to the incoming flow. By doing so, the transverse forces on the tug and consequently the towline forces are maximized, thus proving the effectiveness of this kinds of maneuver.

Figure 76 - Scenario 1: Relative angles for the formulation at $8 \mathrm{kn}$

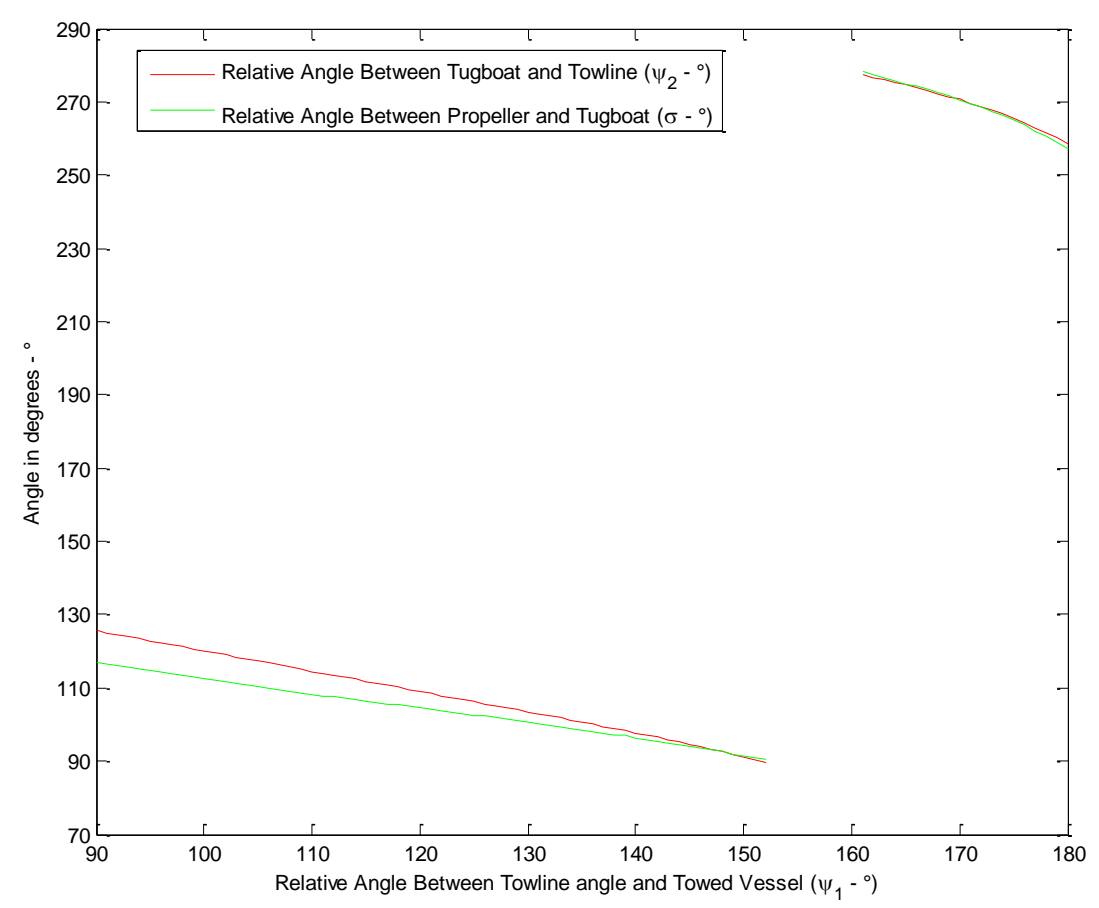

Source: Author 
Figure 77 - Scenario 2: Relative angles for the formulation at $10 \mathrm{kn}$

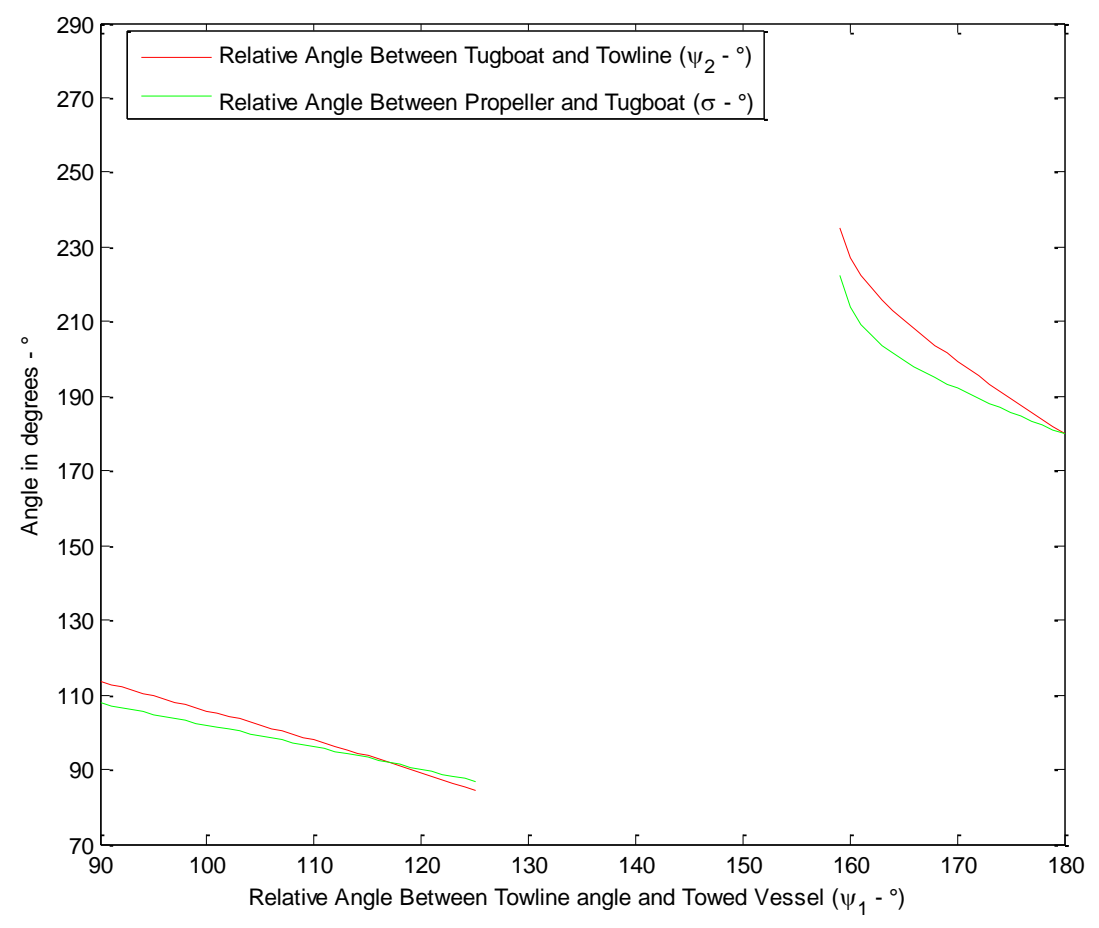

Source: Author

Figure 78 - Scenario 3: Relative angles for the formulation at $12 \mathrm{kn}$

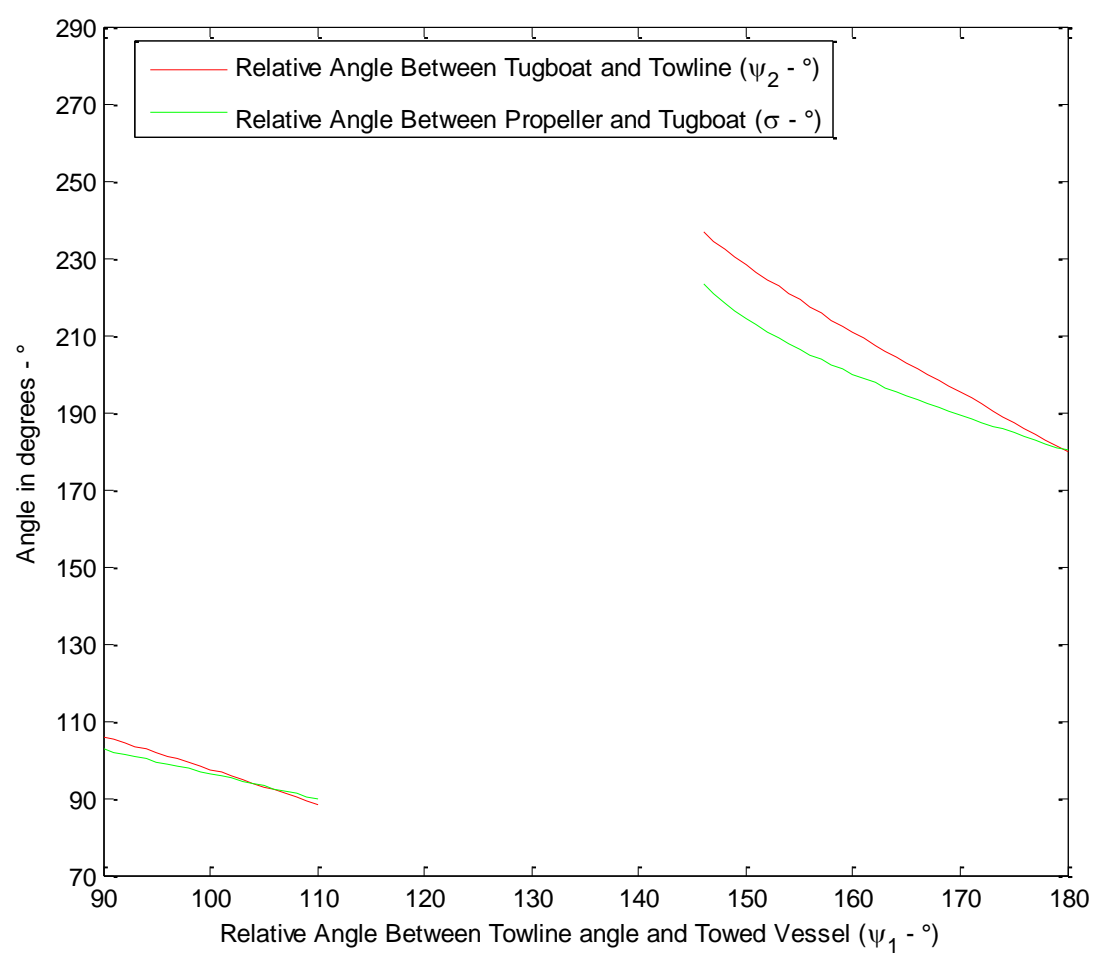

Source: Author 
Figure 79 - Situation where maximum towing force occurs for the 8, 10 and $12 \mathrm{kn}$ scenarios (set of solutions 1)
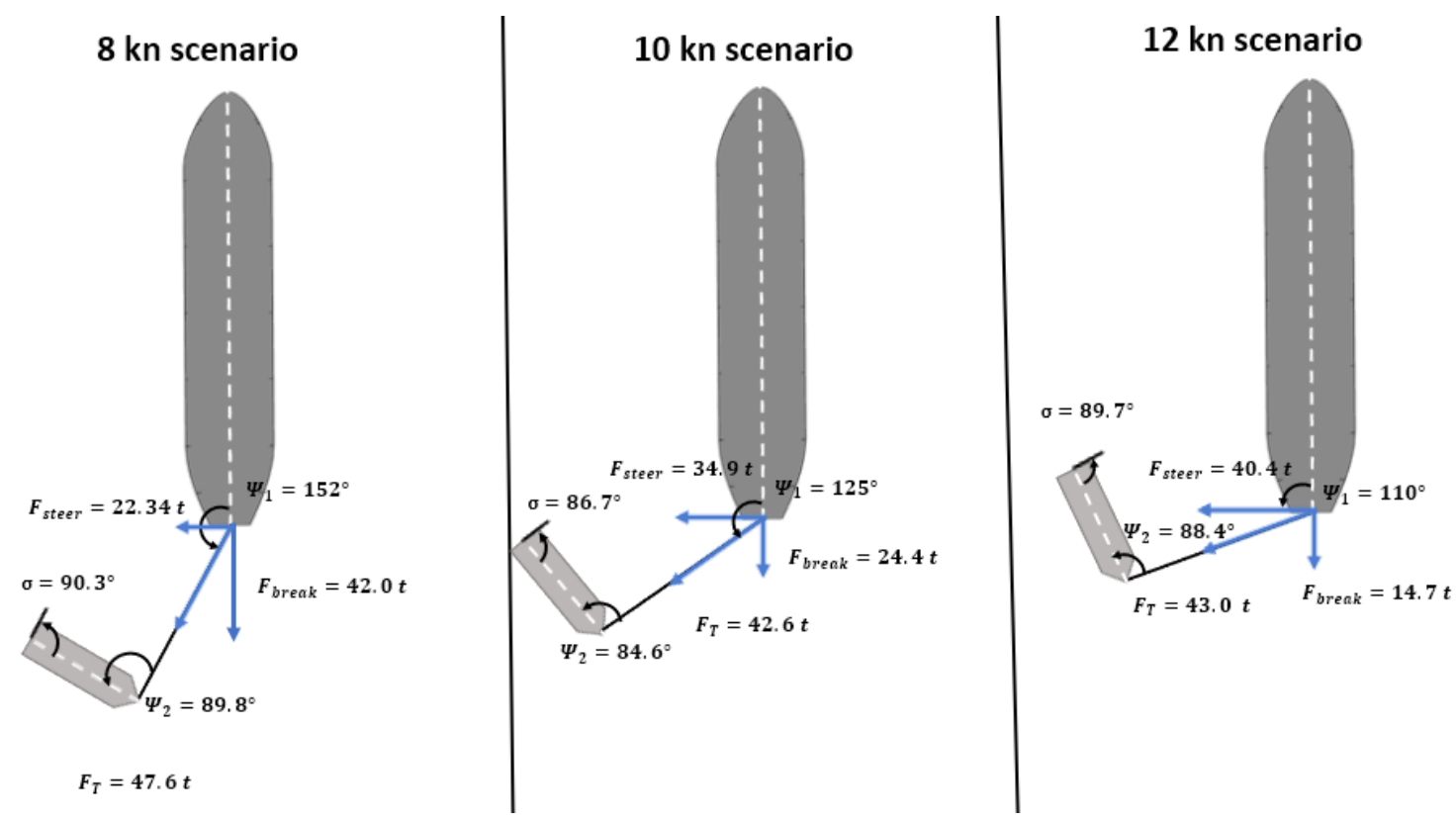

Source: Author

By analyzing the tugboat's roll angle (Figure 80), one can realize that it experiences a positive list (port inclination) for the set of solutions 1 and a negative list (starboard inclination) for the set of solutions 2. Note that, for every scenario, the maximum towing force occurs when the tugboat reaches the maximum misalignment of $-15^{\circ}$, imposed by the optimization constraints.

Still based on Figure 80 one could infer that the missing solutions would occur when the listing angles are smaller than $-15^{\circ}$. Reaching solutions with smaller listing angles is dangerous because the reserve stability area (Figure 71) ends up being decreased. In other words, the dynamic situation to reach a static equilibrium for smaller listing angles may be considerably severe, thus increasing the risks of capsizing. 
Figure 80 - Listing angles for all scenarios - Regular ASD

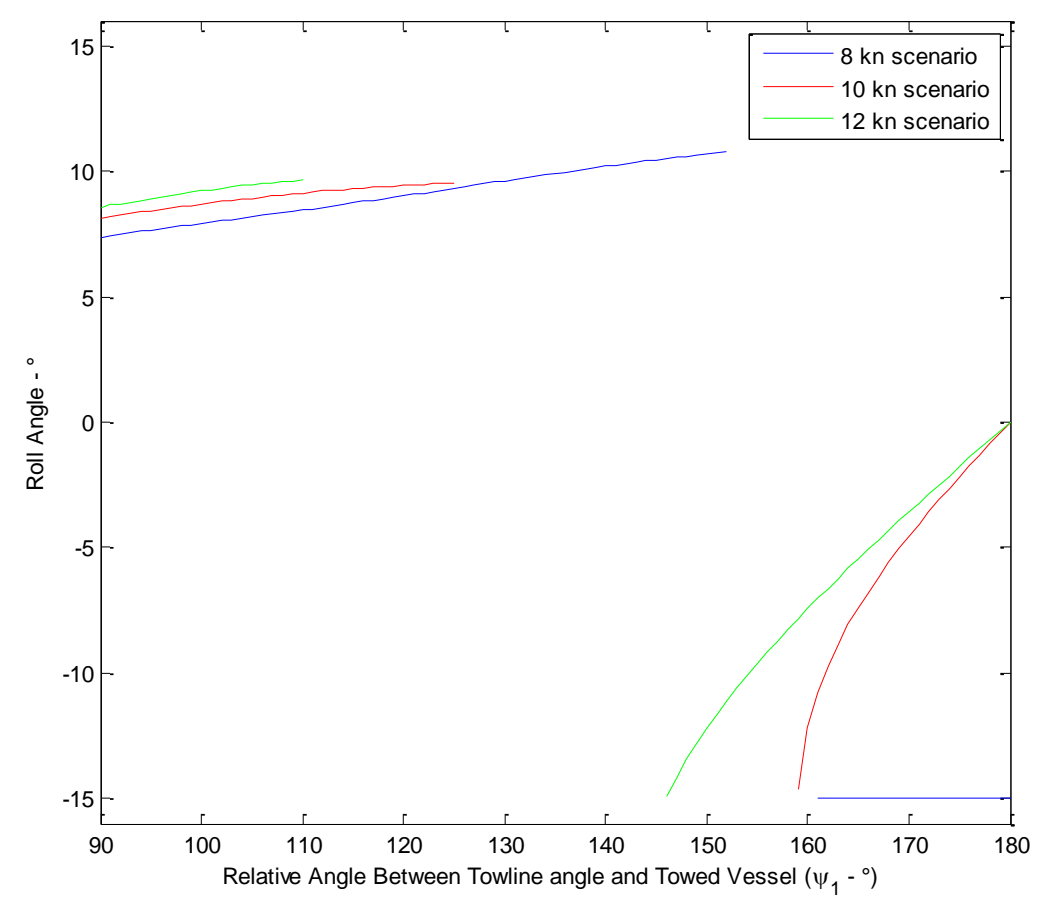

Source: Author

\subsubsection{Escort Tug}

Based on the line curves of a tugboat with similar configuration, a hull was designed using a 3-D drawing software (Figure 81), and the stability curves were generated using a hydrostatic software (Figure 82).

Figure 81 - Modeled hull for an Escort Tug

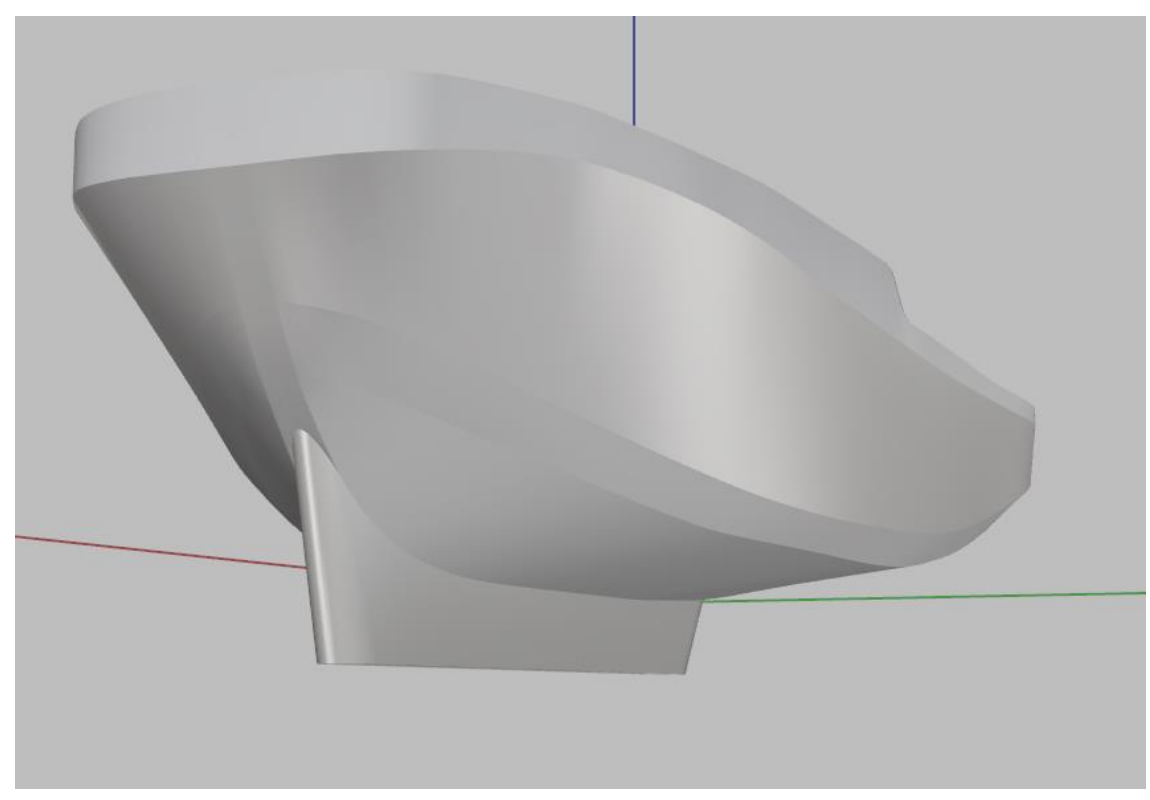

Source: Author 
Figure 82 - Stability curve for the Escort Tug

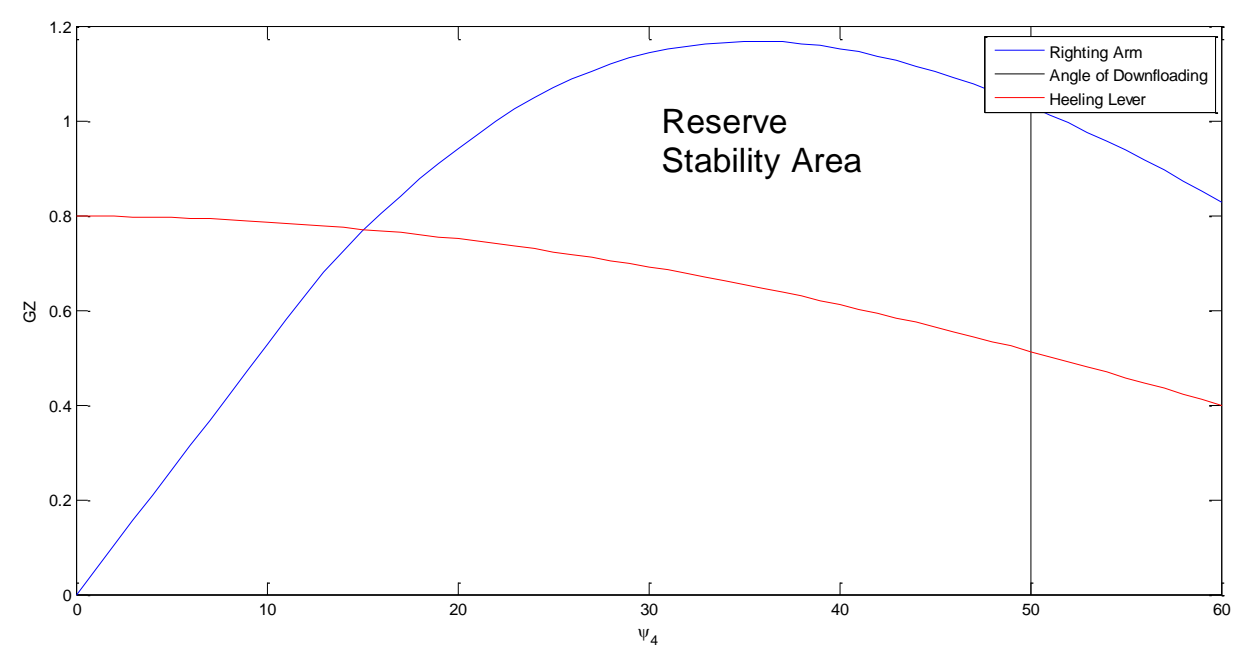

Source: Author

From Figure 83 to Figure 85 one can observe the towing force magnitude for each towline angle and advance speed. For the 8 and $10 \mathrm{kn}$ scenarios, a complete set of solutions is found at the proposed interval, with its maximum efficiency being $\eta=162.53 \%$ at $\Psi_{1}=152^{\circ}$ and $\eta=187.2 \%$ at $\Psi_{1}=134^{\circ}$, respectively. For

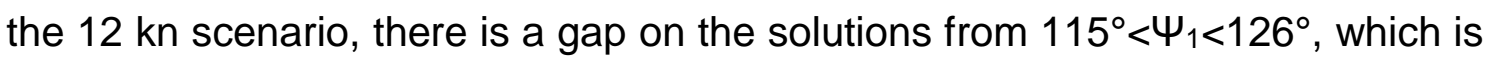
caused due to the optimization constraint of a maximum listing angle of $15^{\circ}$ (Figure 86). Right after the gap, at $\Psi_{1}=126^{\circ}$, the maximum efficiency occurs, being $\eta=193.2 \%$. Note that, if no optimization constraints were imposed for the listing angle, the tugboat would provide a towing force of more than double of its bollard pull.

By analyzing the situations where the efficiency is max (Figure 87), one may realize that, at $8 \mathrm{kn}$, the tugboat's breaking force is larger than the tugboat's steering force; at $10 \mathrm{kn}$, the steering and breaking forces are almost the same; at $12 \mathrm{kn}$, the steering forces are larger than the breaking forces. Therefore, one may conclude that, at $8 \mathrm{kn}$, the indirect maneuver is more effective to break the towed vessel; at $10 \mathrm{kn}$, the indirect maneuver is as effective to break as to steer the towed vessel; at $12 \mathrm{kn}$, the indirect maneuver is more effective to steer than to break. 
Figure 83 - Scenario 1: Escort Tug in indirect maneuver with advance speed of $8 \mathrm{kn}$

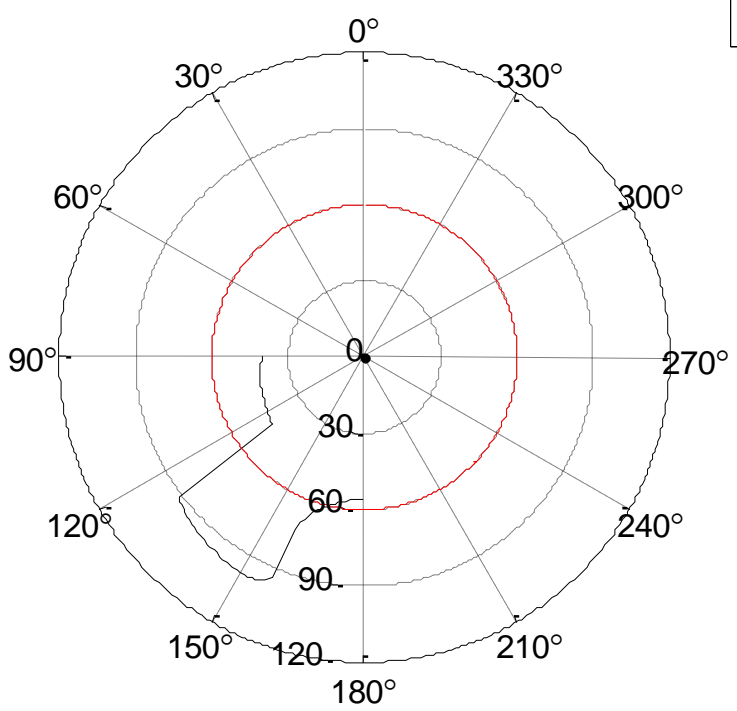

- Towline Force $\mathrm{F}_{\mathrm{T}}$
60 ton

Source: Author

Figure 84 - Scenario 2: Escort Tug in indirect maneuver with advance speed of $10 \mathrm{kn}$

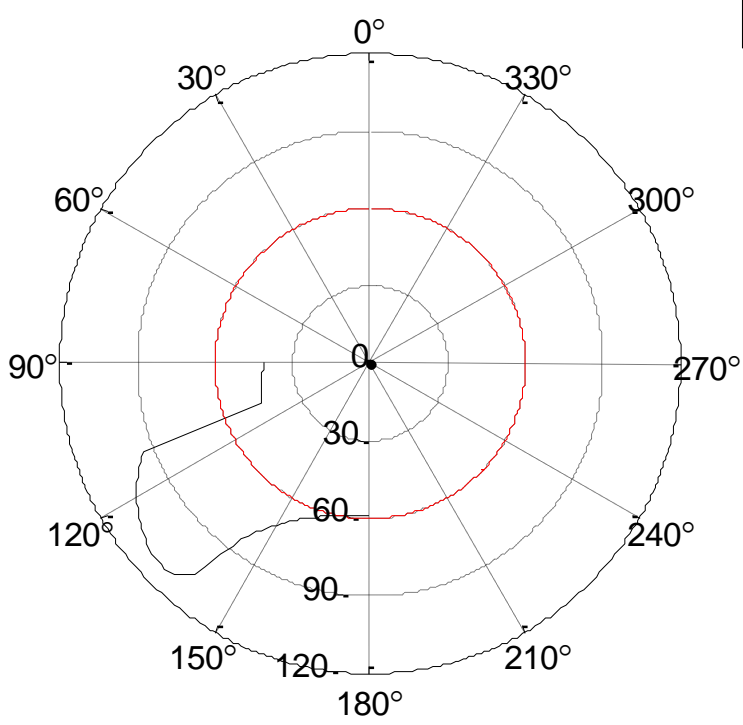

- Towline Force $\mathrm{F}_{\mathrm{T}}$
60 ton

Source: Author 
Figure 85 - Scenario 3: Escort Tug in indirect maneuver with advance speed of $12 \mathrm{kn}$
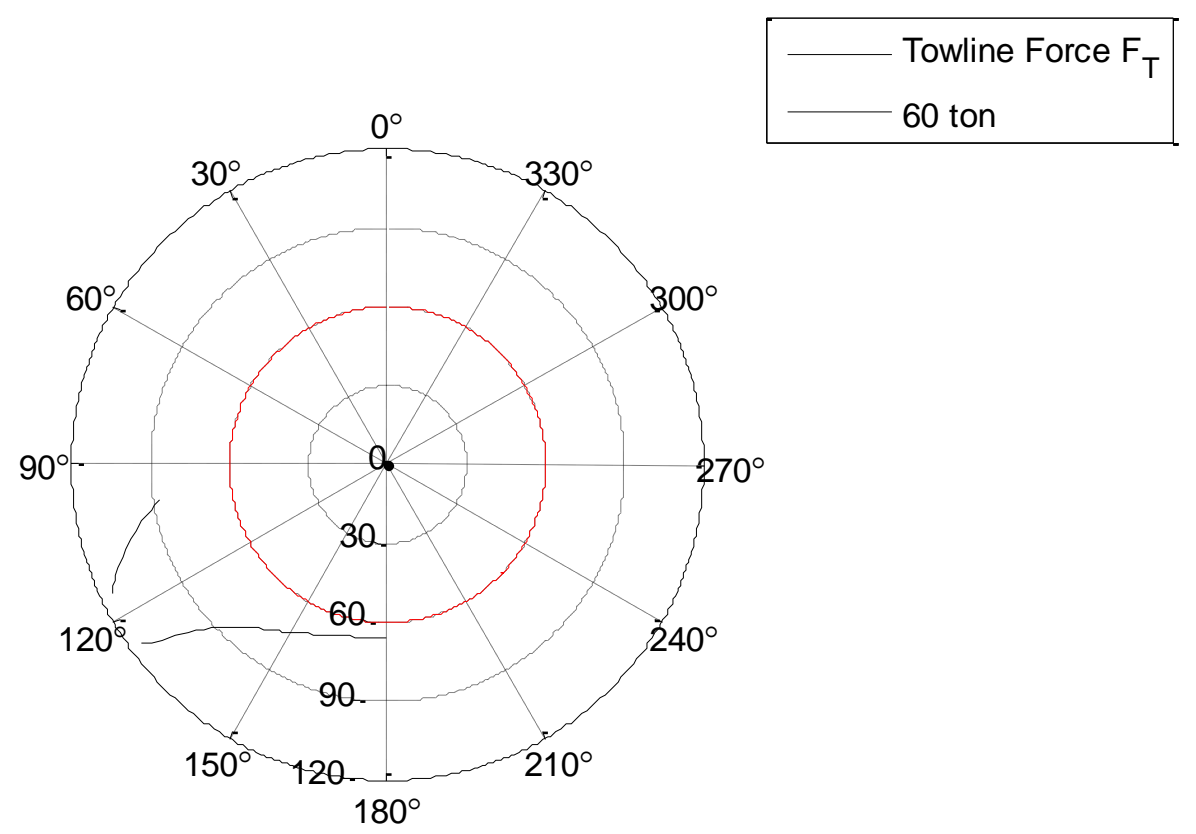

Source: Author

Figure 86 - Listing angles for all scenarios - Escort Tug

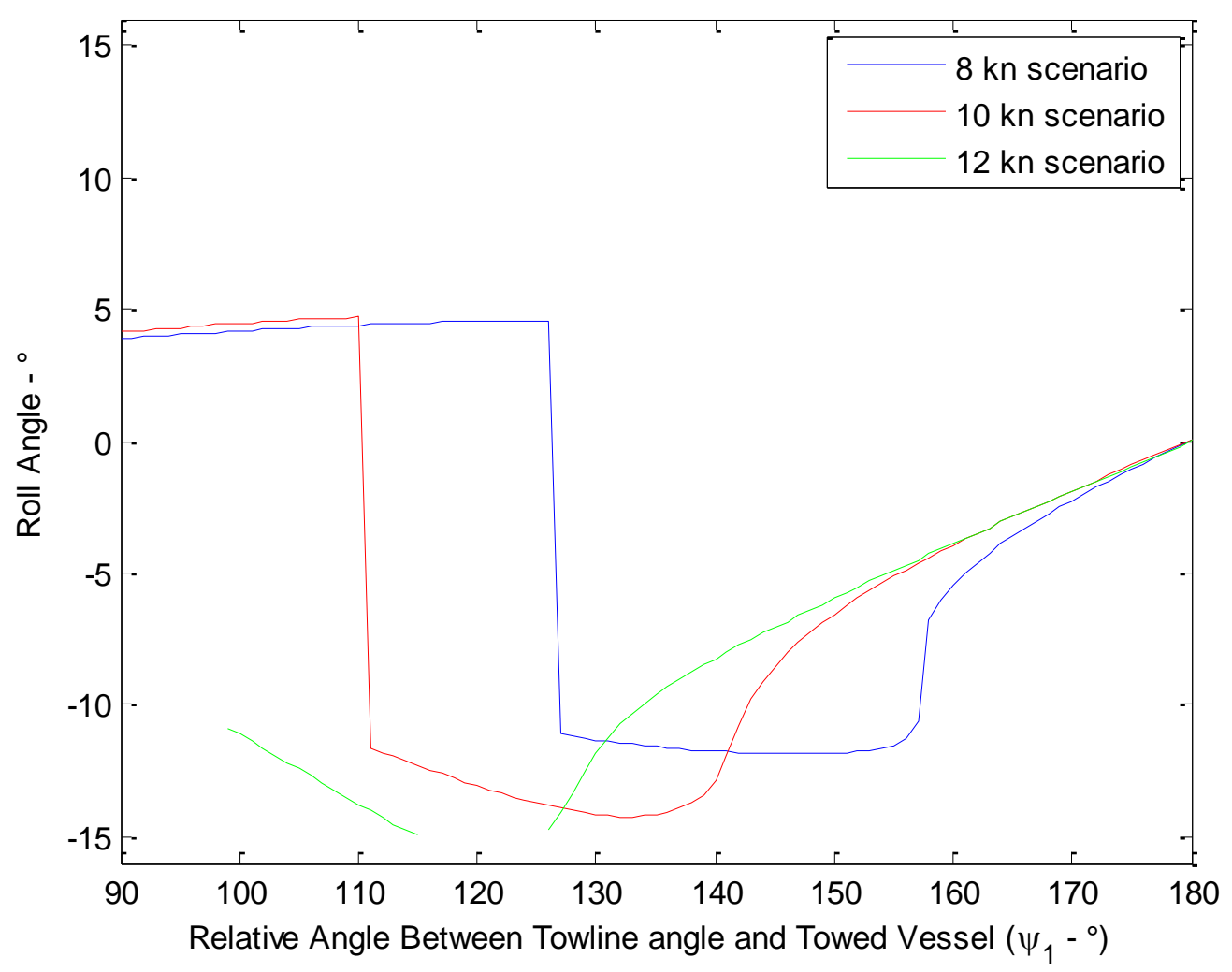

Source: Author 
Figure 87 - Situation where maximum towing force occurs for the 8, 10 and $12 \mathrm{kn}$ scenarios Escort Tug
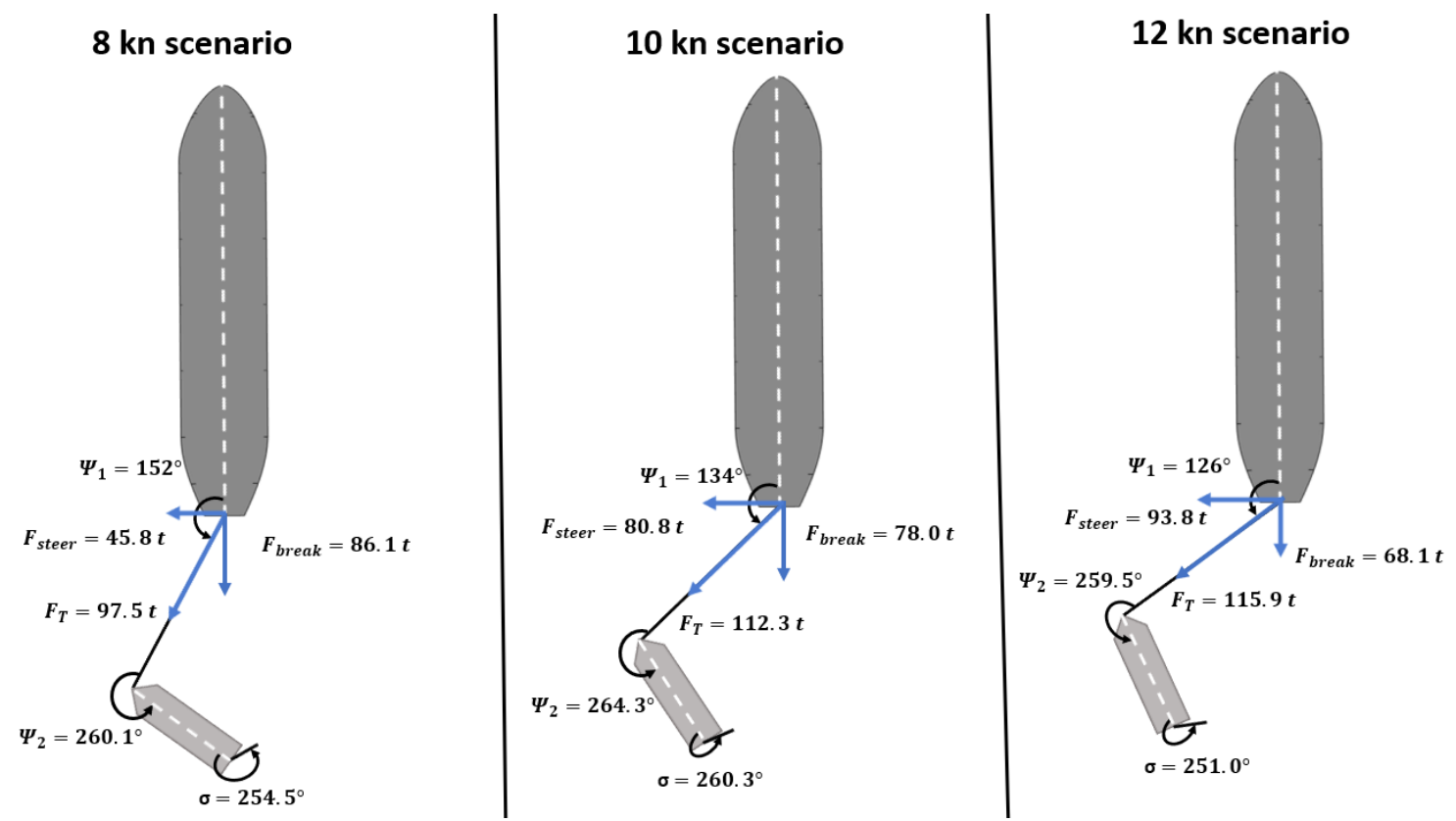

Source: Author

By analyzing Figure 88, Figure 89 and Figure 90 one can realize that the curves for $\Psi_{2}$ and for $\sigma$ have similar configurations. This is the case because, when $\sigma$ has a similar value of $\Psi_{2}$, the reaction towing force actuating on the tug and the propeller force are parallel (refer to Figure 87 as well). In other words, the moments generated by the propeller are always counter-acting the moments generated by the towline and the current, thus keeping the system at equilibrium. In addition, one can realize that, with the increasing on the advance speed, less solutions are found for $\Psi_{2}$ smaller than $180^{\circ}$. This is the case because, for such situations, the increase on the moments caused by the current forces cannot be counter-acted by the moments generated by the propellers. 
Figure 88 - Scenario 1: Relative angles for the formulation at $8 \mathrm{kn}-$ Escort Tug

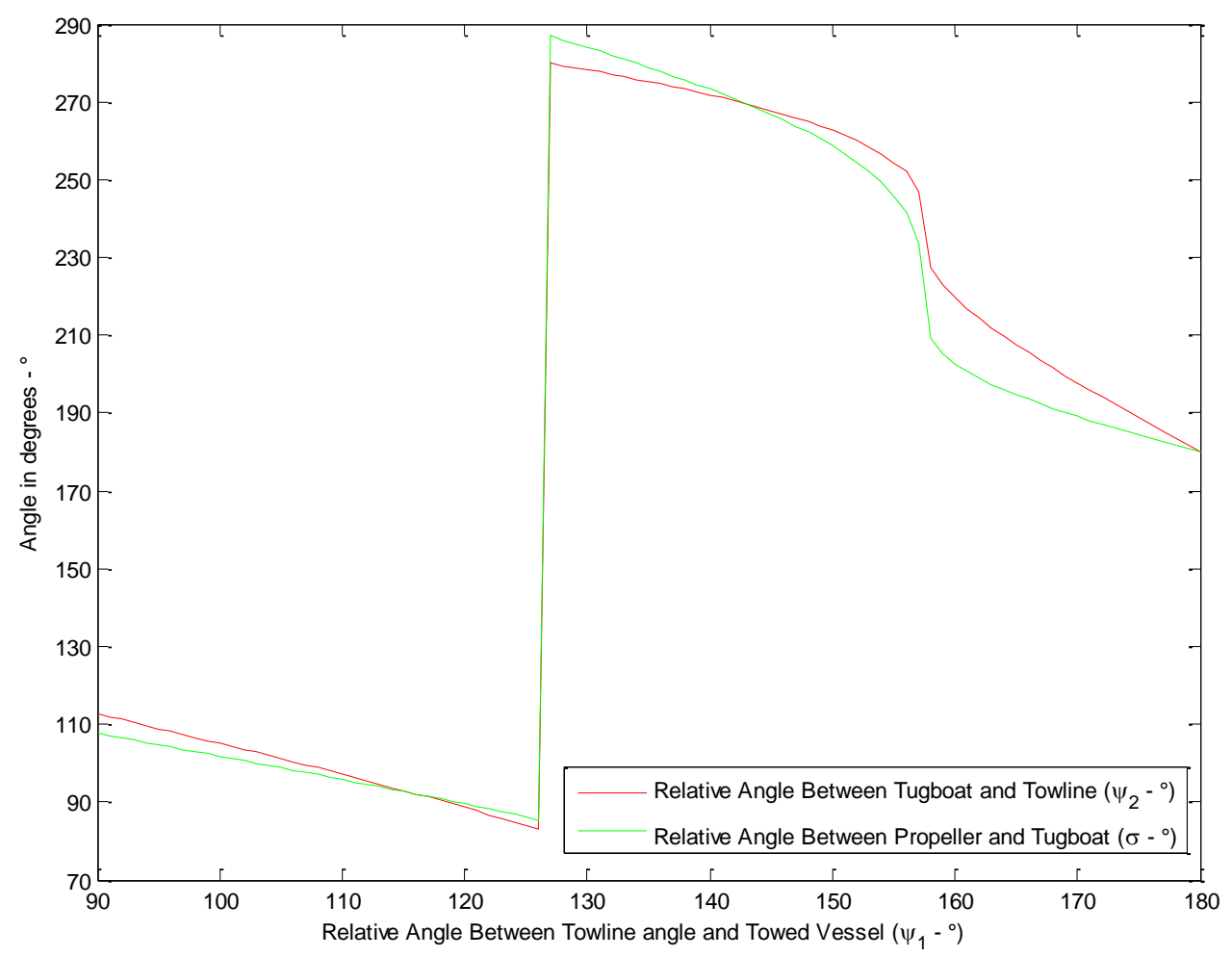

Source: Author

Figure 89 - Scenario 2: Relative angles for the formulation at $10 \mathrm{kn}$ - Escort Tug

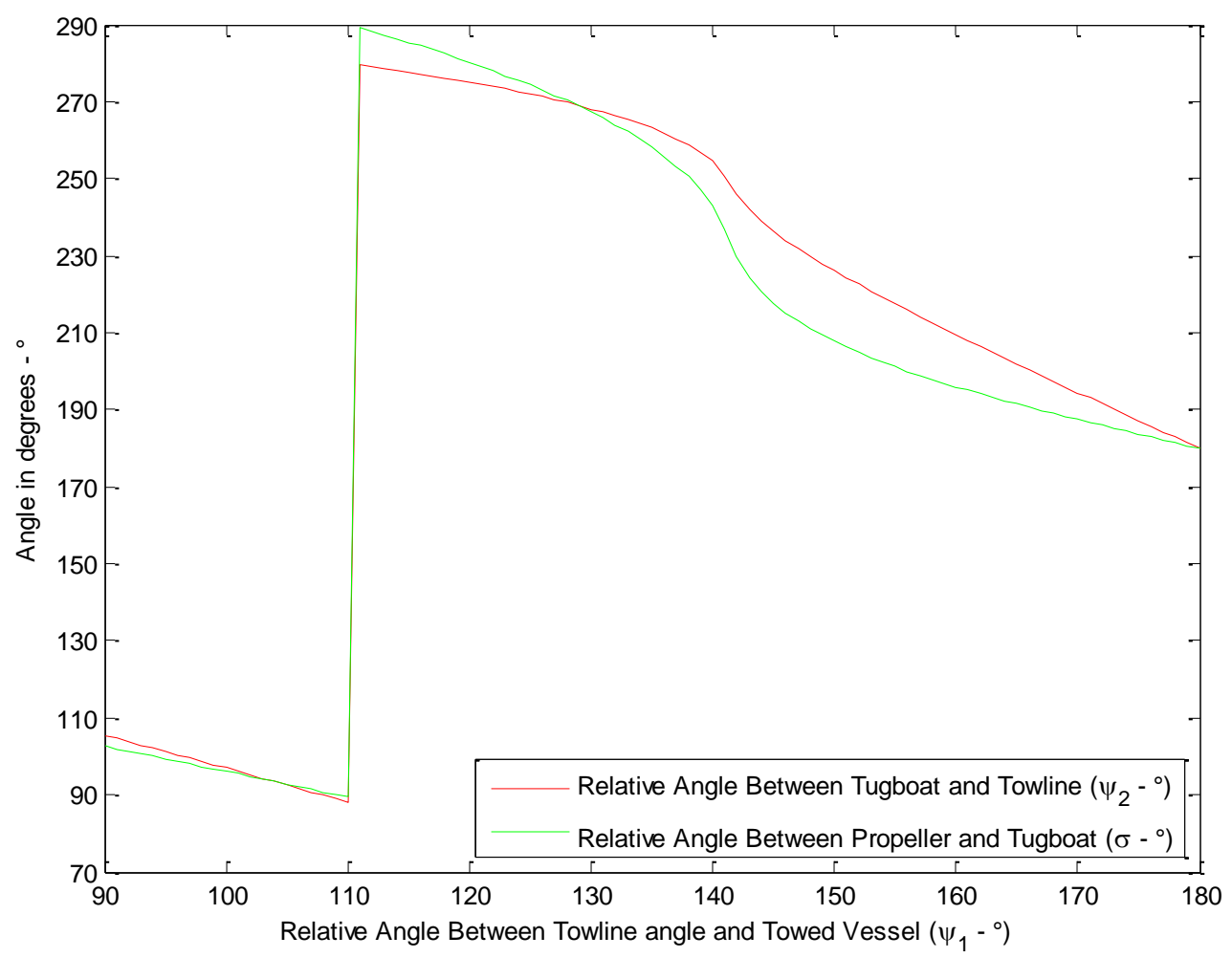

Source: Author 
Figure 90 - Scenario 3: Relative angles for the formulation at $12 \mathrm{kn}$ - Escort Tug

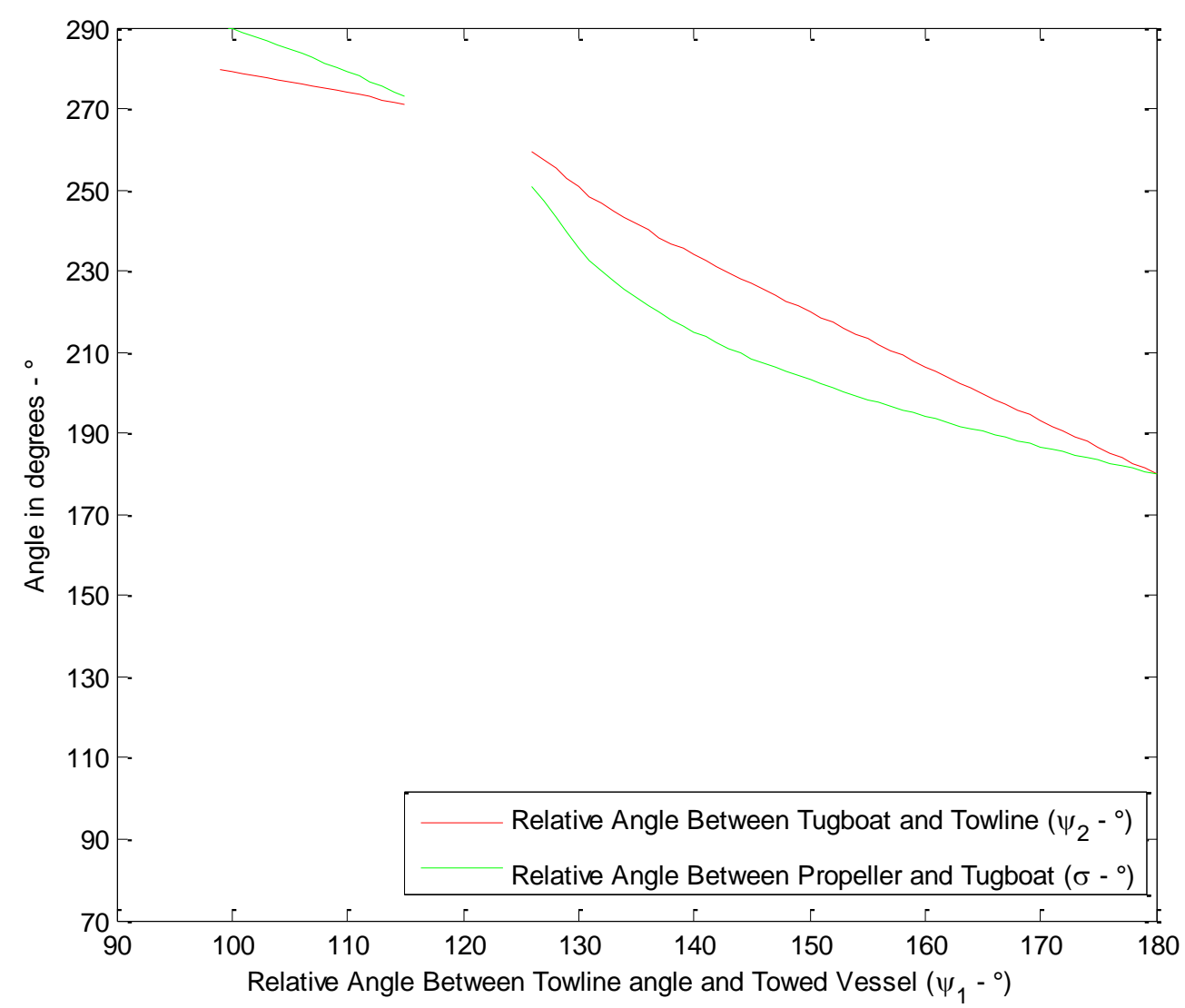

Source: Author

\subsubsection{Comparison Between Regular ASD and Escort Tug Results}

By comparing the towing polar plots of both tugs, one could realize that the efficiency of the Escort Tug is always incredibly larger than the efficiency of the regular ASD tug (50.83\% larger at $8 \mathrm{kn} ; 58.6 \%$ at $10 \mathrm{kn} ; 65.2 \%$ at $12 \mathrm{kn})$. The skeg added to the Escort Tug increased the tugboat's draft in $1.9 \mathrm{~m}$, which direct impact on the drag forces experienced by the hull and consequently on the net towing force. In addition, the skeg mitigates the roll movement of the Escort Tug, thus allowing it to obtain equilibrium solutions at ranges where the regular ASD could not (i.e., for the 8 and $10 \mathrm{kn}$ scenarios, the regular ASD did not have complete sets of solutions due to the listing angles constraints; however, for both of these speeds, the Escort Tug had the complete sets of solutions because its listing was significantly smaller - Figure 91 and Figure 92) 
Figure 91 - Listing angle comparison between Regular ASD and Escort Tug - 8 kn

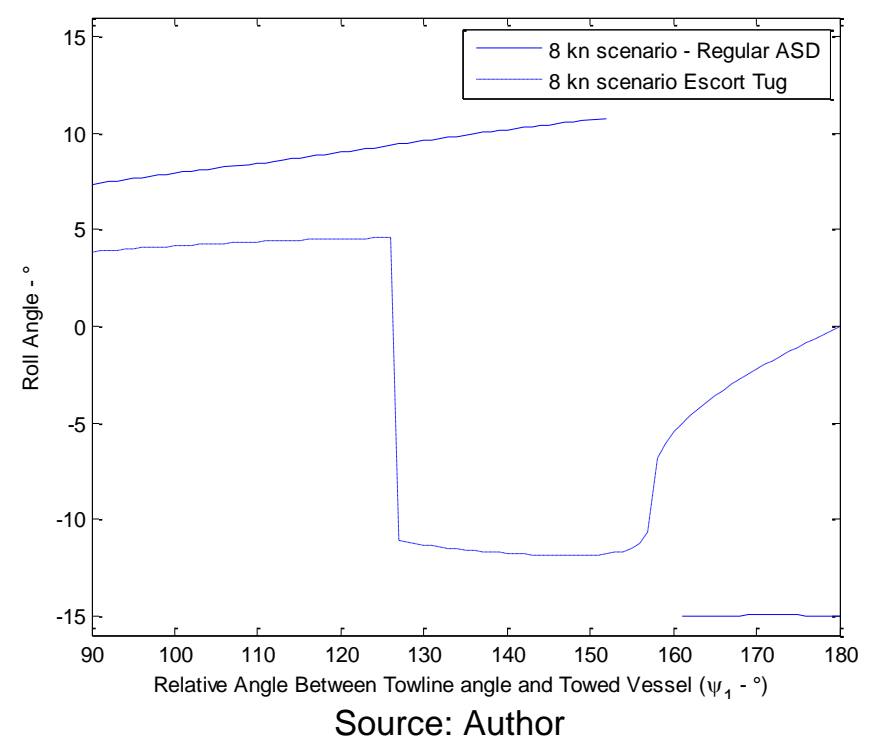

Figure 92 - Listing angle comparison between Regular ASD and Escort Tug - $10 \mathrm{kn}$

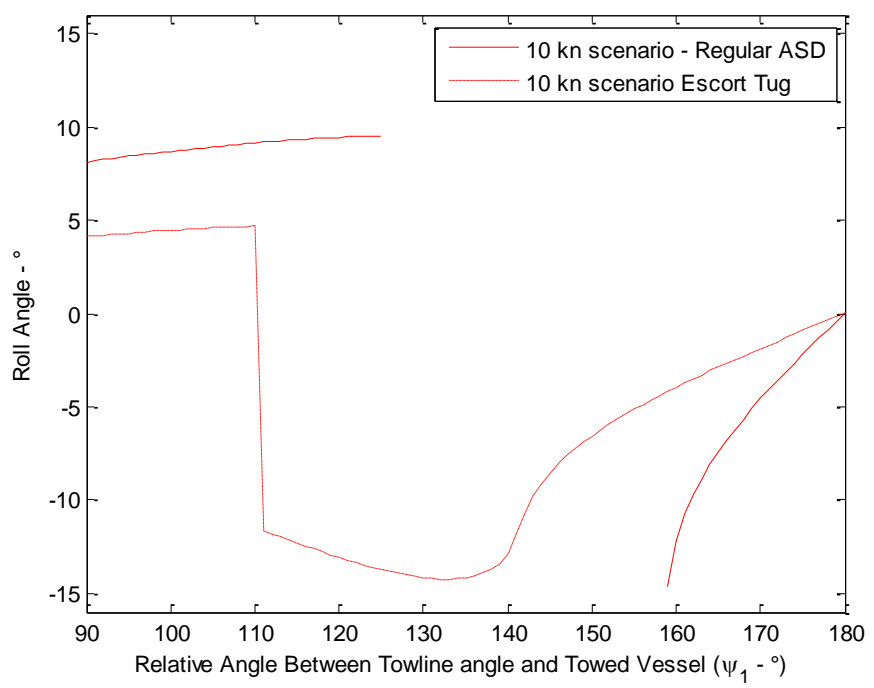

Source: Author

Regarding the operation at maximum efficiency, for the Escort Tug, the values of $\Psi_{2}$ and $\sigma$ always reach the proximity of $270^{\circ}$, while the values for the Regular Tug are smaller (Table 8). Such transversal configuration maximizes the moments generated by the propellers and consequently the counter-acting moments generated by the towline. Therefore, in order to maximize the towing forces on the indirect mode, the tugboat must always stay as transversal as possible to the towline, respecting its limits due to hull configuration constraints. 
Table $8-\Psi_{2}$ and $\sigma$ at maximum condition of operation

\begin{tabular}{|l|l|l|l|l|}
\hline & \multicolumn{2}{|c|}{ Regular ASD } & \multicolumn{2}{c|}{ Escort Tug } \\
\hline & $\Psi_{2}$ & $\sigma$ & $\Psi_{2}$ & $\sigma$ \\
\hline $8 \mathrm{kn}$ & $258.5^{\circ}$ & $257.1^{\circ}$ & $260.1^{\circ}$ & $254.5^{\circ}$ \\
\hline $10 \mathrm{kn}$ & $235.0^{\circ}$ & $222.3^{\circ}$ & $264.3^{\circ}$ & $260.3^{\circ}$ \\
\hline $12 \mathrm{kn}$ & $236.8^{\circ}$ & $223.7^{\circ}$ & $259.5^{\circ}$ & $251.0^{\circ}$ \\
\hline
\end{tabular}

Source: Author

Finally, it is important to mention the difference of operation from both tugboats. At $8 \mathrm{kn}$, both tugboats may provide larger breaking forces than steering forces; at $10 \mathrm{kn}$, the regular ASD still provides more breaking forces than steering forces, while the Escort Tug provides both steering and breaking forces at the same magnitude; at $12 \mathrm{kn}$, the regular ASD continues to provide a larger breaking force than steering force while the Escort Tug provides better steering forces than breaking forces.

It is important to mention that this study was performed considering static equilibrium solutions only, not being concerned with the dynamic transitory situations. Although Regular ASD tugboats have a larger reserve stability than Escort Tugs, they are way more suited for rolling movements, which, in a dynamic situation at high speeds may extrapolate the limits of the reserve stability. Therefore, further studies regarding dynamic stability must be performed in order to guarantee a safety operation of Regular ASD tugboats performing the indirect maneuver. 


\section{RESULTS VALIDATION}

\subsection{Pull Mode - Direct Maneuver}

The SMS located at TPN - USP was used to validate the results regarding the vector tug model in Pull Mode - Direct Maneuver. This simulator has been developed since 1988 at the Escola Politécnica - USP and it is able to integrate dynamic equations of floating bodies, such as vessels and tugboats, in real time (TANNURI, 2014). As input, the simulator requires the main characteristics of the floating bodies, the aerodynamics and hydrodynamics coefficients of such body, the external disturbances characteristics, etc. As output, the simulator calculates a time series of the movement of the floating body on its six-degrees of freedom. In the case of tugboats under towing operation, the simulator can calculate their towage force as well.

In order to perform the validation, a specific scenario was created on the simulator database where three buoys were placed parallel to each other and fixed to the ground. Note that such buoys were positioned towards the north, and the tugboat's towline was attached to the center one, as shown in Figure 93. By having three parallel buoys, one could easily simulate the advance speed of a vessel by applying the same wind and current speed perpendicular to the buoys (i.e., towards east). In such configuration, if the tugboat was towing the buoy to the left, it would mimic a towage operation on a vessel's bow $\left(0^{\circ}\right)$; if the tugboat was towing the buoy parallel to it, it would mimic a transversal towing operation $\left(90^{\circ}\right)$; if the tugboat was towing the buoy to the right side, it would mimic an operation on a vessel's stern $\left(180^{\circ}\right)$. 
Figure 93 - Validation set-up (sky view on a portable pilot unit)

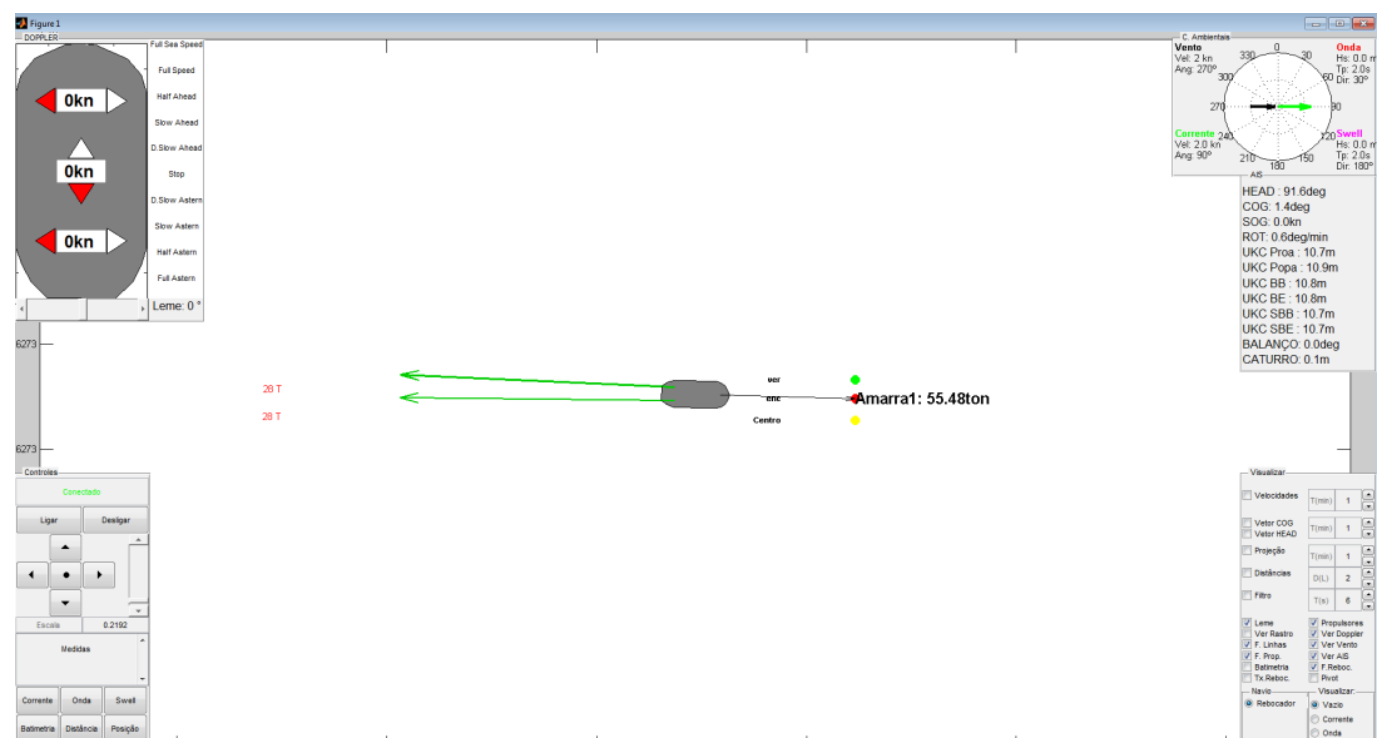

Source: Author

The tugboat used for the validation was a regular ASD tug, possessing the same characteristics previously shown in Table 5 . The main differences between this tugboat and the vector tugs modeled are:

1) The vector tugs have a 3-degree of freedom static model, while the manned tug has a 6 -degree of freedom dynamic model.

2) The vector tugs are modeled with one propeller while the manned tug was modeled with two propellers symmetrically located from its center-line (one by port side and the other by starboard side).

3) The vector tugs have their towline modeled as a fixed-bar while the manned tug has a catenary towline modeled, which may slightly affect the force transferred to the towed vessel.

In order to validate the results obtained with the static equilibrium model, 5 specific towline angles were used as comparison basis: $0^{\circ}, 45^{\circ}, 90^{\circ}, 135^{\circ}, 180^{\circ}$. Therefore, we will maneuver the manned tugboat, having a towline length of 60 $\mathrm{m}$, in such a way that it will approximately reach each of the towline angles 
proposed on each of the three scenarios proposed (vessel with advance speed of 2,4 , and $6 \mathrm{kn})$. After that, we will compare the towline force $\left(F_{t}\right)$, and the relative angle between the tugboat and the towline $\left(\Psi_{2}\right)$ with the results obtained for the vector tugs. The propeller angle of actuation is not be compared since the manned tug has two propellers and the vector tug was modeled only with one. Note that, for the results to be accurate, specialized personnel must be responsible for piloting the manned tugboat. For this experiment, a nautical official was responsible for maneuvering the manned tugboat (Figure 94).

Figure 94 - Maneuvering of manned tugboat in order to perform the experiments.

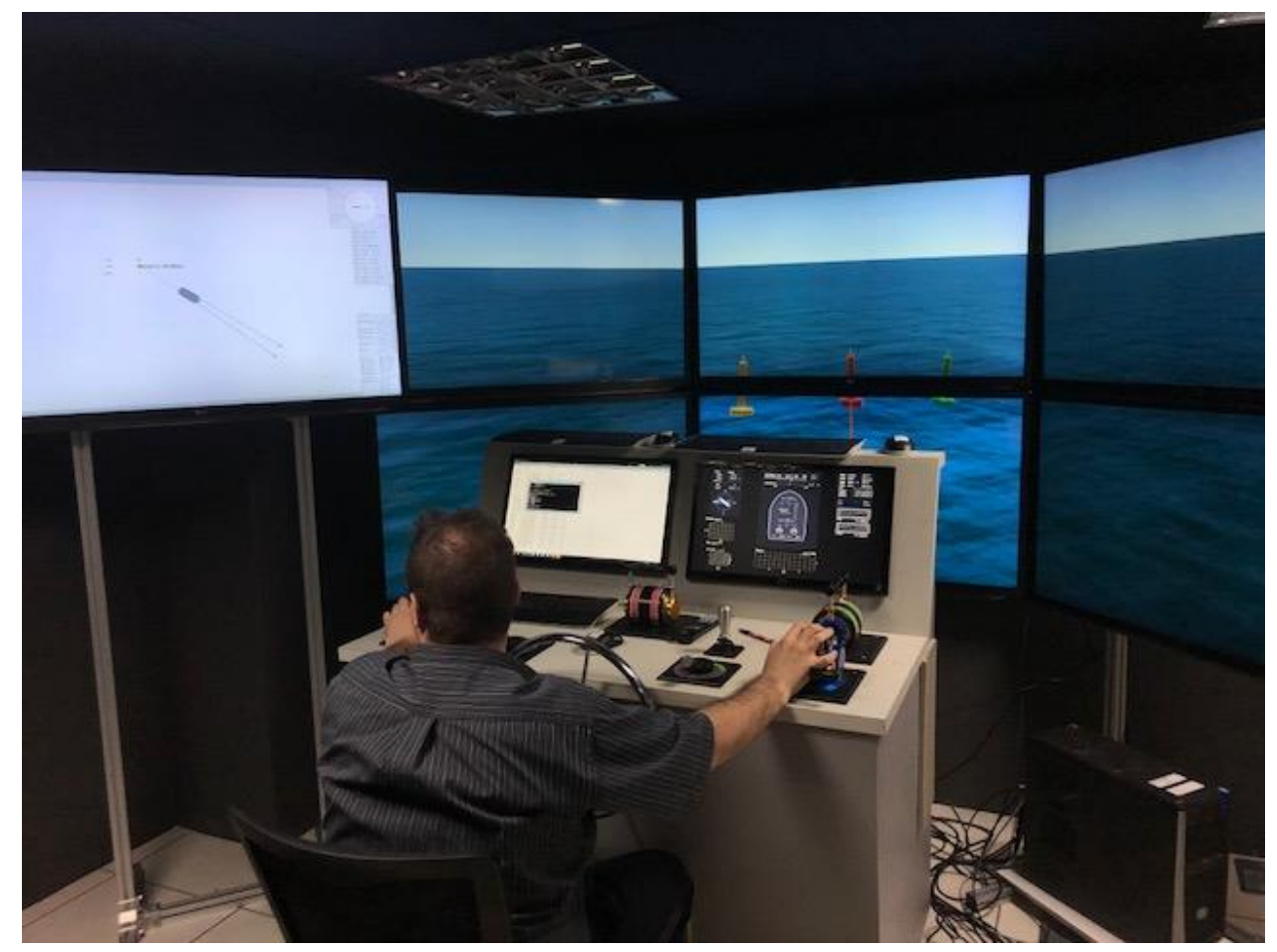

Source: Author

\subsubsection{Vessel's Advance Speed of 2 Knots}

By using the Static Equilibrium calculation software showed on section 4.1, one can calculate the vector tug actuation model for the case where the towed vessel is navigating with a speed of 2 knots. The results for the 5 towline angles in study were presented Figure 54. 
On the following sub-sections, the results obtained using the SMS located at TPN-USP will be provided for each towline angle and compared to the ones presented.

\section{Towline Angle of $0^{\circ}$ :}

After positioning the manned tugboat with a towline angle of approximately $0^{\circ}$ relative to the towed vessel, we obtained an equilibrium towline force on the Simulator of about 55.48 tons, as shown on Figure 95. By comparing such towage force with the one calculated using the mathematical model proposed, the difference is less than $0.2 \%$. In addition, by obtaining the tugboat global heading angle of equilibrium (HEAD: 91.6 deg. shown on Figure 96), transforming it to the coordinate system used ( $0^{\circ}$ east; $90^{\circ}$ north), and applying Eq. (30), one can obtain the relative angle between the tugboat and the towline $\left(\Psi_{2}\right)$ to be $181.6^{\circ}$. By comparing such angle with the one calculated using the mathematical model proposed, we obtain approximately $1.6^{\circ}$ of absolute difference.

By analyzing Figure 95 at approximately 150 s, one may realize a peak force on the towline. Such peak occurred when positioning the tugboat on the right location. Note that, for a situation where only wind and current are present, normally experienced tugboat captains are able to avoid such peaks, thus being not crucial on this situation. However, during the presence of waves, the difficulty to control towline peaks is tremendous and the risk of towline damage is enormous. Refer to section 7 for a further analyze of towline peaks and tugboat's dynamics under the presence of waves. 
Figure 95 - Towing force on equilibrium for $0^{\circ}$ case at 2 knots speed

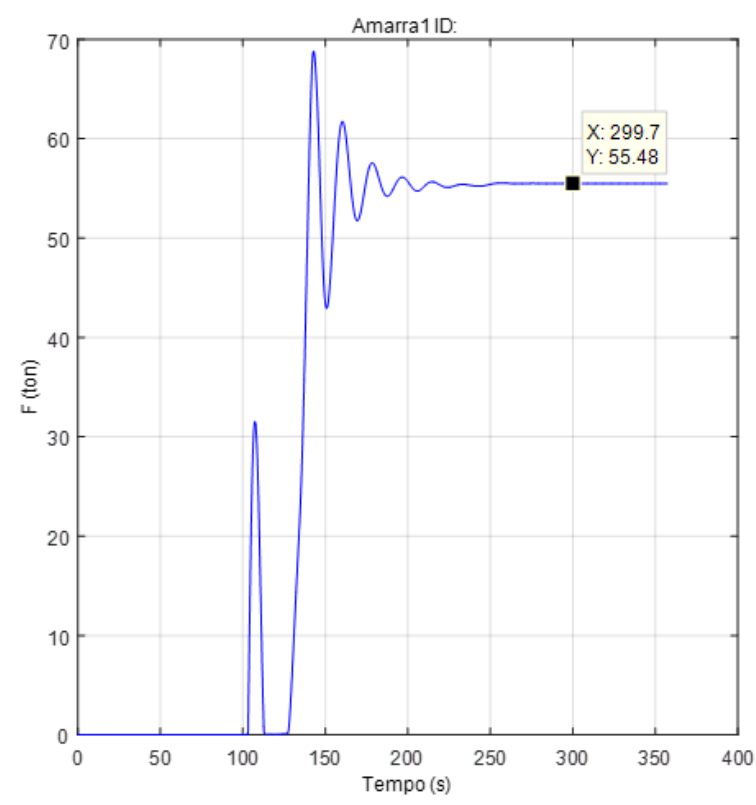

Source: Author

Figure 96 - Results comparison for the $0^{\circ}$ case at 2 knots speed

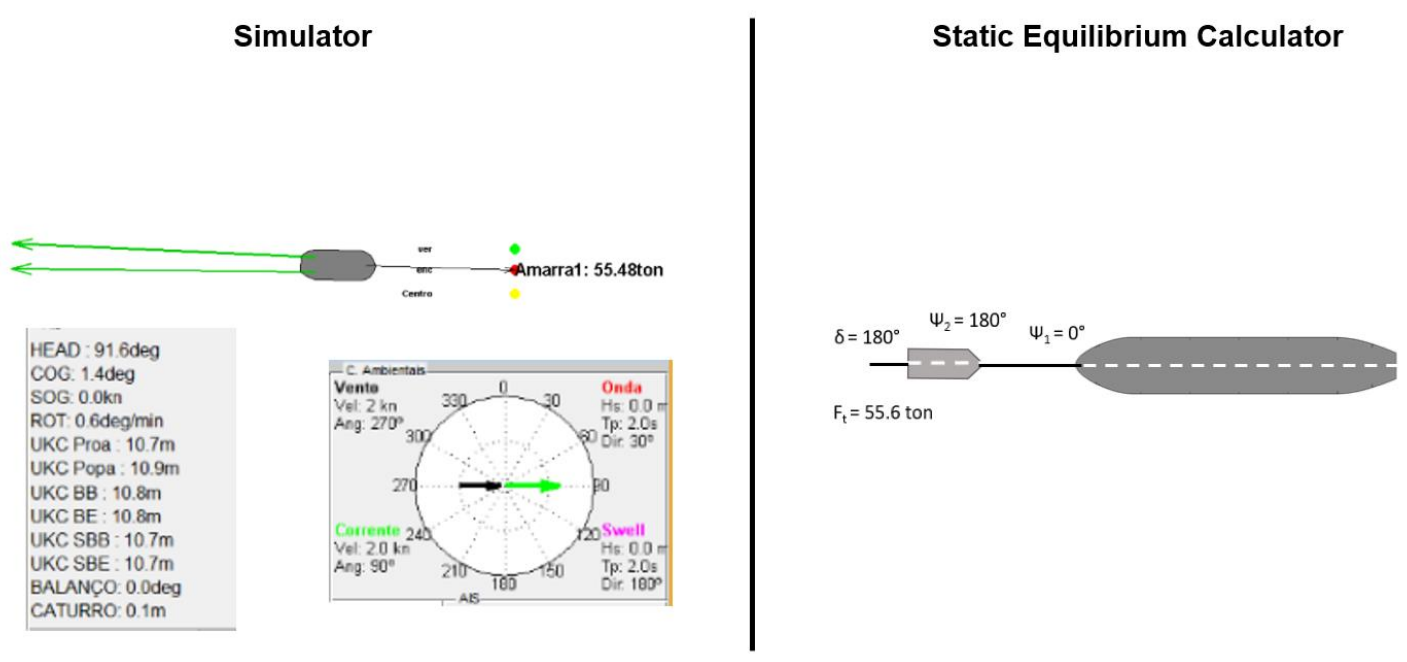

Source: Author

Towline Angles of $45,90^{\circ}, 135^{\circ}$ and $180^{\circ}$ :

A similar procedure to the one described on the last section was performed for each of the towline angles in study. A summary of such results may be seen on Table 9. In addition, the final configuration for each scenario may be encountered from Figure 97 to Figure 100. 
Table 9 - Validation summary for the 2 knots scenario

\begin{tabular}{|l|l|l|l|l|l|l|l|}
\hline Towline Angle & Theoretical $F_{t}$ & Theoretical $\Psi_{2}$ & Simulator & $F_{t}$ & Simulator $\Psi_{2}$ & $F_{t} \%$ error & $\Psi_{2}$ absolute error \\
\hline $0^{\circ}$ & 55.6 & $180^{\circ}$ & 55.5 & 181.6 & $0.2 \%$ & $1.6^{\circ}$ \\
\hline $45^{\circ}$ & 56.9 & $177.9^{\circ}$ & 55.1 & $171^{\circ}$ & $1.4 \%$ & $6.9^{\circ}$ \\
\hline $90^{\circ}$ & 59.7 & $176.5^{\circ}$ & 59.4 & $176.9^{\circ}$ & $0.5 \%$ & $0.4^{\circ}$ \\
\hline $135^{\circ}$ & 61.6 & $176.8^{\circ}$ & 61.4 & 185.2 & $0.3 \%$ & $8.4^{\circ}$ \\
\hline $180^{\circ}$ & 61.9 & $180.0^{\circ}$ & 63.0 & $180^{\circ}$ & & $1.8 \%$ & $0.0^{\circ}$ \\
\hline
\end{tabular}

Source: Author

By analyzing the obtained results, one may conclude that both the theoretical model and the Maneuvering Simulator model match with reasonable accuracy when considering solely the towing force (maximum of $1.8 \%$ error). Since the towing force curves are continuous, having an experimental towline angle differing from the theoretical one in a range smaller than $20^{\circ}$ is not enough to significantly alter the force results. However, the same is not true when comparing the relative angle between the tugboat and the towline $\left(\Psi_{2}\right)$. Since Eq. (30) is a function of the towline angle, inputting an erroneous angle may lead to a discrepancy in obtaining the real $\Psi_{2}$. Since it was difficult to perfectly obtain the towline angles of $45^{\circ}$ and $135^{\circ}$ during the Maneuvering Simulations, the $\Psi_{2}$ angles calculated were expected to be a little discrepant from the theoretical values.

Figure 97 - Results comparison for the $45^{\circ}$ case at 2 knots speed

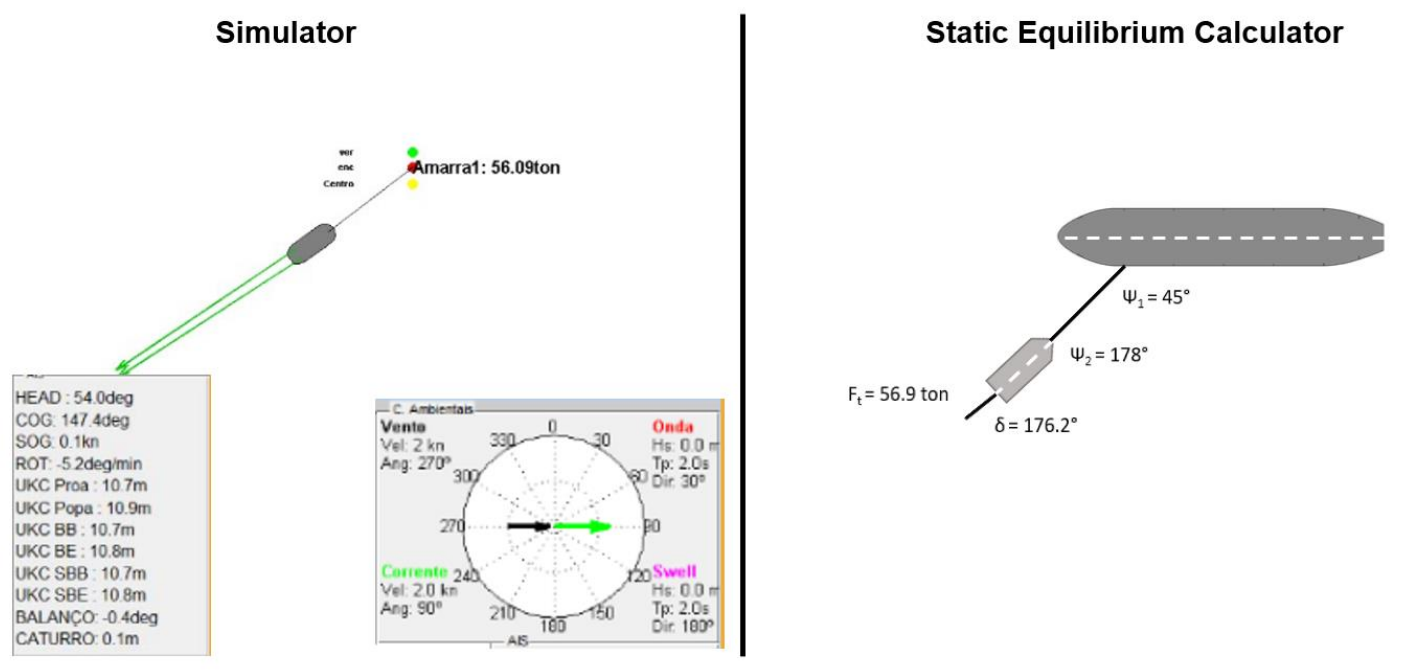

Source: Author 
Figure 98 - Results comparison for the $90^{\circ}$ case at 2 knots speed

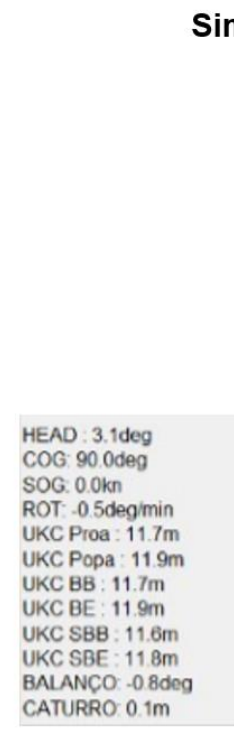

Simulator
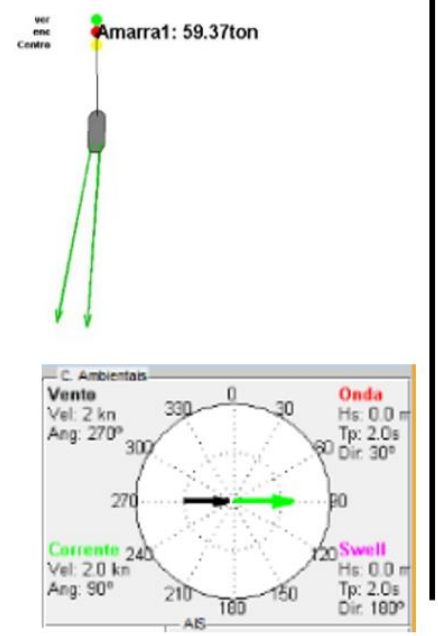

Source: Author
Static Equilibrium Calculator

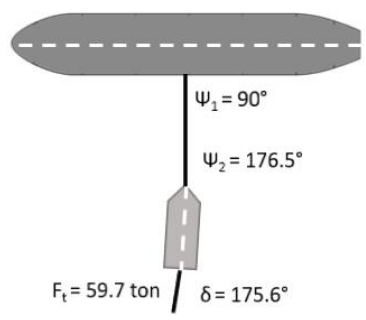

Figure 99 - Results comparison for the $135^{\circ}$ case at 2 knots speed

\section{Simulator}$$
=
$$

HEAD : $309.8 \mathrm{deg}$

COG. $18.4 \mathrm{deg}$

SOG: $0.0 \mathrm{kn}$

ROT: $2.8 \mathrm{deg} / \mathrm{min}$

UKC Proa : $127 \mathrm{~m}$

UKC Popa: $129 \mathrm{~m}$

UKC BB: $12.7 \mathrm{~m}$

UKC BE : $12.8 \mathrm{~m}$

UKC SBB : $127 \mathrm{~m}$

UKC SBE : $128 \mathrm{~m}$

BALANCYO $-0.6 \mathrm{deg}$

CATURRO: $0.1 \mathrm{~m}$
Static Equilibrium Calculator

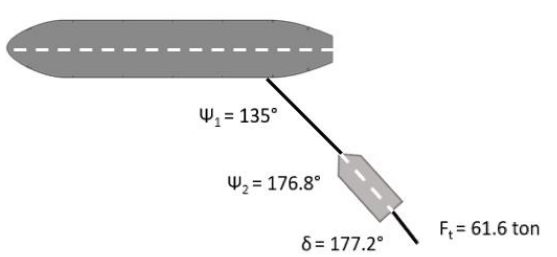

Source: Author 
Figure 100 - Results comparison for the $180^{\circ}$ case at 2 knots speed

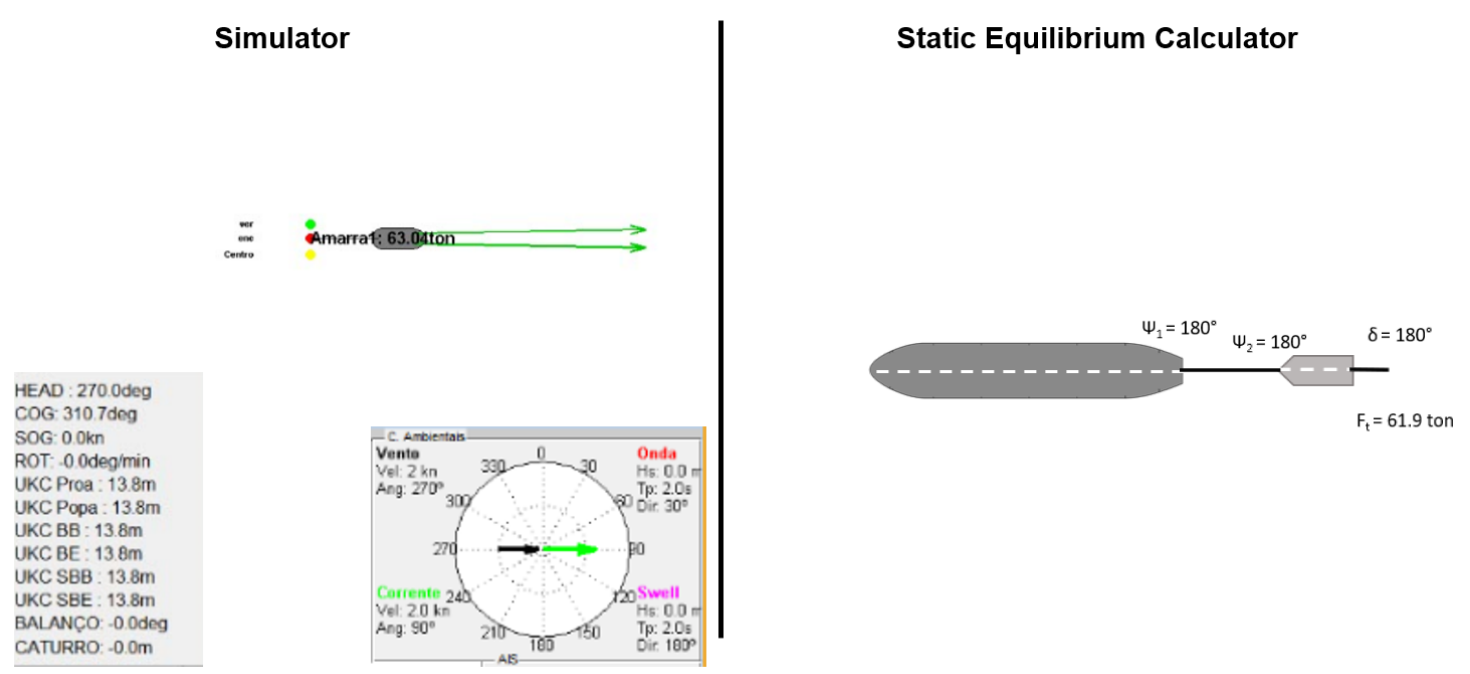

Static Equilibrium Calculator

Source: Author

\subsubsection{Vessel's Advance Speed of 4 Knots}

By using the Static Equilibrium calculation software showed on section 4.3, one can calculate the vector tug actuation model for the case where the towed vessel is navigating with a speed of 4 knots. The results for the 5 towline angles in study were presented Figure 56.

On the following sub-section, the results obtained using the SMS located at TPNUSP will be provided for each towline angle and compared to the ones presented.

Towline Angles of $0^{\circ}, 45^{\circ}, 90^{\circ}, 135^{\circ}, 180^{\circ}$ :

A similar procedure to the one described on the last section was performed for each of the towline angles in study. A summary of such results may be seen on Table 10. In addition, the final configuration for each scenario may be encountered from Figure 101 to Figure 105.

Table 10 - Validation summary for the 4 knots scenario

\begin{tabular}{|l|l|l|l|l|l|l|l|}
\hline Towline Angle & Theoretical $F_{t}$ & Theoretical $\Psi_{2}$ & Simulator $F_{t}$ & Simulator $\Psi_{2}$ & $F_{t} \%$ error & $\Psi_{2}$ absolute error \\
\hline $0^{\circ}$ & 49.5 & $180^{\circ}$ & 49.6 & $179.8^{\circ}$ & $0.2 \%$ & $0.2^{\circ}$ \\
\hline $45^{\circ}$ & 50.8 & 171.7 & 48.8 & $170.6^{\circ}$ & $3.9 \%$ & $1.1^{\circ}$ \\
\hline $90^{\circ}$ & 56.7 & 166.7 & 53.6 & 167.0 & $5.4 \%$ & 0.3 \\
\hline $135^{\circ}$ & 62.2 & 166.2 & 62.4 & $182^{\circ}$ & $0.3 \%$ & $15.8^{\circ}$ \\
\hline $180^{\circ}$ & 61.7 & 180.0 & 61.8 & $180^{\circ}$ & $0.1 \%$ & $0.0^{\circ}$ \\
\hline
\end{tabular}

Source: Author 
By analyzing the obtained results, one can see that, once again, the forces obtained with both the Maneuvering Simulator and the theoretical models match with a high accuracy (maximum \% error of 5.4\%). By analyzing Figure 104, one can clearly see that the relative angle between the tugboat and the towline (on the simulator case) is smaller than $180^{\circ}$, thus showing that the $182^{\circ}$ value calculated is inaccurate. Such result discrepancy is directly associated to the towline angle. As previous stated, during the simulations, we tried to keep the towline angle as close as possible to the desired values, however, it was impossible to keep track of the exact towline angle in real time. After further analysis, it could be noted that, for this case, the towline angle was at approximately $150^{\circ}$ relative to the vessel. By using this new value and recalculating the relative angle between the tugboat and the towline, one may find that $\Psi_{2}$ was about $167^{\circ}$, which gives an absolute error of $0.8^{\circ}$ when compared to the theoretical value.

Figure 101 - Results comparison for the $0^{\circ}$ case at 4 knots speed

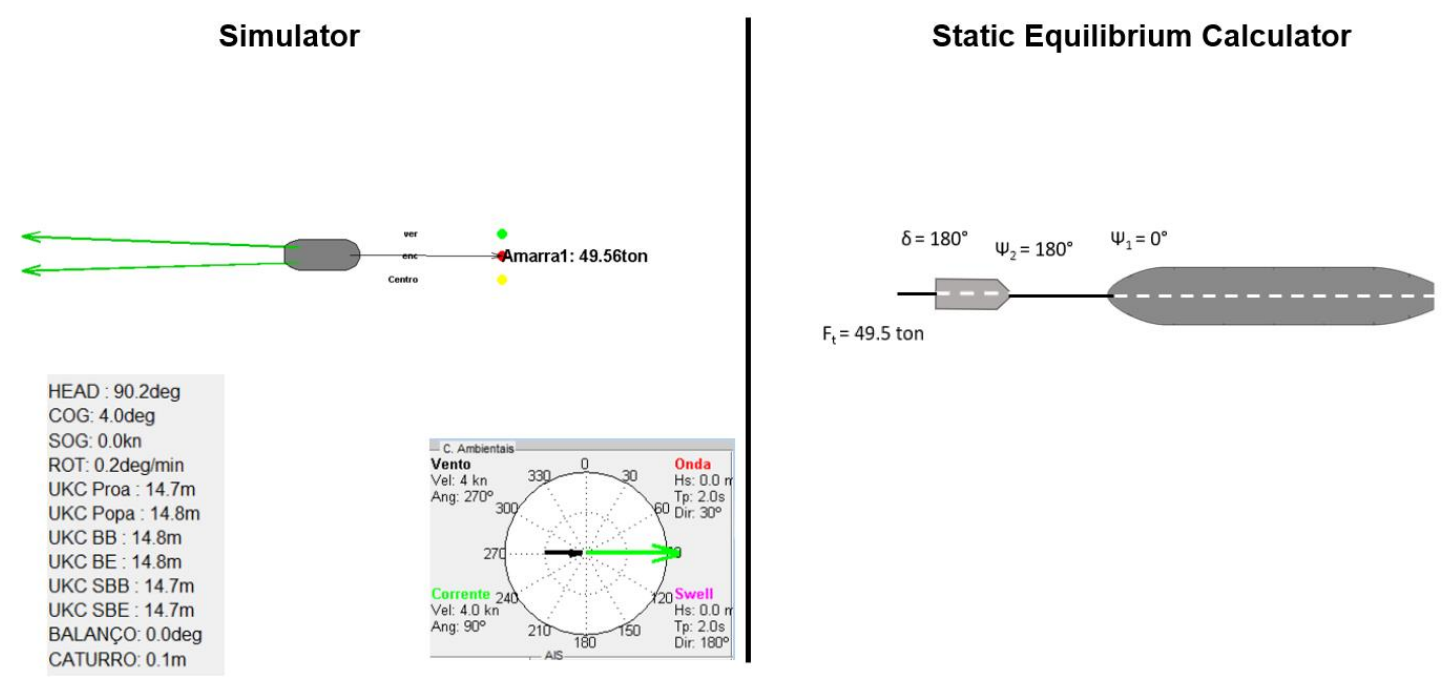

Source: Author 
Figure 102 - Results comparison for the $45^{\circ}$ case at 4 knots speed

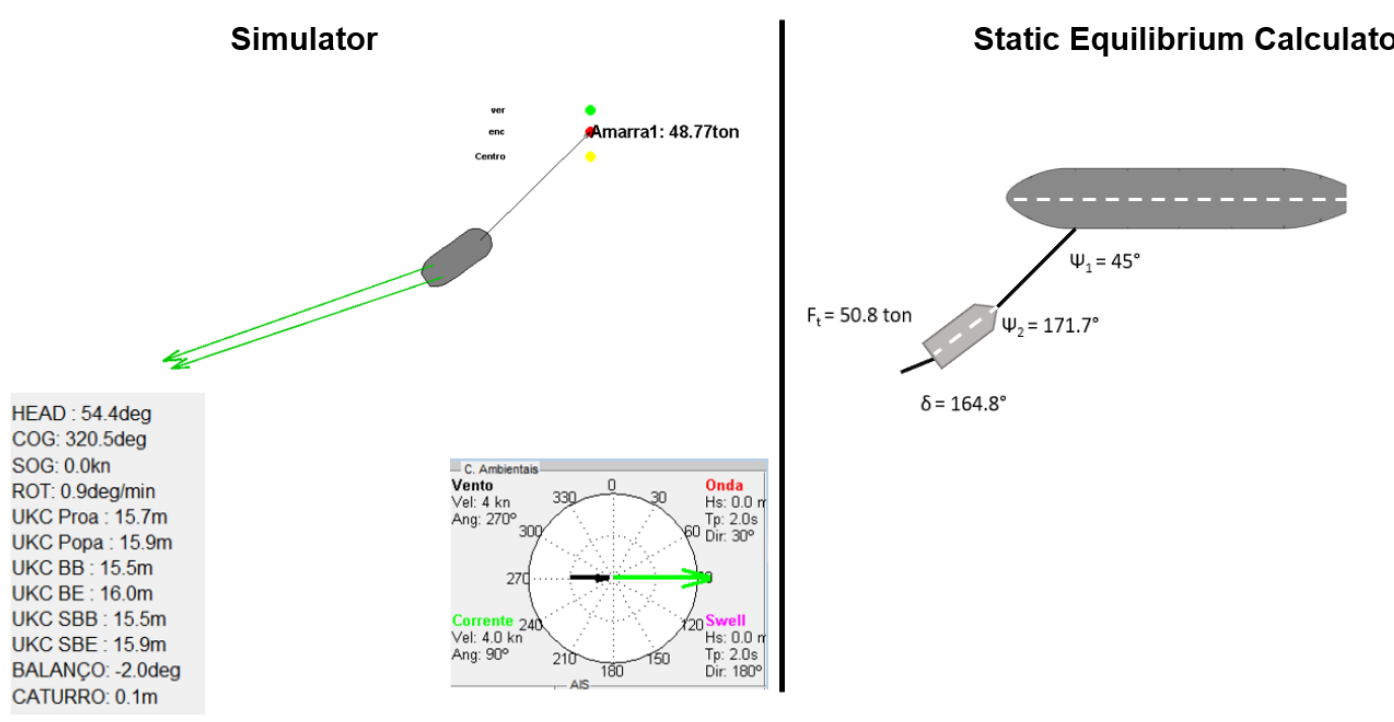

Source: Author

Figure 103 - Results comparison for the $90^{\circ}$ case at 4 knots speed

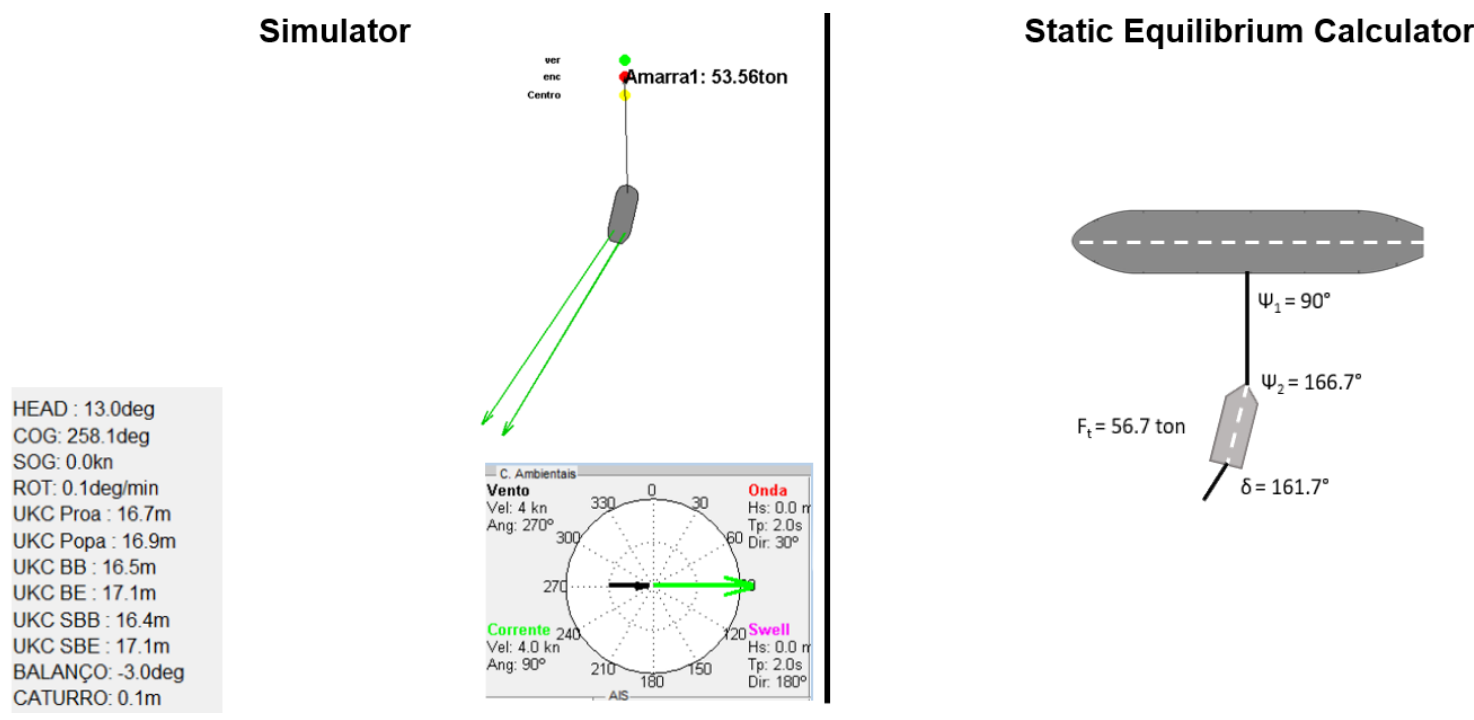

Source: Author 
Figure 104 - Results comparison for the $135^{\circ}$ case at 4 knots speed

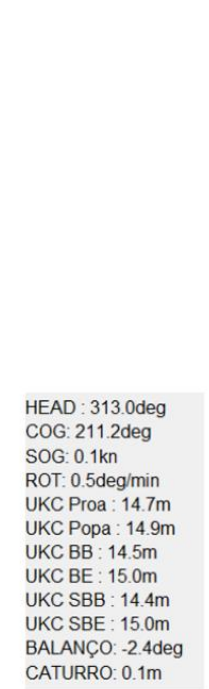

Simulator

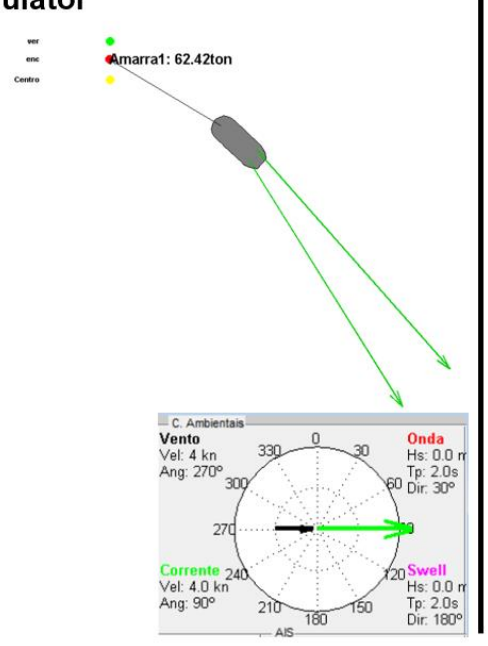

Source: Author
Static Equilibrium Calculator

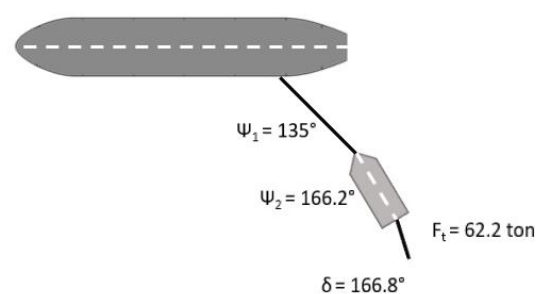

Figure 105 - Results comparison for the $180^{\circ}$ case at 4 knots speed

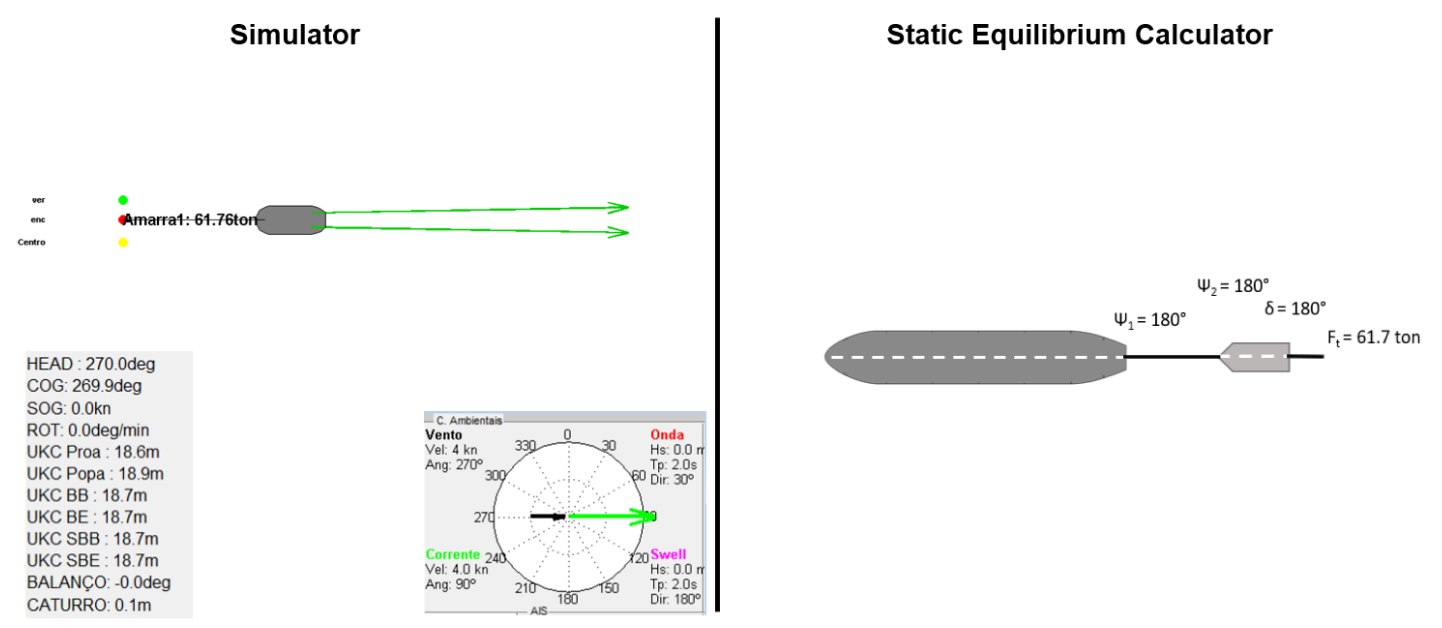

Source: Author 


\subsubsection{Vessel's Advance Speed of 6 Knots}

By using the Static Equilibrium calculation software showed on section 4.3, one can calculate the vector tug actuation model for the case where the towed vessel is navigating with a speed of 6 knots. The results for the 5 towline angles in study were presented Figure 58.

On the following sub-section, the results obtained using the SMS located at TPNUSP will be provided for each towline angle and compared to the ones presented.

Towline Angle of $0^{\circ}, 45^{\circ}, 90^{\circ}, 135^{\circ}, 180^{\circ}:$

A similar procedure to the one described on the last two sections was performed for each of the towline angles in study. A summary of such results may be seen on Table 11. In addition, the final configuration for each scenario may be encountered from Figure 106 to Figure 110.

Table 11 - Validation summary for the 6 knots scenario

\begin{tabular}{|c|c|c|c|c|c|c|}
\hline Towline Angle & Theoretical $F_{t}$ & Theoretical $\Psi_{2}$ & Simulator & Experimental $\Psi_{2}$ & $F_{t} \%$ error & $\Psi_{2}$ absolute error \\
\hline $0^{\circ}$ & 42.5 & $180^{\circ}$ & 42.8 & $178.1^{\circ}$ & $0.7 \%$ & $1.9^{\circ}$ \\
\hline $45^{\circ}$ & 39.8 & 160.7 & 41.8 & $178.1^{\circ}$ & $5.0 \%$ & 17.4 \\
\hline $90^{\circ}$ & 42.2 & 147.6 & 37.0 & $149.8^{\circ}$ & $12.3 \%$ & $2.2^{\circ}$ \\
\hline $135^{\circ}$ & 58.1 & 144.2 & 57.0 & $158^{\circ}$ & $1.9 \%$ & $13.8^{\circ}$ \\
\hline $180^{\circ}$ & 59.7 & 180.0 & 59.7 & $180^{\circ}$ & $0.1 \%$ & $0.0^{\circ}$ \\
\hline
\end{tabular}

Source: Author

By analyzing the obtained results, one can see that, the forces obtained with both the Maneuvering Simulator and the theoretical models match with a high accuracy for the $0^{\circ}, 45^{\circ}, 135^{\circ}$ and $180^{\circ}$ scenarios (maximum \% error of $5.0 \%$ ). For the $90^{\circ}$ scenario, no static equilibrium position could be found during the simulations. This is the case because the predictive model does not consider any water-propeller interaction effects, while in the simulator, there is an effect that attenuates the propeller thrust based on the transversal water velocity relative to the propeller. In other words, the propeller thrust obtained on the simulation is not enough to keep the system on static equilibrium at the $90^{\circ}$ specific location.

In order to still validate the theoretical model, active control of the propellers was applied in order to keep the tugboat on the proximities of $90^{\circ}$. With such kind of active control, we obtained a towline force on the Simulator of about 37.03 tons, 
and a $12.3 \%$ error, which is still in a reasonable \% error range. Therefore, one can conclude that, for the range of operation of an ASD tugboat $(0-6 \mathrm{Kn})$ in Pull Mode - Direct, the predictive model is accurate and within an accepted error margin.

Figure 106 - Results comparison for the $0^{\circ}$ case at 6 knots speed

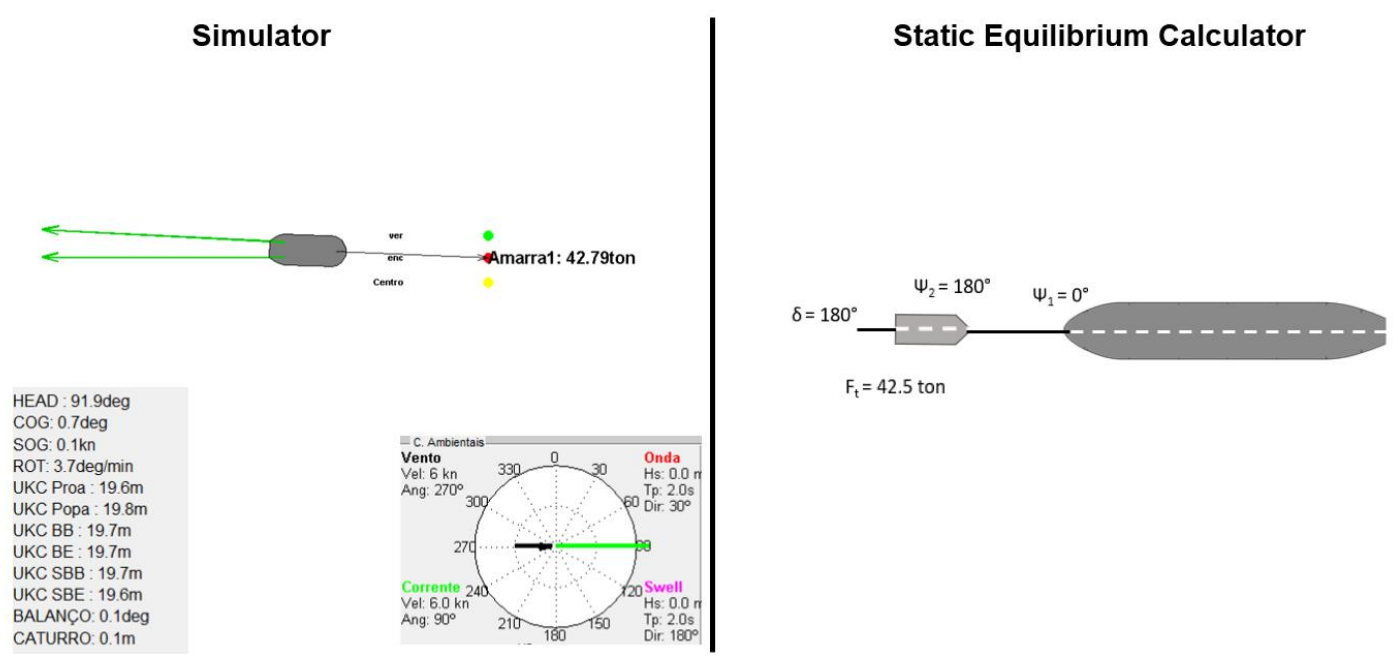

Source: Author

Figure 107 - Results comparison for the $45^{\circ}$ case at 6 knots speed

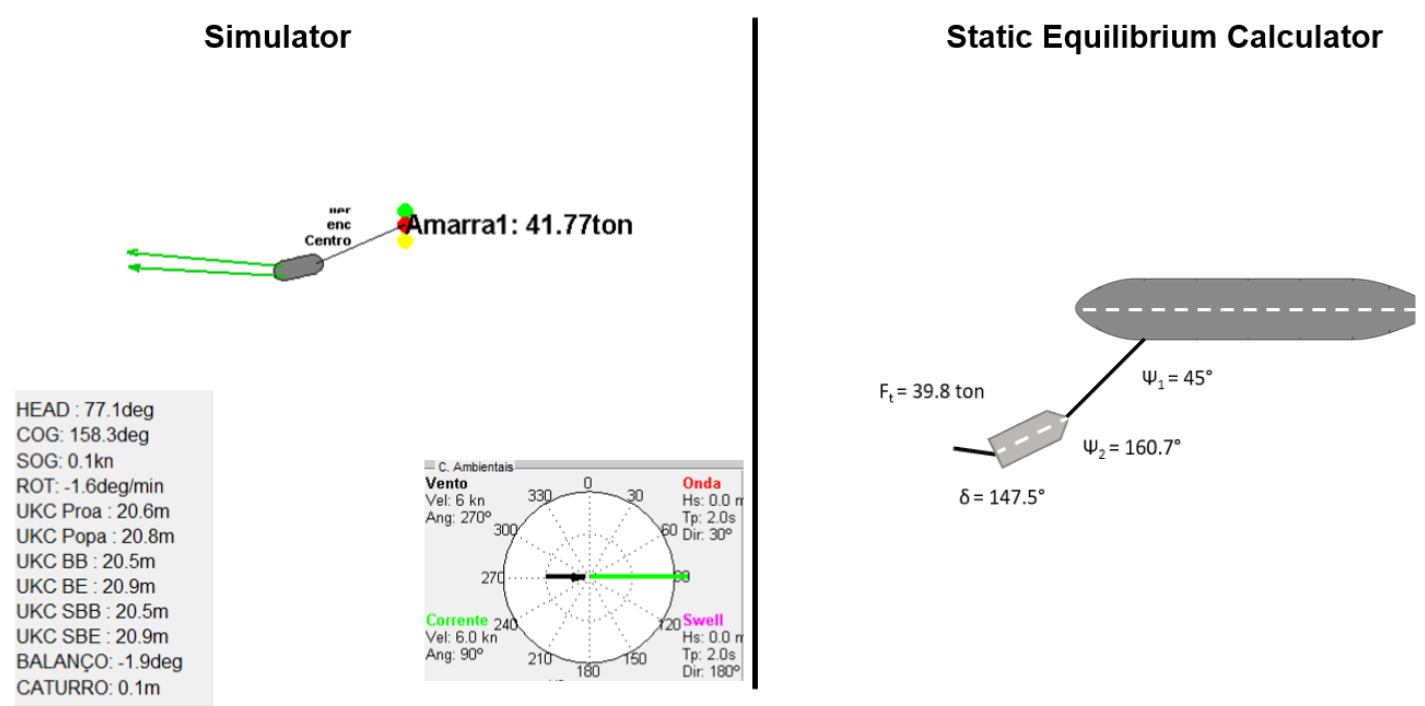

Source: Author 
Figure 108 - Results comparison for the $90^{\circ}$ case at 6 knots speed

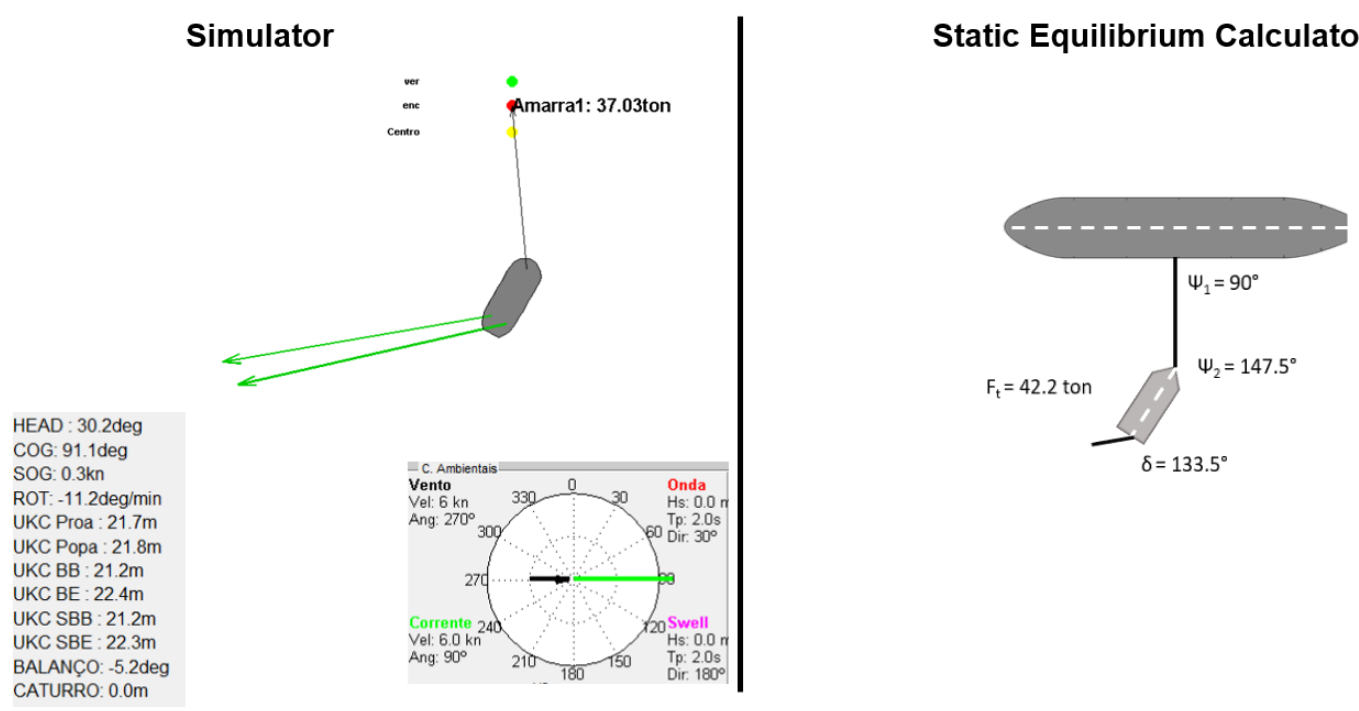

Source: Author

Figure 109 - Results comparison for the $135^{\circ}$ case at 6 knots speed

HEAD : 337.0 deg COG: $34.6 \mathrm{deg}$ SOG: $0.0 \mathrm{kn}$ ROT: $-0.2 \mathrm{deg} / \mathrm{min}$
UKC Proa : $22.7 \mathrm{~m}$ UKC Popa : $22.8 \mathrm{~m}$ UKC BB : $22.0 \mathrm{~m}$ UKC BE : $23.5 \mathrm{~m}$ UKC SBB : $22.0 \mathrm{~m}$ UKC SBE : $23.5 \mathrm{~m}$ BALANCO: $-6.7 \mathrm{deg}$ CATURRO: $0.1 \mathrm{~m}$

\section{Simulator}

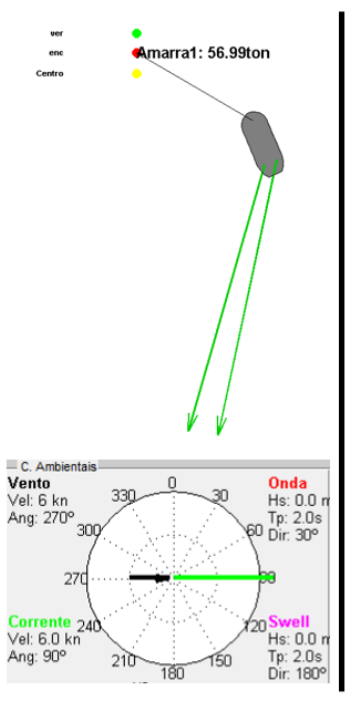

Static Equilibrium Calculator

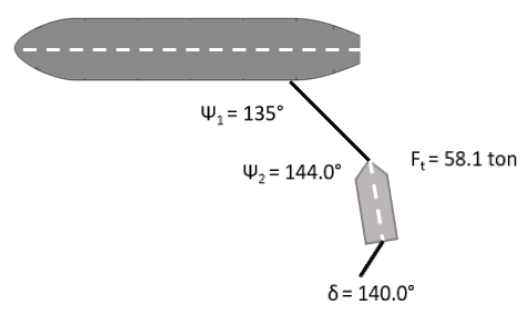

Source: Author 
Figure 110 - Results comparison for the $180^{\circ}$ case at 6 knots speed

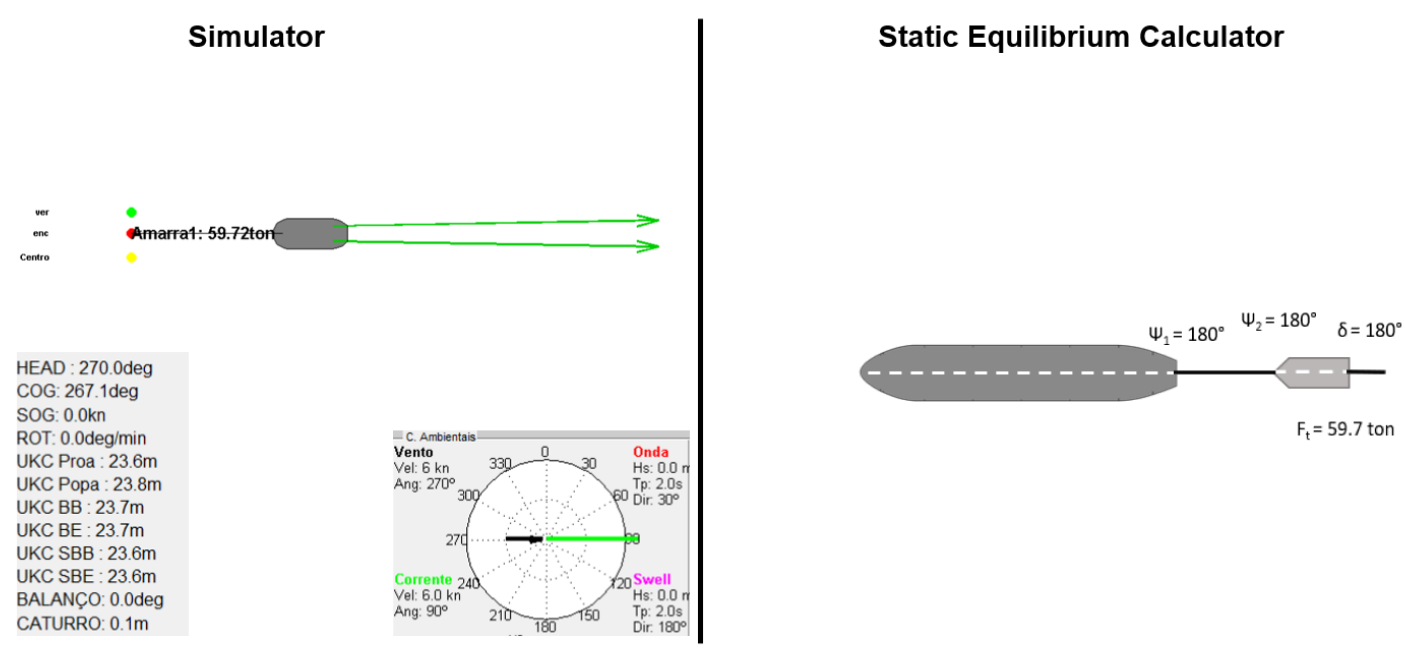

Source: Author 


\subsection{Push Mode}

Unfortunately, the TPN-USP simulator is still finishing its Push Mode model, thus no validation could be perform using its infrastructure.

After reviewing the literature, there are two main works that predict tugboat operation in push mode: (BRANDNER, 1995) and (ARTYSZUK, 2013). Although such works are extremely valuable and were the main inspirations for this thesis, they do not consider friction forces which, as shown in section 5.3, have considerable importance on the model proposed. Therefore, no validation could be performed. We hope that the present work inspires many others to investigate and develop new models taking in consideration friction forces, in such a way that more result become available in the literature. 


\subsection{Pull Mode - Indirect Maneuver}

\subsubsection{Literature Validation}

When discussing the effectiveness difference between the direct and the indirect maneuvers, it is not unusual to see a comparison diagram which presents the steering forces for each maneuver as a function of the advance speed of the assisted vessel. In Figure 111 such comparison diagram is presented for a 36ton bollard pull tractor tug (HENSEN, 2003).

Figure 111 - Approximations of steering forces of a 36-tons tractor tug

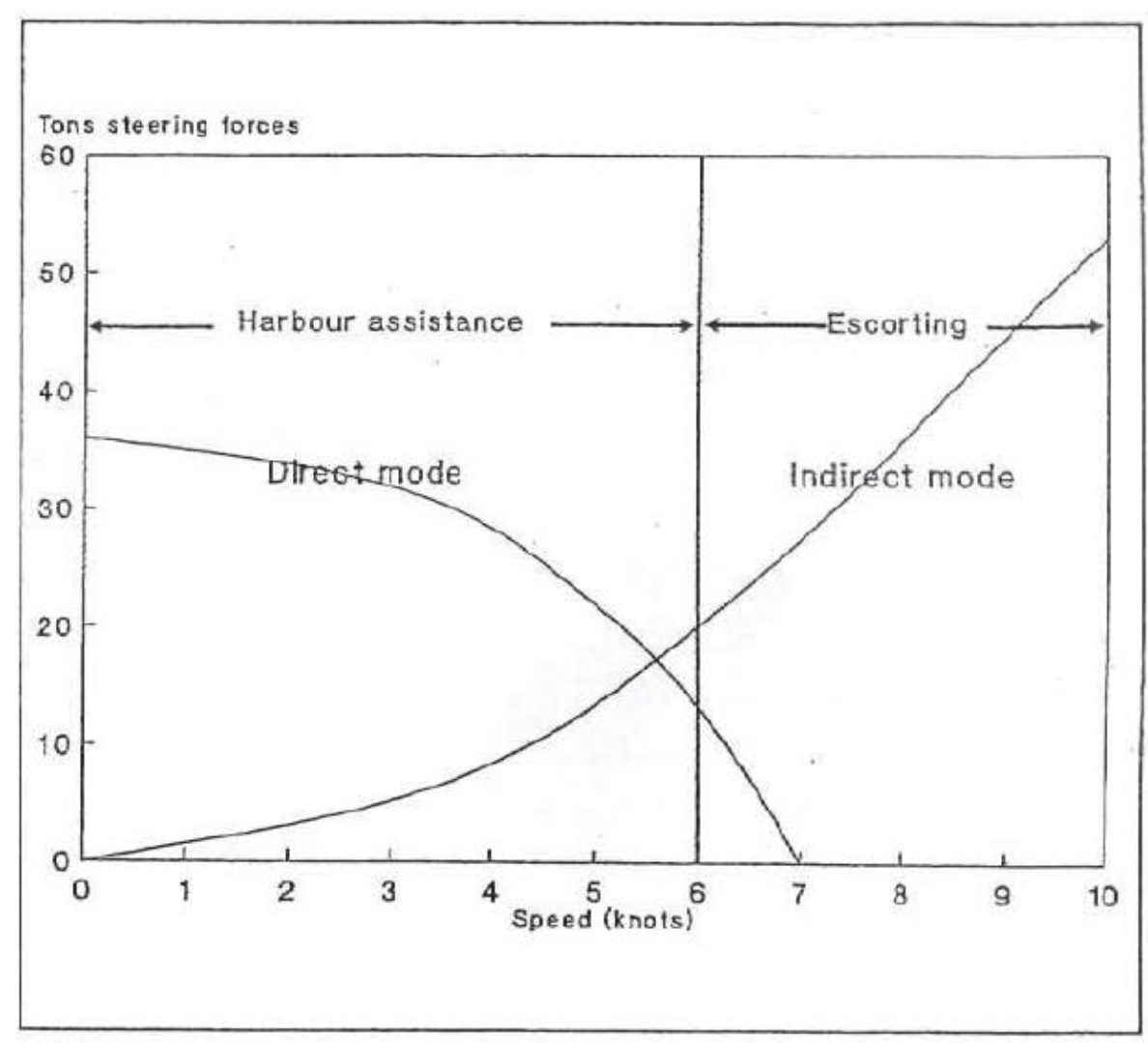

Source: (HENSEN, 2003)

The main difference between the tractor tug used to obtain the chart and the ASD tug modeled throughout this work is the location of the propellers. While the ASD has two azimuthal propellers located on its aft part, the tractor tug has two azimuthal propellers located on its forward part, as shown on Figure 112. Therefore, a tractor tug working with a towline located on its aft may have a similar configuration of an ASD tugboat working with its connection point on the bow. 
Figure 112 - Example of a tractor tug

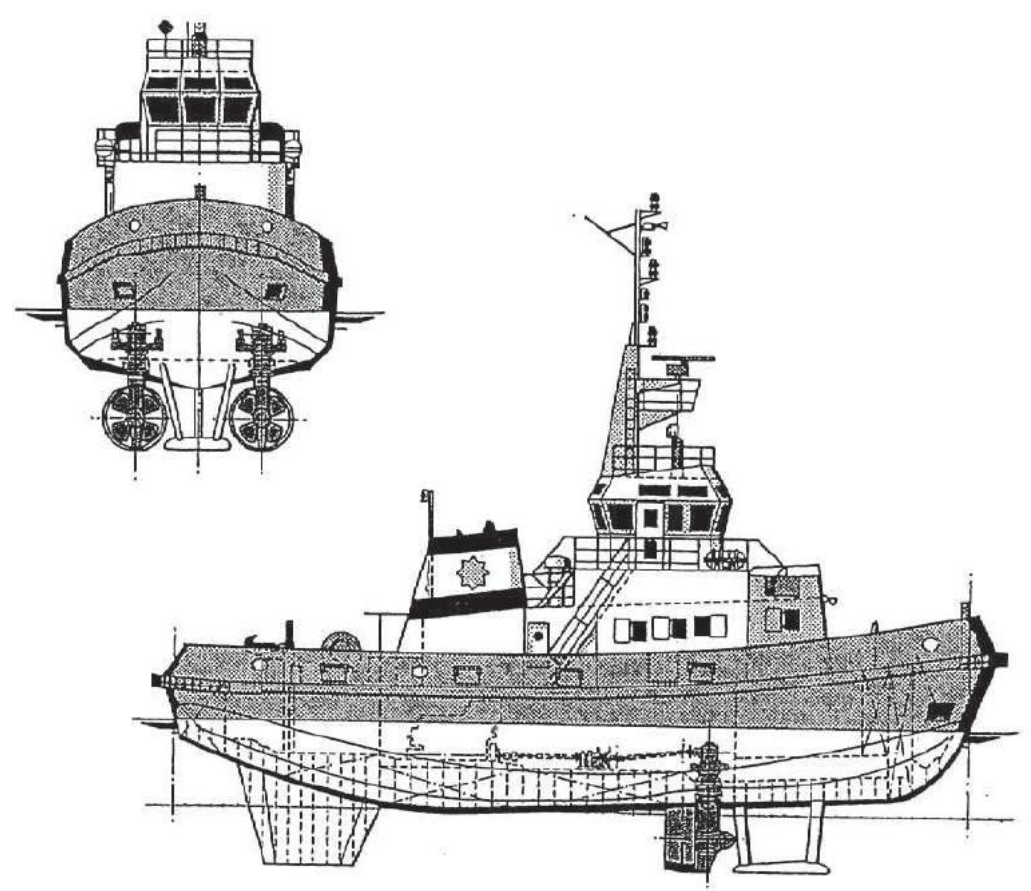

Source: (HENSEN, 2003)

Although no information regarding the tugboat's characteristics are provided besides the bollard pull of 36-ton (i.e., draft, beam, length), one could roughly use the charts provided in order to validate the indirect maneuver model proposed.

In Figure 113, a comparison chart is developed using the results from the models proposed for both the direct and the indirect maneuver applied for a regular 36ton ASD. Besides the change in the bollard pull, the tugboat's characteristics are kept the same, as previously shown in Table 5. In order to follow the chart specification, for the direct maneuver, a towline angle of $90^{\circ}$ was kept constant, thus the steering force being the same as the towline force. For the indirect maneuver, the results are retrieved for the solution where the steering forces are maximized, or in other words, for the solution closest to the towline angle of $90^{\circ}$ (set of solutions 1 of section 5.3.1 but for a 36 ton tugboat). Note that, based on the formulation proposed, under $6 \mathrm{kn}$, several solutions for both the indirect and direct maneuver are be the same. Therefore, the indirect results were retrieved only for speeds above $6 \mathrm{kn}$. 
Table 12 - Results obtained for the Direct and Indirect maneuvers

\begin{tabular}{|c|c|c|c|c|c|}
\hline & \multicolumn{3}{|c|}{ Escort Tug } & \multicolumn{2}{|c|}{ Regular ASD } \\
\hline & $\Psi_{1}$ & $\mathbf{F}_{\mathrm{T}}$ & $\mathbf{F}_{\text {steering }}$ & $\Psi_{1}$ & $F_{\mathrm{T}}=\mathbf{F}_{\text {steering }}$ \\
\hline 0 kn & $x$ & $x$ & $x$ & $90^{\circ}$ & 36.0 \\
\hline 1 kn & $x$ & $x$ & $x$ & $90^{\circ}$ & 35.9 \\
\hline 2 kn & $x$ & $x$ & $x$ & $90^{\circ}$ & 35.7 \\
\hline $3 \mathbf{k n}$ & $x$ & $x$ & $x$ & $90^{\circ}$ & 34.9 \\
\hline 4 kn & $x$ & $x$ & $\mathrm{x}$ & $90^{\circ}$ & 32.8 \\
\hline 5 kn & $x$ & $x$ & $x$ & $90^{\circ}$ & 29.0 \\
\hline $6 \mathrm{kn}$ & $154^{\circ}$ & 41.0 & 17.9 & $90^{\circ}$ & 25.0 \\
\hline 7 kn & $138^{\circ}$ & 45.5 & 30.5 & $90^{\circ}$ & 0.0 \\
\hline 8 kn & $123^{\circ}$ & 49.5 & 41.5 & $x$ & $x$ \\
\hline 9 kn & $113^{\circ}$ & 50.2 & 46.2 & $x$ & $x$ \\
\hline $10 \mathrm{kn}$ & $105^{\circ}$ & 49.2 & 47.6 & $x$ & $x$ \\
\hline
\end{tabular}

Source: Author

Figure 113 - Direct/Indirect comparison chart for proposed models

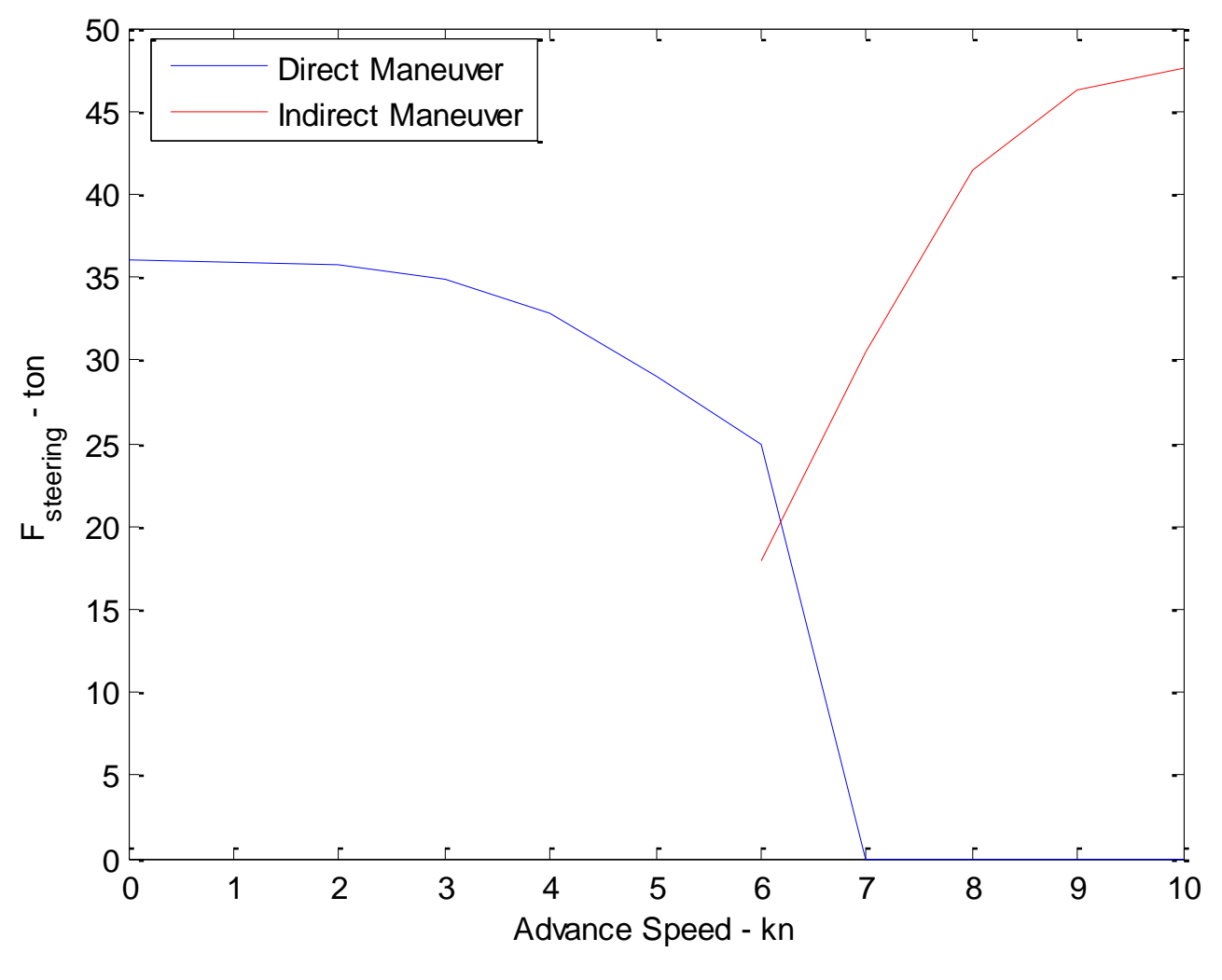

Source: Author

By comparing both charts, one may realize that both de direct and indirect curves have similar configurations. The direct maneuver is more effective for maneuvers 
under $6 \mathrm{kn}$ and the indirect maneuver is more effective for maneuvers above 6 $\mathrm{kn}$. In addition, one may realize that, for speeds of $10 \mathrm{kn}$, the steering forces have an efficiency of $132.2 \%$ with respect to the tug's bollard pull. Note that, as mentioned, the results retrieved were the ones obtained as close as possible to the $90^{\circ}$ towline angle. However, as shown on section 5.3, the indirect results where the towing force are maximum (i.e., results obtained for larger towline angles) may reach up to 2 times de tugboat's bollard pull.

\subsubsection{Simulator Validation}

The indirect maneuver is extremely complex from an execution standpoint, thus requiring tugboat commandants to perform several training exercises prior to its execution on the sea. The main difficulty occurs due to the high current speeds generated by the vessel's advance speed, which difficult the tugboat control.

Although the same nautical official was present to perform this validation, he was not familiarized and did not have special training with respect to the indirect maneuver, thus difficulting the validation process. For this reason, it was decided that the validation would only be performed for the $10 \mathrm{kn}$ scenario, in a dynamic way. In other words, the nautical official would try to reach the configuration where the towing force was maximum for the Escort Tug $10 \mathrm{kn}$ Indirect scenario using active control of the propellers, and, when reaching such position, stay as static as possible in such a way that the dynamic towline effects would not compromise the validation.

In Figure 114 the forces on the towline are present for the time interval where the tugboat was being active controlled in the indirect maneuver. Based on this data, one may obtain the mean towline force to be 104.8 ton which provides a $7.12 \%$ error when compared to the towline force obtained using the proposed model for the same situation (112.3 ton).

The tugboat configuration at around $t=310 \mathrm{~s}$ is also shown in Figure 115 - Left. Based on this Figure, one could obtain the tugboat's heading angle to be $\beta_{t}=235.1^{\circ}$. By using Eq. (30), with a towline angle of $\Psi_{1}=134^{\circ}$, one could 
obtain the a towline-tugboat relative angle to be $\Psi_{2}=260^{\circ}$. By comparing such value to the theoretical $\Psi_{2}=264.3^{\circ}$, one may obtain an error of $4.3^{\circ}$.

Figure 114 - Forces on the towline during validation

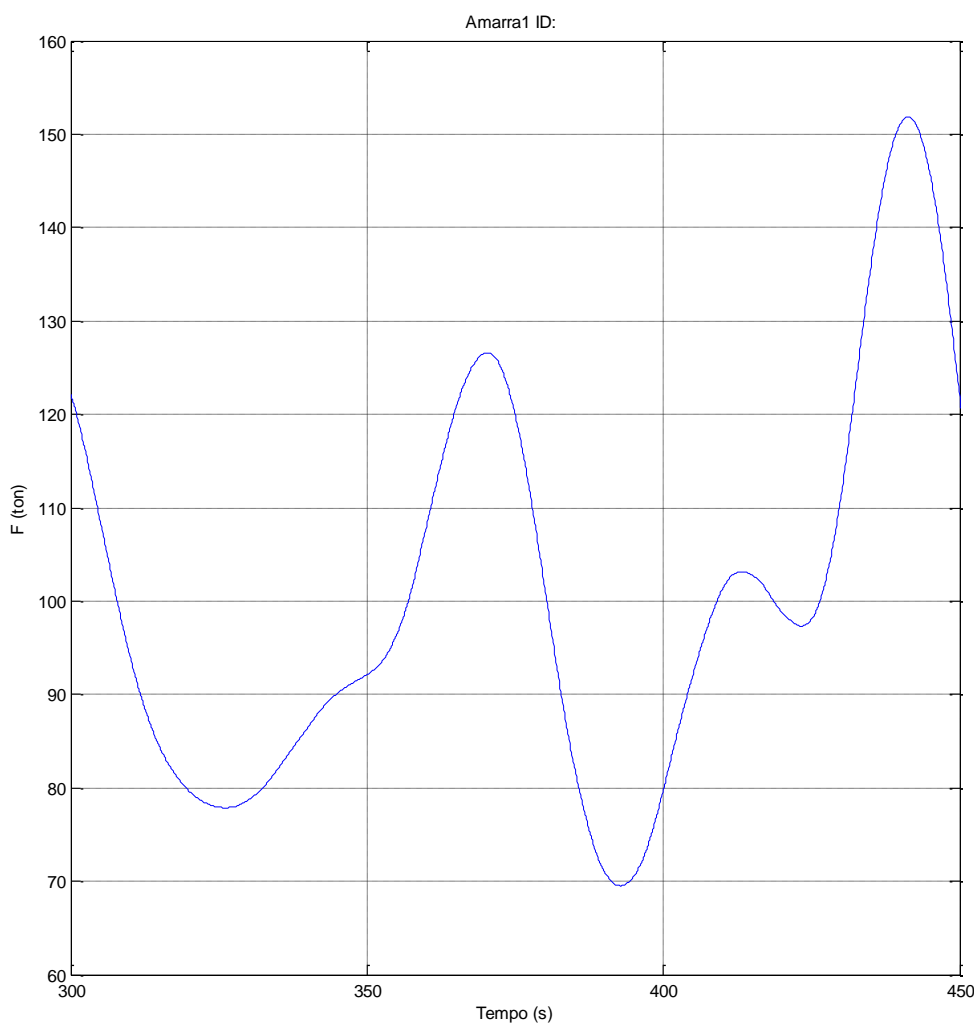

Source: Author

Figure 115 - Comparison between theoretical and simulated results

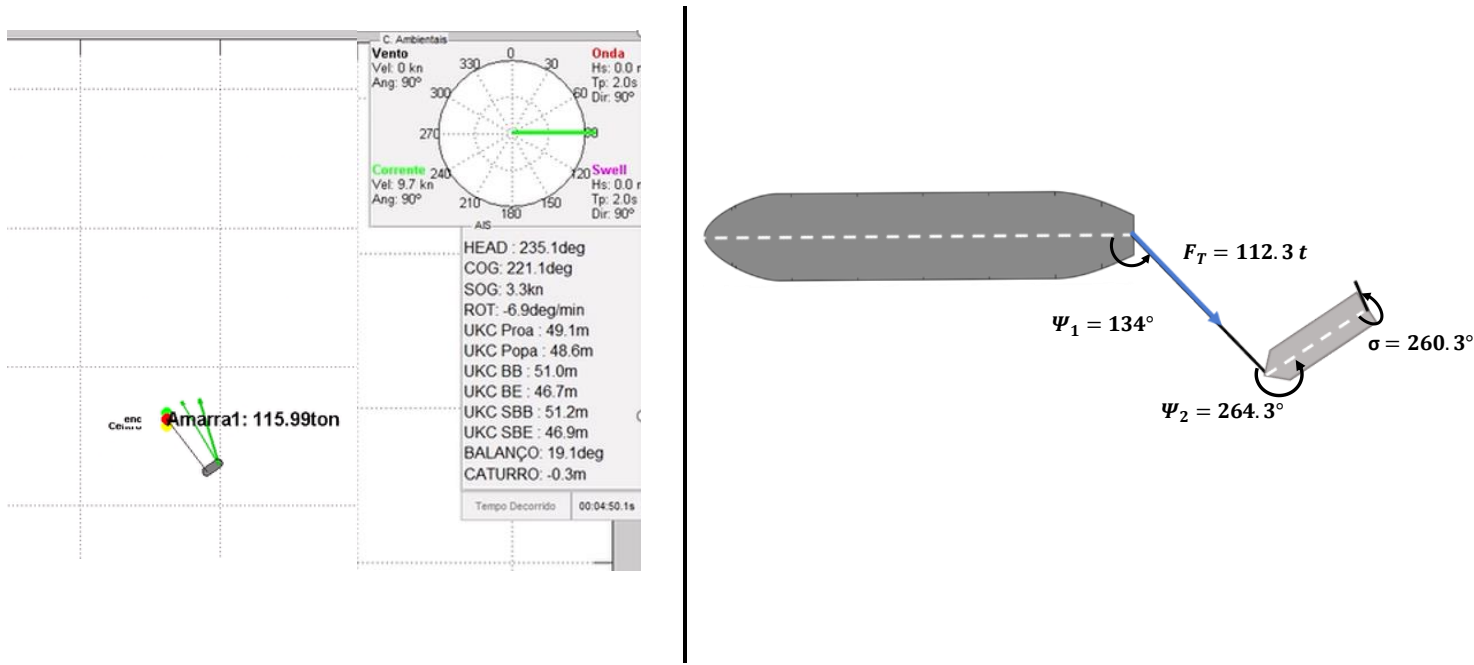

Source: Author 


\section{TUGBOAT DYNAMIC IN WAVES - TOWLINE PEAK LOAD CASE STUDIES}

In this section, both the Regular ASD and the Escort tug presented on section 5.3 will be analyzed regarding their wave motion behavior, more specifically, with focus on the towline peaks experienced during a pure breakage maneuver (tugboat pulling the vessel longitudinally astern) of a LNG vessel in the Açu port - Rio de Janeiro. This port is infamous for being the one where tugboats have the most difficulty to actuate, specifically because the severe wave conditions. All the 3 Escort tugs presented in Brazil are currently operating in this port due to their capability in working under the presence of waves.

As shown in section 3.5, the towline length variation due to the presence of waves is given by $\mathrm{dL}$. By assuming that the towline length behaves as a spring, and polyester as the towline material, the total force on the towline may be given by Eq. (44). Note that no catenary effects were considered.

$$
F_{\text {total }}=F_{t}+\frac{E A}{L} * d L
$$

where:

$L$ is the towline length

$E$ is the polyester Young's Modulus

$A$ is the towline circular area

$E A=28,167 \mathrm{KN}$

For the following experiments, performed at the TPN simulator, the LNG vessel was entering the Açu port channel with an initial speed of $8 \mathrm{Kn}$. No external current or wind was added to the system, besides the one generated by the vessel's advance speed. A constant typical wave condition of that region was present: $H_{s}=1.6 \mathrm{~m}, T_{p}=9 \mathrm{~s}$, Dir. $45^{\circ}$. Both the Escort and the Regular ASD tugboats were pulling the vessel longitudinally with full power (60 tons) for around 120 seconds and their towline forces were recorded for analysis. For each tugboat, 3 specific towline lengths were used: $60 \mathrm{~m}, 80 \mathrm{~m}$ and $100 \mathrm{~m}$. Figure 116 represents the initial configuration of the experiments. 
Figure 116 - Experimental Setup

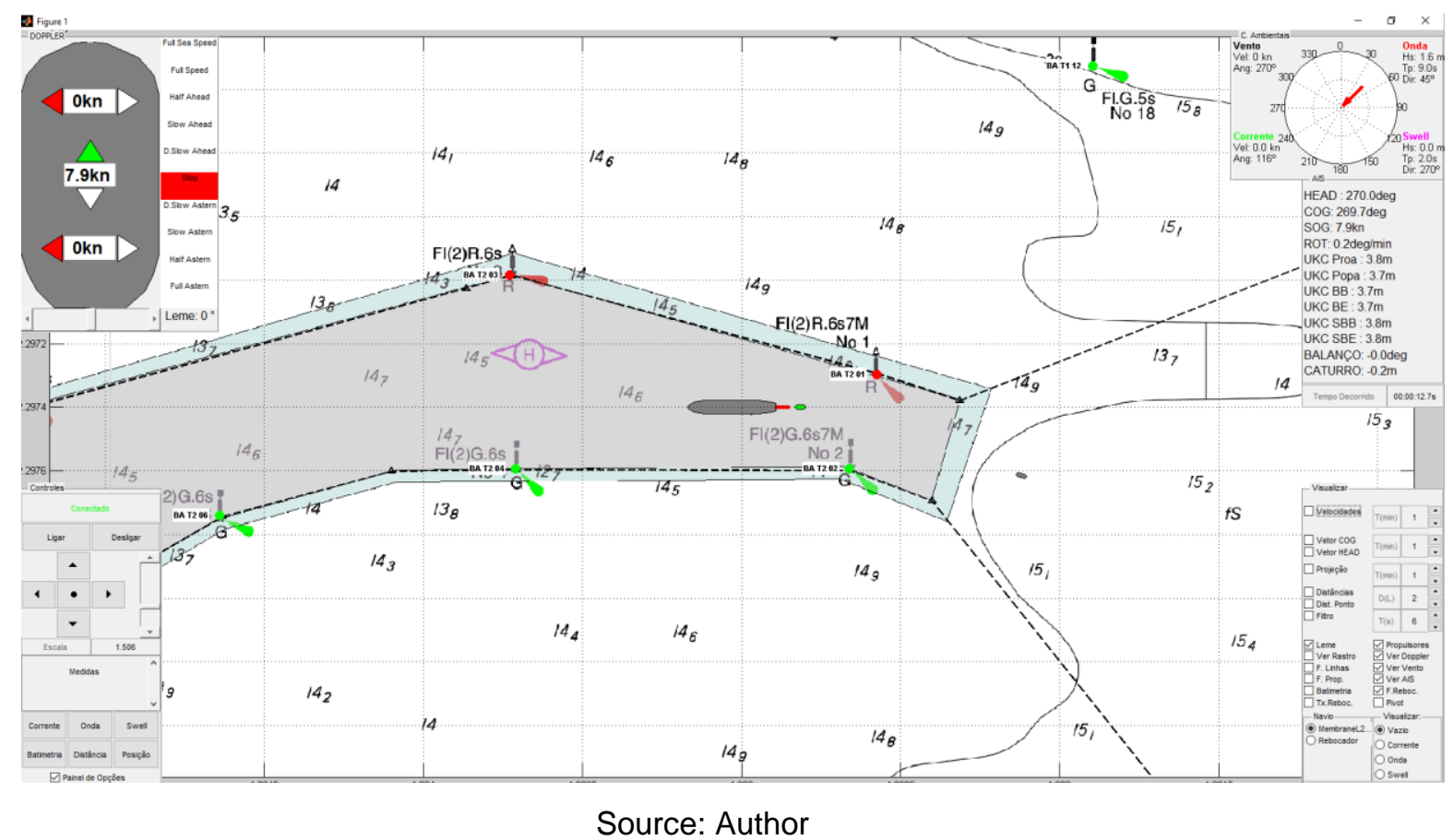

\section{$\underline{\text { Regular ASD Tugboat: }}$}

From Figure 117 to Figure 119 one can observe the obtained results for each towline length. By observing these graphs, one can realize that for every scenario, the towline reached a force of 0 tons or, in other words, the towline loosened. During operation, if the towline begins to get loose due to wave motion, the tugboat commandants immediately let the pilot aware that they cannot actuate on that specific region. This is the case because when the towline gets loosened, larger dynamic peaks may occur, possibly damaging or breaking the towline and making the tugboat unresponsive for Pull maneuvers.

During a simulation, one of the most important analyzed aspects with respect to tugboats is the peak on the towline. If the peaks are too severe, or if the towline gets loosened, a tugboat may not actuate on that region, thus direct impacting on the maneuver feasibility analysis.

From the obtained results, it is clear that larger towline lengths decrease the peak magnitude on the towline. However, since the towline got loose for every 
simulated scenario using Regular ASD tugboats, one may conclude that they cannot be used for escorting under severe wave conditions as the one applied.

Figure 117 - Peaks for towline length of $60 \mathrm{~m}$ - Regular ASD

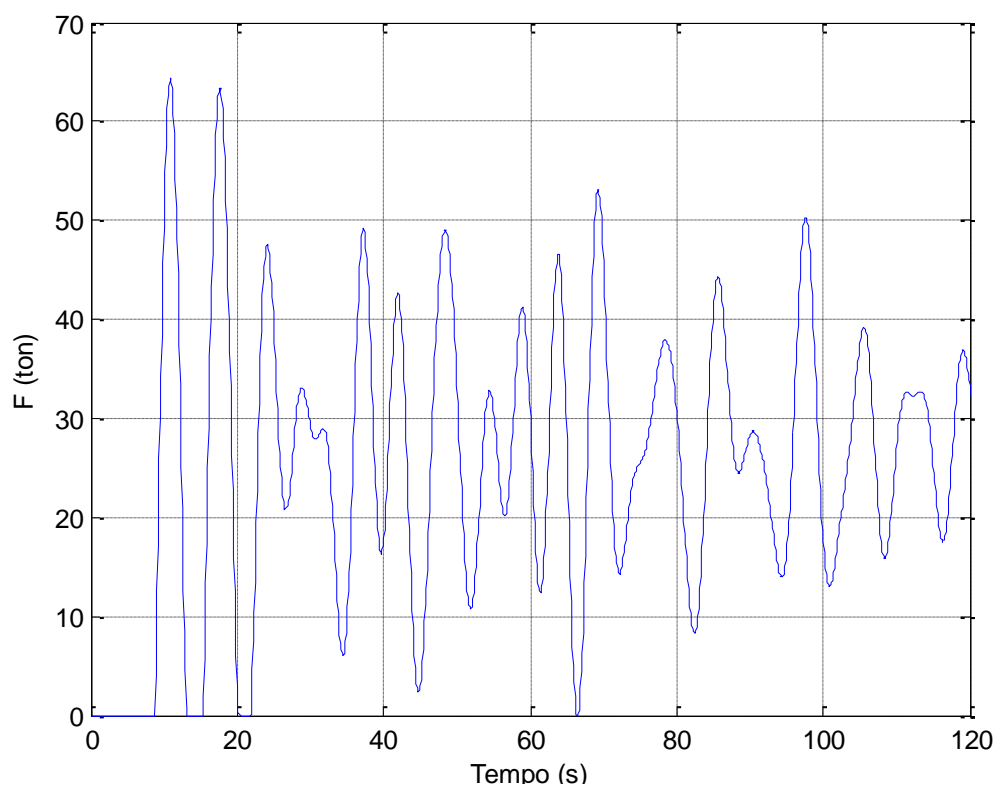

Source: Author

Figure 118 - Peaks for towline length of $80 \mathrm{~m}$ - Regular ASD

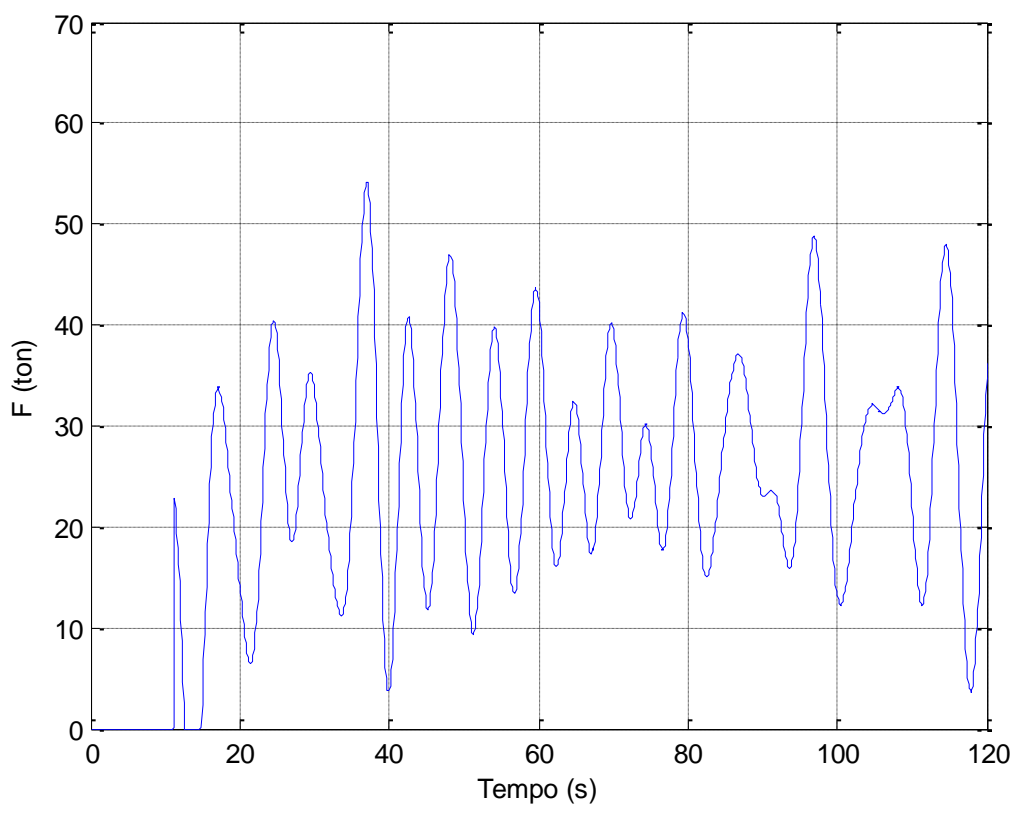

Source: Author 
Figure 119 - Peaks for towline length of $100 \mathrm{~m}$ - Regular ASD

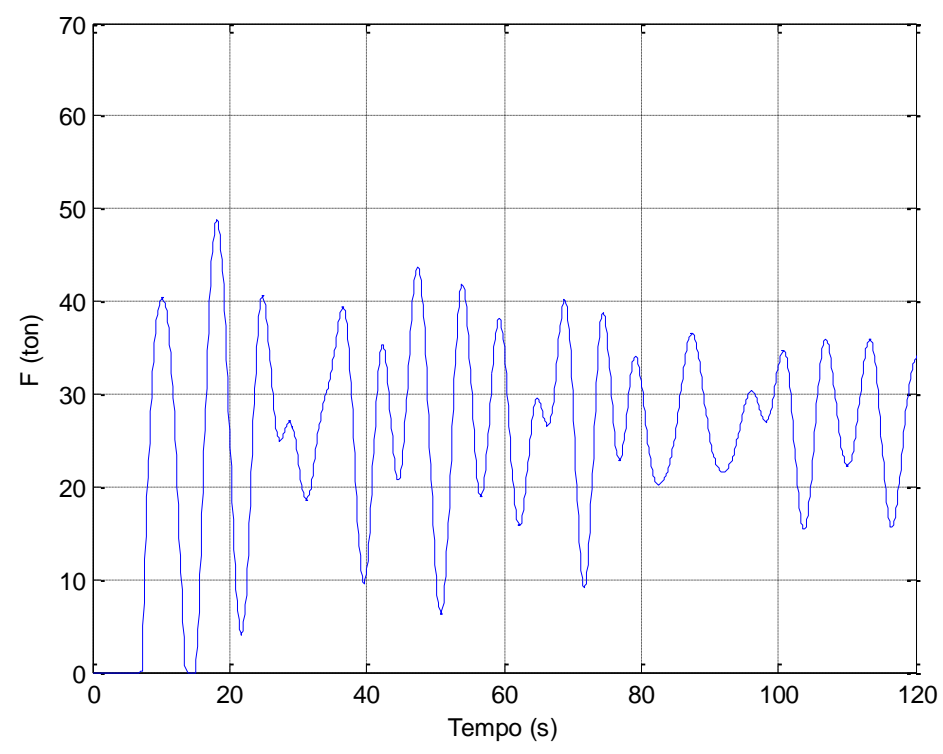

Source: Author

\section{Escort Tug:}

Similarly to what was seen for the Regular ASD tugboats, the increase on the towline length diminished the magnitude of towline peaks, as seen from Figure 120 to Figure 122. However, by analyzing the results, one can realize that the towline did not reach any loose scenario, thus showing that Escort tugs may actuate on severe wave conditions as the one applied. In addition, it is possible to see that the efficiency of the Escort Tugs is around $30 \%$ larger than the Regular ASD tugs for the same wave condition. This happens mainly due to the winch adopted. Escort Tugs have render-recovery winches, increasing and decreasing the towline length according to the wave motion in such a way that the efficiency losses are mitigated 
Figure 120 - Peaks for towline length of $60 \mathrm{~m}$ - Escort Tug

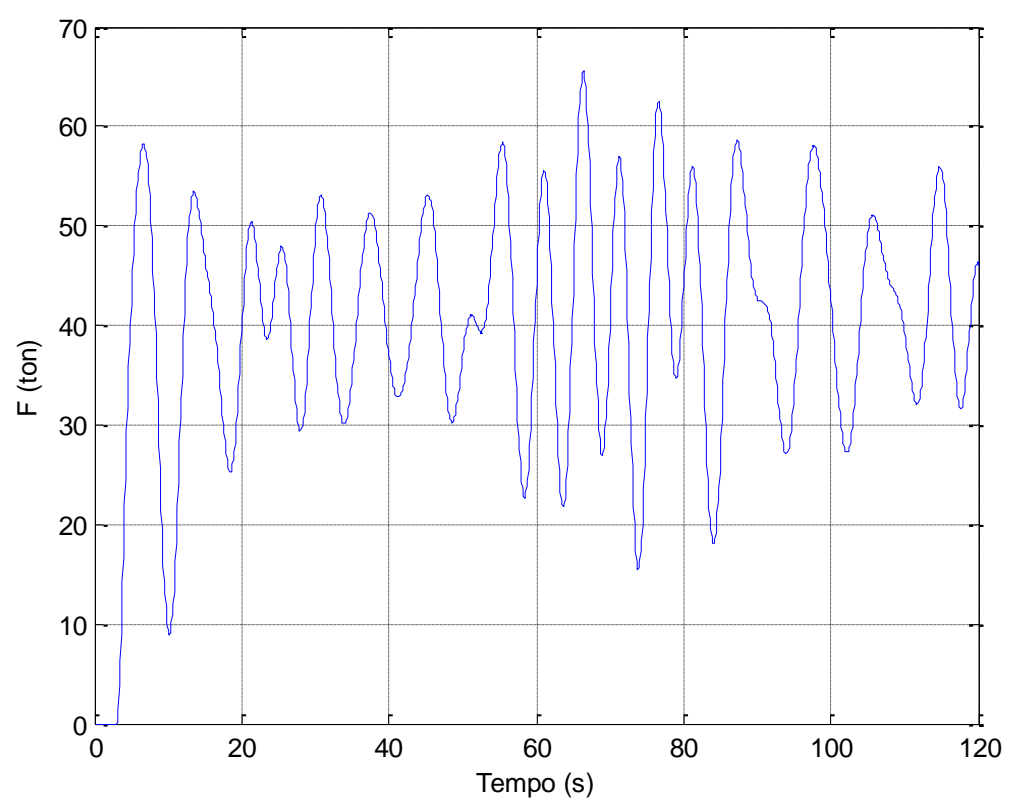

Source: Author

Figure 121 - Peaks for towline length of $80 \mathrm{~m}$ - Escort Tug

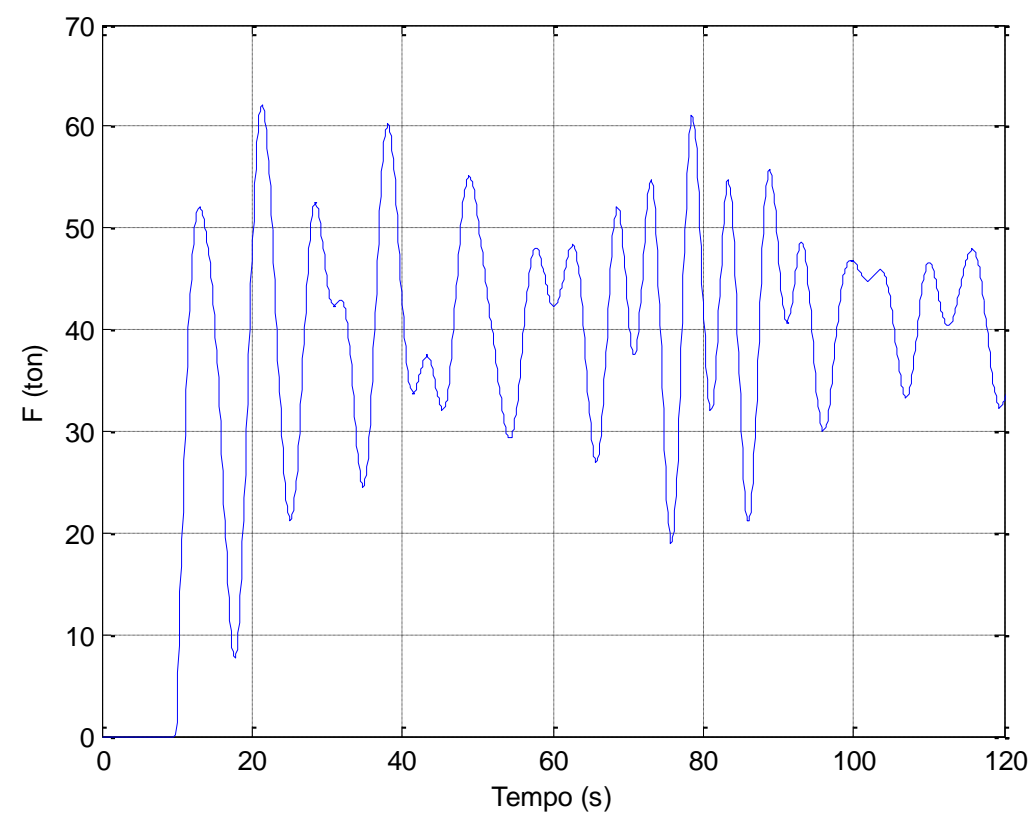

Source: Author 
Figure 122 - Peaks for towline length of $100 \mathrm{~m}$ - Escort Tug

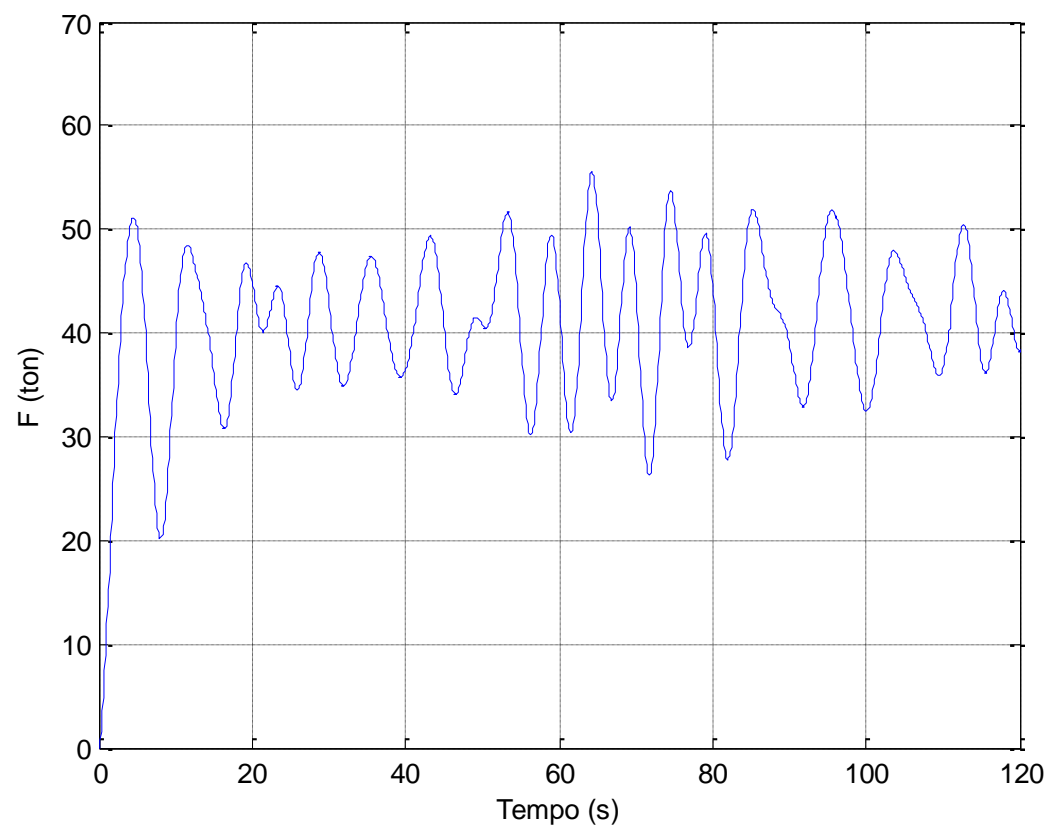




\section{VECTOR TUG RESPONSE TIME MODEL}

In order for a vector tug actuation model to be realistic, more than just the towing force and tugboat towing static equilibrium positions are necessary. One must also model the tugboat's movements around a vessel. Since the vector tugs do not model the tug dynamic, one must model the kinematics for different situations during a tugboat's assisting maneuver. In this work, 3 specific situations were model. In the first one (Figure 123), the tugboat does not experience any translating movements, it only rotates around a fixed point. Such situation occurs frequently when the tugboat is actuating on either Push or Pull modes. If actuating in Push mode, it will be rotating around the contact point with the vessel; if actuating in Pull mode, it will be rotating around the towline's contact point.

Figure 123 - Situation 1: tugboat only experiences rotation

Push

Pull
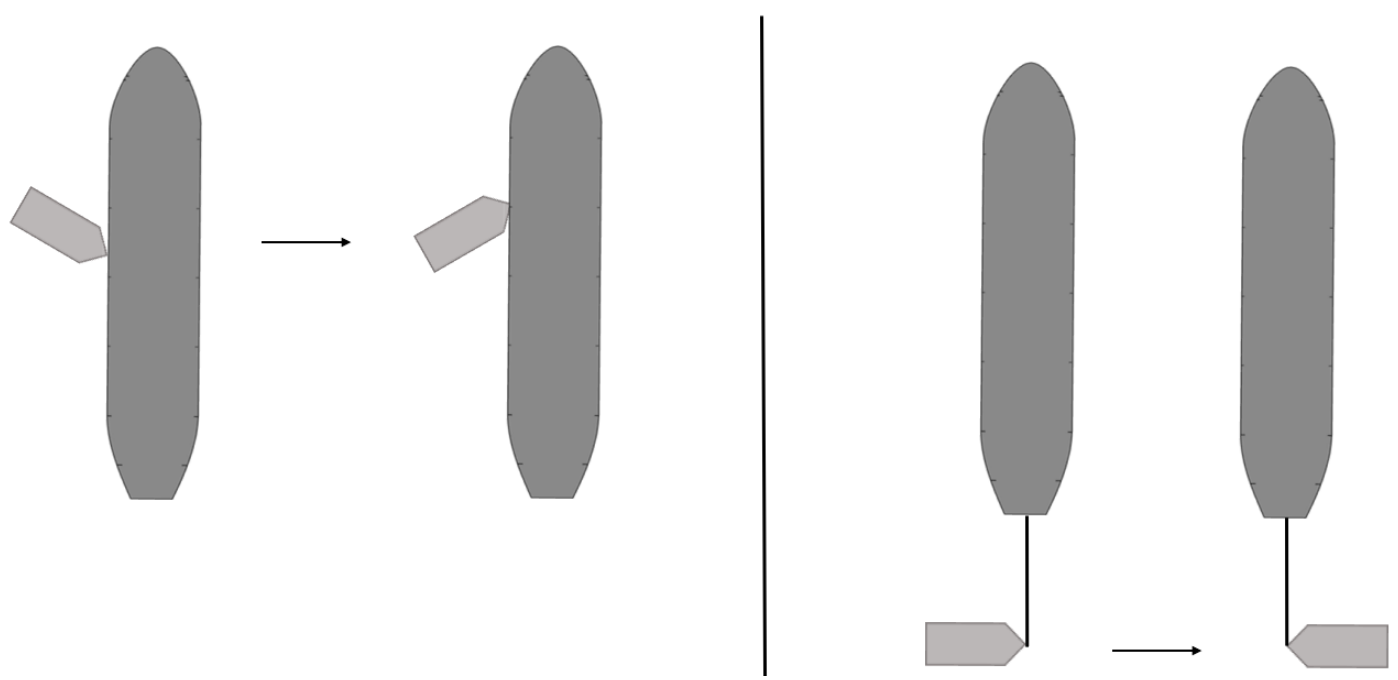

Source: Author

In the second situation, the tugboat will be transitioning from either Push mode to Pull mode or vice-versa (Figure 124). Note that these transitioning movements are neither straightforward nor linear. When a tugboat reaches a Push position, its speed must be relatively slow in order to not danify the towed vessel's hull. Similarly, the tugboat must reach a Pull position under slow speed in order to not 
danify the towline (i.e., the towline can support large static loads, but the same is not true for dynamic loads).

Figure 124 - Situation 2: tugboat transitioning between push and pull modes

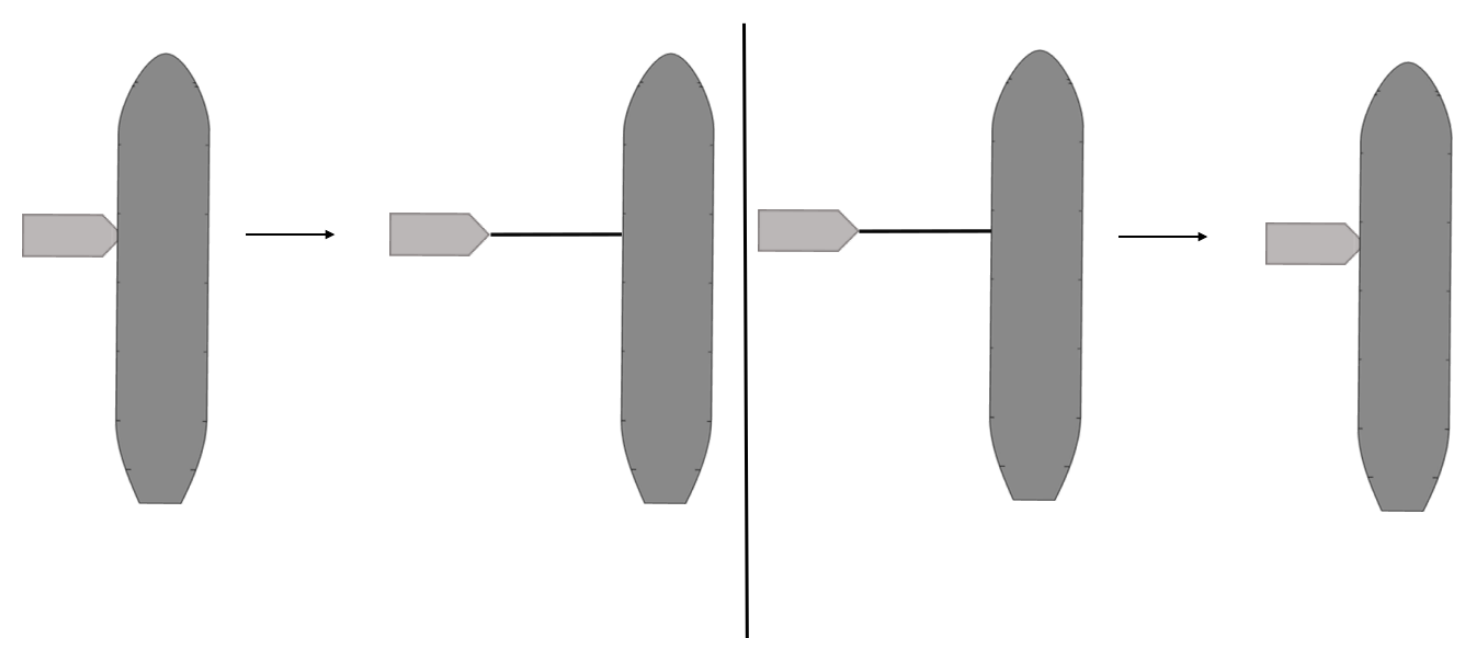

Source: Author

Finally, the third situation will be the movements a tugboat performs when actuating on pull mode. During a towing maneuver, the pilot usually requests tugboats (especially the ones working on the bow and on the stern) to keep changing sides, going from port to starboard, or vice-versa. Such transition times must also be considered (Figure 125). 
Figure 125 - Situation 3: tugboat transitioning from port to starboard

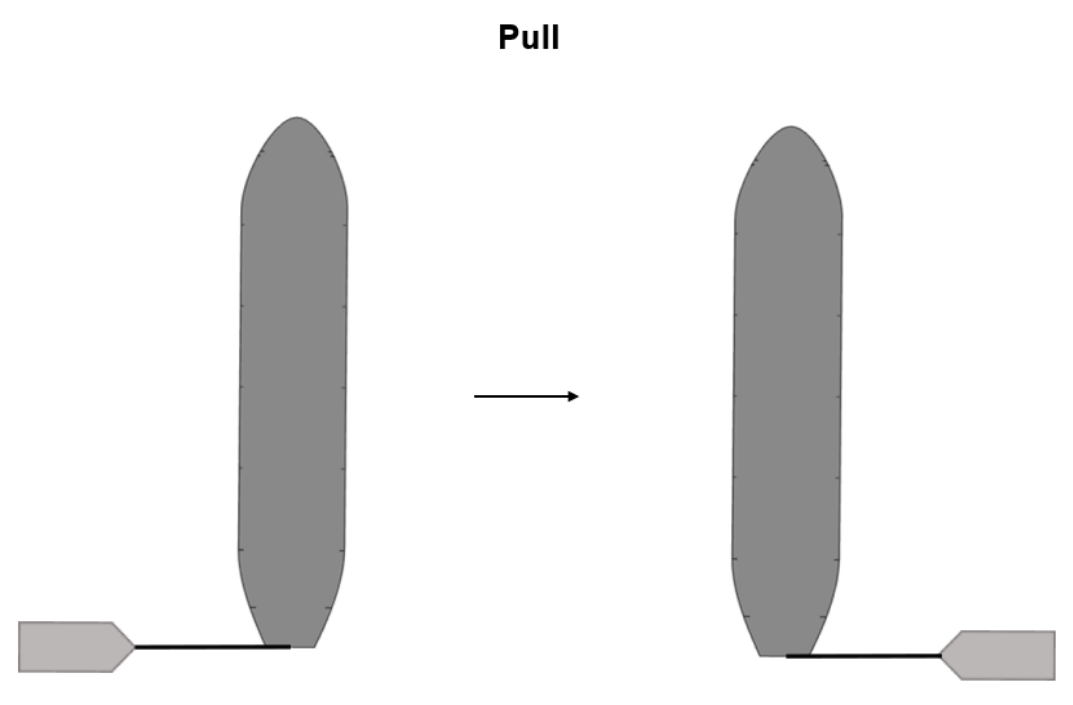

Source: Author 


\subsection{Situation 1: Tugboat Rotating About a Fixed Point Without Translation}

In (FUCHS and HUAN, 2015), several experiments were proposed and performed in order to gather enough information to validate ASD tugboat models on SMS. All the experiments were performed with the tugboat THOR (Figure 126), which is a Robert Allen Ltd. Z-tech design, "equipped with $2 \times 3,150 \mathrm{HP}$ medium diesel Caterpillar engines with two five bladed right handed ASD units." "The engine RPM ranges from approximately 650 (idle) to 1800. The gear reduction is approximately 7.35 resulting in RPM at the propeller on the azimuth drives to be 80 to 145 ." All the tugboat specifications may be seen on Table 13.

Figure 126 - Tugboat THOR

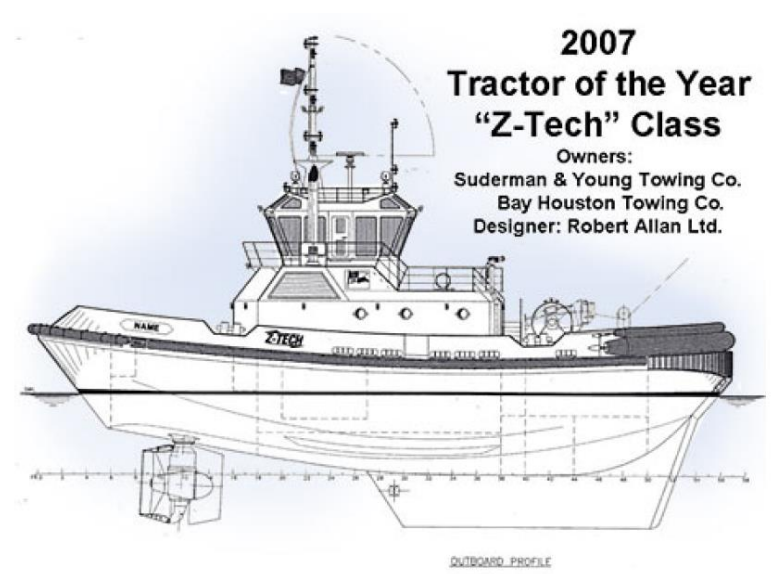

Source: FUCHS and HUAN, 2015

Table 13 - Specifications of tug THOR

\begin{tabular}{|c|c|c|c|c|c|}
\hline Hull & & Engines & & Propellers & \\
\hline LOA [m] & 30.00 & CAT $3516 \mathrm{~B}$ & 2 & Schottel SRP 1520 & 2 \\
\hline Breadth, Mold [m] & 12.00 & Power, Total [HP] & 6,300 & Number & 2 \\
\hline Depth, Mold [m] & 5.00 & Speed Max [RPM] & 1,800 & Blade Numbers & 5 \\
\hline Draft, Max [m] & 5.18 & Speed Idle [RPM] & 650 & Rotate Direction & RHD \\
\hline Speed [knots] & $>13$ & Gear Ratio & 7.35 & Diameter [m] & 2.70 \\
\hline Bollard Pull & & Ahead [t] & 75 & Astern [t] & $70+$ \\
\hline
\end{tabular}


One of the tests performed using THOR was to check how fast it would rotate $360^{\circ}$ around its central axis, without any translation (the times for the movement of a tugboat navigating around a vessel will be shown on section 8.3). For the first test, no additional engine power was input besides the idle one that keeps the propellers constantly rotating in 650 RPM. During this test, THOR took around 30 seconds to complete $360^{\circ}$. On the second test, full engine power was applied. At this time, THOR took 16 seconds to rotate $360^{\circ}$. Based on such tests and using an average approach, we can extrapolate the results and assume that any vector tug working either in push mode or pull mode, will take around 23 seconds to complete a $360^{\circ}$ turn or they will rotate around $15.6^{\circ}$ per second. The information here obtained along with amount of degrees desired for a rotation (information usually input by a vector tug operator) allows us to correctly calculate the response time during such action. 


\subsection{Situation 2: Tugboat Transition Between Push and Pull Modes}

In (ISHIKURA, NAKATANI, et al., 2013), a study regarding tugboat response delay and transitioning time between pull and push modes was performed in the ports of Tokyo and Yokohama. After a certain order was given by a pilot (for a tugboat to move from push to pull or vice-versa), the researchers would use the tugboat's AIS (latitude and longitude coordinates in real-time) data in order to realize how much time this tugboat had taken to start his action and how much time it took from the initial position to the final position. On Table 14, one can see a summary of the time delay between the orders and the tugboat's action. Figure 127 shows the results obtained after several runs where tugboat was switching from Push to Pull mode; Figure 128 shows the results obtained after several runs where tugboat was switching from Pull to Push mode.

Table 14 - Time lag between tugboat's answer and action

\begin{tabular}{|c|c|c|c|c|c|}
\hline & $\begin{array}{c}\text { S/B PUSH } \\
\rightarrow \\
\text { PUSH }\end{array}$ & $\begin{array}{c}\text { S/B PUSH } \\
\rightarrow\end{array}$ & $\begin{array}{c}\text { P/B PUSH } \\
\rightarrow\end{array}$ & $\begin{array}{c}\text { S/B PULL } \\
\text { S/B PULL }\end{array}$ & $\begin{array}{c}\text { S/B PULL } \\
\rightarrow \\
\text { PULL }\end{array}$ \\
\hline Ave. (sec.) & 0.7 & 2.0 & 5.5 & 9.7 & 0.7 \\
\hline Max. (sec.) & 7.0 & 8.0 & 25.0 & 21.0 & 9.0 \\
\hline Min. (sec.) & -6.0 & -3.0 & -4.0 & 3.0 & -8.0 \\
\hline Number of Cases & 10 & 12 & 17 & 31 & 19 \\
\hline
\end{tabular}

Source: ISHIKURA, NAKATANI, et al., 2013 
Figure 127 - Transition time by every length of tug's line from Push to Pull

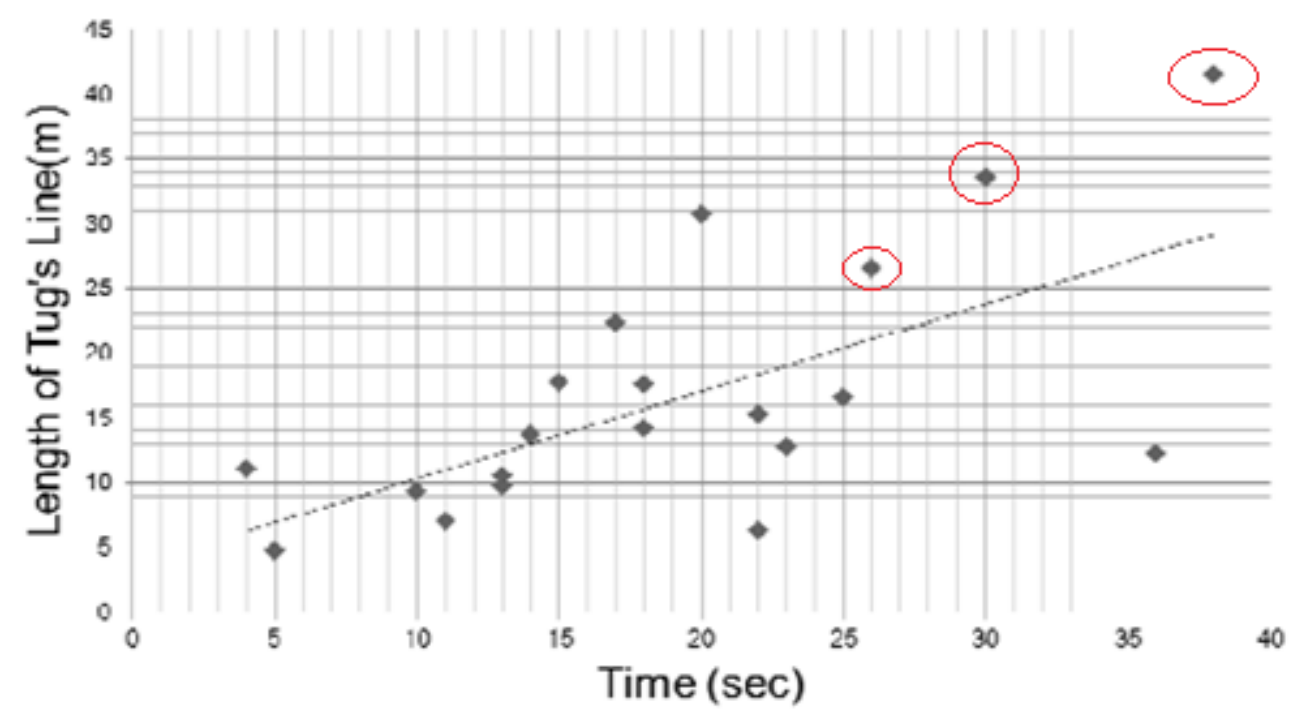

Source: ISHIKURA, NAKATANI, et al., 2013

Figure 128 - Transition time by every length of tug's line from Pull to Push

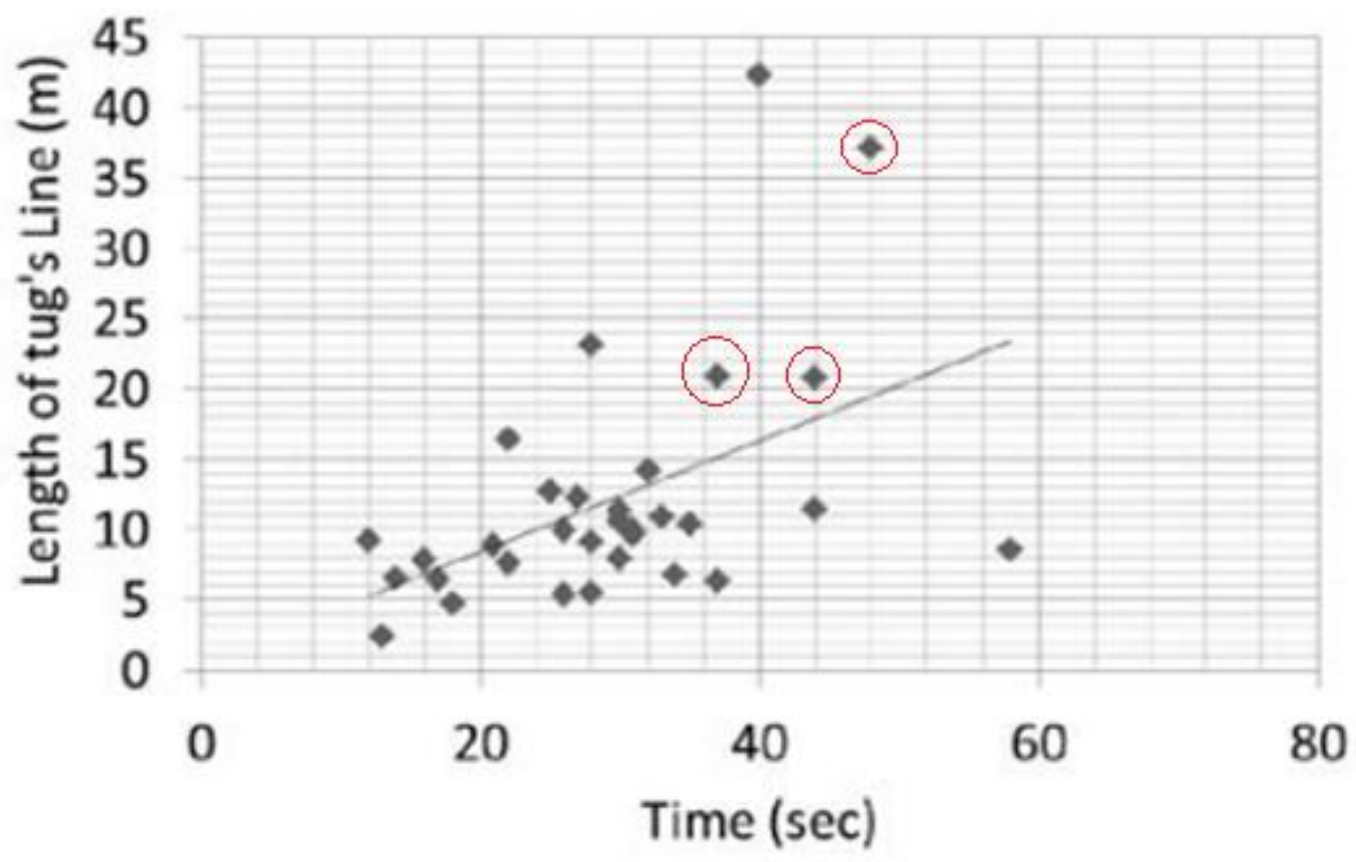

Source: ISHIKURA, NAKATANI, et al., 2013

Based on these results, the transitioning time can be linearly extrapolated between Push and Pull modes by using a towline length input by a vector tug operator and the data provided on Figure 127 and Figure 128. Note, however, 
that such extrapolation must only be performed for towline lengths smaller than $20 \mathrm{~m}$, where we have most of our data. By analyzing the figures, one may realize that for towline lengths greater than $20 \mathrm{~m}$, the linear extrapolation ends up being placed far away from the correct results.

By looking at red marks on Figure 127, one may see that, for a towline of about $40 \mathrm{~m}$, the movement time was 38 seconds; for a towline of about $33 \mathrm{~m}$, the movement time was 30 seconds; for a towline of about $26 \mathrm{~m}$, the movement time was 26 seconds. Therefore, one can infer that, when transitioning from Push to Pull, for towline lengths greater than $20 \mathrm{~m}$, the tugboat will navigate with a speed of around $1 \mathrm{~m} / \mathrm{s}$. Based on such information, the animation response for such transition may be given by Eq. (53).

$$
\text { time }[\mathrm{s}]=\frac{\text { line length }[\mathrm{m}]}{\text { navigation velocity }\left[1 \frac{\mathrm{m}}{\mathrm{s}}\right]}=\text { line length }[\mathrm{m}]
$$

By looking at red marks on Figure 128, one may see that, for a towline of about $22 \mathrm{~m}$, the movement time was 36 seconds; for a towline of about $21 \mathrm{~m}$, the movement time was 43 seconds; for a towline of about $37 \mathrm{~m}$, the movement time was 47 seconds. By assuming that the tugboat navigation speed is still $1 \mathrm{~m} / \mathrm{s}$, one may infer that the extra time taken to switch from Pull to Push mode (around $15 \mathrm{~s}$ ) is necessary in order to decelerate the tugboat avoiding damaging the vessel's hull. Therefore, one can infer that, when transitioning from Pull to Push, for towline lengths greater than $20 \mathrm{~m}$, the tugboat will end up taking the amount of time shown in Eq. (54).

$$
\begin{gathered}
\text { time }[\mathrm{s}]=\frac{\text { line length }[\mathrm{m}]}{\text { navigation velocity }\left[1 \frac{\mathrm{m}}{\mathrm{s}}\right]}+\text { time }_{\text {deceleration }} \\
=\text { line length }[\mathrm{m}]+15 \mathrm{~s}
\end{gathered}
$$




\subsection{Situation 3: Tugboat Movements When Actuating in Pull Mode}

Since no such information is present on the literature, the author decided to perform several experiments using the SMS, located at the TPN-USP, in order to obtain the response times of tugboats actuating under Pull mode. The experiment set-up will be the same as the one used for the validation on Chapter 6, with three buoys placed parallel to each other, tugboat attached to the center one, current and wind conditions being perpendicular to such buoys in order to simulate a navigating vessel. For this experiment we varied the vessel's advance speed between 0 and 8 knots, and the tugboat's towline length between 20 and $100 \mathrm{~m}$. For each scenario combination, the tugboat would start with its heading pointed towards the yellow buoy (Figure 129 - Left), until a timer started. After that, the tugboat would complete a $180^{\circ}$ lap around the buoys, finishing with its heading pointed towards the green one (Figure 129 - Right). After reaching such position, the timer would be turned off.

Figure 129 - Tugboat's movement experiment during Pull mode maneuvers

$$
\text { Beginning of Experiment End of Experiment }
$$

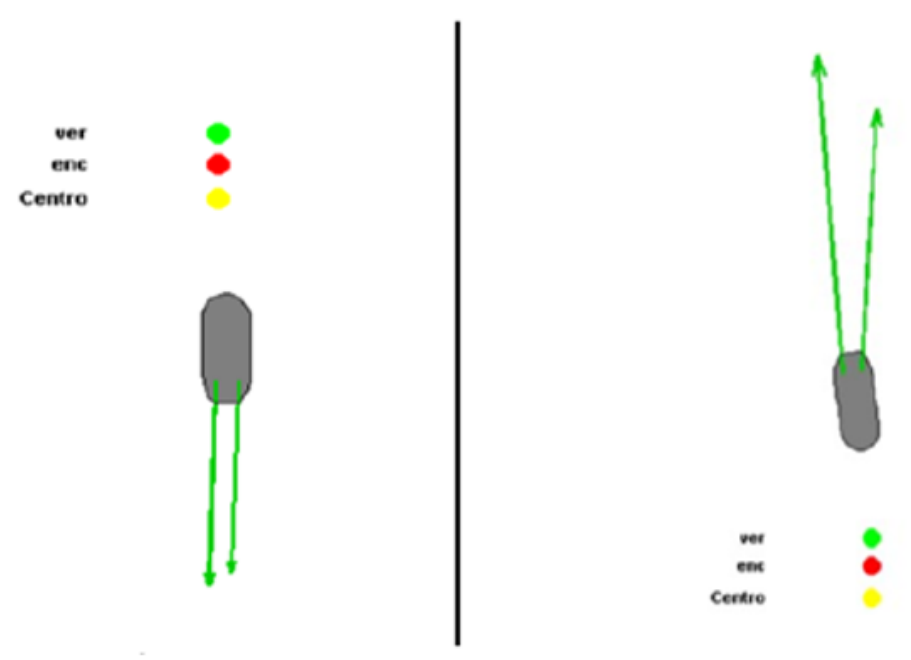

Source: Author

The results for this experiment are shown from Figure 130 to Figure 134. Based on such results, one can calculate the mean lateral velocity each tugboat has taken in order to perform a $180^{\circ}$ arc navigation for each line length (Table 15). 
Of course, this lateral speed is not constant along the whole $180^{\circ}$ arc navigation, since during part of this navigation the relative current reaches the tugboat by its bow, stern or side. Furthermore, the maneuvering simulator experiment is subjected to variation due to the operator skill or instantaneous conditions, and for a matter of available time, we did not repeat each test.

However, for a matter of simplification and aiming to provide an acceptable level of realism in the vector tug model, we adopted the average lateral speed for each speed, as indicated in the Table 15.

Figure 130 - Movement time experiment for advance speed of 0 knots

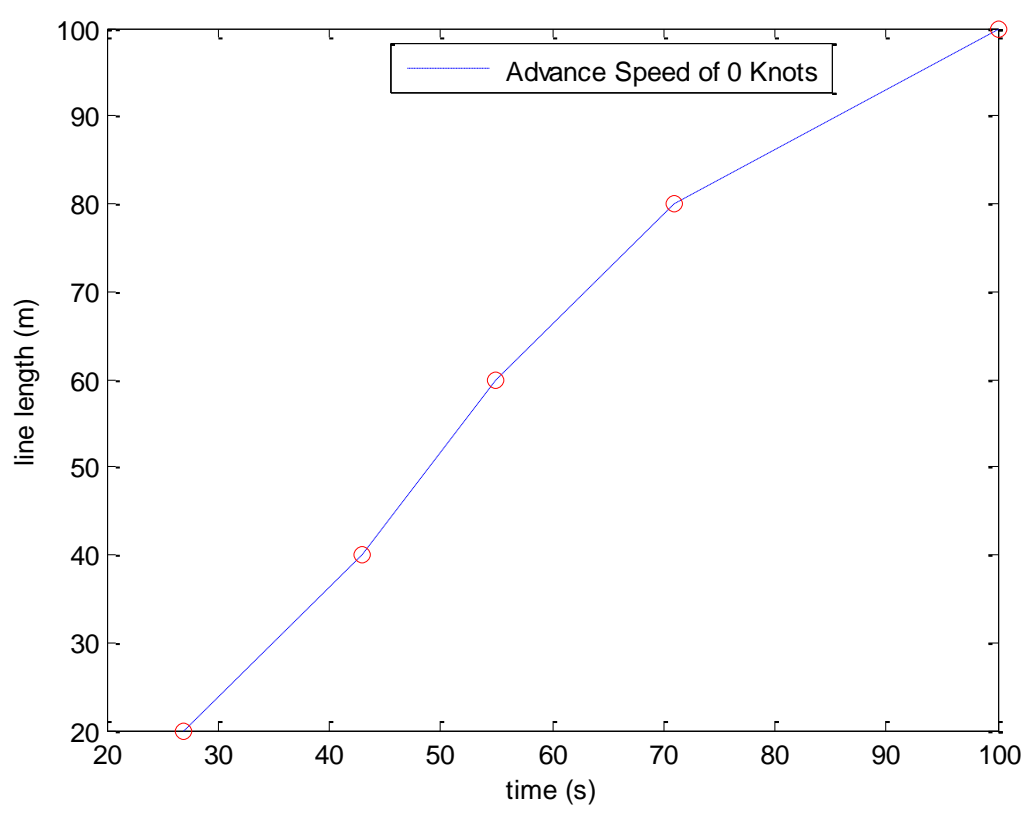

Source: Author 
Figure 131 - Movement time experiment for advance speed of 2 knots

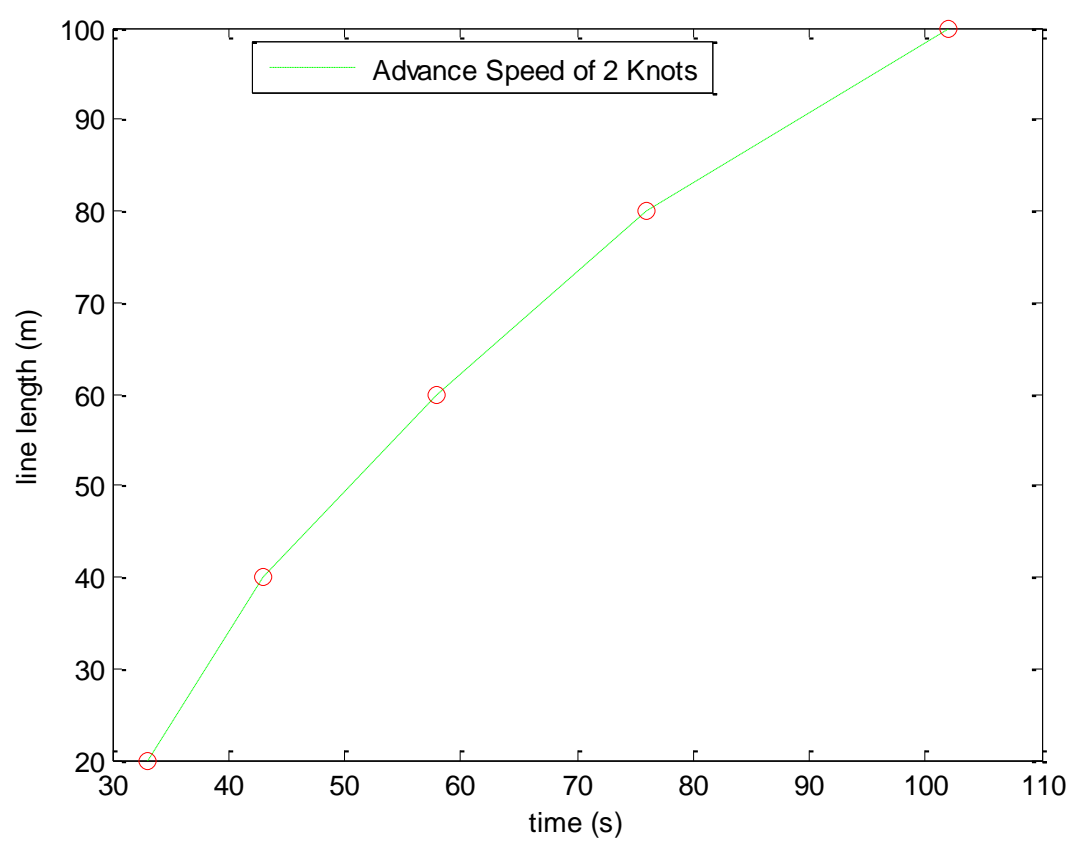

Source: Author

Figure 132 - Movement time experiment for advance speed of 4 knots

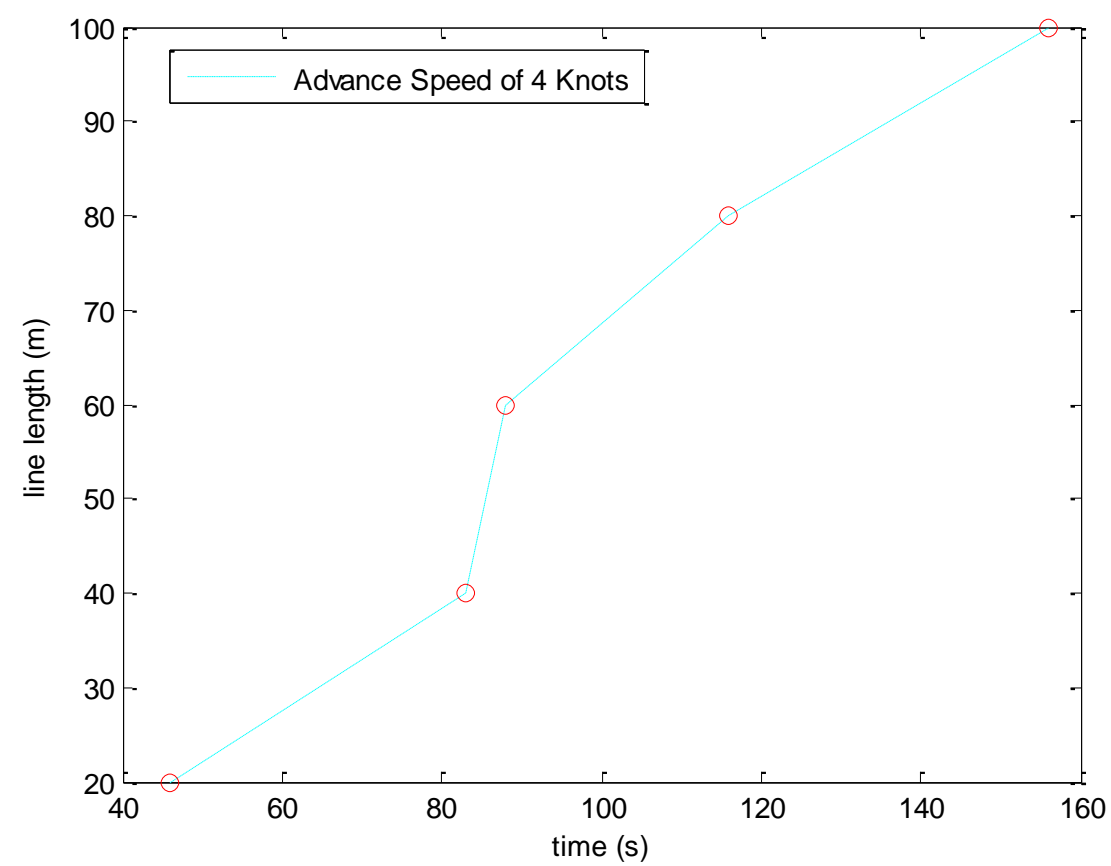

Source: Author 
Figure 133 - Movement time experiment for advance speed of 6 knots

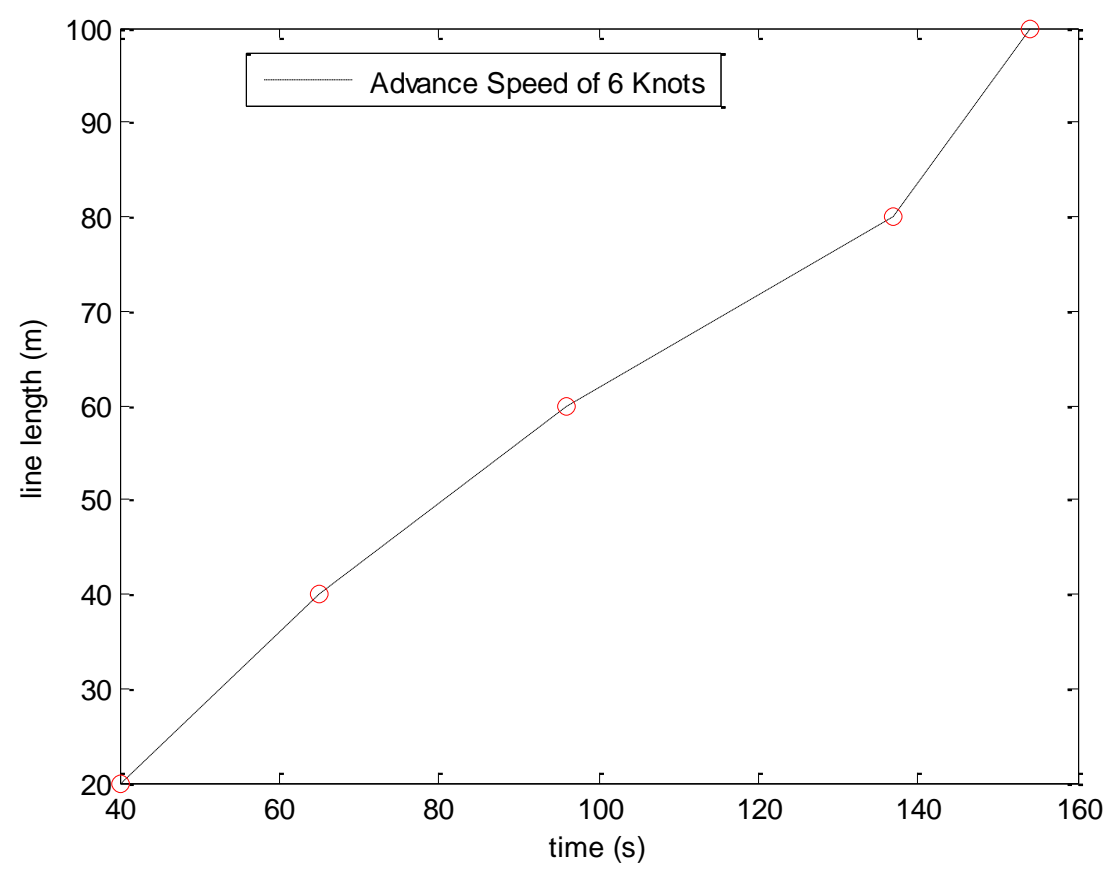

Source: Author

Figure 134 - Movement time experiment for advance speed of 8 knots

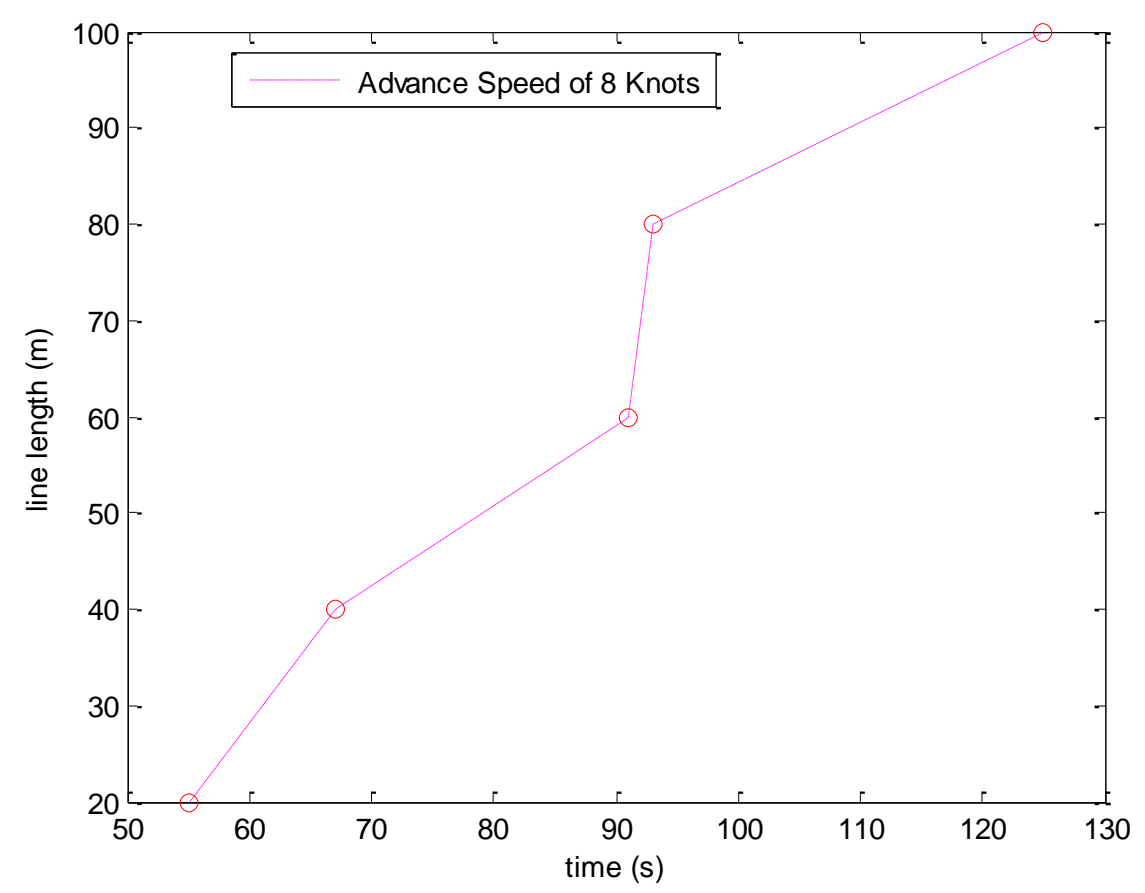

Source: Author 
Table 15 - Average tugboat speed for each scenario

\begin{tabular}{|c|c|c|}
\hline Advance Speed (kn) & Towline length $(\mathrm{m})$ & $\begin{array}{l}\text { Mean lateral } \\
\text { speed }(\mathrm{m} / \mathrm{s})\end{array}$ \\
\hline \multirow[t]{6}{*}{0} & 20 & 4.2 \\
\hline & 40 & 4.1 \\
\hline & 60 & 4.3 \\
\hline & 80 & 4.2 \\
\hline & 100 & 3.7 \\
\hline & Average for Okn & 4.1 \\
\hline \multirow[t]{6}{*}{2} & 20 & 3.4 \\
\hline & 40 & 4.1 \\
\hline & 60 & 4.1 \\
\hline & 80 & 4.0 \\
\hline & 100 & 3.6 \\
\hline & Average for $2 \mathrm{kn}$ & 3.8 \\
\hline \multirow[t]{6}{*}{4} & 20 & 2.5 \\
\hline & 40 & 2.1 \\
\hline & 60 & 2.7 \\
\hline & 80 & 2.6 \\
\hline & 100 & 2.3 \\
\hline & Average for $4 \mathrm{kn}$ & 2.4 \\
\hline \multirow[t]{6}{*}{6} & 20 & 2.8 \\
\hline & 40 & 2.7 \\
\hline & 60 & 2.5 \\
\hline & 80 & 2.2 \\
\hline & 100 & 2.4 \\
\hline & Average for $6 \mathrm{kn}$ & 2.5 \\
\hline \multirow[t]{6}{*}{8} & 20 & 2.0 \\
\hline & 40 & 2.6 \\
\hline & 60 & 2.6 \\
\hline & 80 & 3.2 \\
\hline & 100 & 2.9 \\
\hline & Average for $8 \mathrm{kn}$ & 2.6 \\
\hline
\end{tabular}

Source: Author

Based on the curves provided, one can easily interpolate the advance speed of the towed vessel and the tugboat's towline length in order to correctly obtain the vector tug movement velocity. After that, for a specific arc angle pre-defined by the vector tug operator, one can use the obtained velocity in order to calculate the animation time. 


\section{CONCLUSIONS}

In this work, a novel mathematical formulation including an optimization algorithm was developed to represent the actuation of vector tugs within SMS. The proposed algorithm was able to correctly represent the towing forces exerted, the towing position of actuation and response times for tugboat operation in Pull Direct, Pull Indirect, and Push Modes. In order to correctly represent such actuation, several aspects were taken into consideration, including the attenuations and towline peaks due to wave motions, and wave shadowing effects.

For the Pull - Direct maneuver, the results were validated using the SMS located at the Numerical Offshore Tank laboratory. In the 2 and $4 \mathrm{kn}$ scenarios, the maximum towing force discrepancy between the theoretical and simulator data was around $5.4 \%$. For the $6 \mathrm{kn}$ scenarios, the maximum towing force discrepancy reached $12.3 \%$. Such discrepancy for the last scenario was due to an unmodeled effect present on the simulator, which decreases the propeller force based on the transversal relative current. Since the Direct Maneuver is used only up to $6 \mathrm{kn}$, the model was validated within an accepted \% error range.

For the Push maneuver, no validation was performed because the SMS used was still finishing its model implementation, and the data available on the literature did not consider the friction force of the hull-hull direct contact. This work hopes to inspire many others to keep researching on this field, providing new comparison results for the Push maneuver implementation.

For the Pull - Indirect maneuver, data present on the literature was used to validate the model with great accuracy. Such mathematical implementation was not trivial, and most, if not all, simulators still lack the ability to perform Pull-indirect maneuvers with their vector tugs. Hopefully, the extension of the art state presented on this work may help several SMS around the world to implement the Indirect maneuver for their vector tugs.

Although the optimization formulations presented in this work are crucial on obtaining the optimal actuation of the vector tugs for each desired scenario, they are still time consuming and rely on the correct choice of initial conditions. In order 
to apply such model in SMS, one must gather data for several advance speeds and several tugboat types, save it on a database, and interpolate the results in real-time. By doing so, all the optimization solution difficulties are dealt beforehand, thus allowing a smooth and reliable vector tug implementation in real-time.

Finally, the mathematical model presented does improve the realism of nautical maneuvers in SMS when vector tugs are used, reaching the main goal of this research. 


\section{REFERENCES}

ADGRUP, K.; OLSEN, A. S.; JURGENS, D. DEVELOPMENT OF A MATHEMATICAL MODEL OF A VOITH SCHENEIDER TUG AND EXPERIENCE FROM ITS APPLICATIONS IN AN OFFSHORE SIMULATION STUDY. International Conference on Marine Simulation and Ship Manoeuvrability, Terschelling, The Netherlands, 2006. 382 - 392.

ANKUDINOV, V. K. et al. MANEUVERING PERFORMANCE OF TUG/BARGE ASSEMBLIES IN RESTRICTED WATERWAYS. International Conference on Marine Simulation and Ship Manoeuvrability, Tokyo, Japan, 1990. 515-525.

ARTYSZUK, J. Simplified steady-state analytical model for manoeuvring and control of ASD tug in escort push operations. Scientific Journals Zeszyty Naukowe, 2013. 5-14.

ARTYSZUK, J. Steady-state Manoeuvring of a Generic ASD Tug in Escort Pull and Bow-rope Aided Push Operation. Proocedings of the International Journal of Marine Navigation and Safety of Sea Transportation, TRANSNAV, 2014. 449-457.

BARRERA, R. D.; TANNURI, E. A. MANOEUVRING AND CONTROL OF VECTOR TUGS IN MARITIME SIMULATORS - AN ACTUATION MODEL SUBJECTED TO HYDRODYNAMIC AND WIND EFFECTS DURING PULL OPERATIONS. Proceedings of the 24th International Congress of Mechanical Engineering, COBEM, Curitiba, Brazil, 2017.

BARRERA, R. D.; TANNURI, E. A. Offline Vector Tugs Acuation Model - An Efficiency Analysis of Towage Forces During Pull Operations. International Conference on Marine Simulation and Ship Manoeuvrability, Halifax, Canada, 2018.

BARUH, H. Analytical Dynamics. New York: Mcgraw-Hill, 1999.

BEADON, R. C. The design, implementation and evaluation of simulatorbased bridge watchkeeping training for cadets. International Conference on Marine Simulation and Ship Manoeuvrability, Rotterdam, The Netherlands, 1984. 95 $-106$.

BRANDNER, P. A. SIMULATION OF SHIPHANDLING USING OMNI DIRECTIONAL STERN DRIVE TUGS. International Conference on Marine Simulation and Ship Manoeuvrability, St. John's, Newfoundland, Canada, 1993. 49-58.

BRANDNER, P. A. HYDRODYNAMIC ASPECTS OF SHIPHANDLING TUGS. Third Combined Technical Meeting: The Royal Institute of Naval Architects (Australian Division) \& The Institute of Marine Engineers (Sydney Division), 1994.

BRANDNER, P. A. PERFORMANCE AND EFFECTIVENESS OF OMNIDIRECTIONAL STERN DRIVE TUGS. University of Tasmania. [S.I.], p. 264. 1995. (Ph.D Thesis). 
BROOKS, G.; HARDY, G. A CASE STUDY IN IMPROVING TUG ESCORT PROCEDURES WITH THE AID OF SIMULATION. International Conference on Marine Simulation and Ship Manoeuvrability, Panama City, Panama, 2009. $239-245$.

BUCHNER, B.; DIERX, P.; WAALS, O. The Behaviour of Tugs in Waves Assisting LNG Carriers During Berthing Along Offshore LNG Terminals. Proceedings of the 24th International Conference on Offshore Mechanics and Artic Engineering, 2005.

CARD, J. C. Report to the president of an evaluation of devices and techniques to improve maneuvering and stopping abilities of large tank vessels. Washington D.C: National Technical Information Service, 1979.

CARLTON, J. MARINE PROPELLERS AND PROPULSION. Second Edition. ed. Burlington, MA, USA: [s.n.], 2007.

CARPENTER, M. H.; NOLAN, T. P.; CHEONG, H. Development and Current Status of the M.I.T.A.G.S Ship Simulator. International Conference on Marine Simulation and Ship Manoeuvrability, Kings Point, New York, USA, 1981. 138 $-147$.

CLARKE, D.; WELLMAN, F. THE STOPPING OF LARGE TANKERS AND THE FEASIBILITY OF USING AUXILIARY BRAKING DEVICES. Naval Architect, n. ISSN:0306-0209, p. 139-166, 1971.

CROSS, S.; OLOFSSON, M. Classification of Maritime Simulators, the Final Attempt Introducing DNV's New Standards. International Conference on Marine Simulation and Ship Manoeuvrability, Orlando, Florida, USA, 2000. 1 $-7$.

DAGGETT, L. L.; HEWLETT, J. C.; HELTZEL, S. Ship navigation simulator study Savannah Harbor widening project Savannah, Georgia. International Conference on Marine Simulation and Ship Manoeuvrability, Trondheim, Norway, 1987. 234 - 242.

DNV-GL. Maritime simulator systems. [S.I.]. 2017.

EDA, $\mathrm{H}$. et al. DYNAMIC BEHAVIOR OF A TANKER AND TUG IN A RIVER. International Conference on Marine Simulation and Ship Manoeuvrability, Terschelling, The Netherlands, 2006. 212 - 216.

FILHO, A. N. Q. ESTUDO DA INFLUÊNCIA DOS EFEITOS DE INTERAÇÃO HIDRODINÂMICOS EM OPERAÇÕES DE ALÍVIO POR SISTEMAS DP. Master Thesis, São Paulo, 2009.

FILHO, A. N. Q.; TANNURI, E. A. DP Offloading Operation: a Numerical Evaluation of Wave Shielding Effect. Proocedings of the 8th IFAC, Guaruja, Brazil, 2009. 382 - 387.

FOSSEN, T. I.; TRISTAN, P. Kalman Filtering for Positioning and Heading Control of Ships and Offshore Rigs. IEEE control systems, January 2010. 3246. 
FRAGOSO, O. A.; CAJATY, M. Rebocadores Portuários. Rio de Janeiro: Conselho Nacional de Praticagem, 2012.

FUCHS, B.; HUAN, W. THE COLLECTION OF TUGBOAT OPERATIONAL FIELD DATA AND THE USAGE FOR SIMULATOR MODELING \& VALIDATION. International Conference on Marine Simulation and Ship Manoeuvrability, Newcastle, UK, 2015. 387 - 401.

FURUKAWA, Y. et al. EXPERIMENTAL STUDY OF INTERACTION FORCES ACTING ON SHIP HULL BY BANK EFFECT. International Conference on Marine Simulation and Ship Manoeuvrability, Newcastle, United Kingdom, 2015. 135 - 149.

GRONARZ, A. A Mathematical Model for Manoeuvring Simulation on Shallow Water. International Conference on Marine Simulation and Ship Manoeuvrability, St. John's, Newfoundland, Canada, 1993. 143 - 152.

HAMAMATSU, M. et al. ONLINE NONLINEAR OPTIMAL CONTROL FOR SHIP POSITIONING AND TRACKING. International Conference on Marine Simulation and Ship Manoeuvrability, Kanazawa, Japan, 2003. 367 - 370.

HATTERMANN, H. A DYNAMIC PARALLEL PROCESSOR SYSTEM FOR 3D IMAGE GENERATION IN REAL TIME, COMPLETE FOR SIMULATION BY A UNIVERSAL SYSTEM FOR DESIGN AND MANAGEMENT OF DATA BASES. International Conference on Marine Simulation and Ship Manoeuvrability, Tokyo, Japan, 1990. 103 - 109.

HENSEN, H. TUG USE IN PORT. 2nd edition. ed. London: The Nautical Institute, 2003.

HENSEN, H.; LAAN, M. V. Tug Stability - A Pratical Guide to Safe Operations. [S.I.]: The ABR Company Limited, 2016. 110 p.

HILTER, J. V.; WULDER, J. H. THE USE OF A SIMULATOR FOR THE DEVELOPMENT AND TRAINING OF OPTIMISED USE OF HARBOUR TUGS. International Conference on Marine Simulation and Ship Manoeuvrability, Terschelling, The Netherlands., 2006. 10 - 18.

IMO, I. M. O. Resolution MSC.415(97). In: Ammendments to Part B of the International Code on Intact Stability. [S.I.]: [S.n.], 2016.

ISHERWOOD, R. M. Wind Resistance of Mechant Ships. The Royal Institution of Naval Architects, 1972. 327-338.

ISHIKURA, A. et al. Investigation of TugBoats' Behavior during Ships' Berthing and Unberthing. The Journal of Japan Institute of Navigation, Japan, 2013. 191-197.

ITTC. Report of the Seakeeping Committee. Proceedings of the 17 th International Towing Tank Conference, 1984. 531-534.

J.E.W, W. A Simulation Model for a Single Point Moored Tanker. MARIN, Wagenigen, 1988. 
JAKOBSEN, B. K. et al. The simulation of tug operations in a multiple simulator environment. International Conference on Marine Simulation and Ship Manoeuvrability, Copenhagen, Denmark, 1996. 29 - 37.

KHATTAB, O. A SIMULATION PROGRAM FOR ESTIMATION OF THE TUG HANDLING BEHAVIOR IN DESIGN STAGE. International Conference on Marine Simulation and Ship Manoeuvrability, Tokyo, Japan, 1990. 185 - 191.

KIJIMA, K.; FURUKAWA, Y.; YUKAWA, K. On a prediction method of hydridynamic forces acting on ship hull including the effect of hull form. International Conference on Marine Simulation and Ship Manoeuvrability, Copenhagen, Denmark, 1996. 411 - 418.

KOBAYASHI, H. STANDARD MARINER'S BEHAVIOR IN AVOIDING COLLISION MANEUVER. International Conference on Marine Simulation and Ship Manoeuvrability, Terschelling, The Netherlands, 2006. 142 - 151.

LEWIS, E. V. Principles of Naval Architecture. Jersey City, NJ: The Society of Naval Architects and Marine Engineers, v. 2, 1988.

LLOYD, J.; RODRIGUES, I. Simulation, an effective tool in the risk management of vessels under pilotage. International Conference on Marine Simulation and Ship Manoeuvrability, Singapore, 26 April 2012. 749-757.

MATSUURA, Y. IHI Ship Manoeuvring Simulator and its applications. International Conference on Marine Simulation and Ship Manoeuvrability, Southhampton, United Kingdom, 1978. 41- 42.

MILLAR, I. C.; REYNOLDS, J. Marine Simulator Developments in the United Kingdom. International Conference on Marine Simulation and Ship Manoeuvrability, Kings Point, New York, USA, 1981. 123 - 137.

NEWMAN, J. N. Marine Hydrodynamics. [S.I.]: [s.n.], 1977.

NEWMAN, J. N. Marine Hydrodynamics. [S.I.]: [s.n.], 1977.

NISHIMURA, T.; KOBAYASHI, H. A STUDY ON MARINERS' BEHAVIOR FOR AVOIDING COLLISIONS IN CONGESTED TRAFFIC CONDITIONS: A STUDY ON THE CAUSES OF COLLISIONS UNDER RESTRICTED VISIBILITY. International Conference on Marine Simulation and Ship Manoeuvrability, Terschelling, The Netherlands, 2006. 97 - 104.

NONAKA, K. International Conference on Marine Simulation and Ship Manoeuvrability, St. John's, Newfoundland, Canada, 1993. 437 - 446.

OCIMF. Prediction of Wind and Current Loads on VLCCs. London: Oil Companies International Marine Forum, 1977.

OCIMF. Mooring Equipment Guidelines. II. ed. [S.I.]: Oil Companies International Marine Forum, 1997.

OOSTERVELD, M. W. C.; OORTMERSSEN, G. V. Thruster Systems for Improving the Manueverability and Position-Keeping Capability of Floating 
Objects. Proceedings of the Offshore Technology Conference, OTC, Dallas, Texas, 1972. 1625.

PIANC. SAFETY ASPECTS AFFECTING THE BERTHING OPERATIONS OF TANKERS TO OIL AND GAS TERMINALS. 116. ed. [S.I.]: Maritime Navigation Comission, 2012.

PUGLISI, J. J. et al. The proposed plan for widening of the Panama canal and application of simulator techniques for the development and validation of the proposed solution. International Conference on Marine Simulation and Ship Manoeuvrability, Trondheim, Norway, 1987. 166 - 177.

QING, L.; XIU-HENG, W.; ZAO-JIANG, Z. Study on Ship Course Fuzzy Selflearning Control System. International Conference on Marine Simulation and Ship Manoeuvrability, Kanazawa, Japan, 2003. 371 - 374.

QIU, W. et al. Real-Time Computation Of Ship Motions In Waves. International Conference on Marine Simulation and Ship Manoeuvrability, Panama City, Panama, 2009.

RANWSON, A. J. The combined training of vessel traffic services operators and shipmasters/pilots using a ship-handling simulator. International Conference on Marine Simulation and Ship Manoeuvrability, Rotterdam, the Netherlands, 1984. $69-75$.

REN, J.; ZHANG, X.; HUO, H. MODELING AND SIMULATION OF AZIMUTH STERN DRIVE TUG IN SHIPHANDLING SIMULATION. International Conference on Marine Simulation and Ship Manoeuvrability, Newcastle, UK, 2015. 208- 219.

RHEN, J.; ZHANG, X.; SUN, X. MATHEMATICAL MODELING OF A TOWAGE OPERATION FOR INTERACTIVE TUG SIMULATOR. International Conference on Marine Simulation and Ship Manoeuvrability, Singapore, 2012. 258 - 266.

ROCHA, C. F. O transporte de cargas no Brasil e sua importância para a economia. ljuí: [s.n.], 2015. 71 p.

SEIXAS, N. A. B. Clima de Ondas da Bacia de Campos: Análise dos Dados Proposta de Parametrização. Rio de Janeiro: Ph.D thesis, 1997.

SORENSEN, P. K.; DAMSGAARD, A.; H., N. J. TACLKING THE ROTOR TUG CHALLENGE. International Conference on Marine Simulation and Ship Manoeuvrability, Singapore, 2012. 458 - 464.

SPEIGHT, R.; STRANNIGAN, D. Culturally Aware Simulation. International Conference on Marine Simulation and Ship Manoeuvrability, New Castle, 8 September 2015. 1.2.5.

TAKASHINA, J.; HIRANO, M. SHIP MANEUVERING MOTION BY TUGS IN DEEP AND SHALLOW WATERS. International Conference on Marine Simulation and Ship Manoeuvrability, Tokyo, Japan, 1990. 379-385. 
TANNURI, E. A. Modular Mathematical Model for a Low-Speed Maneuvering Simulator. Proceedings of the 33th International Conference on Ocean, Offshore and Artic Engineering, OMAE, 2014.

TAYLOR, H. F.; SANBORN, J.; BUCHANAN, D. C. A SIMULATOR-BASED TRAINING RESEARCH PROGRAM FOR TUGBOAT OPERATIONS. International Conference on Marine Simulation and Ship Manoeuvrability, Rotterdam, The Netherlands, 1984. 271 - 278.

TEJADA, F. ESCORT TOWING IN THE EXPANDED PANAMA CANAL. International Conference on Marine Simulation and Ship Manoeuvrability, Panama City, Panama, 2009. 86 - 95.

TPN-USP. Ensaios para a aquisição de coeficientes hidrodinâmicos e aerodinâmicos para rebocadores oceânicos de operação offshore. University of São Paulo. São Paulo. 2009.

VARYANI, K. S. et al. SIMULATION OF THE DYNAMICS OF A TUG TOWING A DISABLED TANKER IN EMERGENCY SALVAGE OPERATION. International Conference on Marine Simulation and Ship Manoeuvrability, Terschelling, The Netherlands, 2006. 26 - 35.

VLUGT, J. V. D. et al. NEW TECHNOLOGIES FOR PREPARATION AND VISUALIZATION OF ENVIRONMENTS FOR MARINE SIMULATION PURPOSES. International Conference on Marine Simulation and Ship Manoeuvrability, Tokyo, Japan, 1990. 117 - 124.

WICHER, J. E. L. A Simulation Model for a Single Point Moored Tanker. MARIN, Wageningen, 1988.

WULDER, J. H. et al. APLICATIONS OF INTERACTIVE TUG SIMULATION. International Conference on Marine Simulation and Ship Manoeuvrability, Orlando, Florida, 2000. 28 - 42.

XIUFENG, Z.; YONG, Y.; YICHENG, J. THE MOVING MATHEMATICAL MODEL OF TUG WITH VOITH SCHNEIDER PROPELLER. International Conference on Marine Simulation and Ship Manoeuvrability, Terschelling, The Netherlands, 2006. 343 - 348.

XU, Y.; SUN, Y. Study on Ship-ship Hydrodynamic Interaction by ANN Optimization. International Conference on Marine Simulation and Ship Manoeuvrability, Singapore, 2012. 602 - 611.

YASUKAWA, H.; NAKAYAMA, Y. 6-DOF Motion SImulations Of A Turning Ship In Regular Waves. International Conference on Marine Simulation and Ship Manoeuvrability, Panama City, Panama, 2009. 508 - 517.

ZADE, G. The Cost and Beneft of Nautical SImulators. A User's Point of View. International Conference on Marine Simulation and Ship Manoeuvrability, Southhampton, United Kingdom, 1978. 18-21.

ZHOU, Y.; WANG, D.; GUO, Y. The Reduction of Static Friction of Rubber Contact Under Sea Water Droplet Lubrication. Lubricants, Beijing, May 2017. 


\section{APPENDIX - DEVELOPED SOFTWARES FOR VECTOR TUG ANALYSIS}

\section{A1: Static Equilibrium Software}

In order to calculate and graphically visualize the vector tug static equilibrium solutions, a user-friendly interface was developed using MATLAB. As shown on Figure 135, under the Initial Conditions Panel, the user is able to input information regarding the tugboat physical characteristics, the towed vessel's speed and navigation angle, the external disturbances characteristics and the pilot's orders such as towline angle and demanded tug force.

Figure 135 - Static equilibrium calculation software - Initial Configuration

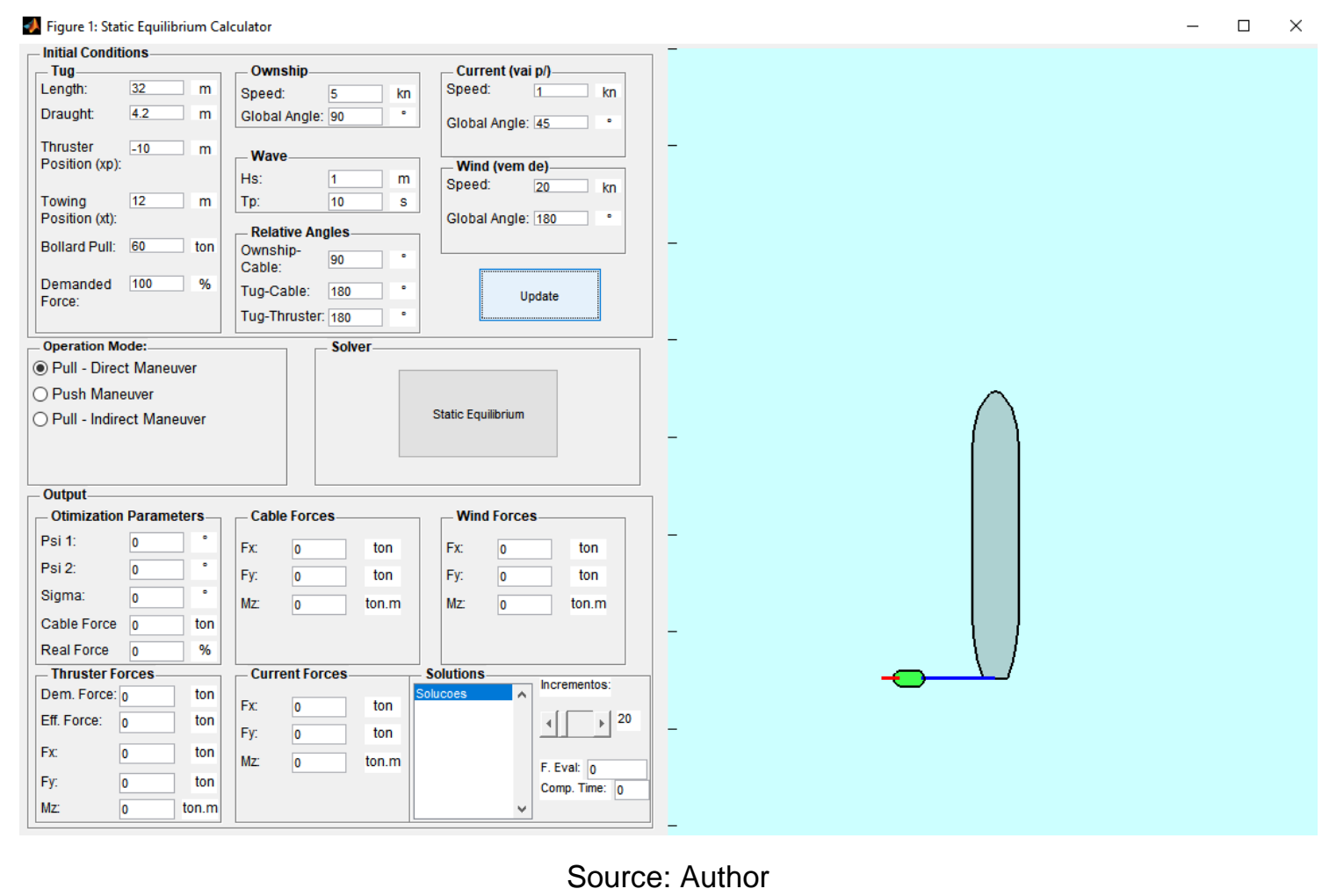

After choosing the operation mode, the user can press the "Static Equilibrium" button and the interactive optimization will run. After the calculation procedure is performed, the user has information about the wind, current, propeller and cable force on the tugboat's local coordinate system. In addition, the user obtains what are the parameters (i.e., the towage force, the tugboat's heading angle, the propeller's angle, etc) in order to achieve such equilibrium solution. The graphical solution of such static equilibrium position may also be seen on the right window 
(Figure 136). Note that, the parameters obtained are the ones that will be sent to the TPN-USP SMS in order to correct represent the actuation of the vector tugs.

Figure 136 - Static equilibrium calculation software - Final Configuration

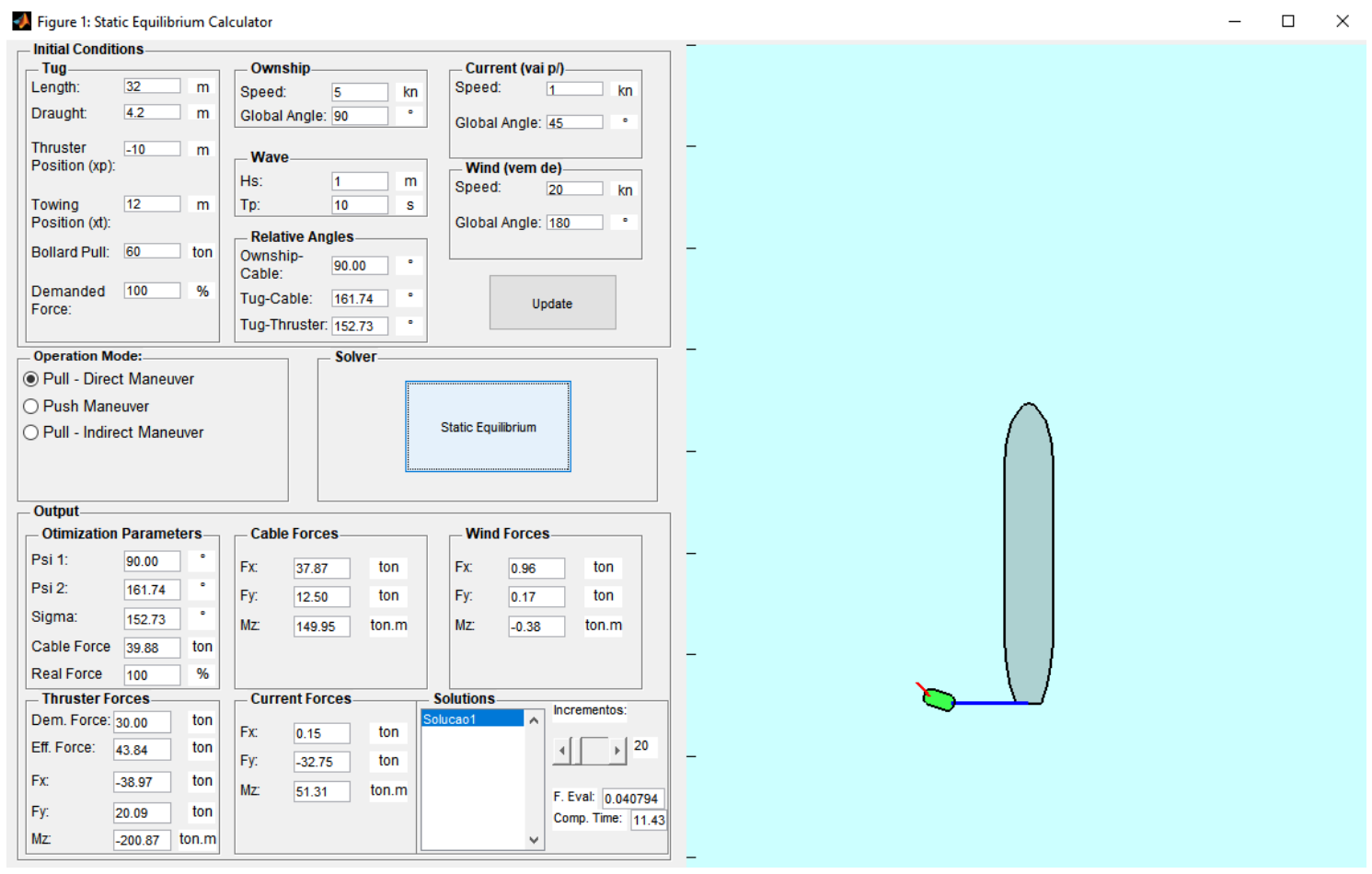

Source: Author

\section{A2: Vector Tug Graphical Interface}

In order to control the vector tugs presented on the SMS located at the TPN USP, a user-friendly graphical interface was developed in MATLAB (Figure 137). In this interface, an operator is able to control several parameters related to a tugboat during a simulation, such as the tugboat type, its bollard pull, its winch characteristics, etc. In addition, the operator may use the tugboat panel (Figure 138) to control the tugboat actuation, such as its operation mode, its cable length, tugboat heading movements, towline angular movements, connection to ownship, fairleads position, and actuation force. 
Figure 137 - Vector tug control

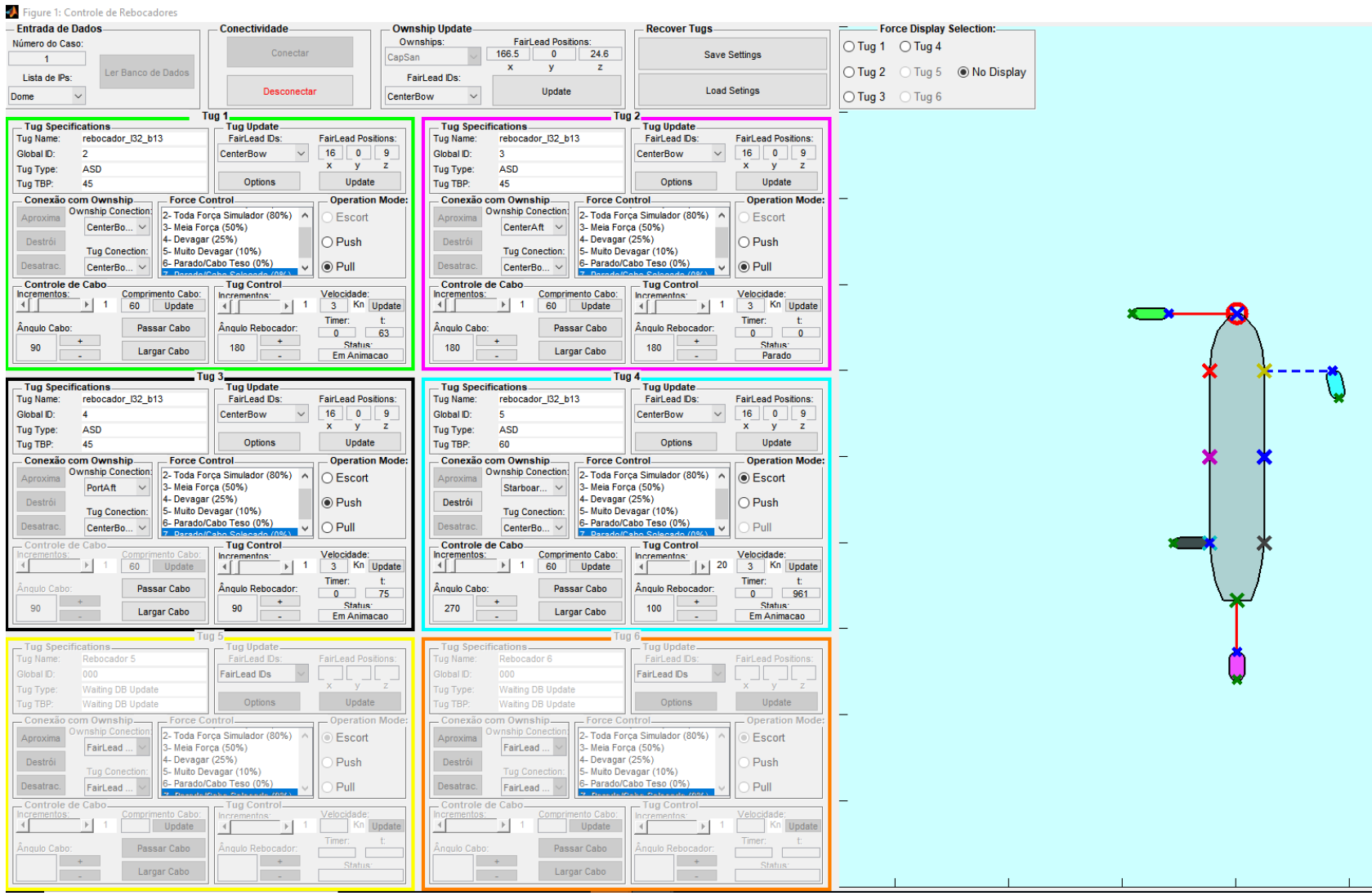

Source: Author

Figure 138 - Individual control panel for each vector tug

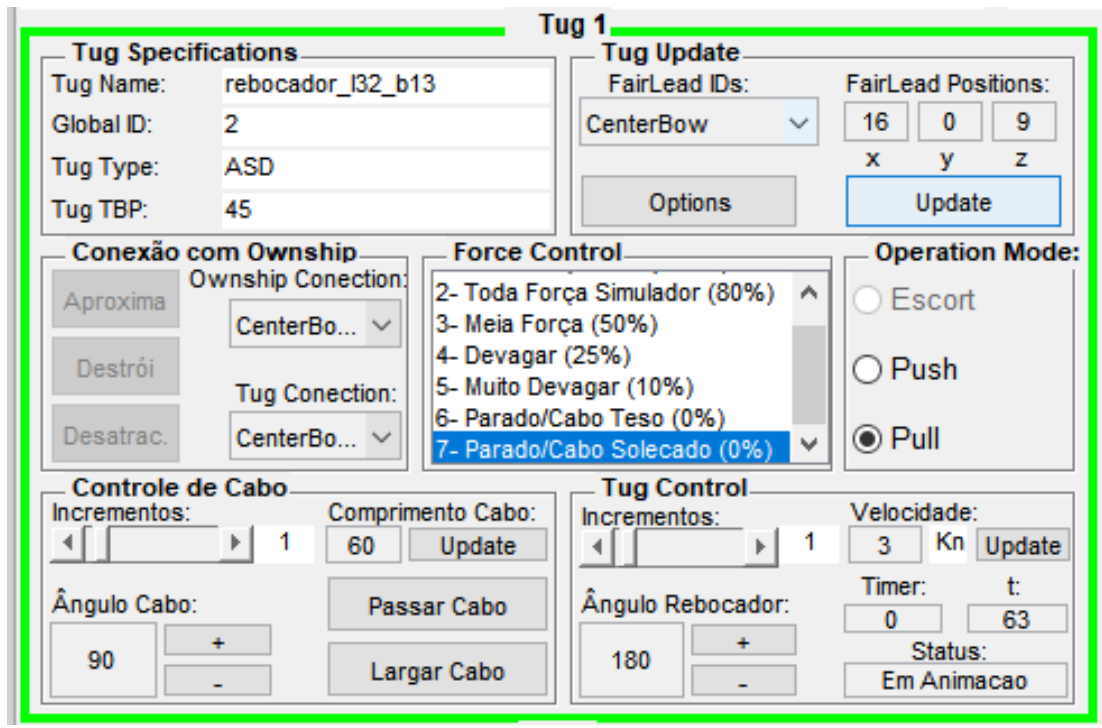

Source: Author 